\title{
USING MICROSIMULATION AND CRASHES TO EVALUATE THE SAFETY OF LEFT TURN LANES AT RURAL SIGNALIZED INTERSECTIONS
}

\author{
By \\ Nima Farid \\ Bachelor of Applied Science, University of Toronto, Toronto, Ontario, Canada, 2016
}

\author{
A thesis \\ presented to Ryerson University \\ in partial fulfillment of the \\ requirements of the degree of \\ Master of Applied Science \\ in the program of \\ Civil Engineering
}

Toronto, Ontario, Canada, 2018

(C) Nima Farid, 2018 


\section{AUTHOR'S DECLARATION}

I hereby declare that I am the sole author of this thesis. This is a true copy of the thesis, including any required final revisions, as accepted by my examiners.

I authorize Ryerson University to lend this thesis to other institutions or individuals for the purpose of scholarly research

I further authorize Ryerson University to reproduce this thesis by photocopying or by other means, in total or in part, at the request of other institutions or individuals for the purpose of scholarly research.

I understand that my thesis may be made electronically available to the public. 


\title{
USING MICROSIMULATION AND CRASHES TO EVALUATE THE SAFETY OF \\ LEFT TURN LANES AT RURAL SIGNALIZED INTERSECTIONS
}

\author{
By \\ Nima Farid \\ 2018, Master of Applied Science \\ Department of Civil Engineering \\ Ryerson University
}

\begin{abstract}
Left turn movements at intersections can be particularly unsafe. One treatment aimed at making the movement safer is the provision of left turn lanes. However, there is a missing piece in the related research, specifically how the length of left turn lanes impacts the safety of intersections. The Ministry of Transportation Ontario (MTO) has defined this as a high priority research topic. There were two major objectives in this research, both of which were addressed with microsimulation. The first was to determine a relationship between a length of left-turn lanes and safety performance of an intersection, and second was to examine the combined impact of simultaneous installation of left turn lanes with varying lengths and protected left-turn signal phasing. The findings suggested that the longer a left turn lane is, the safer the intersection would be, especially with regard to rear-end crashes.
\end{abstract}




\section{ACKNOWLEDGEMENTS}

First and foremost, I would like to thank God, whose blessing I owe everything to.

I would like to thank my supervisor, Prof. Bhagwant Persaud, for all of his educational and financial support throughout my education, and for helping me become a more competent professional.

I would also like to thank my committee members, Dr. Farooq and Dr. Yuan for offering their time and guidance during the oral examination and in their reviewing of this document.

I would also like to thank my family and friends for all of their emotional support and for being by my side through all of the ups and downs of this process.

I would like to thank Mr. Craig Lyon, a project consultant, for his continued and timely help throughout this research.

I would also like to thank the Ministry of Transportation of Ontario, specifically Mr. Justin White, for providing us with the necessary data and funding to conduct the research.

Lastly, I would like to thank Ms. Maria Espinosa, Mr. Taha Saleem, and my fellow colleagues, Mr. Mark Eskandar, and Mr. Iliya Nemstov for their assistance with the data, and all of their support. 
TABLE OF CONTENTS

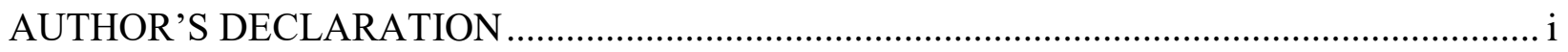

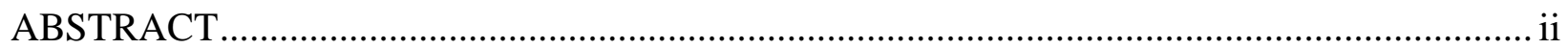

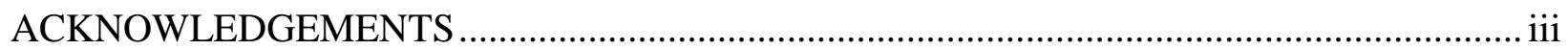

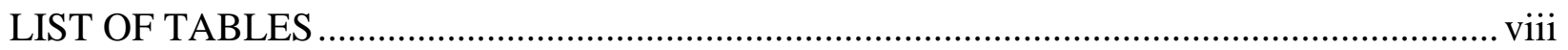

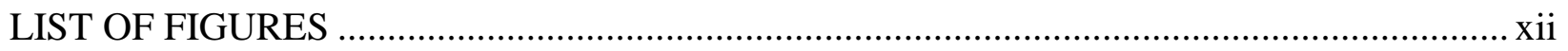

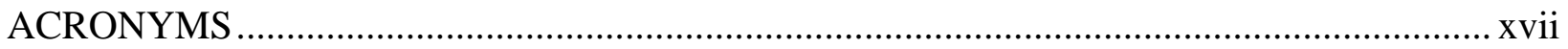

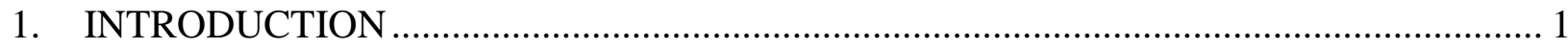

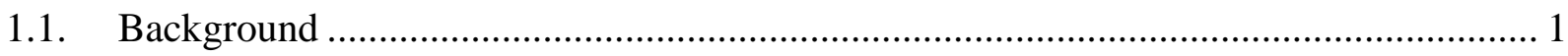

1.2. Problem Statement and Objectives .................................................................... 3

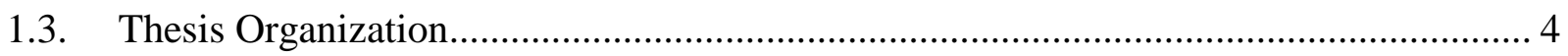

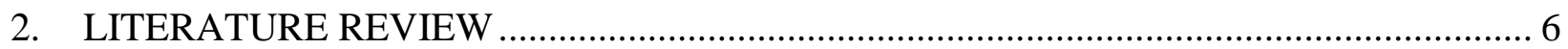

2.1. Current Design Practices ...................................................................................... 6

2.2. Left Turn Movement Safety ............................................................................ 10

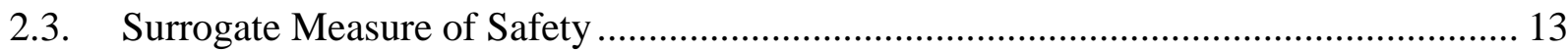

2.4. Combined CMF of Implementation of Multiple Treatments ........................................ 17

2.5 Conclusion

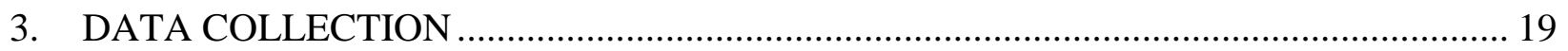

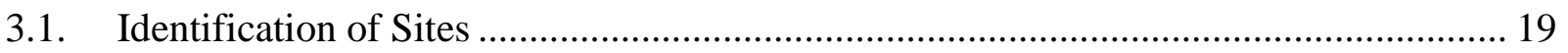




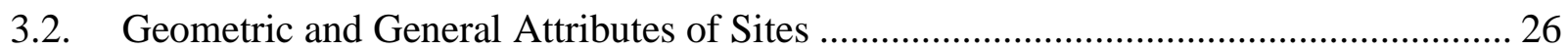

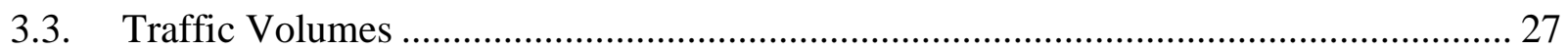

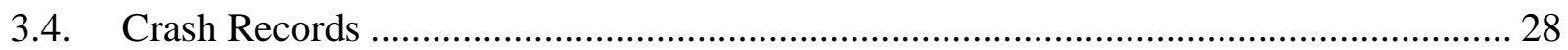

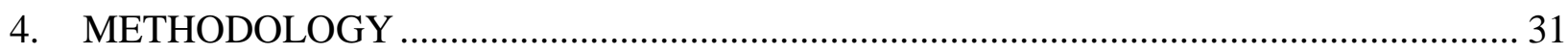

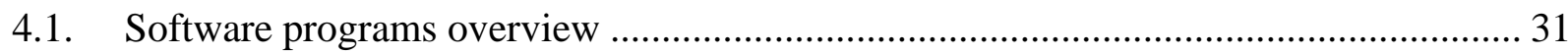

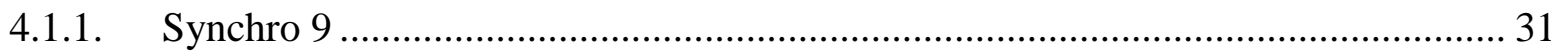

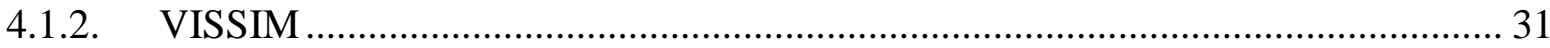

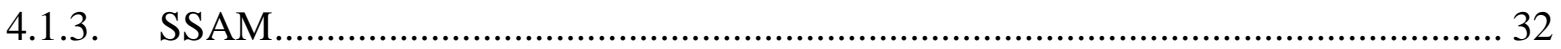

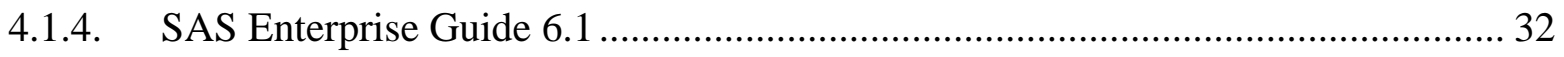

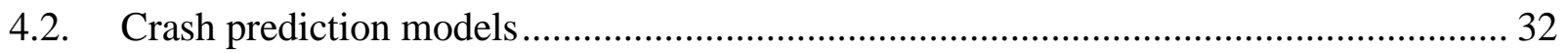

4.3. Crash-based analysis of safety performance ……......................................................... 35

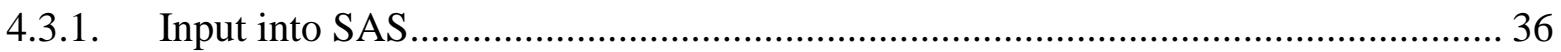

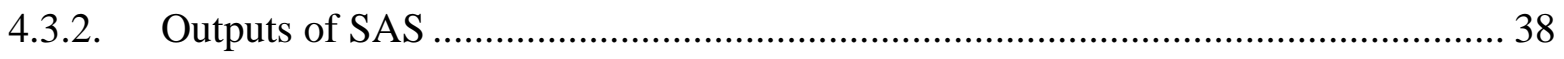

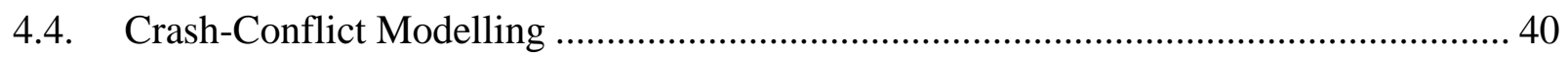

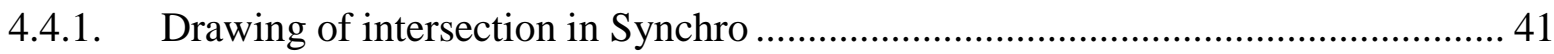

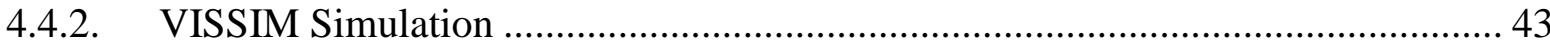

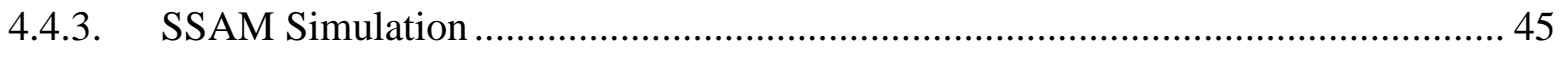

4.4.4. SAS Analysis and crash conflict models ............................................................ 46

4.5. Conflict-Based Analysis of safety performance........................................................... 47

4.6. Combined CMF of implementation of multiple treatments ......................................... 52 


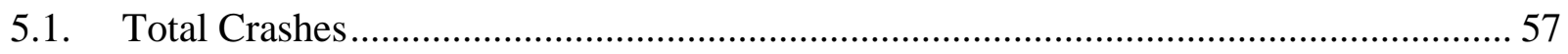

5.2. Fatal and Injury Crashes and Property Damage Only Crashes ................................. 64

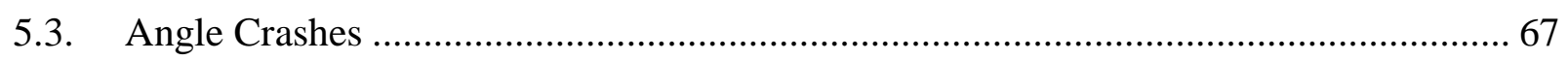

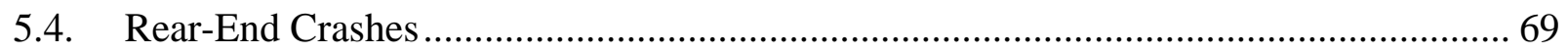

5.5. Turning Movement Crashes ....................................................................... 70

6. CONFLICT-BASED ANALYSIS OF SAFETY PERFORMANCE .............................. 75

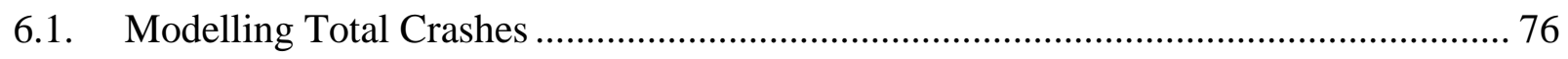

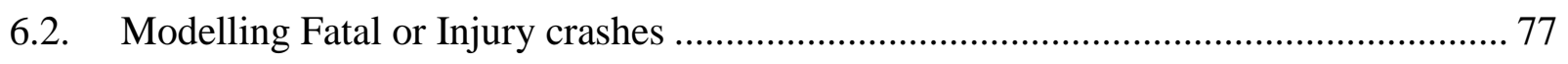

6.3. Modeling Property damage only crashes ...................................................... 79

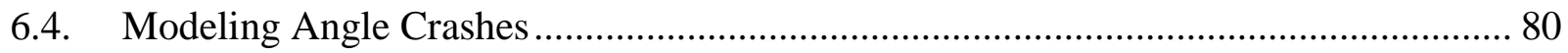

6.5. Modelling Rear-End Crashes ......................................................................... 81

6.6. Modelling Turning Movement Crashes ............................................................... 82

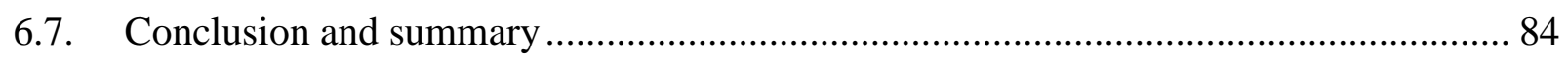

7. CONFLICT-BASED ANALYSIS OF SAFETY PERFORMANCE .............................. 86

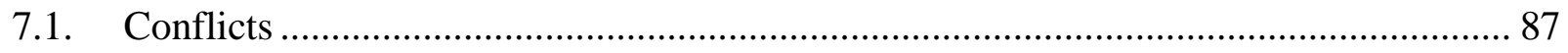

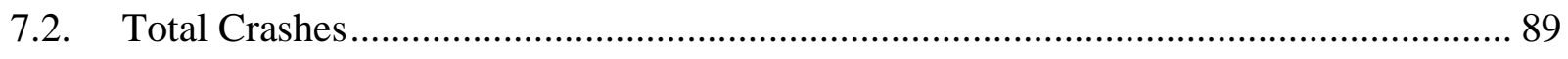

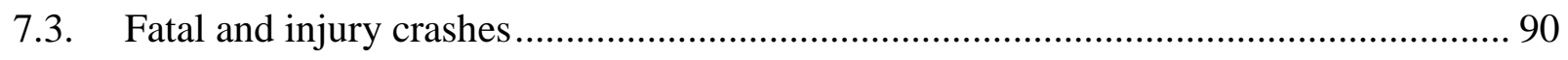

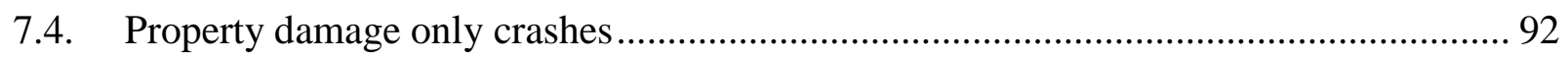

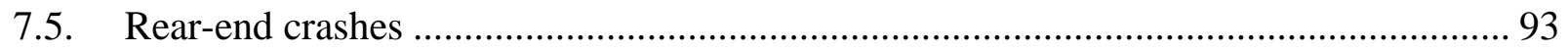




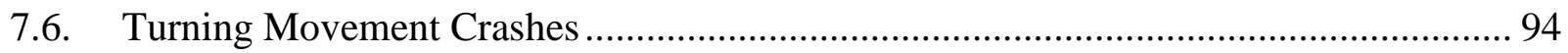

8. COMBINED CMF OF IMPLEMENTATION OF MULTIPLE TREATMENTS ................ 95

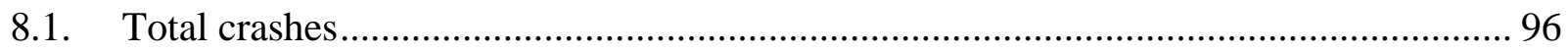

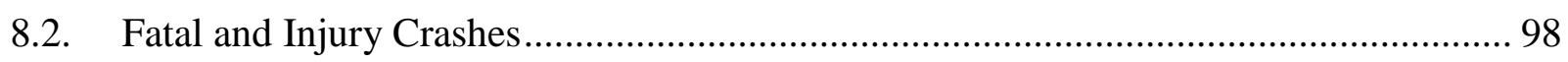

8.3. Property Damage Only Crashes ……………………............................................ 100

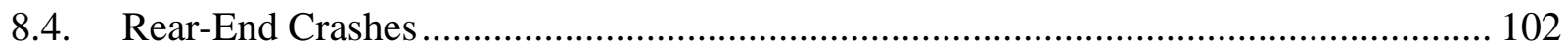

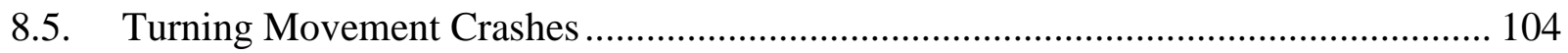

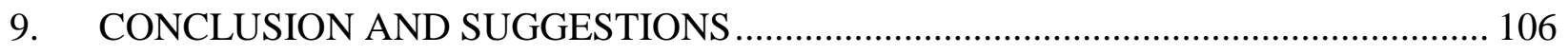

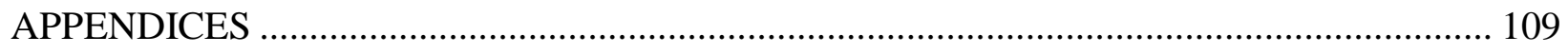

Appendix A: MTO Intersections .................................................................................. 109

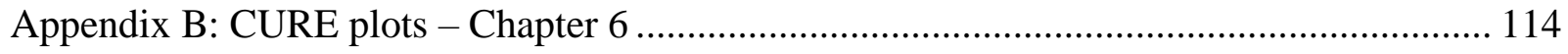

Appendix C: Conflict counts - Chapter 6 ................................................................... 134

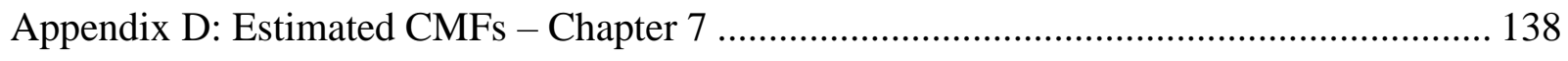

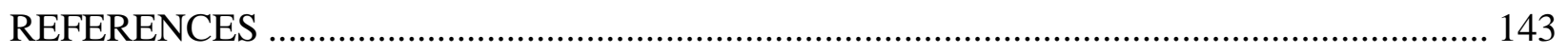




\section{LIST OF TABLES}

Table 1 Table for length of taper and deceleration lane length of left turn lane at a signalized

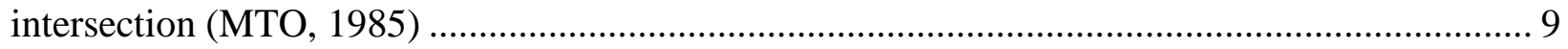

Table 2 CMFs for the before-after studies conducted (Abdel-Aty et al., 2014) ........................ 12 Table 3 A comparison of the CMF values for HSM and the EB before-after method for 3-legged, and CG before-after for 4-legged (Abdel-Aty et al., 2014) ................................................. 12 Table 4 Summary of AADT data for the sites used in the analysis ....................................... 28

Table 5 Numbers in each column and their corresponding categories (MTO, 2004)................. 29 Table 6 Example of crash counts from the year 2003 for some of the intersections, with the

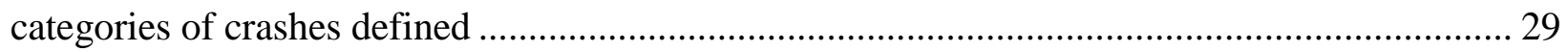

Table 7 Summary of crash data for the sites used in the analysis............................................ 30

Table 8 Part of the headers of the independent variables in the input file for SAS .................. 38

Table 9 Part of the headers of the dependent variables in the input file for SAS ...................... 38 Table 10 Table of the assembly of the 3 defined VOL.s to create one line of data to be inputted

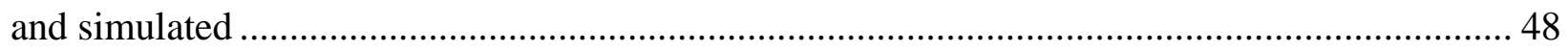
Table 11 Illustration of how different left turning volume ratio percentages are applied to the volume combinations, resulting in 27 possible scenarios .................................................... 49

Table 12 List of the hypothetical intersections and their attributes ..................................... 51

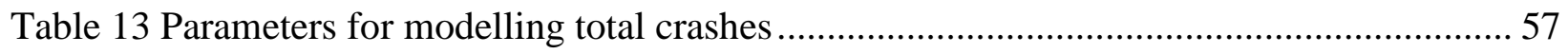

Table 14 Parameters for modelling total crashes including average length of left turn lanes along

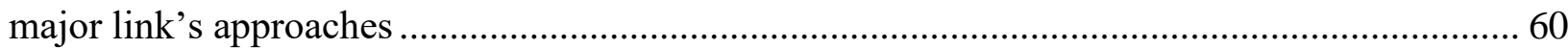

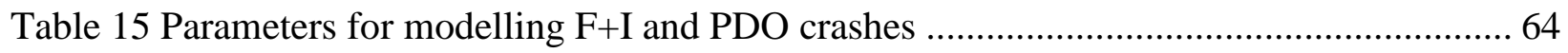


Table 16 Parameters for modelling fatal and injury crashes including average length of left turn

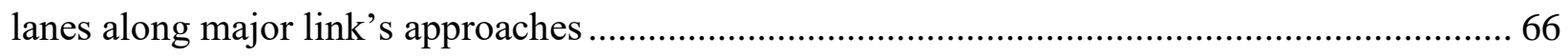

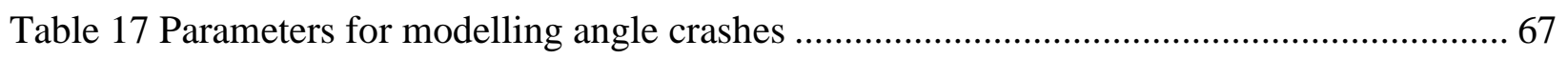

Table 18 Parameters for modelling angle crashes including average length of left turn lanes along

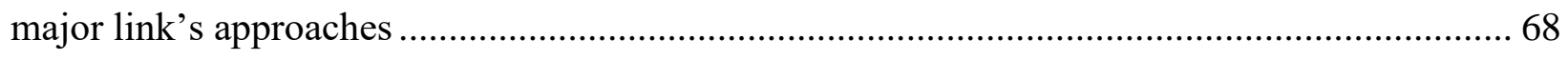

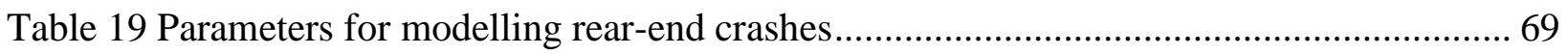

Table 20 Parameters for modelling rear-end crashes including average length of left turn lanes

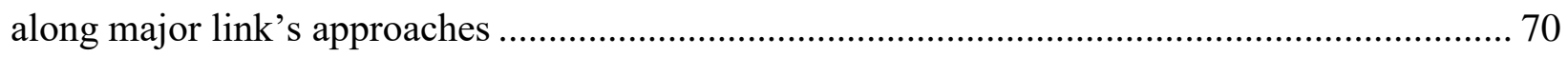

Table 21 Parameters for modelling turning movement crashes......................................... 71

Table 22 Parameters for modelling turning movement crashes including average length of left turn

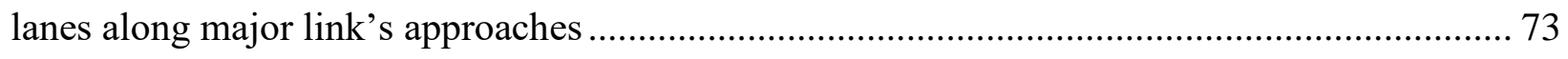

Table 23 Parameters for modelling total crashes using VISSIM-SSAM output ....................... 76

Table 24 Parameters for modelling crashes involving fatality or injury using VISSIM-SSAM

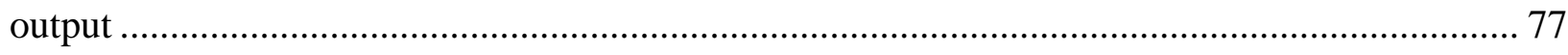

Table 25 Parameters for modelling PDO crashes involving fatality or injury using VISSIM-SSAM

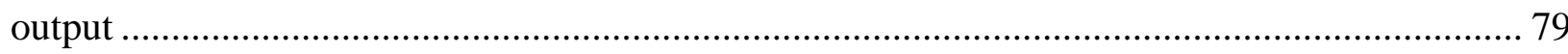

Table 26 Parameters for modelling angle crashes using VISSIM-SSAM output...................... 81

Table 27 Parameters for modelling rear-end crashes using VISSIM-SSAM output.................. 81

Table 28 Parameters for modelling turning movement crashes using VISSIM-SSAM output.... 83

Table 29 Summary of crash conflict models for each crash type ....................................... 85

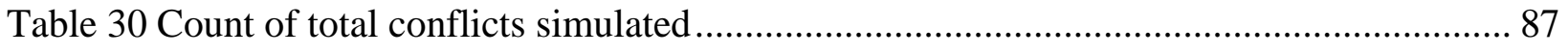

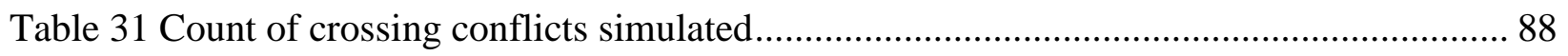

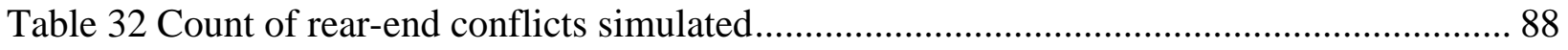


Table 33 Count of lane change conflicts simulated 89

Table 34 CMF for predicted total crashes at the 27 hypothetical intersections......................... 90

Table 35 CMF for predicted fatal and injury crashes at the 27 hypothetical intersections ......... 91

Table 36 CMF for predicted PDO crashes at the 27 hypothetical intersections ....................... 92

Table 37 CMF for predicted rear-end crashes at the 27 hypothetical intersections................... 93

Table 38 CMF for predicted turning movement crashes at the 27 hypothetical intersections ..... 94

Table 39 CMF for Total crashes, from base condition of no left turn lane and no left turn protective phase, Mult. indicating multiplied CMF, and Comb the combined CMF .............................. 96 Table $40 \mathrm{CMF}$ for Fatal and injury crashes, from base condition of no left turn lane and no left

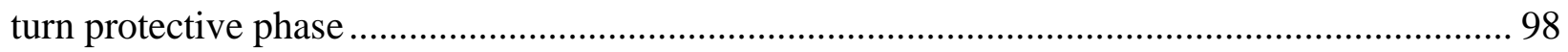
Table $41 \mathrm{CMF}$ for PDO crashes, from base condition of no left turn lane and no left turn protective phase 100

Table 42 CMF for rear-end crashes, from base condition of no left turn lane and no left turn protective phase 102 Table 43 CMF for turning movement crashes, from base condition of no left turn lane and no left turn protective phase 104

Table 44 Location of the 48 MTO intersections 109 Table 45 Years 2000 to 2013, 14-year crash count, and 10 hour long simulated conflicts for maximum TTC threshold of 1.5 seconds for MTO intersections . 112

Table 46 Number of total conflict counts recorded from the hypothetical intersections. 134 Table 47 Number of crossing conflict counts recorded from the hypothetical intersections ..... 135 Table 48 Number of rear-end conflict counts recorded from the hypothetical intersections ..... 136 Table 49 Number of crossing conflict counts recorded from the hypothetical intersections ..... 137 
Table 50 Estimated CMFs for total crashes at the 27 hypothetical intersections .................... 138

Table 51 Estimated CMFs for Fatal and injury crashes at the 27 hypothetical intersections ..... 139

Table 52 Estimated CMFs for PDO crashes at the 27 hypothetical intersections ................... 140

Table 53 Estimated CMFs for rear-end crashes at the 27 hypothetical intersections ................ 141

Table 54 Estimated CMFs for turning movement crashes at the 27 hypothetical intersections. 142 


\section{LIST OF FIGURES}

Figure 1 Left turning movement and the other directions of travel ........................................ 1

Figure 2 Breakdown of crashes at an intersection based on a collision study done by FHWA

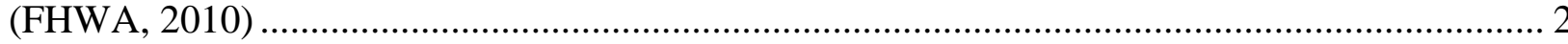

Figure 3 Breakdown of crashes at an intersection based on the 2000-2013 MTO Data provided . 2

Figure 4 Simplified Flowchart of steps undertaken in the analysis ........................................ 5

Figure 5 Components of a left turn lane (MTO, 1985) .......................................................... 7

Figure 6 Example warrant graph for left turn lane on unsignalized intersections (MTO, 1985) ... 7

Figure 7 Two segments at a signalized intersection (MTO, 1985) ......................................... 8

Figure 8 Nomograph for length of deceleration lane of a left turn lane at a signalized intersection

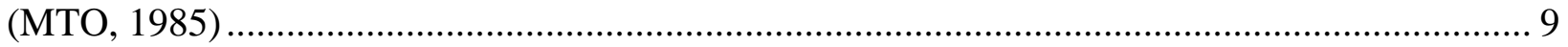

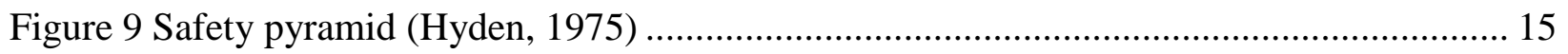

Figure 10 Hurontario St-Highway 10 and Buena Vista Drive and Broadway, Orangeville, example

of two left turn lanes ............................................................................................... 21

Figure 11 Hurontario St.-Highway 10 and Old Baseline Rd-Peel Regional Road 12, example of

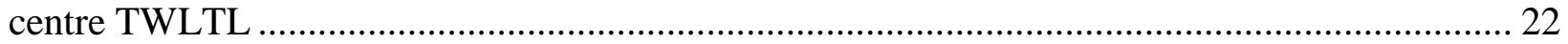

Figure 12 Highway 3 east of St. Thomas, an example of the main highway having two directional

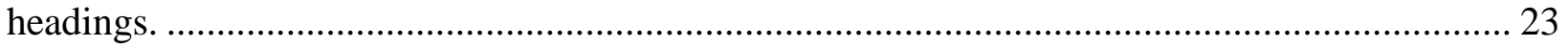

Figure 13 Highway 7A and Queen St., Port Perry, example of irregular intersection geometry. 24

Figure 14 Map of distribution of the final list of sites across the province ............................. 25

Figure 15 Breakdown of components of a left turn lane along its length................................. 27

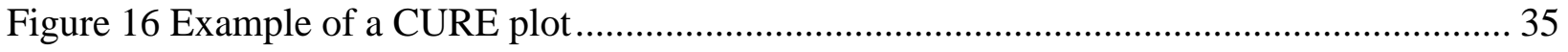


Figure 17 Example of the outcome of generalized linear model with binomial distribution on Excel

Figure 18 An example SAS Enterprise 6.1's output model............................................... 39

Figure 19 Typical distribution of AADT during the day in percentage of AADT (VanDelen et al., 2008) 42

Figure 20 Synchro diagram of one of the intersections .................................................. 42

Figure 21 Intersection in VISSIM after being imported ................................................. 44

Figure 22 VISSIM simulation parameters .................................................................. 45

Figure 23 CURE Plots for Major and Minor AADTs for total crashes ................................. 58

Figure 24 CURE Plots for Major and Minor AADTs and left turn volume ratio for total crashes

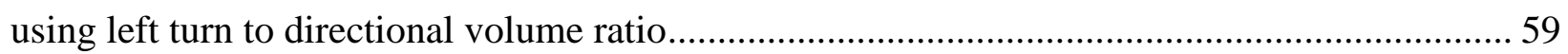

Figure 25 CURE Plots for Major and Minor AADTs and left turn volume ratio for total crashes

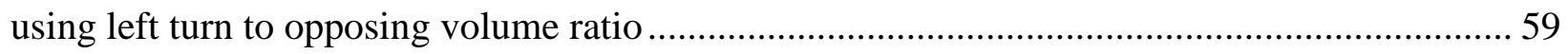
Figure 26 CURE Plots for Major and Minor AADTs and length of left turn lane for total crashes

Figure 27 CURE Plots for Major and Minor AADTs, left turn volume ratio, and length of left turn lane for total crashes using left turn to directional volume ratio 62

Figure 28 CURE Plots for Major and Minor AADTs, left turn volume ratio, and length of left turn

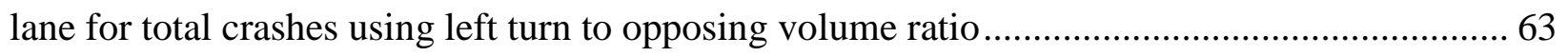

Figure 29 CURE Plots for conflicts for total crash conflict model..................................... 77

Figure 30 CURE Plot for conflicts for fatal and injury crash conflict model ........................... 78

Figure 31 CURE Plots for conflicts for PDO crash conflict model..................................... 80

Figure 32 CURE Plots for conflicts for Rear end crash conflict model ................................ 82 
Figure 33 CURE Plot for conflicts for turning movement crash conflict model...................... 84

Figure 34 Average total crash CMF vs length of left turn lane graph ................................... 97

Figure 35 Average fatal and injury crash CMF vs length of left turn lane graph.................... 99

Figure 36 Average PDO crash CMF vs length of left turn lane graph ................................ 101

Figure 37 Average Rear end crash CMF vs length of left turn lane graph ............................ 103

Figure 38 Average turning movement crash CMF vs length of left turn lane graph................ 105

Figure 39 CURE Plots for Major and Minor AADTs for fatal and injury crashes................... 114

Figure 40 CURE Plots for Major and Minor AADTs and left turn volume ratio for fatal and injury crashes using a left turn to directional volume ratio ....................................................... 114

Figure 41 CURE Plots for Major and Minor AADTs and left turn volume ratio for fatal and injury crashes using a left turn to opposing volume ratio ...................................................... 115

Figure 42 CURE Plots for Major and Minor AADTs and length of a left turn lane for fatal and

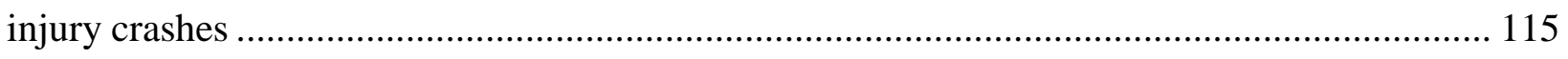

Figure 43 CURE Plots for Major and Minor AADTs, left turn volume ratio, and length of a left turn lane for fatal and injury crashes using a left turn to directional volume ratio................... 116 Figure 44 CURE Plots for Major and Minor AADTs, left turn volume ratio, and length of a left turn lane for fatal and injury crashes using a left turn to opposing volume ratio .................... 117 Figure 45 CURE Plots for Major and Minor AADTs for PDO crashes ............................... 118 Figure 46 CURE Plots for Major and Minor AADTs and left turn volume ratio for PDO crashes using a left turn to directional volume ratio................................................................ 118 Figure 47 CURE Plots for Major and Minor AADTs and left turn volume ratio for PDO crashes using a left turn to opposing volume ratio ................................................................... 119 
Figure 48 CURE Plots for Major and Minor AADTs and length of a left turn lane for PDO crashes

Figure 49 CURE Plots for Major and Minor AADTs, left turn volume ratio, and length of left turn lane for PDO crashes using a left turn to directional volume ratio...... 120

Figure 50 CURE Plots for Major and Minor AADTs, left turn volume ratio, and length of a left turn lane for PDO crashes using a left turn to opposing volume ratio. 121

Figure 51 CURE Plots for Major and Minor AADTs for angle crashes 122

Figure 52 CURE Plots for Major and Minor AADTs and left turn volume ratio for angle crashes using a left turn to directional volume ratio. 122

Figure 53 CURE Plots for Major and Minor AADTs and left turn volume ratio for angle crashes using a left turn to opposing volume ratio 123 Figure 54 CURE Plots for Major and Minor AADTs and length of a left turn lane for angle crashes 123

Figure 55 CURE Plots for Major and Minor AADTs, left turn volume ratio, and length of left turn lane for angle crashes using a left turn to directional volume ratio 124 Figure 56 CURE Plots for Major and Minor AADTs, left turn volume ratio, and length of a left turn lane for angle crashes using a left turn to opposing volume ratio 125

Figure 57 CURE Plots for Major and Minor AADTs for rear-end crashes. 126 Figure 58 CURE Plots for Major and Minor AADTs and left turn volume ratio for rear-end crashes using a left turn to directional volume ratio. 126 Figure 59 CURE Plots for Major and Minor AADTs and left turn volume ratio for-rear end crashes using a left turn to opposing volume ratio 127 
Figure 60 CURE Plots for Major and Minor AADTs and length of a left turn lane for rear-end crashes

Figure 61 CURE Plots for Major and Minor AADTs, left turn volume ratio, and length of a left turn lane for rear-end crashes using a left turn to directional volume ratio. 128 Figure 62 CURE Plots for Major and Minor AADTs, left turn volume ratio, and length of a left turn lane for rear-end crashes using a left turn to opposing volume ratio 129 Figure 63 CURE Plots for Major and Minor AADTs for turning movement crashes 130 Figure 64 CURE Plots for Major and Minor AADTs and left turn volume ratio for turning movement crashes using a left turn to directional volume ratio 130 Figure 65 CURE Plots for Major and Minor AADTs and left turn volume ratio for turning movement crashes using a left turn to opposing volume ratio. 131 Figure 66 CURE Plots for Major and Minor AADTs and length of a left turn lane for turning movement crashes 131 Figure 67 CURE Plots for Major and Minor AADTs, left turn volume ratio, and length of left turn lane for turning movement crashes using a left turn to directional volume ratio 132 Figure 68 CURE Plots for Major and Minor AADTs, left turn volume ratio, and length of a left turn lane for turning movement crashes using a left turn to opposing volume ratio 133 


\section{ACRONYMS}

\begin{tabular}{|c|c|}
\hline AADT & Annual Average Daily Traffic \\
\hline $\mathrm{CG}$ & Comparison Group \\
\hline $\mathrm{CMF}$ & Crash Modification Factor \\
\hline Comb & Combined CMF \\
\hline C.R. & Crash Reduction \\
\hline CURE & Cumulative Residual \\
\hline EB & Empirical Bayes \\
\hline FHWA & Federal Highway Administration \\
\hline GLM & Generalized linear model \\
\hline HIIFP & Highway Infrastructure Innovation Funding Program \\
\hline HSM & Highway Safety Manual \\
\hline LHRS & Linear Highway Referencing System \\
\hline LOS & Level of Service \\
\hline Maj & Major Link \\
\hline Min & Minor Link \\
\hline MLE & Maximum likelihood estimate \\
\hline Mult & Multiplication based Combined CMF \\
\hline MTO & Ministry of Transportation Ontario \\
\hline MVAB & Motor Vehicle Accident data master file \\
\hline PDO & Property Damage Only \\
\hline PET & Post Encroachment Time \\
\hline RE & Rear End collision \\
\hline
\end{tabular}


SAS Statistical Analysis software

SPF Safety Performance Function

SSAM Surrogate Safety Assessment Tool

TM Turning Movement Collison

TTC Time to Collision

Vol. Volume 


\section{INTRODUCTION}

\subsection{Background}

Intersections are one of the most critical aspects of transportation networks. All of the road links for each direction of travel cross one another at intersections, allowing vehicles to move from one road link to another. Intersections are associated with the highest number of conflicts and the highest risk of collisions compared to any other part of roadways. At an intersection, the left turning maneuver has the highest number of possible conflicts as this movement involves an interaction with all four directions of travel (see Figure 1).

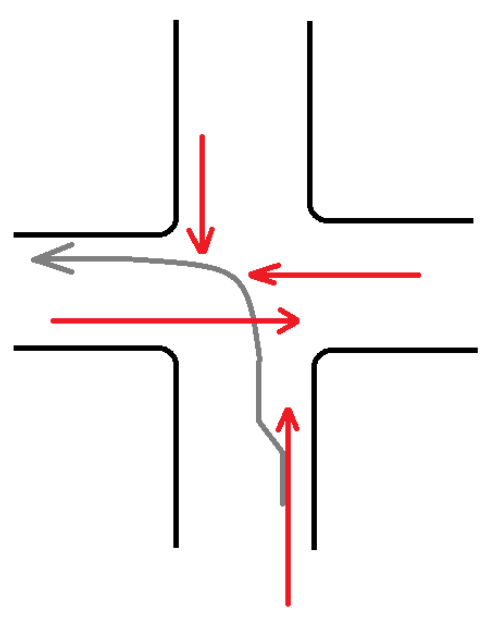

Figure 1 Left turning movement and the other directions of travel

According to a study conducted by the FHWA (2010), collisions related to a left turn movements (classified as approach turns) represent $54 \%$ of the total number of collisions at intersections (see Figure 2). The data provided by the MTO for the intersections of interest in this study also revealed 
that the number of collisions involving turning movements and approach turns represented 36\% of the total collisions at intersections in Ontario.

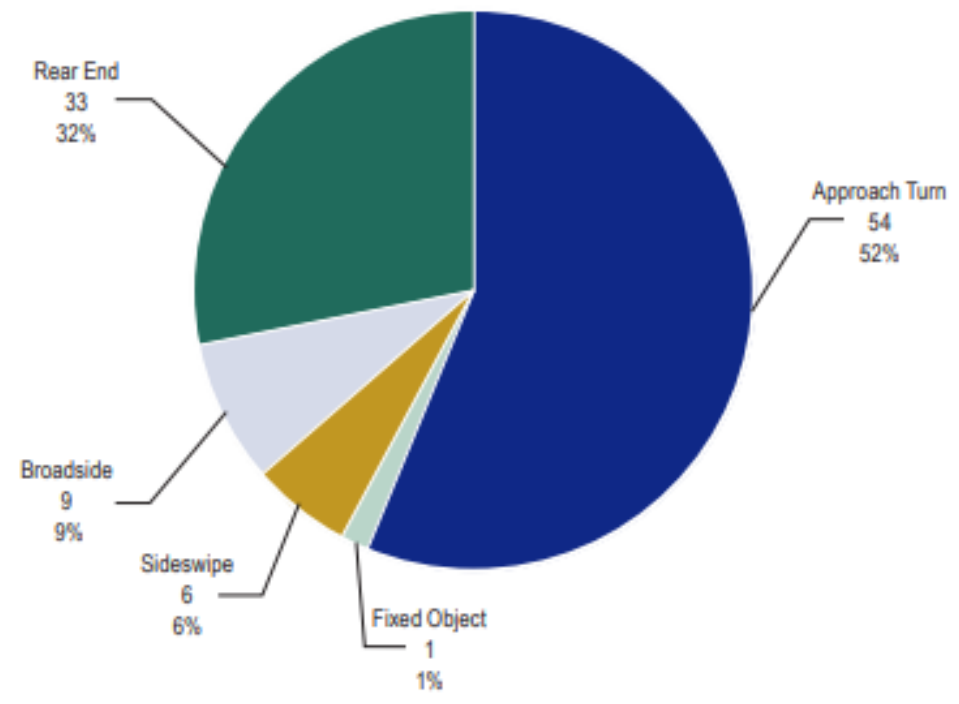

Figure 2 Breakdown of crashes at an intersection based on a collision study done by FHWA (FHWA, 2010)

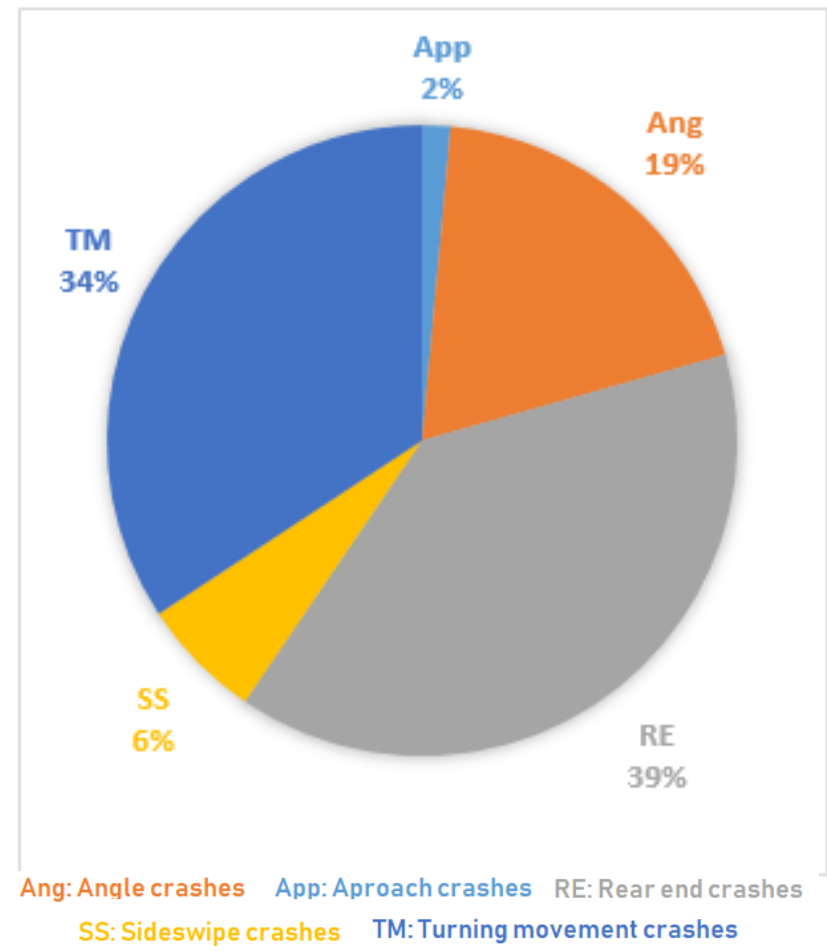

Figure 3 Breakdown of crashes at an intersection based on the 2000-2013 MTO Data provided 
Road designers make provisions in order to reduce the risk of a collision when making a left turn movement at intersections. This is done in order to ensure that left turn maneuvers are as safe as possible given the conditions of the intersection, such as traffic volume in the opposing direction and the number of vehicles making a left turn. These provisions include the addition of a left turn lane, a signal phase during which left turning vehicles are protected from incoming traffic (i.e. protected left turn phase), and the addition of a second left turn phase, parallel to the first one (in suburban settings).

\subsection{Problem Statement and Objectives}

As explained in the literature review (Chapter 2 section 1), the current MTO practices (MTO, 1985) for signalized intersections are based on physics and geometric attributes and do not include empirical data regarding driver behavior under various conditions. They are only designed to provide enough space for one vehicle to decelerate safely and enough storage space to queue up at the intersection for the duration of the cycle length.

The first objective of this study was to estimate models relating the existing MTO crash records with various intersection conditions, with a special focus on the length of left turn lanes.

The second objective of the study was to use microsimulations for a series of hypothetical intersections in order to eliminate all other factors that may impact the safety of an intersection beside the length of the left turn, to find crash modification factor (CMF) values that would be only reflective of the impact of an increase in a left turn lane. CMF is the ratio of predicted crashes after the proposed treatment, in this case lengthening of a left turn lane, and predicted crashes had 
the treatment not been installed. The microsimulation utilized conflicts as a surrogate measure of safety. The necessity of doing this, and what this means is explained further in a literature review.

Thirdly, microsimulations were also used for determining the CMF of the simultaneous implementation of left turn lanes with varying lengths and a left turn protective phase. The CMF was then compared to what the CMF would be following HSM's suggestion of multiplying CMFs.

\subsection{Thesis Organization}

This thesis is organized into 8 chapters. Chapter 2 provides an overview of the literature in the fields related to the topic of interest and provides a summary of the current guidelines used to determine the length of left turn lanes. Chapter 3 explains the data collection process. Chapter 4 describes the step-by-step methodology used for the data analysis. Chapter 5 presents the models for a direct crash to a variable relationship, i.e. AADTs, left turning volume ratios, and length of left turn lanes. Chapter 6 demonstrates the estimated crash-conflict models. Chapter 7 presents the estimated CMF values for a series of hypothetical intersections simulated for three different treatments. Chapter 8 analyzes the safety impact of a dual treatment involving the installation of a left turn protective phase and a left turn lane (varying lengths). Chapter 9 provides a summary of the results, concluding remarks, and the shortcomings of the study. 

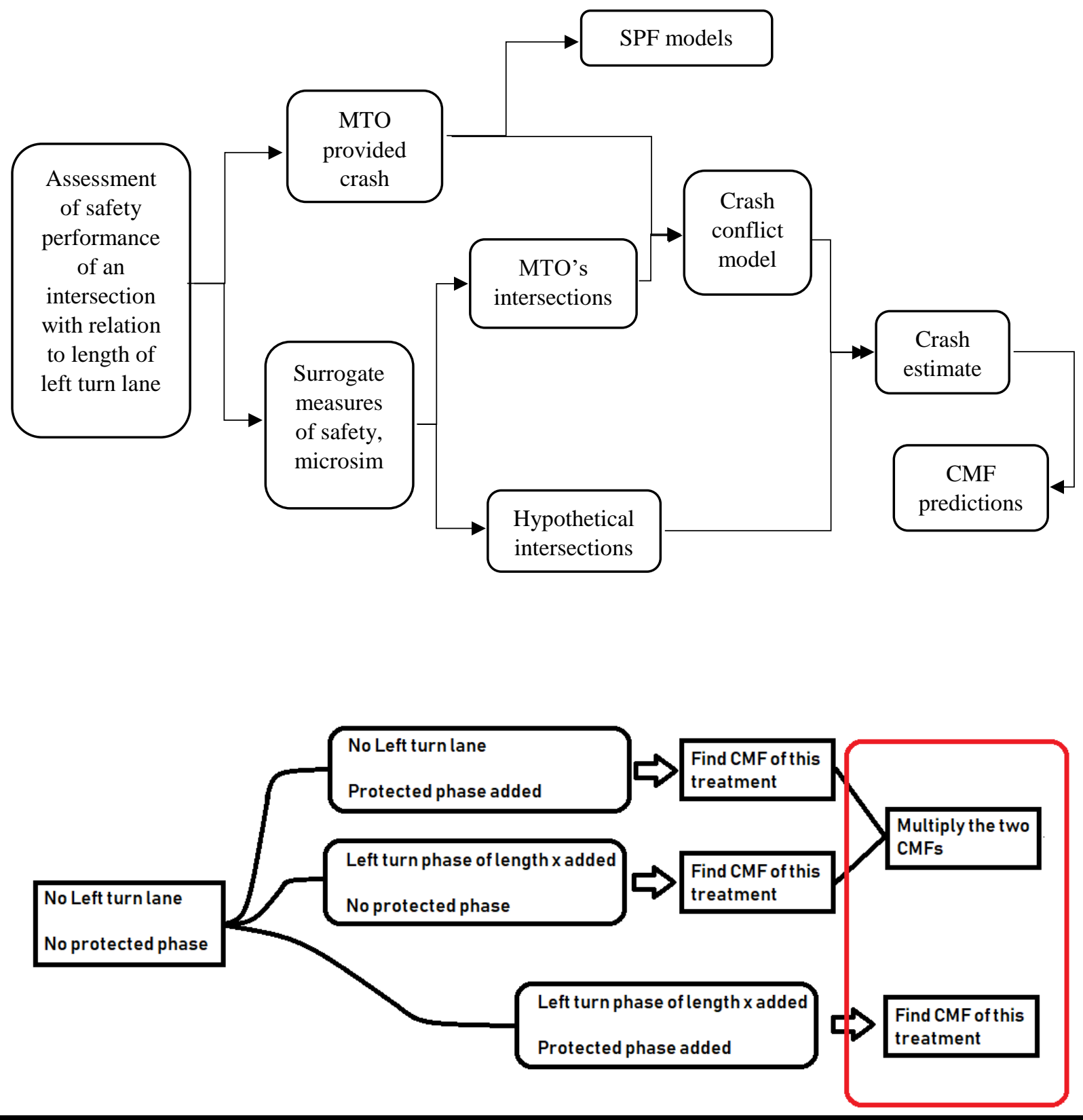

Figure 4 Simplified Flowchart of steps undertaken in the analysis 


\section{LITERATURE REVIEW}

This chapter presents an extensive review of the relevant literature conducted in preparation for the data analysis in this study. This chapter covers the current guidelines used by the MTO, previous research conducted in the field regarding the various aspects of left turn lanes and how they impact the safety of intersections as well as the use of surrogate measures to predict the safety performance of various road elements, and an overview of the software that was used in this study.

\subsection{Current Design Practices}

The topic of interest in this study was the length of left turn lanes on rural highways in the province of Ontario. It is therefore critical to have an understanding of the current design guidelines and practices in order to determine the current state of intersections and to accurately recreate hypothetical intersections that reflect real-life conditions in the province.

The guideline text states that the warrants and standards were determined based on field studies and the theoretical analysis of traffic behavior at intersections (MTO, 1985). The guideline provides two different sets of standards, one for unsignalized intersections and another for signalized intersections. The standards for unsignalized intersections are more thorough and include more variables than those for signalized intersections. 


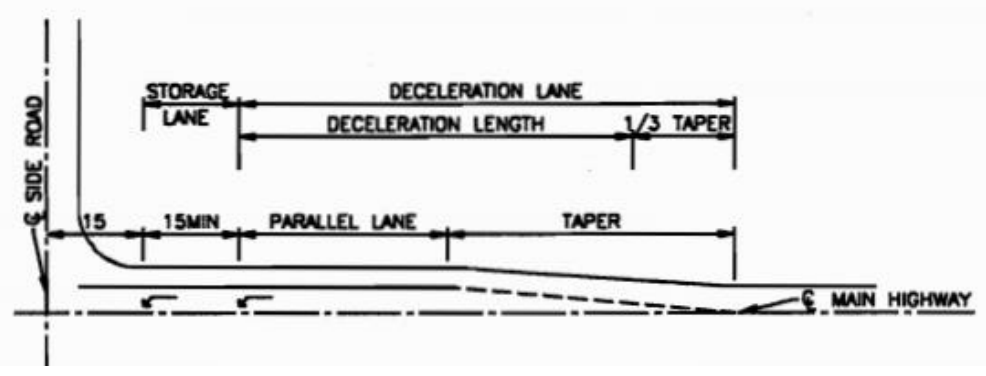

Figure 5 Components of a left turn lane (MTO, 1985)

There is a warrant regarding whether or not left turn lanes are to be installed at an intersection based on accident records. This warrant states that the installation of a left turn lane may be considered if there are four or more left turn related accidents in a year or 6 or more left turn related accidents within two years. The warrant for unsignalized intersections is based on the following variables: opposing volume, directional volume, storage length (minimum length of $15 \mathrm{~m}$ ), design speed, and the percentage ratio of left turning volume to directional through volume.

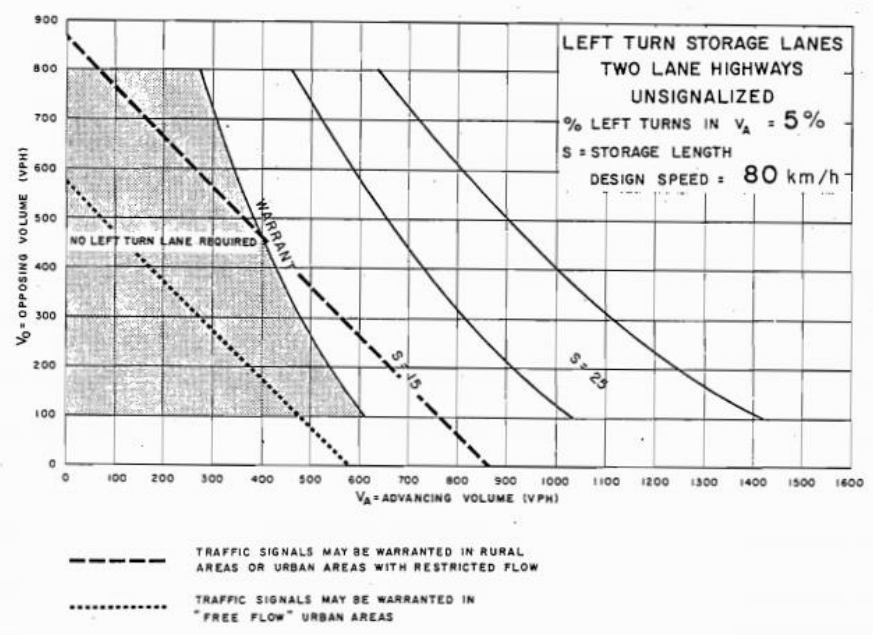

Figure 6 Example warrant graph for left turn lane on unsignalized intersections (MTO, 1985) 
The current focus is on the standards for signalized intersections, as this is the type of intersection being studied in this research paper. Left turn lanes have three distinct segments: a taper lane, a deceleration lane (which covers a portion of the taper lane), and a storage lane (Figure 5).

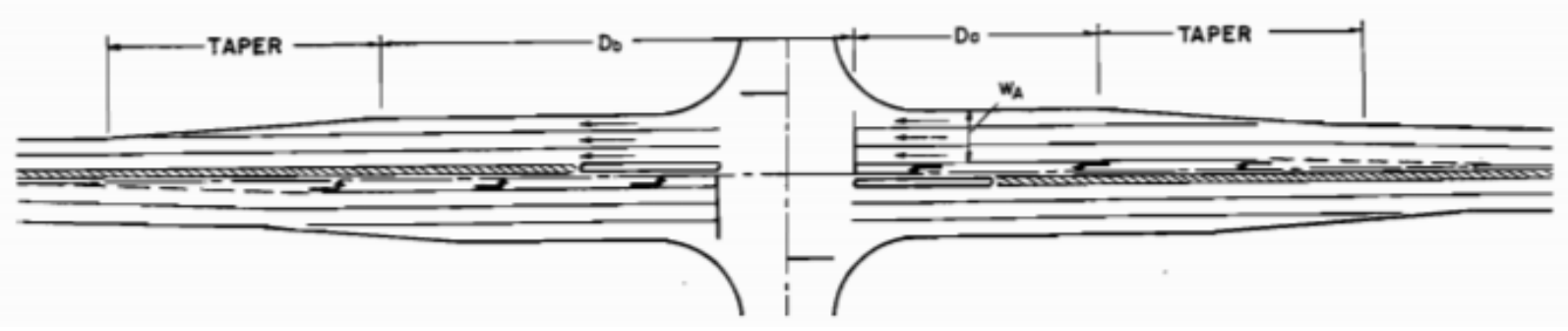

Figure 7 Two segments at a signalized intersection (MTO, 1985)

The length of the taper lane depends on the design speed of the roadway and is determined using the values in the chart shown in figure 8 . The length of the rest of the left turn lane (marked as $D_{a}$ in figure 7), which includes the length of the storage and deceleration lanes but excluding the taper lane, also depends on the design speed and can be determined using the chart in Table 1. Alternatively, it can be determined using the nomograph shown in figure 9. The lengths in the nomograph depend on the through traffic volume per lane, the signal cycle length, and the percentage of heavy traffic using the road (MTO, 1985). As previously stated, these guidelines are purely based on physics and geometry and are designed to provide adequate length for vehicles to safely change lanes, decelerate, and have enough storage space to stop at the light without shortening the length of the lane that could be used by incoming vehicles to decelerate. 
Table 1 Table for length of taper and deceleration lane length of left turn lane at a signalized intersection (MTO, 1985)

\begin{tabular}{|c|c|c|c|}
\hline \multicolumn{4}{|c|}{$\begin{array}{l}\text { Length of Widening } \\
\text { In Advance of Intersections ( Deceleration + Taper ) }\end{array}$} \\
\hline \multirow{2}{*}{$\begin{array}{c}\text { Design } \\
\text { Speed } \\
\mathrm{km} / \mathrm{h}\end{array}$} & \multicolumn{2}{|c|}{ Deceleration } & \multirow{2}{*}{$\frac{\text { Taper }}{3.0 \mathrm{~s} \mathrm{~m}}$} \\
\hline & $\mathrm{Da} \mathrm{m}$ & Da - Nomograph & \\
\hline 50 & 20 & \multirow{6}{*}{$\begin{array}{l}\text { Divide approach } \\
\text { volume by no. of } \\
\text { lanes in } \mathrm{W}_{\mathcal{A}} \text { use } \\
\text { volume per lane } \\
\text { in chart, find 'Da" } \\
\text { on desirable } \\
\text { scale. }\end{array}$} & 40 \\
\hline 60 & 30 & & 50 \\
\hline 70 & 45 & & 60 \\
\hline 80 & 60 & & 70 \\
\hline 90 & 70 & & 75 \\
\hline 100 & 85 & & 80 \\
\hline
\end{tabular}

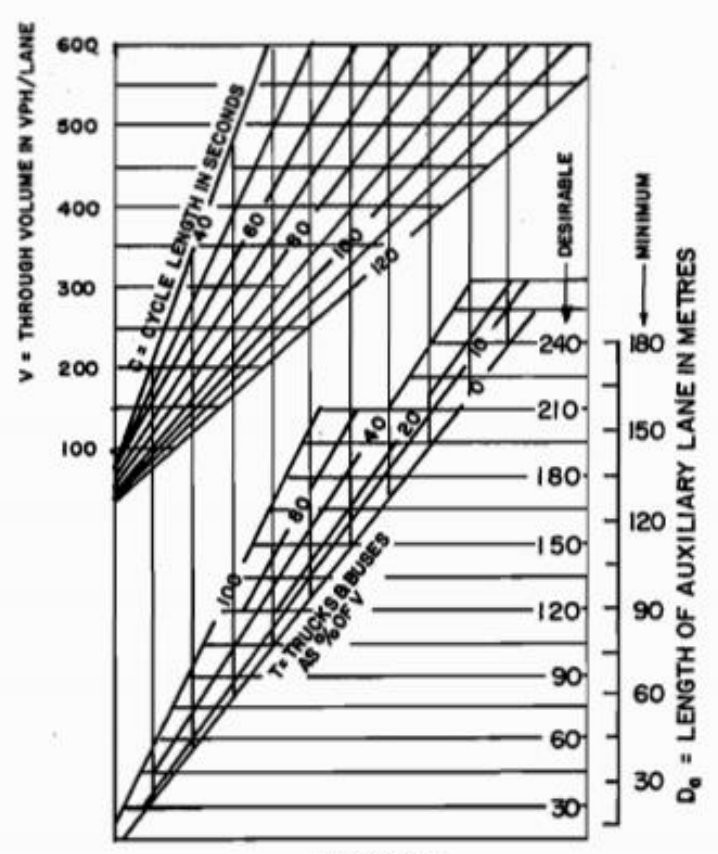

NOMOGRAPH

Figure 8 Nomograph for length of deceleration lane of a left turn lane at a signalized intersection (MTO, 1985) 


\subsection{Left Turn Movement Safety}

An extensive review of the existing literature on road safety was conducted for the purpose of this research paper, and a summary of the findings are presented in this section. The results revealed a lack of research on the impact of the length of left turning lanes on the safety performance of intersections. However, a large number of studies have been conducted on left turn lanes in general and protected left turn phases.

Shahdah (2014) investigated changing the signal phasing setup from permissive to protectedpermissive. The study used nine years of traffic volume and crash records for 47 urban sites in Toronto. Two crash categories, rear-end (RE) and left-turn opposing (LTOPP), were examined. The 47 intersections were then simulated using VISSIM for maximum TTC thresholds of 0.5 and 1.5. The simulation results were then used to create crash conflict models. Models from each of the two thresholds were used to find the treatment CMF. The results indicated that the CMFs obtained from crash-conflict integrated models are consistent with those estimated using the empirical Bayes before-after study method.

Srinivasan et al. (2014) looked at the safety impact of the installation of signalized intersections with and without left turn lanes in rural and suburban areas. 117 intersections in North Carolina were used for the before-after study using the empirical Bayes method. In the before scenario, all of the intersections were stop-controlled on minor roads. The results demonstrated that the installation of signalized intersections without left turn lanes results in a decrease in the number of all of the crash categories with the exception of the number of rear end crashes, which are increased. Rear-end crashes are decreased following the addition of left-turn lanes. The results 
indicated that the addition of left-turn lanes has the greatest impact on the rear end and fatal and injury crashes, but no benefit was observed for the two frontal crash categories (Srinivasan et al., 2014). Based on these results, we expect to see a significant reduction in rear-end crashes with increases in the length of left turn lanes, but no change in turning movement crashes.

Abdel-Aty et al. (2014) conducted a thorough study of the application and validation of the Highway Safety Manual guidelines (HSM) in Florida. A portion of the study examined the impact of the installation of left-turn lanes. 18 3-legged and 9 4-legged rural intersections were used in the analysis. Three methods were used for the calibration of CMFS: the naïve before-after method, before-after with a comparison group, and before after with the Empirical Bayes method. 90 sites were identified for the comparison group for the before-after method with a comparison group. As illustrated in Table 2, the CMF for the installation of left turn lanes was larger than 1.0 for total crashes at 3-legged intersections for all three methods, and for one of the methods for fatal and injury crashes, indicating that there was not much benefit from the installation of left-turn lanes at 3-legged intersections. The same can be seen for 4-legged intersections for the Empirical Bayes method. Overall, the estimated CMF values were larger than those listed in HSM (see Table 3) (Abdel-Aty et al., 2014). 
Table 2 CMFs for the before-after studies conducted (Abdel-Aty et al., 2014)

\begin{tabular}{|c|c|c|c|}
\hline \multirow{2}{*}{ CMF Method } & \multicolumn{3}{|c|}{ Florida-Specific CMF } \\
\hline & Naïve & CG & EB \\
\hline \multicolumn{4}{|c|}{ Rural 3-Leg Intersections } \\
\hline $\begin{array}{c}\text { Total Crashes } \\
\text { (S.E.) }\end{array}$ & 1.110 & $\begin{array}{c}1.32 \\
(0.24)\end{array}$ & $\begin{array}{c}1.07 \\
(0.19)\end{array}$ \\
\hline $\begin{array}{l}\mathrm{F}+\mathrm{I} \text { crashes } \\
\text { (S.E.) }\end{array}$ & 0.751 & $\begin{array}{c}1.11 \\
(0.25)\end{array}$ & $\begin{array}{l}0.73^{*} \\
(0.17)\end{array}$ \\
\hline \multicolumn{4}{|c|}{ Rural 4-Leg Intersections } \\
\hline $\begin{array}{c}\text { Total Crashes } \\
\text { (S.E.) }\end{array}$ & 0.816 & $\begin{array}{l}0.69^{*} \\
(0.11) \\
\end{array}$ & $\begin{array}{c}1.12 \\
(0.19) \\
\end{array}$ \\
\hline $\begin{array}{c}\mathrm{F}+\mathrm{I} \text { Crashes } \\
\text { (S.E.) }\end{array}$ & 0.821 & $\begin{array}{l}0.64^{*} \\
(0.14)\end{array}$ & $\begin{array}{c}1.33 \\
(0.28)\end{array}$ \\
\hline
\end{tabular}

*Significant at a $85 \%$ confidence level.

Table 3 A comparison of the CMF values for HSM and the EB before-after method for 3-legged, and CG before-after for 4-legged (Abdel-Aty et al., 2014)

\begin{tabular}{|c|c|c|}
\hline Crash type & Florida-Specific CMF & CMF in HSM \\
\hline \multicolumn{3}{|c|}{ Rural 3-Leg Intersections } \\
\hline $\begin{array}{c}\text { Total Crashes } \\
\text { (S.E.) }\end{array}$ & $\begin{array}{l}1.07 \\
(0.19)\end{array}$ & $\begin{array}{l}0.56^{*} \\
(0.07)\end{array}$ \\
\hline $\begin{array}{c}\mathrm{F}+\mathrm{I} \text { crashes } \\
\text { (S.E.) }\end{array}$ & $\begin{array}{l}0.73^{*} \\
(0.17)\end{array}$ & $\begin{array}{l}0.45^{*} \\
(0.10)\end{array}$ \\
\hline \multicolumn{3}{|c|}{ Rural 4-Leg Intersections } \\
\hline $\begin{array}{c}\text { Total Crashes } \\
\text { (S.E.) }\end{array}$ & $\begin{array}{l}0.69^{*} \\
(0.11)\end{array}$ & $\begin{array}{l}0.52^{*} \\
(0.04)\end{array}$ \\
\hline $\begin{array}{c}\text { F+I Crashes } \\
\text { (S.E.) }\end{array}$ & $\begin{array}{l}0.64^{*} \\
(0.14)\end{array}$ & $\begin{array}{l}0.42^{*} \\
(0.04)\end{array}$ \\
\hline
\end{tabular}

Note: The values in bold are recommended CMFs for Florida.

*Significant at a $85 \%$ confidence level. 


\subsection{Surrogate Measure of Safety}

Using surrogate measure of safety was determined to be necessary in the analysis as there are attributes of actual intersections that vary from one another and the extent of their impacts doesn't specifically depend on the length of left turn lanes on major approaches. But they do influence the number of crashes, perhaps more than the length of left turn lane on major approaches would. Example of such attributes is the volumes on minor approaches, and the turning movement breakdown on the minor approaches. Other attributes that would have an impact on the number of crashes are whether minor approaches have left turn lanes on them, and what their lengths are. These were not part of the scope of the study, due to the fact that the resulting models would have required knowing many variables to input, at times not accessible to those interested in determining the safety of an intersection. Therefore, intersections at which the mentioned attributed were assumed to be constant and only the attributes in question, which were length of left turn lanes, and other attributes whose influence on safety of an intersection would be impacted by any change in length of left turn lanes were varied among the hypothetical sites created. These variables are AADTs on major approaches and the turning movement breakdown of this AADT.

Surrogate safety measures are events and attributes, that can be correlated with crashes. They are primarily used as an alternative to crashes, as sometimes the crash data may not be enough, or for any given reason, an accurate count could not be possible. Surrogate safety measures are also used in cases that simply have a premise that is a hypothetical scenario in the future and thus counting crashes would have been meaningless in her case, as was the case for Espinosa et al.'s (2017) research on determining impact of presence of autonomous vehicles on safety of urban 
intersections. The following list is an example of parameters that can be used as surrogate measures of safety by FHWA (2008):

- Vehicle delay

- Travel time

- Approach speed

- Percent of stopped vehicles or queue length

- Stop bar encroachment

- Red light violations

- Traffic conflict counts

Traffic conflicts are defined as observable situations in which there would be a risk of collision if the movement of the vehicles approaching one another remained unchanged (FHWA, 2008). The techniques were first developed and applied by Perkins and Harris (1967).

Since the number of conflicts is significantly higher than the number of collisions, the use of conflicts would result in estimating models that are statistically more significant for the measurement of intersection safety. Some of the other items listed by FHWA (2008) as surrogate measures of safety, such as stop bar encroachments and red light violations cannot be simulated and have to be measured in the field; this would not have been possible for hypothetical intersections. Travel time, vehicle delay, queue length, and approach speed would not have varied extensively as the intersections were rural in nature and did not have the same traffic volumes as urban intersections. Thus, their range would have been very small and they wouldn't have provided enough information. 


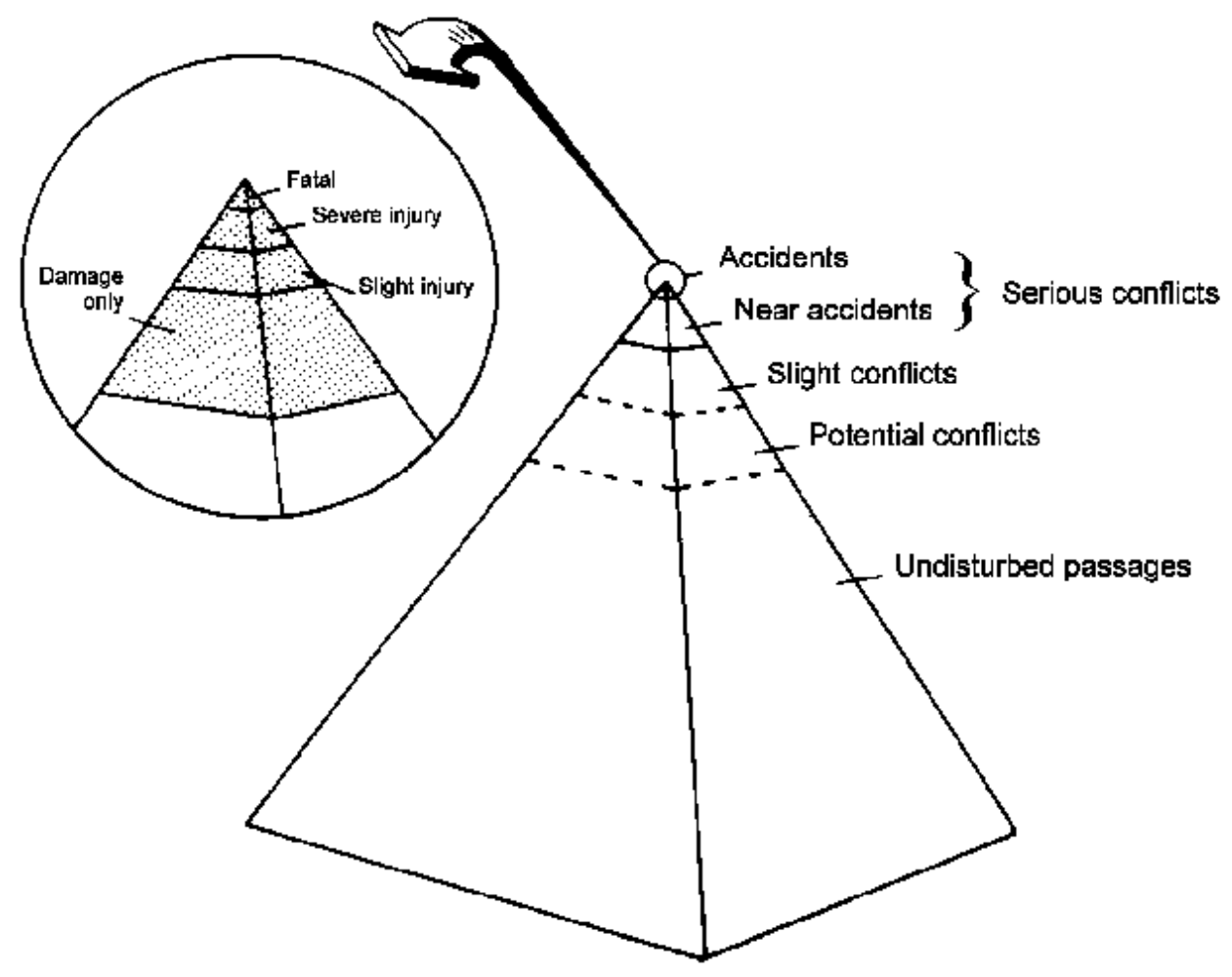

Figure 9 Safety pyramid (Hyden, 1975)

(Source: http://www.hupferingenieure.de/html/diss_ch_engl.htm)

Conflicts can be measured in the field by identifying events at which there are strong braking and evasive maneuvers. This method has had a long history of testing and development (FHWA, 2008) However, this method would be very time consuming, and counting conflicts in the field is not an option. Also, the intersections in this chapter of the analysis were hypothetical. Hypothetical intersections allow for a focus on variables that are thought to have their amount of influence on safety performance of the intersection impacted by a change in length of left turn lanes. They also allow defining variables as constants that do influence safety performance of the intersection but do not interact with major roadway's approaches' left turn lanes, such as minor approaches' 
turning volumes as constants. Using computer based microsimulation to obtain the number of expected conflicts at an intersection, including hypothetical ones, was an option. The study done by Sayed et al. (1994) demonstrated that the simulated conflicts are reasonably correlated with actual conflicts in the field

Lorion (2014) simulated 78 three-legged urban intersections and 55 four-legged urban intersections using crash data provided by the city of Toronto and derived models correlating crashes to conflicts, total delay, and movement delay. Both of the types of delay in Lorion's study were obtained using Synchro. The models were used for derivation of crashes before and after the implementation of a hypothetical treatment, in this case, installation of a left turn lane at 33 threelegged intersections (Lorion, 2014). The crashes predicted were then used by Lorion (2014) to find CMF values for this treatment.

Shahdah et al. (2014) explain that there is no guarantee that the conditions and situations at one site are comparable to the conditions and situations of another site that is being compared. Surrogate measures can, therefore, be used to eliminate the chance that factors that were unaccounted for may have impacted the results of the analysis. This study estimated crash conflict models and applies them to 47 intersections that had already been treated by changing the left turn signal priority from permissive to protected-permissive in order to find CMFs. The results of the study were in agreement with the analysis using a traditional crash-based Empirical Bayes beforeafter study, indicating that the use of surrogate safety measures is suitable for signalized intersections for the proposed treatments. 


\subsection{Combined CMF of Implementation of Multiple Treatments}

Chapter 3 of the Highway Safety Manual (HSM, 2010) suggests that the CMFs of multiple treatments should be multiplied in order to estimate the combined CMF for scenarios in which the treatments are implemented at the same time. This is a simplistic approach and more studies for specific sets of treatments are required in order to validate or refute the accuracy and realism of this method. Park and Abdel-Aty (2014) studied the CMFs of the simultaneous implementation of two safety treatments, the addition of rumble strips and the widening of the shoulder. The study revealed that the HSM method overestimates the positive impact of the combined treatment procedure.

\subsection{Conclusion}

There's been a lot of research done on left turn lanes, and what impact their installation has on the safety performance of an intersection. Overall, the literature concluded that rear-end crashes are most closely related to left turn lanes. However, no specific study that has looked into the length of left turn lanes has been done before. Thus, as current design practices were explained, this consideration has been something that's been left out, and so the study presented in this paper would be a starting step in the direction of filling this gap.

However, the findings presented in the previous research focusing on left turn lanes did offer an insight regarding what to expect from a change in length of a left turn lane at an intersection. Rear end crashes were expected to be reduced noticeably more than the other categories of crashes, whereas turning movement crashes were expected to not be impacted by any change in length of the left lane. 
Furthermore, the literature did provide previous examples of using conflict counts obtained from microsimulation as surrogate measures of safety. It also provided empirical analysis that stated that doing so would be a reasonably accurate representation of reality.

Lastly, based on the literature, the expected result from studying the differences between a combined CMF and HSM's multiplicative approach to installation of multiple treatments was that the HSM's method is expected to be too optimistic in estimating the amount of crash reduction predicted. However, the literature has been focused on highway segments and implementing treatments such as widening a shoulder and installation of rumble strips. No study on implementing measures aimed at addressing the safety of left turn movement has been done, and none that focuses specifically on the length of the left turn lane installed. 


\section{DATA COLLECTION}

This chapter explain the process of data collection for this analysis. Various sets of data were reorganized and compiled to make this study possible, these include traffic volume, turning movement breakdowns, crash record data, and geometric data. This data was first used in determining SPF models based on crash records, in an attempt to find models relating predicted crashes to AADTs, left turning volume ratios, and length of left turn lanes. In the next step, the geometric attributes were used so that the intersections could be drawn for microsimulation as accurately as possible. Then the simulation results obtained from the drawings of the intersection and crash records were the input that is used for modeling predicted crashes based on conflict counts.

\subsection{Identification of Sites}

The MTO provided the motor vehicle collision database (MVAB) for intersections from 2000 to 2013. There are several thousand kilometers of provincial highways under the jurisdiction of the MTO, with thousands of intersections (signalized and unsignalized). The analysis involved intersections that meet the following criteria:

\section{Signalized}

2. Left turn lanes at least on both approaches of the major link for 4-legged intersections, and on the one approach that would be able to accommodate a left turn at 3-legged intersections.

3. A maximum of only one lane dedicated to left turn movement in each direction, i.e. excluding intersections at which there are two parallel left turn lanes. 
4. No centre two-way left-turn lanes in any of the directions unless there is an end to it (with an island or other means) as it approaches the intersection.

5. No extra signal head provided for protected left turn phase

6. The provincial highway, defined as a major link, would clearly go through the intersection in the same heading that it entered the intersection

Criteria number 1 and 2 defined the scope of the study. Criteria number 3 was necessary because when there are two left turn lanes at an intersection, they are normally built at differing lengths (the inner lane is normally shorter than the outer one). For example, in Figure 10, each of the lanes reserved for left turn movement starts at two different locations (as indicated by the red line). Therefore, the distribution of the traffic between the two lanes would be an issue requiring a more detailed count not available. Even if these issues were to be addressed, the simulation software would not have had the ability to accurately simulate these cases. Synchro does not allow users to define the length of each storage lane individually. 


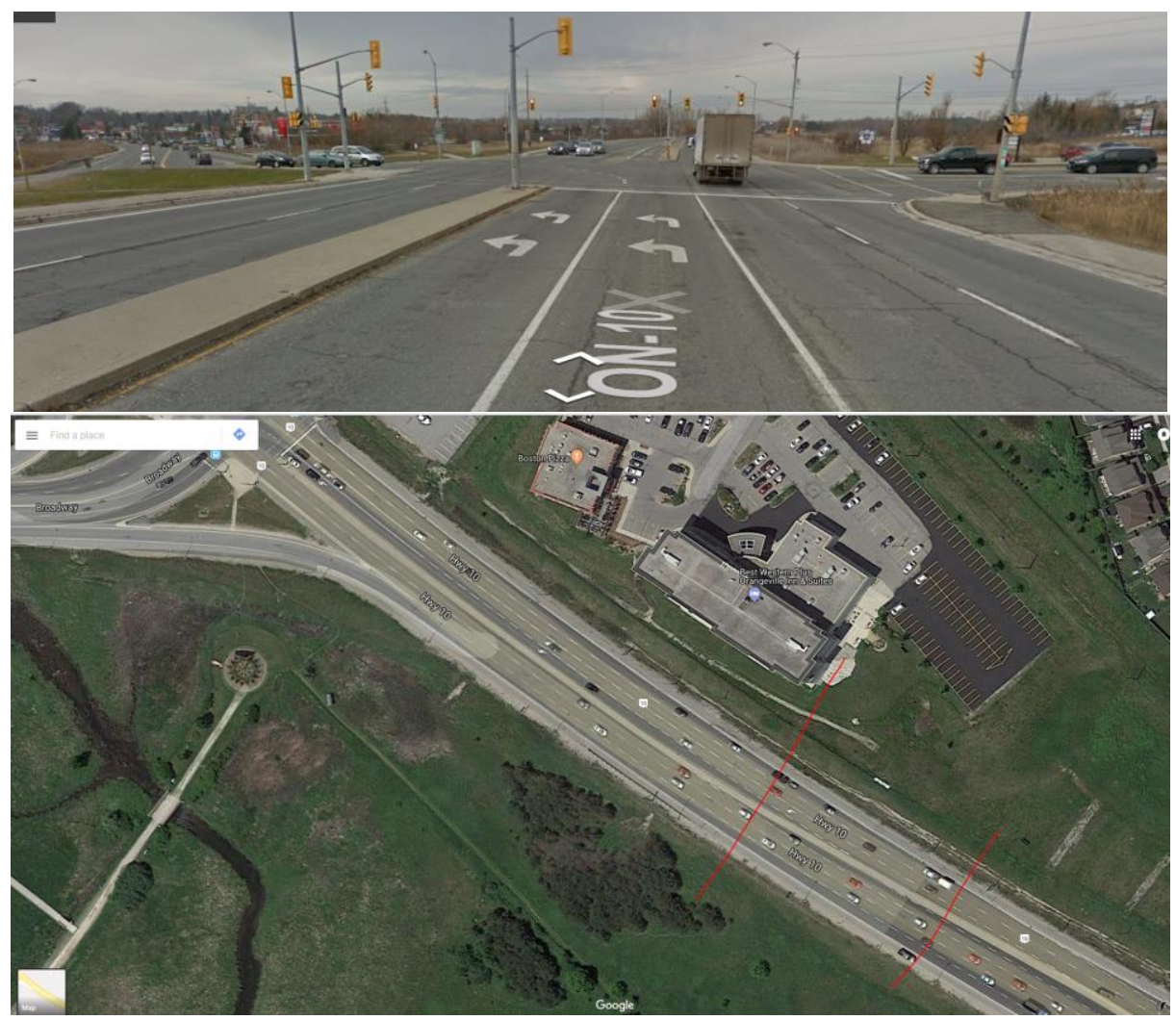

Figure 10 Hurontario St-Highway 10 and Buena Vista Drive and Broadway, Orangeville, example of two left turn lanes

(Source: Google Maps)

Criteria number 4 was needed because it was essential to be able to measure the length of the left turn lane and a centre two-way left turn lane would have a length much longer than can be measured, even possibly reaching downstream intersections. Figure 11 depicts an example of an intersection dismissed from the analysis because of a two-way left turn lane. 


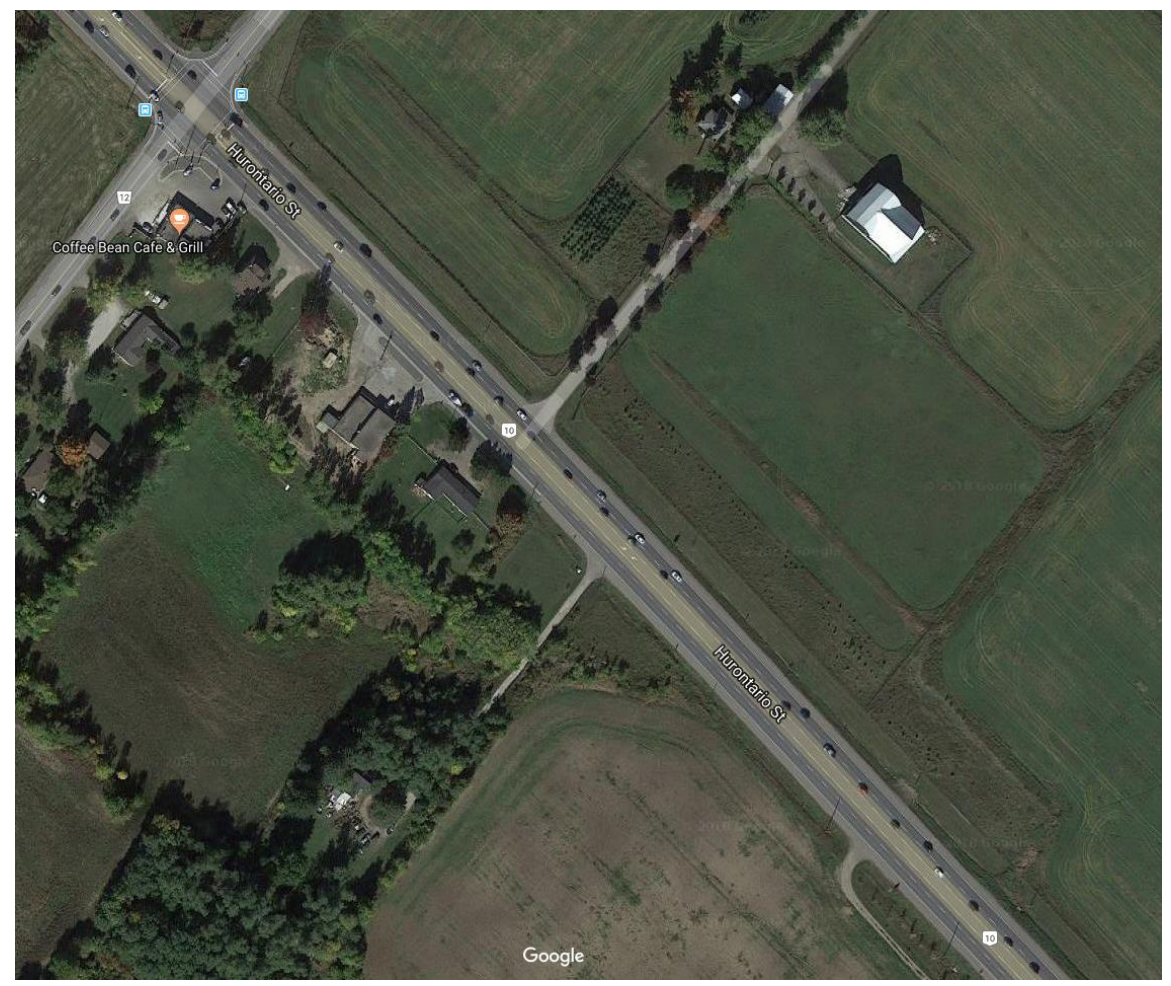

Figure 11 Hurontario St.-Highway 10 and Old Baseline Rd-Peel Regional Road 12, example of centre TWLTL

(Source: Google Maps)

Criteria number 5 was defined because the protected left turn phase would significantly impact the safety of left turns, resulting in two groups with differing safety performance function models (SPFs). Signal timing was entered in Synchro in order to draw the most accurate representation of the intersections to be simulated using VISSIM. However, not all of the necessary signal timings were provided by MTO, as it involved a more complex bureaucratic process and communication with individual sub regions of the MTO.

Criteria 6, was necessary in order to end up with a list of intersections with a clear N-S or E-W direction for the major link. Figure 12 is an example of an intersection where the major link is 
Westbound and Southbound, making a turn through the intersection. This intersection was therefore dismissed from the analysis.

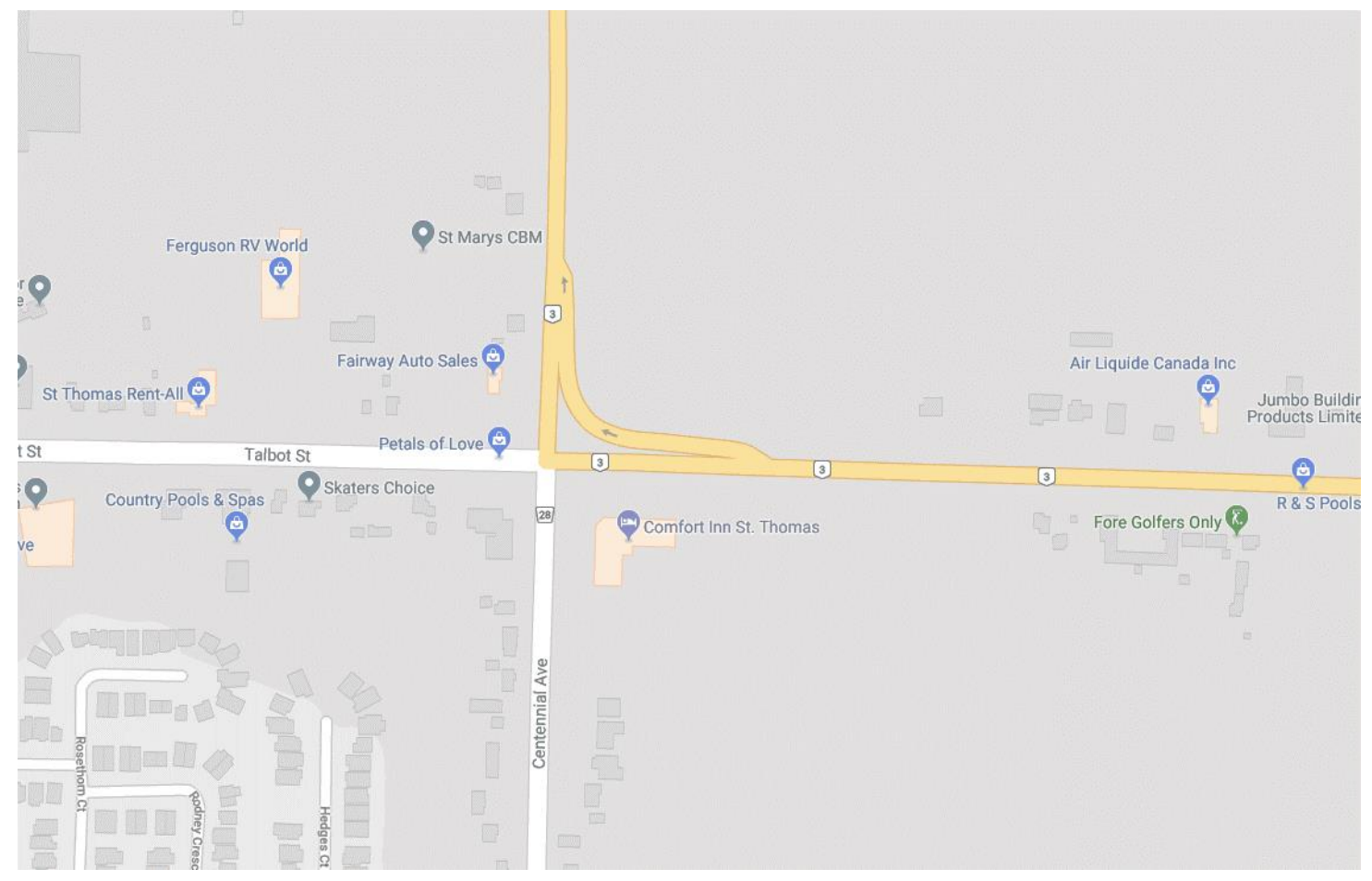

Figure 12 Highway 3 east of St. Thomas, an example of the main highway having two directional headings.

(Source: Google Maps)

In addition, any irregularly shaped intersections with features that could have impacted the safety performance of the intersection or change the behavior of the intersection were dismissed from the study in order to obtain an accurate objective model. The intersection illustrated in Figure 13 is an example of an intersection that would be documented as normal. In practice, this intersection does not possess a typical $\mathrm{T}$ geometry with the highway going through as an East-West link. This intersection was therefore dismissed. 


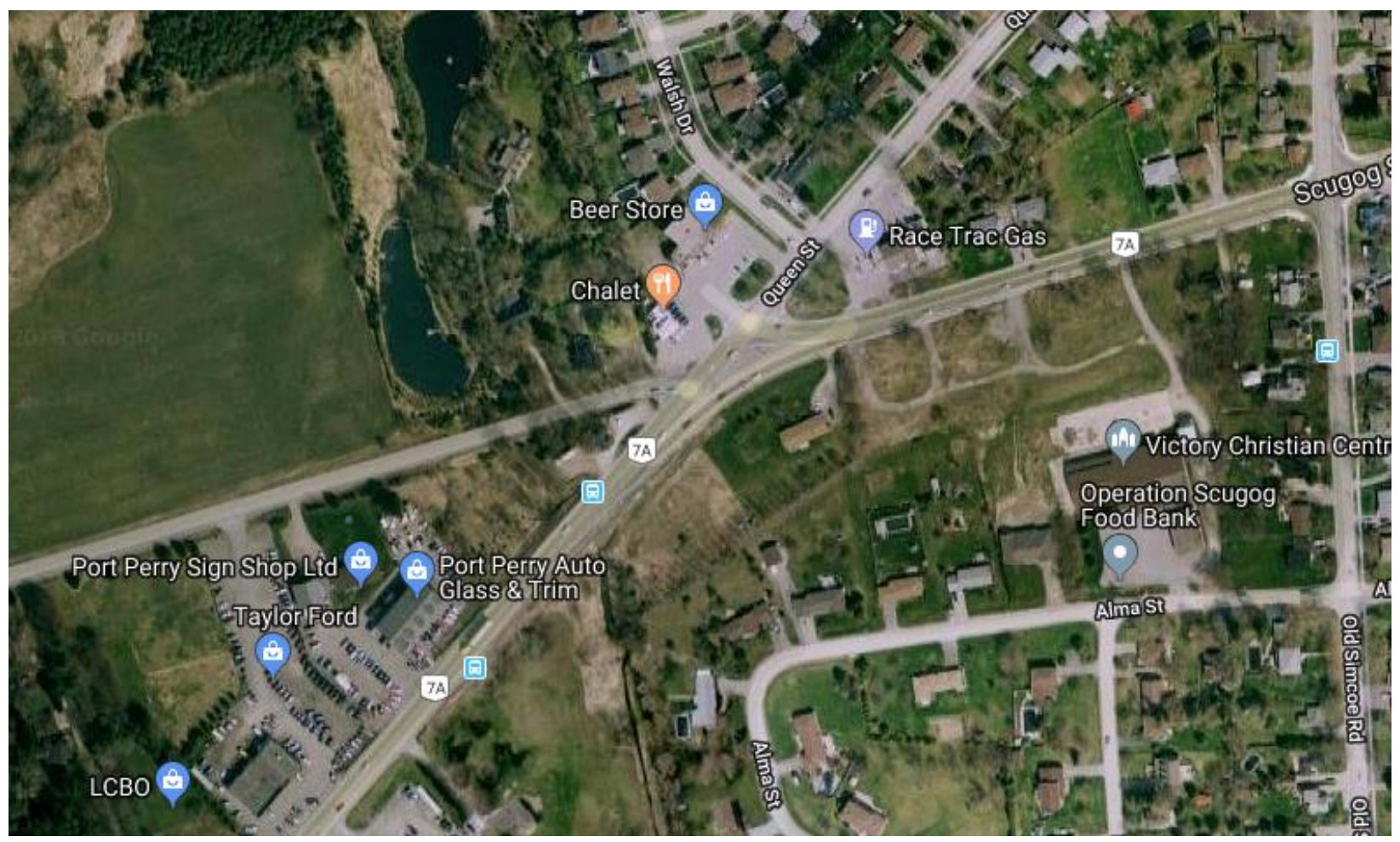

Figure 13 Highway 7A and Queen St., Port Perry, example of irregular intersection geometry.

(Source: Google Maps)

Therefore, the first step of the data collection was a one on one comparison of the list of intersections in the database of MTO with their Google maps satellite imagery and street view and checking whether they meet the criteria. After having done this, 48 intersections throughout the province remained as the final database to be used for the analysis, a list of which is presented in Appendix A, and their location in the province shown in Figure 14. Each intersection had an LHRS code and an offset, from which, using the following equation, a unique code associated with the intersection, and constant in all of the documents provided by the MTO was determined.

$$
L H R S+\text { OFFSET } c o d e=L H R S \times 10,000+\text { OFFSET } \times 100
$$

\section{Equation 1}



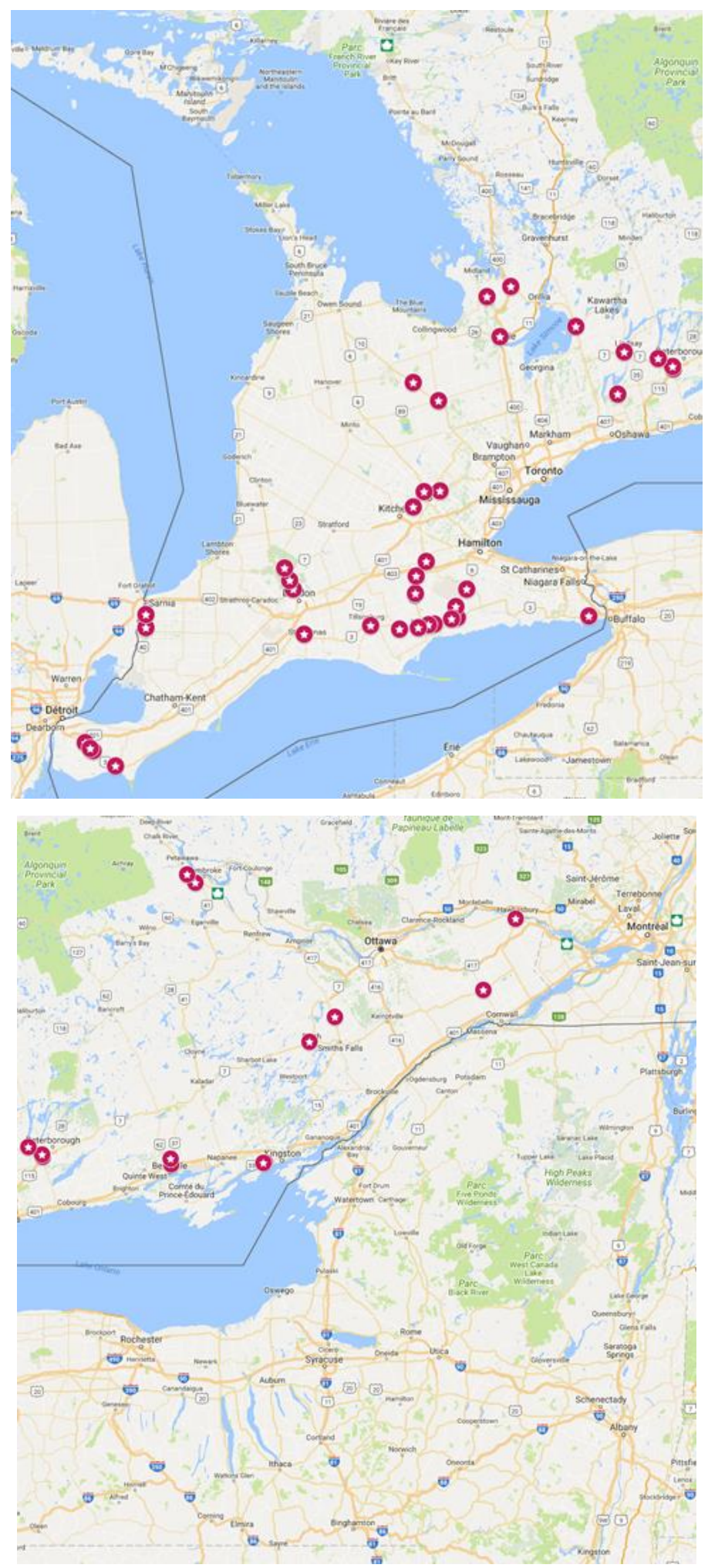

Figure 14 Map of distribution of the final list of sites across the province

(Source: Google Maps) 


\subsection{Geometric and General Attributes of Sites}

The base file provided included codes and basic geometric information such as a number of lanes and their turning movements. This provided information could be used to filter intersections that did not have left turn lanes provided. This narrowed the search down significantly. After doing that and going along the highways removing intersections not meeting the criteria, there was other information that needed to be collected for the analysis to happen.

As it is the main focus of this research, one piece of information that was needed to be measured was the length of left turn lanes. Left turn lanes are made up of two segments generally, a straight segment, i.e. fixed width deceleration and storage lane, and a tapered segment. A taper has a changing width, and it couldn't be modeled with the microsimulation software that was available. Thus approximating the length of the left turn lane by picking a reasonable point along the length of the taper where it can be assumed that the taper would behave and thus be accurately simulated as a straight fixed width segment in the microsimulation software past that point was deemed as the solution to this matter.

An approximation of two thirds into the taper lane, with the final left turn lane length, rounded to the closest 5 meters, was chosen as the point from which the length was measured. The other end of the left turn lane was the stop line traversing across the width of the road. In the diagram shown in Figure 15, the two red segments at the top are the two components of a left turn lane and the purple segment is approximately what was measured. 


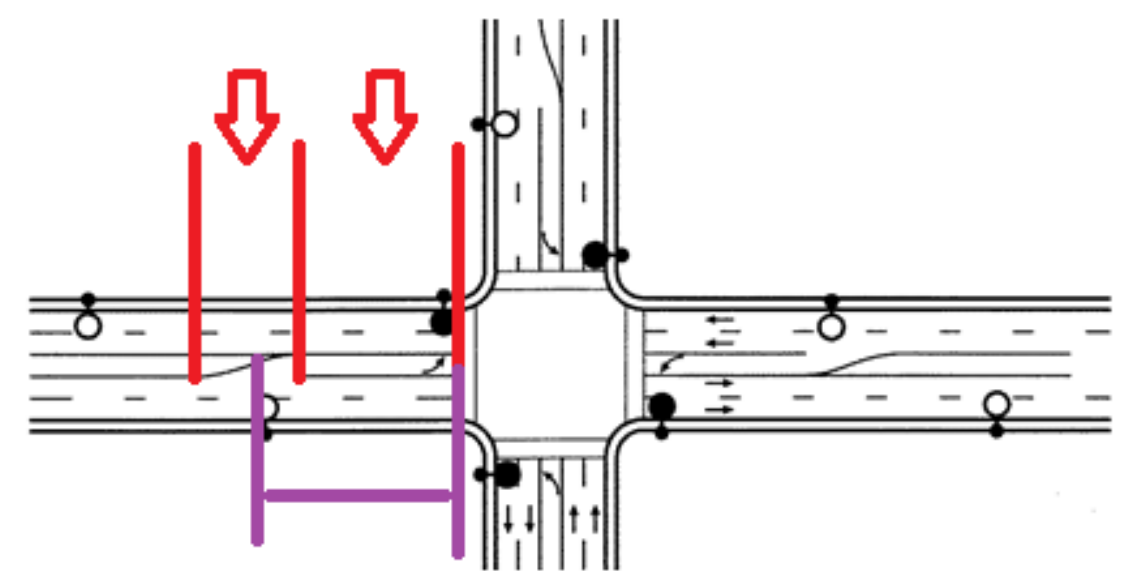

Figure 15 Breakdown of components of a left turn lane along its length

\subsection{Traffic Volumes}

Another important part of the dataset used for SPF modeling was the traffic flow, expressed as the Annual Average Daily Traffic Flow (AADT). The AADT for 2016 was obtained from the ARCGIS database. One of the major shortcomings of this study was that the AADT of a single year was used with the crash records of a 14 year period. In addition, the year of the AADT provided was not included in the 14-year range.

Two AADT values were provided, one for the major link and one for the minor link. A breakdown of the volumes for each movement at the intersection was necessary for the SPF analysis and for the accuracy of the simulation. Upon request, the MTO provided the Turning Movement Counter (TMC) database for the province from 2011 to 2013. The TMC file contained the turning movement counts for 15 min periods at each row over a varying length of time for all intersections in the province. This information was used for calculating a weighted average of the AADTS of each link in order to determine the AADT values of the turning movements of the intersections. It 
was assumed that the time frame for which TMC was provided has the same distribution of the movement of traffic as the rest of the day.

Table 4 Summary of AADT data for the sites used in the analysis

\begin{tabular}{r|rrrrrrrrr} 
& $\begin{array}{l}\text { Total } \\
\text { AADT }\end{array}$ & $\begin{array}{l}\text { Major } \\
\text { AADT }\end{array}$ & $\begin{array}{l}\text { Minor } \\
\text { AADT }\end{array}$ & $\begin{array}{l}\text { Major } \\
\text { left } \\
\text { turn }\end{array}$ & $\begin{array}{l}\text { Minor } \\
\text { left } \\
\text { turn }\end{array}$ & $\begin{array}{l}\text { Major } \\
\text { thru }\end{array}$ & $\begin{array}{l}\text { Minor } \\
\text { thru }\end{array}$ & $\begin{array}{l}\text { Avg LT } \\
\text { to thru } \\
\text { dir } \\
\text { volume }\end{array}$ & $\begin{array}{l}\text { Avg LT to } \\
\text { thru opp } \\
\text { volume }\end{array}$ \\
\hline $\begin{array}{r}\text { Total } \\
\text { mean 1 }\end{array}$ & 656739 & 499314 & 163679 & 43257 & 66033 & 301667 & 62791 & $\underbrace{2}$ & \\
$\begin{array}{r}\text { intersection } \\
\text { Maximum }\end{array}$ & 43682 & 10402 & 3410 & 901 & 1376 & 6285 & 1308 & 0.0790 & 0.0945 \\
Minimum & 4392 & 2946 & 1148 & 84 & 138 & 2211 & 0 & 0.0071 & 0.0103
\end{tabular}

\subsection{Crash Records}

As previously mentioned, the crash records from the year 2000 to 2013 were provided by the MTO through the MVAB files. The dataset included all of the intersections along provincial highways, each row containing attributes associated with each incident (for data from 2000 to 2011), and each vehicle involved in a crash (for data from 2012 onward). The list of crash records for each year was first filtered based on the LHRS+OFFSET so that only intersections that were to be part of the analysis remain in the final count and classification.

The next step was the identification and dismissal of crashes that did not contain sufficient data. The numbers assigned to each crash attribute, specifically, the severity of the crash and the impact type were then converted into numbers that could be summed up in order to obtain a final count of collisions at intersections. 
Table 5 Numbers in each column and their corresponding categories (MTO, 2004)

\begin{tabular}{|c|c|c|c|}
\hline \multicolumn{2}{|l|}{ INTIMP } & \multicolumn{2}{|l|}{ CLASAC } \\
\hline 2 & Angle & 1 & fatal \\
\hline 3 & Rear End & 2 & injury \\
\hline 4 & Sideswipe & 3 & $\begin{array}{l}\text { Property } \\
\text { damage } \\
\text { only }\end{array}$ \\
\hline 5 & Turning & & \\
\hline
\end{tabular}

The collision records of intersections for each year were then added to the main database for this study in columns such as the ones illustrated in table 6 . The numbers were then added in order to obtain collision numbers and categories for a period of 14 years.

Table 6 Example of crash counts from the year 2003 for some of the intersections, with the categories of crashes defined

\begin{tabular}{|c|c|c|c|c|c|c|c|}
\hline F_03 & I_03 & PD_03 & App_03 & Ang_03 & RE_03 & SS_03 & TM_03 \\
\hline 0 & 0 & 0 & 0 & 0 & 0 & 0 & 0 \\
\hline 0 & 0 & 2 & 0 & 0 & 0 & 0 & 2 \\
\hline 0 & 0 & 2 & 0 & 0 & 2 & 0 & 0 \\
\hline 0 & 0 & 0 & 0 & 0 & 0 & 0 & 0 \\
\hline 0 & 1 & 1 & 0 & 0 & 1 & 0 & 1 \\
0 & 0 & 0 & 0 & 0 & 0 & 0 & 0 \\
\hline 0 & 1 & 0 & 0 & 0 & 0 & 0 & 1 \\
\hline 0 & 3 & 1 & 0 & 0 & 0 & 0 & 4 \\
\hline
\end{tabular}


Table 7 Summary of crash data for the sites used in the analysis

\begin{tabular}{r|rrrrrrrrrr} 
& Fatal & Injury & PDO & App. & Angle & R.E. & S.S. & T.M. & \multicolumn{1}{c}{ Total } \\
\hline $\begin{array}{r}\text { Total for 14 } \\
\text { yrs. }\end{array}$ & 8 & 239 & 441 & 10 & 132 & 268 & 43 & 236 & 688 \\
$\begin{array}{r}\text { mean 1 } \\
\text { intersection }\end{array}$ & 0.17 & 4.98 & 9.19 & 0.21 & 2.75 & 5.58 & 0.90 & 4.92 & 14.33 \\
Maximum & 2 & 22 & 40 & 2 & 17 & 39 & 4 & 23 & 57 \\
Minimum & 0 & 0 & 0 & 0 & 0 & 0 & 0 & 0 & 0
\end{tabular}




\section{METHODOLOGY}

This chapter provides a description of the steps that were undertaken in order to conduct the

analysis. Firstly, an overview of the software programs that were utilized in this research is presented. Secondly, a background of crash prediction modelling and its general equation format is shown. Then, the steps of tasks for each of the chapters of the analyses and the rationale behind making the decision on what the steps were are described.

\subsection{Software programs overview}

For the study, the 4 following software programs were used: Synchro 9, VISSIM, SSAM, and SAS Enterprise Guide 6.1.

\subsection{1. $\underline{\text { Synchro } 9}$}

Synchro is a macrosimulation and optimization software. The main purpose of this software is to model and optimize the networks of links with various types of intersections and lane configurations (Trafficware, 2018). The software was only used for drawing of the intersections that were to be simulated using VISSIM and SSAM. Synchro was used for this purpose instead of the VISSIM drawing tool due to its relative ease of use.

\subsection{2. $\underline{\text { VISSIM }}$}

VISSIM is a microsimulation software that allows for the simulation of the behavior of individual vehicles for various intersection control types, signal timings, and geometry at signalized intersections (PTV Group UK, 2018). The software allows the geometric attributes drawn in 
Synchro to be imported, and produces an output compatible with other analysis software, such as SSAM. The desired output contains trajectories of each individual vehicle that VISSIM produced at random intervals (PTV Group UK, 2018).

\subsection{3. $\underline{\text { SSAM }}$}

The Surrogate Safety Assessment Model, commonly referred to as SSAM, is a post-processor software that analyzes the TRJ output files from VISSIM. The software analyzes vehicle trajectories in order to identify conflict events and finds attributes related to the conflicts such as TTC, PET, speed, and angles, which are used for the classification of the conflicts, vehicle velocity changes, etc. (FHWA, 2008).

\subsection{4. $\quad$ SAS Enterprise Guide 6.1}

SAS Enterprise is a statistical analysis software that was used to estimate models correlating various variables. In this study, SAS was used for generalized linear regression modeling.

\subsection{Crash prediction models}

A generalized linear model with a negative binomial and logarithm link function was used to develop SPFs. This is considered common practice in this area of study (Persaud et at., 2012). The basic model in this study related AADT values to the number of crashes. Other variables were added as necessary. The variables were inputted into SAS as a logarithm of actual data, similar to the AADT values, or as themselves. For example, Qin (2016) used the following 
model to find crashes at a freeway ramp merge segment, using freeway AADT, ramp AADT and the length of the acceleration lane.

$$
S P F=e^{(\alpha+\beta 3 \times \text { Length AL })} \times F W A A D T^{\beta 1} \times R A A D T^{\beta 2}
$$

Equation 2 (Qin, 2016)

In equation 2, freeway AADT and ramp AADT were inputted into SAS as a logarithm of the actual data, and length of acceleration lane was inputted as measured in the field and recorded in the data. The model presented is a generalized linear model (GLM). A GLM is a flexible generalization of ordinary linear regression that allows for multiple variables that have an error distribution other than normal distribution. The GLM generalizes linear regression by allowing the linear model to be related to the variables via a link function (Jain et al., 2017). A link function of logarithm was used for the purpose of calibrating the models in this study. Some of the categories of the data, such as the AADT values, were inputted after having their logarithm taken. Thus after the application of the link function, they would be, as shown in equation 2, multiplied as themselves and not in the power of Euler's number ' $\mathrm{e}$ '.

In order to set the settings in SAS for the analysis to run, a probability distribution type for the resulting expected value had to be chosen. In this study, a negative binomial distribution was deemed appropriate. Negative binomial distribution is used for over dispersed data counts, as is the case with collision records, as collisions are rare incidents (UCLA, 2017). What overdispersion means is that the variance of the data is much larger than the mean of the data (Ford, 2016). Negative binomial was preferred over Poisson distribution, as negative binomial is a generalization of Poisson distribution, but with an extra parameter modeling the over dispersion (UCLA, 2017). A Poisson distribution has one parameter, $\lambda$, which represents both the mean and 
the variance, as it assumes them to be converged, but the negative binomial regression model considers their difference. Negative binomial assumes the variance to be a function of the mean, and an additional parameter, k, called the dispersion parameter. (Ford, 2016).

$$
\operatorname{Var}(y)=\mu+\mu^{2} / k
$$

Equation 3 (Ford, 2016)

Other types of distributions weren't appropriate for this type of data, i.e. collision records.

The goodness of fit of SPF models can be measured using various measures. The list below outlines some of them:

- P-Value: P-value is one of the direct outputs of SAS Enterprise Guide 6.1 general linear model result. $\mathrm{P}$-value, shown as 'Pr $>$ ChiSq' indicates the probability that a statistical summary of the data, such as the mean of the sample between two different groups would be equal to or greater than the observed values.(Wassersteinm, 2016). The desired value for $\mathrm{Pr}>\mathrm{ChiSq}$ for a model to be a good fit is 0.05 for a $95 \%$ confidence, but values up to around 0.10 or 0.15 are given a pass if need be.

- CURE plots: The plot graphs cumulative residuals, which would be the cumulative difference between observed actual and predicted outcome of the model over the course of a variable of interest sorted from smallest to largest, overlaid on 95\% confidence limits on both the positive and negative side of the graph. 


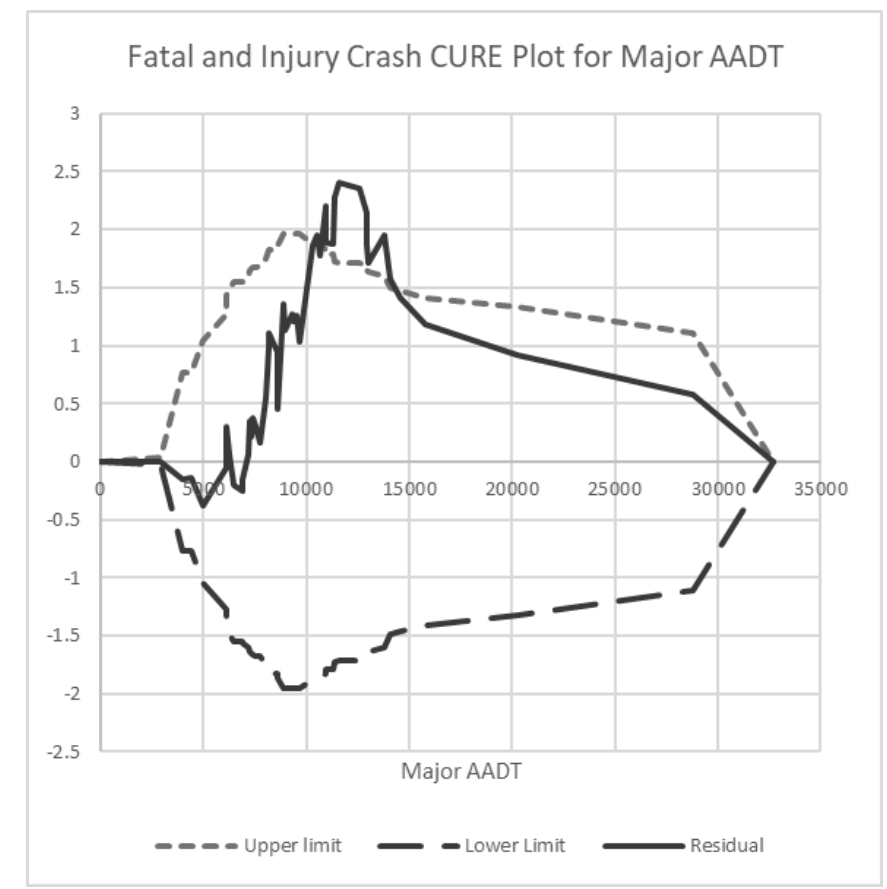

Figure 16 Example of a CURE plot

\subsection{Crash-based analysis of safety performance}

The safety performance function (SPF) models were estimated using SAS Enterprise 6.1 software SPF is an equation that would be used for predicting the number of annual crashes at a site as a function of exposure, which in this case would be AADTs and ratio of left-turning volumes, and other intersection characteristics, specifical length of left turn lane (FHWA, 2016).

SAS was used instead of Excel as it is more user-friendly. In addition, SAS shows the statistical significance of each individual independent variable using the P-value, which is not the case for Excel (see Figures $17 \& 18$ for a comparison). This was critical in this study since P-values were used to determine the statistical significance of the variables. P-values were also used in the initial 
steps of this study in order to determine whether different variable combinations would yield a more statistically significant model. In addition, since the analysis involved repetition and the use of different columns of the same data set multiple times, which would have required setting up a new model each time, SAS's user-friendliness reduced the chance of manual errors during this process. Lastly, SAS kept track of every modeling and analysis step and saved the results of each analysis, allowing for a comparison of the models estimated from different combinations of variables.

\begin{tabular}{|c|c|c|c|c|c|c|c|c|c|c|}
\hline $\operatorname{GLM}(2,3,20)$ & \multirow[b]{2}{*}{ Value } & \multicolumn{2}{|c|}{ Goodness-of-fit } & & & \multicolumn{4}{|c|}{ Residuals (standardized) Analysis } & $5.00 \%$ \\
\hline Param & & LLF & AIC & CHECK & & AVG & STDEV & SKEW & KURTOSIS & Normal? \\
\hline$\beta_{0}$ & -1.02 & -31.79 & 72.59 & 1. & & -0.06 & 1.63 & -0.25 & -1.35 & TRUE \\
\hline$\beta_{1}$ & 0.09 & & & & Target & 0.00 & 1.00 & 0.00 & 0.00 & \\
\hline$\beta_{2}$ & -0.86 & & & & SIG? & FALSE & TRUE & FALSE & FALSE & \\
\hline$\Phi$ & 0.05 & & & & & $\operatorname{Pr}$ & & & & \\
\hline Lvk & 5.00 & & & & & & 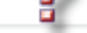 & & & \\
\hline
\end{tabular}

Figure 17 Example of the outcome of generalized linear model with binomial distribution on

$$
\text { Excel }
$$

(Source: http://www.spiderfinancial.com/support/documentation/numxl/tips-and-tricks/numxlcookbook-glm-with-binary-data )

\subsubsection{Input into SAS}

In order to input the data into SAS, they need to be cleaned up of all intermediate columns containing data such as yearly collisions and detailed lane configurations and be saved in. XLS format. The desired outcome was a generalized linear model. A generalized linear model is estimated by a fitting of a line to the inputted data using a maximum likelihood estimation (MLE). The traditional format of a linear model is shown in equation 3 (SAS Institute Inc., 2008). 


$$
y_{i}=x_{i}^{\prime} \beta+\varepsilon_{i}
$$

Equation 4 (SAS Institute Inc., 2008)

In equation 4 , yi is the response variable for one of the observations, $i$. The quantity $x_{i}$ is an independent explanatory variable for the observation, and $\varepsilon_{\mathrm{i}}$ would be a residual term for the observation. The coefficient $\beta$ is, as stated, estimated by the least squares fit to the data. What this means is simply the goal is to minimize the sum of the squares of the residuals $\varepsilon_{\mathrm{i}}$ in the model through an iterative numerical process (SAS Institute Inc., 2008). Therefore, this results in the following model, where $\eta_{\mathrm{i}}$ is the expected value of $\mathrm{y}_{\mathrm{i}}$ :

$$
\mu_{i}=x^{\prime}{ }_{i} \beta
$$

Equation 5 (SAS Institute Inc., 2008)

$$
\frac{\text { Crashes }_{\text {Total }}}{1 \text { Year }}=\frac{1}{14} \exp \left[\alpha+\beta 1 x_{1}+\beta 2 x_{2}+\cdots+\beta i x_{i}\right] \times x_{3}^{\beta 3} \times x_{4}^{\beta 4} \times \ldots \times x_{j}^{\beta_{j}}
$$

\section{Equation 6}

As can be seen in table 8, AADTs and length of left turn lanes were taken a logarithm before being inputted into SAS for the GLM. But left turning ratios were not. The reason and implications of this were explained previously. 
Table 8 Part of the headers of the independent variables in the input file for SAS

\begin{tabular}{|c|c|c|c|c|c|c|c|}
\hline $\begin{array}{l}\text { avg_LT_ } \\
\text { lane }\end{array}$ & $\begin{array}{l}\text { avg_ratio } \\
\text { _left_tur } \\
n\end{array}$ & In_major & $\begin{array}{l}\text { In_tot } \\
\text { _aadt }\end{array}$ & In_minor & $\begin{array}{l}\text { ratio_LT_ } \\
\text { opp }\end{array}$ & $\begin{array}{l}\text { ratio_maj } \\
\text { or_minor }\end{array}$ & $\begin{array}{l}\text { In_LT_ } \\
\text { major }\end{array}$ \\
\hline 135 & 0.091173 & 7.988204 & 8.3875 & 7.276556 & 0.091165 & 2.037344 & 5.593 \\
\hline 187.5 & 0.092512 & 9.180293 & 9.6931 & 8.779711 & 0.109008 & 1.492693 & 6.8 \\
\hline 175 & 0.064062 & 8.771525 & 9.4372 & 8.715716 & 0.066785 & 1.057396 & 6.024 \\
\hline 157.5 & 0.013978 & 9.465293 & 9.7505 & 8.35679 & 0.01275 & 3.029819 & 5.195 \\
\hline 87.5 & 0.041606 & 9.301369 & 9.5129 & 7.855545 & 0.0417 & 4.245349 & 6.667 \\
\hline
\end{tabular}

Table 9 Part of the headers of the dependent variables in the input file for SAS

\begin{tabular}{|c|c|c|c|c|c|c|c|}
\hline $\mathrm{F}+\mathrm{I}$ & PD & App & Ang & RE & SS & TM & TOT_1 \\
\hline 2 & 1 & 0 & 1 & 2 & 0 & 0 & 3 \\
\hline 11 & 9 & 0 & 7 & 3 & 1 & 9 & 20 \\
\hline 9 & 14 & 0 & 5 & 11 & 0 & 7 & 23 \\
\hline 5 & 18 & 0 & 1 & 14 & 2 & 6 & 23 \\
\hline 1 & 0 & 0 & 0 & 0 & 0 & 1 & 1 \\
\hline 4 & 9 & 0 & 0 & 6 & 0 & 7 & 13 \\
\hline
\end{tabular}

The data, a snapshot of which is shown in tables 8 and 9, were then inputted into SAS enterprise 6.1 Software for modeling and analysis.

\subsubsection{Outputs of SAS}

The desired output for this part of the analysis was the SPF models produced to correlate different variables to different crash categories. Figure 18 is an example of a generalized linear model output of SAS. In this example, the total crashes for the data set were estimated using the major and minor AADTs and the average ratio of left turn lane to through traffic. 


\section{Generalized Linear Models Analysis}

The GENMOD Procedure

\begin{tabular}{|l|r|}
\hline \multicolumn{2}{|c|}{ Model Information } \\
\hline Data Set & WORK.SORTTEMPTABLESORTED \\
\hline Distribution & Negative Binomial \\
\hline Link Function & Log \\
\hline Dependent Variable & TOT_1 \\
\hline
\end{tabular}

Dependent Variable

\begin{tabular}{|l|l|}
\hline Number of Observations Read & 48
\end{tabular}

Number of Observations Used 48

\begin{tabular}{|l|r|r|r|}
\hline \multicolumn{4}{|c|}{ Criteria For Assessing Goodness Of Fit } \\
\hline Criterion & DF & Value & Value/DF \\
\hline Deviance & 44 & 57.2890 & 1.3020 \\
\hline Scaled Deviance & 44 & 57.2890 & 1.3020 \\
\hline Pearson Chi-Square & 44 & 44.8269 & 1.0188 \\
\hline Scaled Pearson X2 & 44 & 44.8269 & 1.0188 \\
\hline Log Likelihood & & 1287.0715 & \\
\hline Full Log Likelihood & & -166.1729 & \\
\hline AIC (smaller is better) & & 342.3458 & \\
\hline AICC (smaller is better) & & 343.7743 & \\
\hline BIC (smaller is better) & 351.7018 & \\
\hline
\end{tabular}

Algorithm converged.

\begin{tabular}{|l|r|r|r|r|r|r|r|}
\hline \multicolumn{7}{|c|}{ Analysis Of Maximum Likelihood Parameter Estimates } \\
\hline Parameter & DF & Estimate & Standard Error & Wald 95\% Confidence Limits & Wald Chi-Square & Pr > ChiSq \\
\hline Intercept & 1 & -9.1962 & 2.4887 & -14.0740 & -4.3184 & 13.65 & 0.0002 \\
\hline In_major & 1 & 0.6597 & 0.2435 & 0.1823 & 1.1370 & 7.34 & 0.0068 \\
\hline In_minor & 1 & 0.7027 & 0.2556 & 0.2017 & 1.2038 & 7.56 & 0.0060 \\
\hline avg_ratio_left_turn & 1 & 1.0118 & 1.5620 & -2.0497 & 4.0732 & 0.42 & 0.5171 \\
\hline Dispersion & 1 & 0.4033 & 0.1075 & 0.2391 & 0.6801 & & \\
\hline
\end{tabular}

Figure 18 An example SAS Enterprise 6.1's output model

As seen in Figure 18, the GENMOD procedure was used by SAS to fit a GLM to the model. How the model estimates the coefficients $\beta_{\mathrm{i}}$ was previously explained. Also, as previously mentioned, this is an iterative method which means that there isn't an absolute final perfect model (SAS Institute Inc., 2008). As seen in Figure 18, the following parameters are outputted:

- $\alpha=-9.1962$

- $\quad \beta 1=1.0118$

- $\quad \beta 2=0.6597$

- $\beta 3=0.7027$ 
Therefore, the following equation form would be what Equation 6 be simplified into:

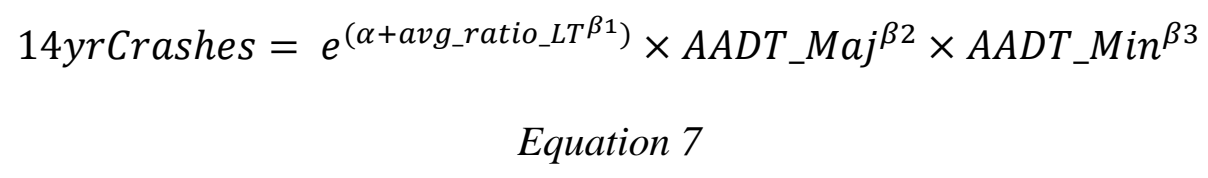

And with the estimated parameters:

$$
14 y r C r a s h e s=e^{\left(-9.1962+\text { avg_ratio_LT }^{1.0118}\right)} \times A A D T_{-} M a j^{0.6597} \times A A D T_{-} M i n^{0.7027}
$$

\section{Equation 8}

This study involved the crash rates over a period of 14 years, however, the desired outcome of the model was annual crashes. A simple mathematical adjustment was therefore necessary, resulting in the following model:

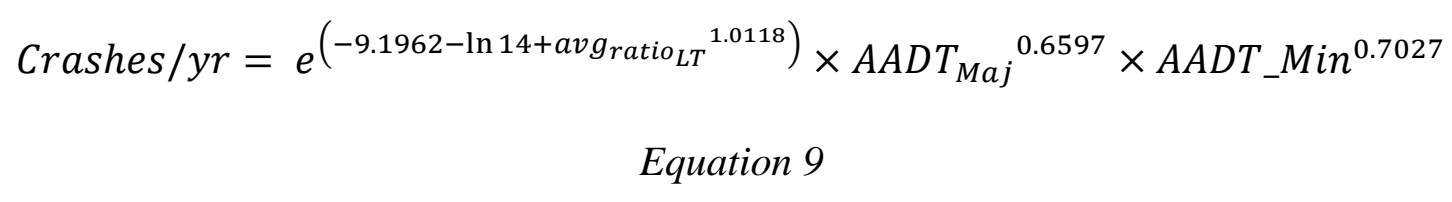

\section{Equation 9}

\subsection{Crash-Conflict Modelling}

The 48 intersection sites under the jurisdiction of MTO were modeled, and the conflicts extracted and then used for estimating crash-conflict models. These models were estimated so that they would become tools to be used on intersections beyond the 48 used for their estimation, with which crashes at those intersections could be predicted using the number of conflict counts obtained from microsimulation. 


\subsubsection{Drawing of intersection in Synchro}

VISSIM is what was used to conduct microsimulation on the intersections. However, Synchro was used for drawing of the intersection and inputting of the attributes of the intersection, as it was more efficient and more accurate to do than in VISSIM. The following information was inputted in Synchro to make the intersection as accurate as possible:

- Major link's peak hour volumes broken down to the three movements in each direction

- Same volume information for the minor link

- Any curvature close enough to the intersection that could potentially impact behavior of drivers

- Number of lanes, their configuration, and turning movements in each lane

- The length of left turn lanes

- Length and if applicable, an approximate curb curvature radius of a right turn lane

- If provided, signal timings

The AADT volumes in the original dataset were converted into peak hour volumes. A conversion value of 0.08 was used, as it was the peak of an estimation conducted by VanDelen et al. (2008) in the distribution of AADT in a day volume ratio. 


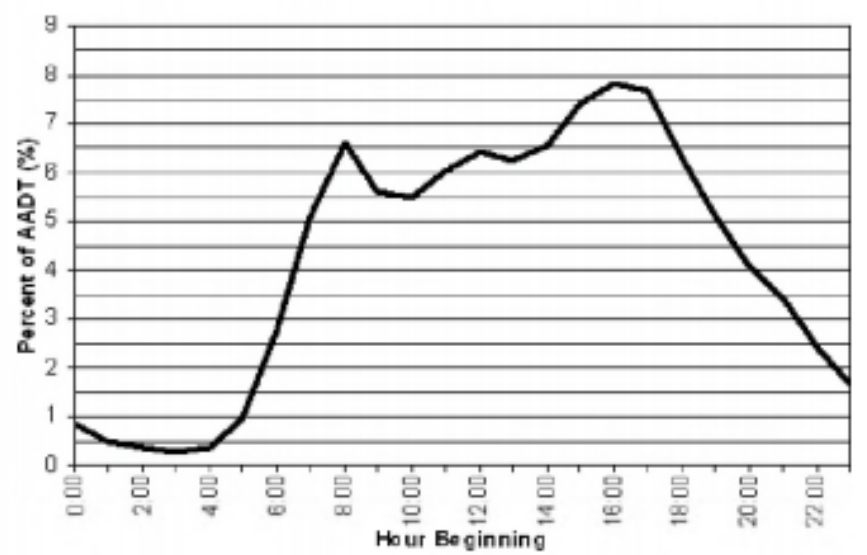

Figure 19 Typical distribution of AADT during the day in percentage of AADT (VanDelen et al., 2008)

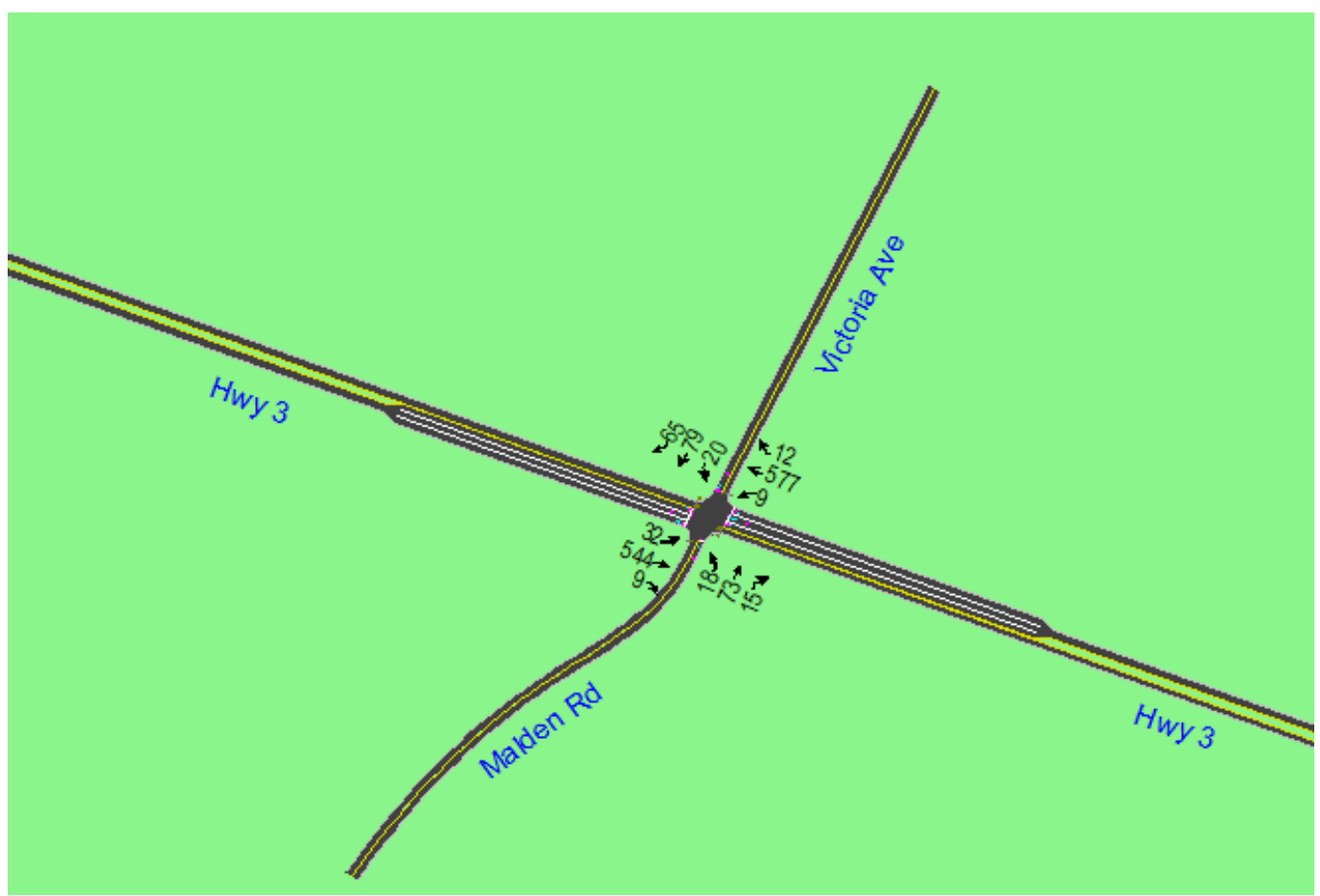

Figure 20 Synchro diagram of one of the intersections 
When the signal timing information was not provided, the timing was determined using the Synchro optimization tool. The final result was then saved in the CSV format to be imported into VISSIM for microsimulation.

The simulation software (VISSIM) did not have the capability to draw out and simulate merging with the taper lane, thus the $2 / 3$ length assumption made when measuring the length of left turn lanes now demonstrates its relevance.

\subsubsection{VISSIM Simulation}

The intersection drawings done using Synchro were inputted into VISSIM 8 for simulation. VISSIM produced individual vehicles at a random interval, simulating an arrival pattern at an actual intersection, and it recorded the trajectories of these vehicles. These trajectories were later then used by SSAM for deriving conflicts and their attributes. 


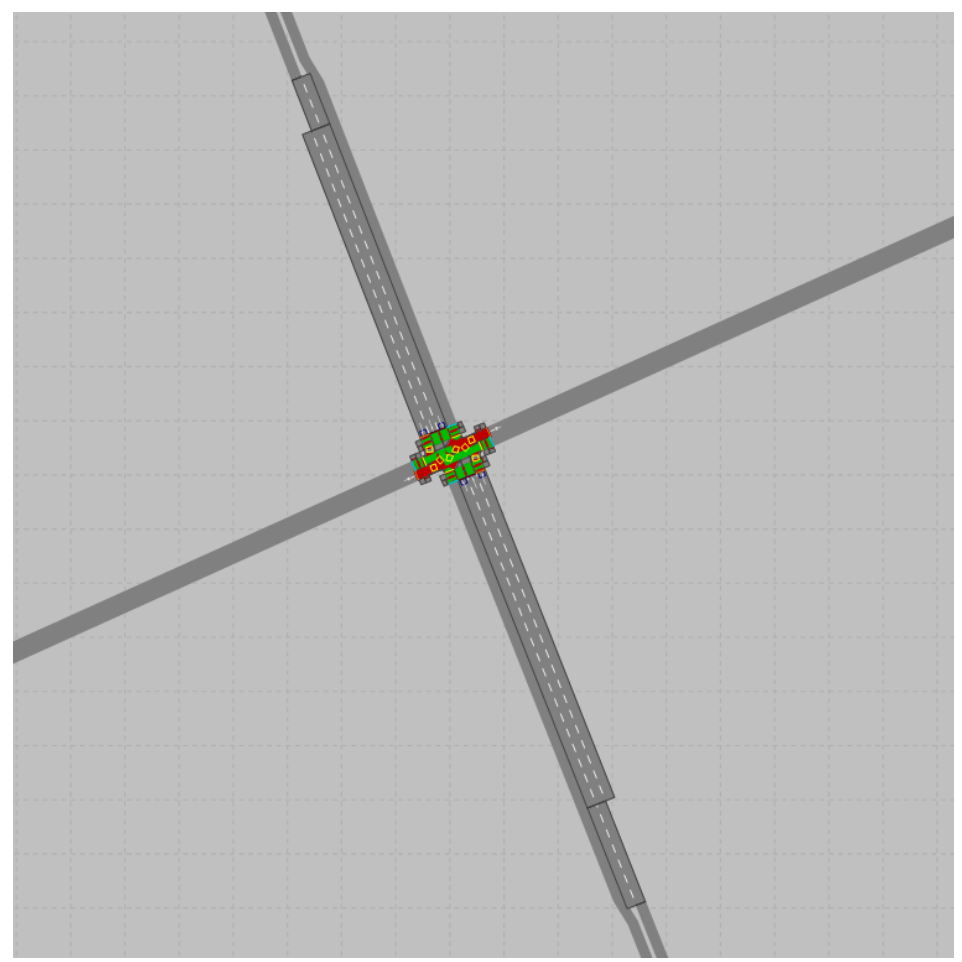

Figure 21 Intersection in VISSIM after being imported

The simulation had 10 runs and each run was 3600 seconds long. Every other setting was left as default. The output of the simulation was 10 files with the suffix TRJ, which would be functional when inputted into SSAM. The simulation involved 10 runs because the software relies on random seed generation for the vehicles arriving at the intersection. A large number of runs was required in order to ensure that the simulation results would have an average that is representative of the true average of the model and to ensure that the simulation results were not skewed in any way (WSDOT, 2014). Since other studies have used this number of runs (Espinosa, 2017; Qin, 2016), a decision was made that 10 runs would be the protocol followed for this analysis. 


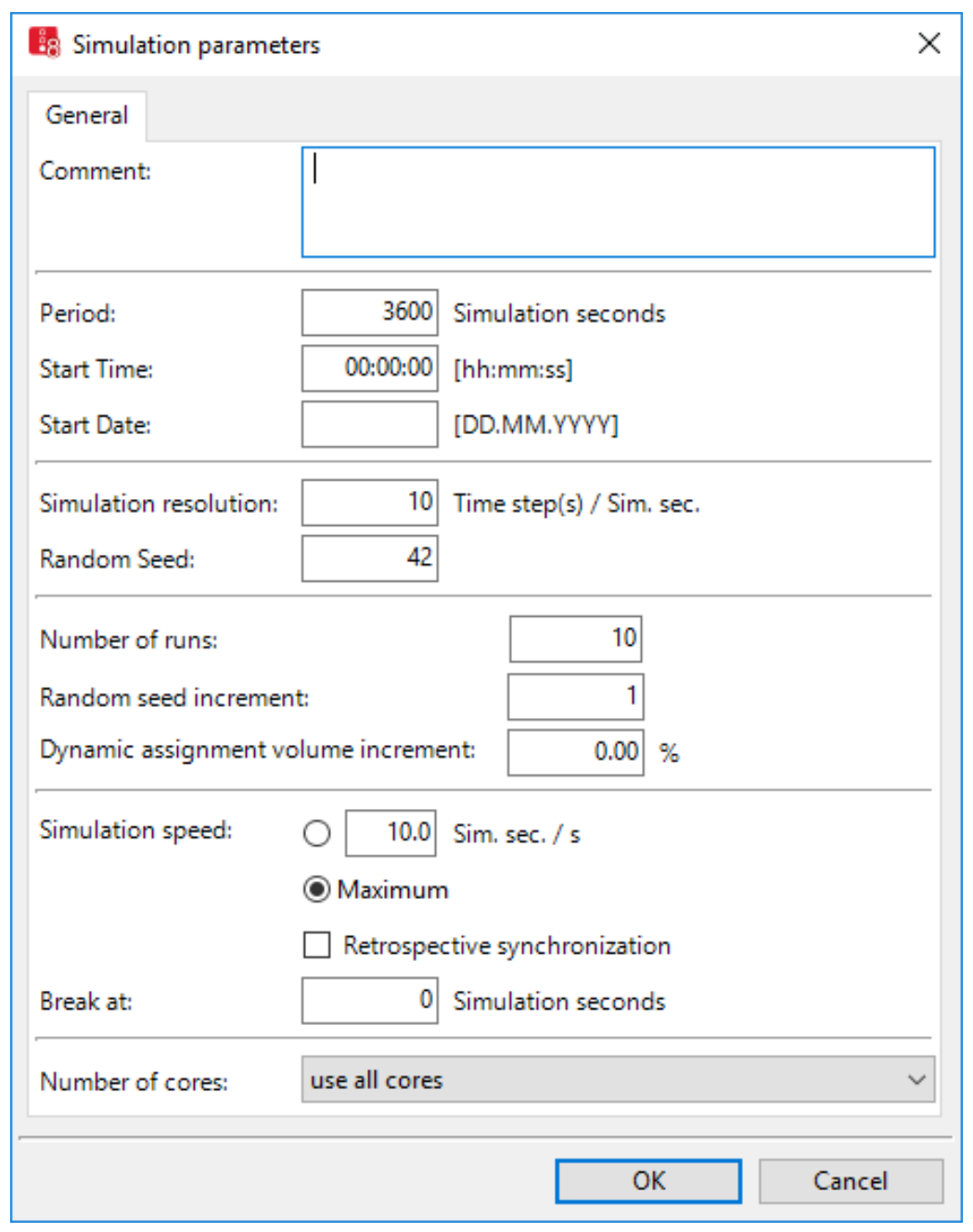

Figure 22 VISSIM simulation parameters

\subsubsection{SSAM Simulation}

The 'TRJ' file outputs from VISSIM were added to SSAM, and the program was run which produced the total number of conflicts at the intersection. The total number of conflicts and the number of crossing, rear end, and lane change conflicts, with a maximum TTC threshold of 1.5, 1.0, 0.5, and 0 were extracted. A TTC threshold of zero was necessary since these represent actual collisions which are not simulated by VISSIM. 


\subsubsection{SAS Analysis and crash conflict models}

The following form was used for the equations to be derived. This equation describes the relationship between a number of conflicts and various types of crashes.

$$
\frac{\text { Crashes }}{\text { Year }}=\exp (\alpha) \times \text { number conflicts } \beta_{\text {TTC Threshold }}^{\beta_{T T C \text { threshold }}}
$$

\section{Equation 10}

The above equation has a similar format as equations used for crash-conflict relationship analysis used in Qin's paper (2016). Therefore, the number of conflicts obtained from SSAM needed to be taken a natural logarithm before being modeled against crashes.

The analysis used crash data from 14 years, spanning from 2000 to 2013, and included the 48 intersections on MTO's provincially maintained highways used in the previous chapter of this study for SPF modeling, and conflict counts over a period of 10 hours. Therefore, the parameters estimated via SAS Enterprise Guide 6.1 software, which is shown as $\alpha$ and $\beta$, would not have directly produced the desired model, and they had to go through a transformation, as shown in the following equation:

$$
\frac{\text { Crashes }}{14 \text { Years }}=\exp (\alpha) \times \text { number conflicts in } 10 h^{\beta}
$$

\section{Equation 11}

The resulting final model format would be the following:

$$
\frac{\text { Crashes }}{1 \text { Year }}=\exp [\alpha-\ln 14+\beta \ln (10)] \times[\text { number of conflicts in } 1 h]^{\beta}
$$

\section{Equation 12}




\subsection{Conflict-Based Analysis of safety performance}

This chapter used the crash-conflict models from the previous chapter, integrating them with simulations of hypothetical intersections with varying through, opposing, and left turning volumes. Three different traffic volume levels and three different left turn lane lengths were used. This allowed us to determine the impact of the length of left turn lanes on intersection safety performance, and to determine how this impact varies under different conditions. These findings can be used to establish a relationship between this impact and different variables.

4 legged signalized intersections were used for the analysis. The two directions were defined as a major road (a typical rural segment of a provincial highway), and a minor road (a low volume rural or local access road). Both the major and minor roads were assumed to be two-lane roads, one for each direction. The major road then widened to accommodate a left turn lane for each direction at the intersection. The main lane on the major road was then reversed for through and right turn movements. On the minor road, the one lane for both directions was to accommodate all 3 of the movements.

Several of the volumes were assumed to be constant in all the scenarios. These were the minor street volumes defined as $100 \mathrm{veh} / \mathrm{h}$ for each of the movements as it was a low enough number, and since they weren't the focus of the analysis, its amount would not have needed to be varied. Also, the major Right turning volumes were chosen as $60 \mathrm{veh} / \mathrm{h}$, defined separately and independently of the through and left turning volumes. 
The timing of the signal was determined using the Synchro optimization tool. This was based on the assumption that the signals are not pre-timed to a defined timing or connected to loops on minor streets that detect when the occasional traffic requiring the light to change would arrive.

As seen in Figure 19, for most hours of the day, the traffic volume varies between $0.5 \%$ and $8 \%$ of the AADT in each hour. A conversion factor of 0.8 was determined to best represent the peak hourly volume rate. A look at the 2016 MTO AADT volumes, excluding freeways or controlled access highways (i.e. 400 series highways and other equivalent highways such as Highway 85 through Kitchener) revealed that the typical AADT range is between 1500 and 25000, with outliers as low as 300 and as high as 30000 (MTO, 2017). Three AADT numbers were deemed fit for the analysis: 6000, 10000, and $16000 \mathrm{veh} /$ day. These correspond to hourly volumes of $480 \mathrm{veh} / \mathrm{h}, 800$ $\mathrm{veh} / \mathrm{h}$, and $1120 \mathrm{veh} / \mathrm{h}$. The major road peak hourly volumes were assumed to be $8 \%$ of the AADT volumes. The three defined AADTs were converted into hourly volumes (using a factor of 0.8 ) and assembled into the 9 possible combinations shown in Table 4 .

Table 10 Table of the assembly of the 3 defined VOL.s to create one line of data to be inputted and simulated

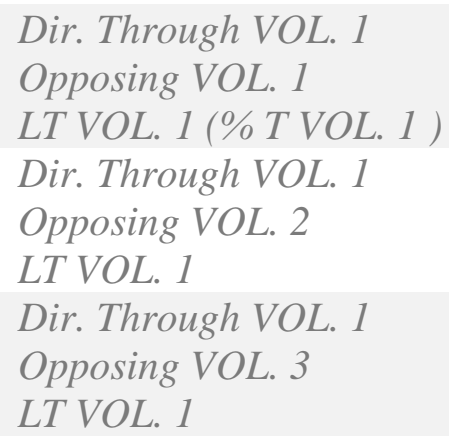

Dir. Through VOL. 2 Opposing VOL. 1

LT VOL. 2

Dir. Through VOL. 2 Opposing VOL. 2 LT VOL. 2 Dir. Through VOL. 2 Opposing VOL. 3 LT VOL. 2
Dir. Through VOL. 3 Opposing VOL. 1 LT VOL. 3

Dir. Through VOL. 3 Opposing VOL. 2 LT VOL. 3 Dir. Through VOL. 3 Opposing VOL. 3 LT VOL. 3 
The 9 combinations shown in Table 10 all correspond to one left turn volume percentage. One of the variables of interest was the effect of variations in the ratio of left turning vehicles on the impact of length of the left turn lanes have on the safety performance of the intersection. 3 left turning volume percentages were used, $10 \%, 20 \%$, and $30 \%$.

Table 11 Illustration of how different left turning volume ratio percentages are applied to the volume combinations, resulting in 27 possible scenarios

9 combination of volumes using Left turning volume of $10 \%$

9 combination of volumes using Left turning volume of $20 \%$

9 combination of volumes using Left turning volume of $30 \%$

The next step involved determining the length of the left turn lanes in these hypothetical intersections. The MTO design guidelines explained in chapter two section 2.1 were used for this purpose. The lengths in the design nomograph depend on the through traffic volume per lane, the signal cycle length, and the percentage of heavy traffic using the road (MTO, 1985). Thus, the following inputs were used for the nomograph and the design chart in the figures.

- Assumed heavy vehicle volume of $20 \%$

- Signal cycle time determined using Synchro optimization tool

- Through directional volume is the total defined directional volume minus the left turning volume.

- A major link speed of $90 \mathrm{~km} / \mathrm{h}$ (used to determine the length of the taper lane) and a minor link speed of $70 \mathrm{~km} / \mathrm{h}$. 
The minimum required length was used from the right axis of the design nomograph instead of the one labeled "desired". The taper length was determined using an assumed constant speed of 90 $\mathrm{km} / \mathrm{h}$ for through traffic. That length was then multiplied by $2 / 3$ and added to the length of the auxiliary lane. This is because the width of the taper lane is not constant along its length. It is therefore assumed that the first $1 / 3$ of the length is not sufficient for vehicles to safely merge into the lane. In addition, the simulation software (VISSIM) did not have the ability to draw out and simulate merging with the taper lane. A 2/3 length assumption was therefore made.

The 27 sites and their respective left turn lane lengths were duplicated three more times. The length of the left turn lane was decreased by $40 \%$ for one of the sets, $60 \%$ for the third set, and $80 \%$ for the fourth set. The end result was 108 intersections to be simulated. These intersections were set up in Synchro, exported to VISSIM, inputted into SSAM where the conflicts were extracted and used for analysis.

The analysis was based on a proposed treatment of increasing the length of the left turn lane from the three short lengths to the initial adequate length and finding the CMF values for each of the three proposed treatments for the 27 sites. The impact of the treatment was then measured against the variables that differed between the intersections in order to investigate whether there is a pattern or trend. 


\section{Table 12 List of the hypothetical intersections and their attributes}

Intersection Thrudir. Thru opp. Left turning Signal Adequate length

\begin{tabular}{|c|c|c|c|c|c|}
\hline & volume & volume & volume & cycle time & of left turn lane \\
\hline 1 & 1008 & 1120 & 112 & 70 & 180 \\
\hline 2 & 1008 & 800 & 112 & 90 & 180 \\
\hline 3 & 1008 & 480 & 112 & 80 & 180 \\
\hline 4 & 720 & 1120 & 80 & 75 & 180 \\
\hline 5 & 720 & 800 & 80 & 60 & 180 \\
\hline 6 & 720 & 480 & 80 & 50 & 180 \\
\hline 7 & 432 & 1120 & 48 & 100 & 180 \\
\hline 8 & 432 & 800 & 48 & 55 & 180 \\
\hline 9 & 432 & 480 & 48 & 50 & 180 \\
\hline 10 & 896 & 1120 & 224 & 65 & 180 \\
\hline 11 & 896 & 800 & 224 & 100 & 180 \\
\hline 12 & 896 & 480 & 224 & 70 & 180 \\
\hline 13 & 640 & 1120 & 160 & 65 & 180 \\
\hline 14 & 640 & 800 & 160 & 80 & 180 \\
\hline 15 & 640 & 480 & 160 & 55 & 180 \\
\hline 16 & 384 & 1120 & 96 & 75 & 180 \\
\hline 17 & 384 & 800 & 96 & 60 & 180 \\
\hline 18 & 384 & 480 & 96 & 50 & 180 \\
\hline 19 & 784 & 1120 & 336 & 55 & 180 \\
\hline 20 & 784 & 800 & 336 & 120 & 180 \\
\hline 21 & 784 & 480 & 336 & 120 & 180 \\
\hline 22 & 560 & 1120 & 240 & 60 & 120 \\
\hline 23 & 560 & 800 & 240 & 130 & 180 \\
\hline 24 & 560 & 480 & 240 & 55 & 120 \\
\hline 25 & 336 & 1120 & 144 & 65 & 90 \\
\hline 26 & 336 & 800 & 144 & 80 & 105 \\
\hline 27 & 336 & 480 & 144 & 50 & 80 \\
\hline
\end{tabular}


After doing the analysis and estimating the CMFs of the three proposed treatments, it was desirable to conduct a test to examine whether the CMFs for an increase from shorter lengths of left turn lanes are smaller than those for an increase from longer lengths. It is also desirable to conduct such test for ranges of left turning volume ratio, in order to determine whether the lengthening of left turn lane has more impact on intersections where there is a higher left turning ratio or not. However conducting such tests accurately is not possible as given this small sample size, it is not possible to estimate the variance of these estimates or determine what type of probability distribution the data follows.

\subsection{Combined CMF of implementation of multiple treatments}

This chapter involves the analysis of the CMF of a combination of two different treatments, the introduction of a left turn protected phase to the signal and the addition of a left turn lane (4 length categories).

16 of the 27 hypothetical intersections were selected where an addition of a left turn phase didn't result in a change in the level of service of the intersection, defined as a change for the worse of the LOS letter code. An initial round of filtering was done, and intersections that saw a CMF of larger than 1.0 for the introduction of a left turn protective phase in an initial situation where there was no left turn lane in place were eliminated, as the addition of a left turn protective phase was deemed as not a suitable treatment for the intersection. In the end, 5 intersections were remaining.

The addition of left turn protective phase was done in Synchro, using its optimization tool. Similar to the previous VISSIM/SSAM simulations, the 5 intersections were simulated for the four categories length but with protected left turn phase added. A scenario in which no left turn phase 
exists, both before and after the addition of a protected left turn phase was simulated. Thus the output was the following:

1. No left turn lane

a. Without protected left turn phase

b. With protected left turn phase

2. Left turn lane with length $20 \%$ of what's adequate

a. Without protected left turn phase

b. With protected left turn phase

3. Left turn lane with length $40 \%$ of what's adequate

a. Without protected left turn phase

b. With protected left turn phase

4. Left turn lane with length $60 \%$ of what's adequate

a. Without protected left turn phase

b. With protected left turn phase

5. Left turn lane with a length of what's adequate

a. Without protected left turn phase

b. With protected left turn phase

The simulation results and the previously derived crash-conflict models were used for the crash estimations that were then used for estimating the CMFs. First, the CMFs of the set with no existing left turn lane were estimated. Then the CMFs for the addition of a left turn lane at an intersection without a left turn protective phase were estimated. These CMFs was then multiplied with the CMFs of the addition of a left turn protective phase at an intersection with no left turn lane. This 
is simply a multiplication of the CMFs of two treatments in order to find the CMF of the installation of both treatments, which is the method suggested by HSM. The CMFs of the simultaneous addition of both treatments were then estimated using the crash counts for an intersection without either of the two treatments and the same intersection with both treatments. 


\section{CRASH-BASED ANALYSIS OF SAFETY PERFORMANCE}

The purpose of this chapter is to present findings with regards to attempts at estimating relationships relating the variables and the attributes of intersections to the crash data provided by the MTO. The models in this chapter were estimated using the SAS Enterprise 6.1 software. The goodness of fit of the models is then examined.

Since the crashes cover a period of 14 years (from 2000 to 2013), the equations needed to be converted into the desired crash per year format by dividing the model by 14 years. The general form of the potential model is as follows:

$$
\begin{gathered}
\frac{\text { Crashes }_{\text {Total }}}{1 \text { Year }}=\frac{1}{14} \exp \left[\alpha+\beta 1 x_{1}+\beta 2 x_{2}+\cdots\right] \times x_{3}^{\beta 3} \times x_{4}^{\beta 4} \times \ldots \\
\text { Equation 13 } \\
\frac{\text { Crashes }_{\text {Total }}}{1 \text { Year }}=\exp \left[\alpha-\ln (14)+\beta 1 x_{1}+\beta 2 x_{2}+\cdots\right] \times x_{3}^{\beta 3} \times x_{4}^{\beta 4} \times \ldots \\
\text { Equation } 14
\end{gathered}
$$

The above equations and their formulation are explained in more detail in the methodology chapter.

This chapter is broken down into crash categories. Each subsection has two parts.

The first part presents the two following models: 1) the relationship between traffic volumes with crashes, and 2) the relationship between traffic volumes and turning volume breakdown with crashes. The purpose was to verify that the crash data is as it was expected for it to be, i.e. more crashes when there is a higher traffic volume. 
The model involved the following parameters:

- Major volume AADT inputted as a natural logarithm

- Minor volume AADT inputted as a natural logarithm

- The two left turn ratio variables are added as themselves and not as natural logarithms.

The second part of each subsection includes the addition of the average length of the left turn lanes along major approaches in order to investigate whether there was a good model including the variable of focus of this research correlating directly with crashes at the 48 sites.

An analysis of CURE plots for total crash models is shown. The rest of the relevant CURE plots are in Appendix B. 


\subsection{Total Crashes}

The following table shows parameters with respect to the model for total crashes.

Table 13 Parameters for modelling total crashes

\begin{tabular}{|c|c|c|c|c|c|c|}
\hline & \multicolumn{2}{|c|}{ AADTs only } & \multicolumn{2}{|c|}{$\begin{array}{l}\text { Average ratio of left } \\
\text { turn to directional } \\
\text { through traffic }\end{array}$} & \multicolumn{2}{|c|}{$\begin{array}{l}\text { Average ratio of left } \\
\text { turn to opposing } \\
\text { through traffic }\end{array}$} \\
\hline Parameter & Estimate & $\begin{array}{l}\text { Pr > } \\
\text { ChiSq }\end{array}$ & Estimate & $\begin{array}{l}\text { Pr }> \\
\text { ChiSq }\end{array}$ & Estimate & $\begin{array}{l}\operatorname{Pr}> \\
\text { ChiSq }\end{array}$ \\
\hline$\alpha$ & -9.3211 & 0.0002 & -9.1962 & 0.0002 & -9.2388 & 0.0002 \\
\hline$\beta 1(L T$ vol ratio $)$ & & & 1.0118 & 0.5171 & 0.5252 & 0.6450 \\
\hline$\beta 2(M a j A A D T)$ & 0.6107 & 0.0088 & 0.6597 & 0.0060 & 0.6431 & 0.0080 \\
\hline B3(Min AADT) & 0.7844 & 0.0005 & 0.7027 & 0.0068 & 0.7308 & 0.0038 \\
\hline
\end{tabular}

The AADT based model was a good fit and revealed a positive relationship between the major and minor volumes. Equation 15 would, therefore, be the model used for total crashes.

$$
\frac{\text { Crashes }_{\text {Total }}}{1 \text { Year }}=\exp [-11.9602] \times \text { MajAADT }^{0.6107} \times \operatorname{MinAADT}^{0.7844}
$$

Equation 15 


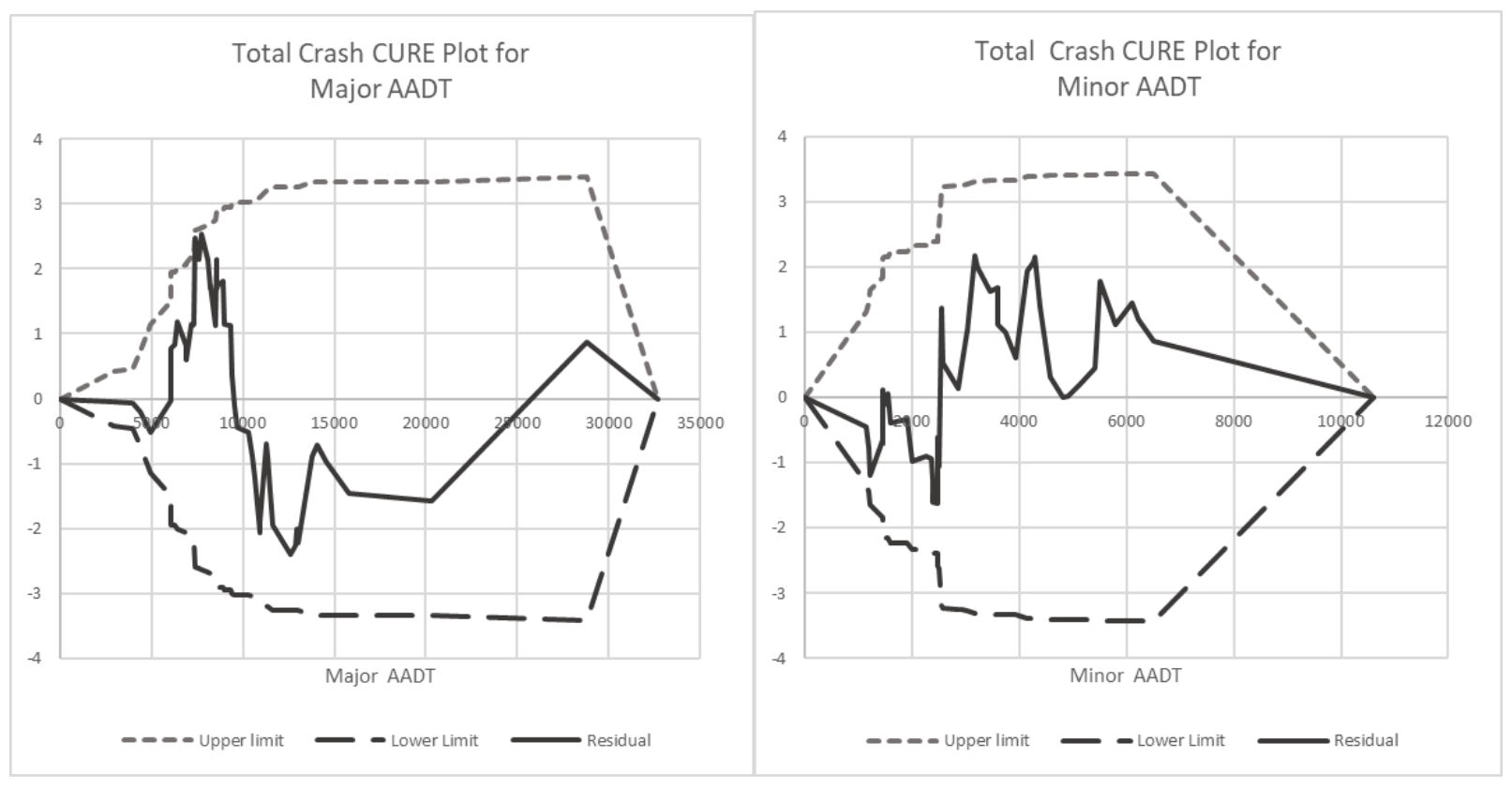

Figure 23 CURE Plots for Major and Minor AADTs for total crashes

The CURE plots showed that the model's residuals remain within the $95 \%$ confidence range, however, neither of the left turning volume ratio-based models were a good fit for the left turn movement variables. This indicates that total crashes do not correlate well with the volume of left turns at the intersections. Based on the parameters alone, it can be concluded that the ratio of left turning to directional through volume had more of an impact on the total crashes than the ratio of left turning to opposing through volume. 

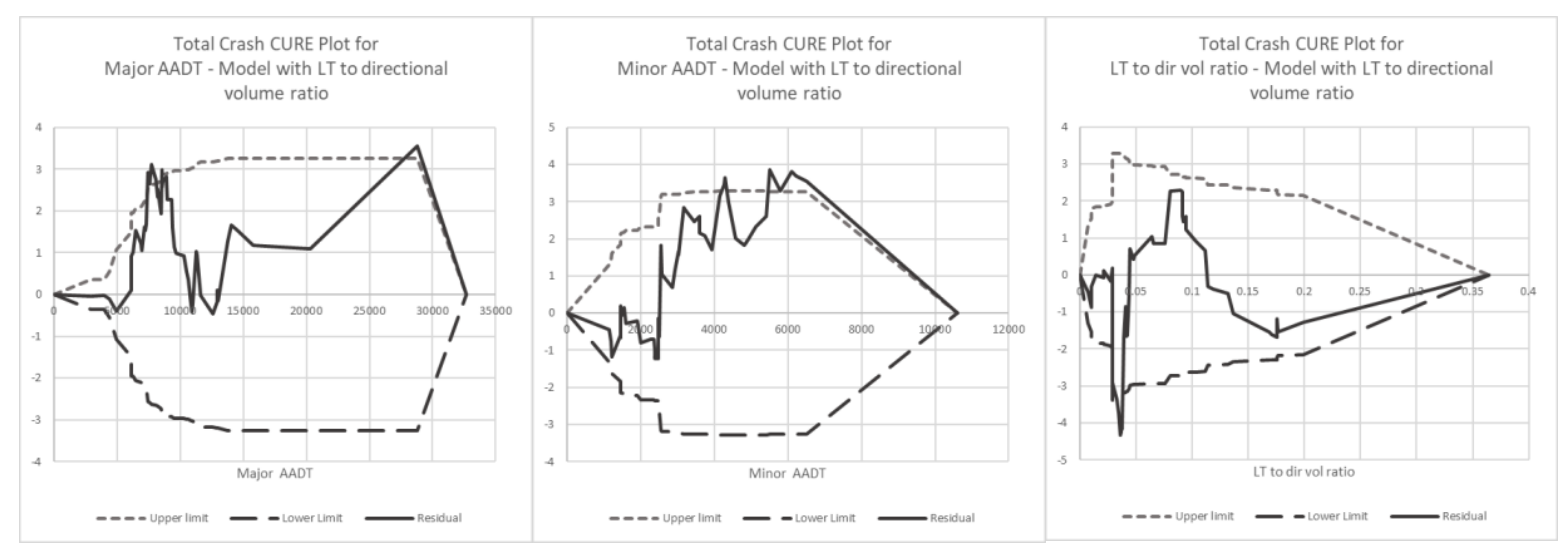

Figure 24 CURE Plots for Major and Minor AADTs and left turn volume ratio for total crashes using left turn to directional volume ratio
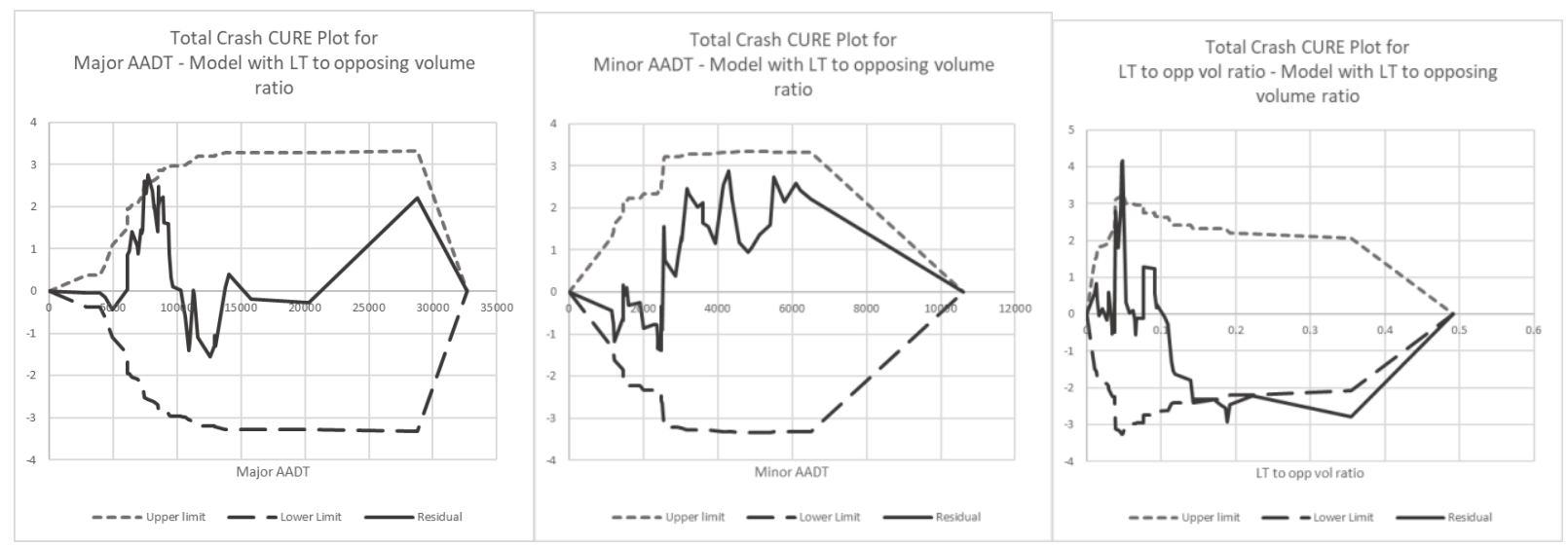

Figure 25 CURE Plots for Major and Minor AADTs and left turn volume ratio for total crashes using left turn to opposing volume ratio

The results indicated that the model using the left turn to directional volume ratio had more outlying residual values than the model using the left turn volume to opposing volume ratio. Overall, matching the p-values, the residuals estimated for the ratios exceeded the $95 \%$ confidence limit for both models at most portions. 
The following table shows the parameters used to model total crashes with the inclusion of the average length of the left turn lanes along major link approaches.

Table 14 Parameters for modelling total crashes including average length of left turn lanes along major link's approaches

\begin{tabular}{|c|c|c|c|c|c|c|}
\hline & \multicolumn{2}{|c|}{ AADTs only } & \multicolumn{2}{|c|}{$\begin{array}{l}\text { Average ratio of left } \\
\text { turn to directional } \\
\text { through traffic }\end{array}$} & \multicolumn{2}{|c|}{$\begin{array}{l}\text { Average ratio of left turn } \\
\text { to opposing through } \\
\text { traffic }\end{array}$} \\
\hline Parameter & Estimate & $\begin{array}{l}\operatorname{Pr}> \\
\text { ChiSq }\end{array}$ & Estimate & $\begin{array}{l}\text { Pr }> \\
\text { ChiSq }\end{array}$ & Estimate & $\begin{array}{l}\operatorname{Pr}> \\
\text { ChiSq }\end{array}$ \\
\hline$\alpha$ & -13.8874 & $<0.0001$ & -13.8574 & $<0.0001$ & -13.9628 & $<0.0001$ \\
\hline $\begin{array}{r}\beta 1(L T \text { vol } \\
\text { ratio })\end{array}$ & & & 1.1037 & 0.4617 & 0.7137 & 0.5230 \\
\hline $\begin{array}{r}\text { B2(length of LT } \\
\text { lane) }\end{array}$ & 1.0242 & 0.0748 & 1.0439 & 0.0687 & 1.0622 & 0.0652 \\
\hline$B 3(M a j A A D T)$ & 0.5914 & 0.0101 & 0.6480 & 0.0070 & 0.6378 & 0.0077 \\
\hline$B 4($ Min $A A D T)$ & 0.7261 & 0.0010 & 0.6341 & 0.0109 & 0.6499 & 0.0086 \\
\hline
\end{tabular}

The AADT based model in the table was statistically significant and a good fit for the set of data However, the estimated relationship doesn't make intuitive sense, and was therefore dismissed. The expected outcome would be a decrease in the total crashes as the length of left turn lane is increased. 

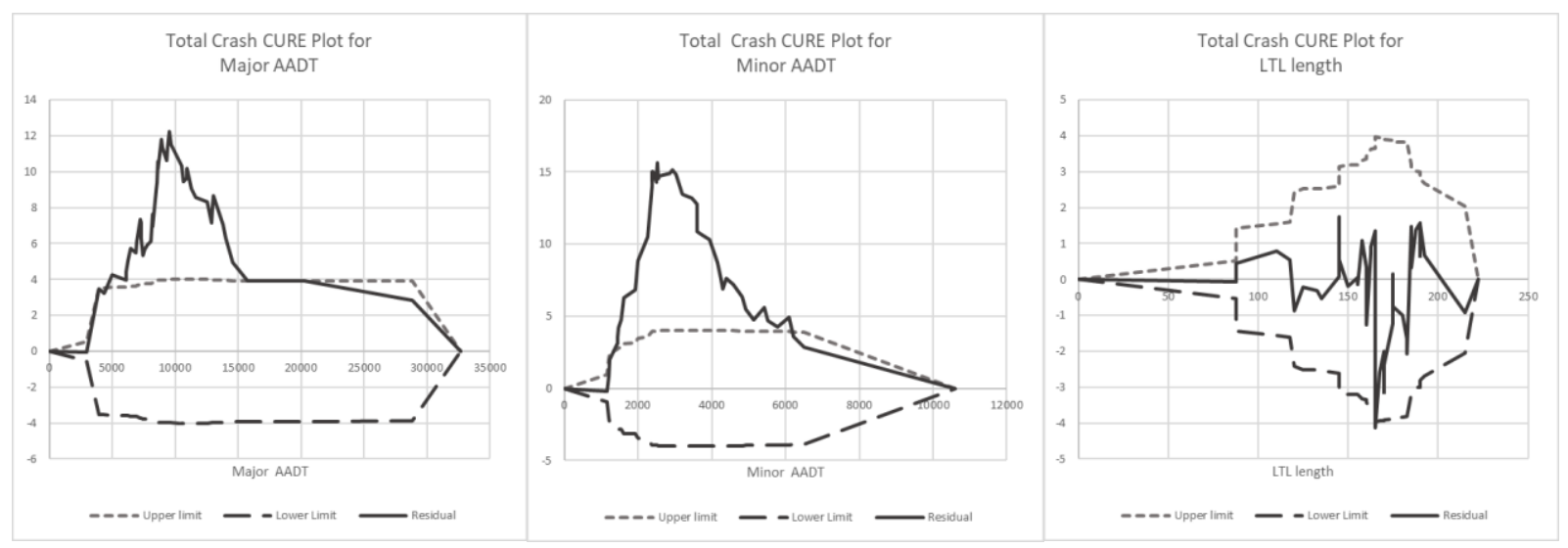

Figure 26 CURE Plots for Major and Minor AADTs and length of left turn lane for total crashes

The CURE plots showed an overestimation with respect to the major and minor AADTs, but a confident residual with respect to the length of the left turn lane. Unlike the AADT based model, neither of the two left turning volume ratio-based models were a good fit and neither of them demonstrated the expected crash left turn lane length relationship. 

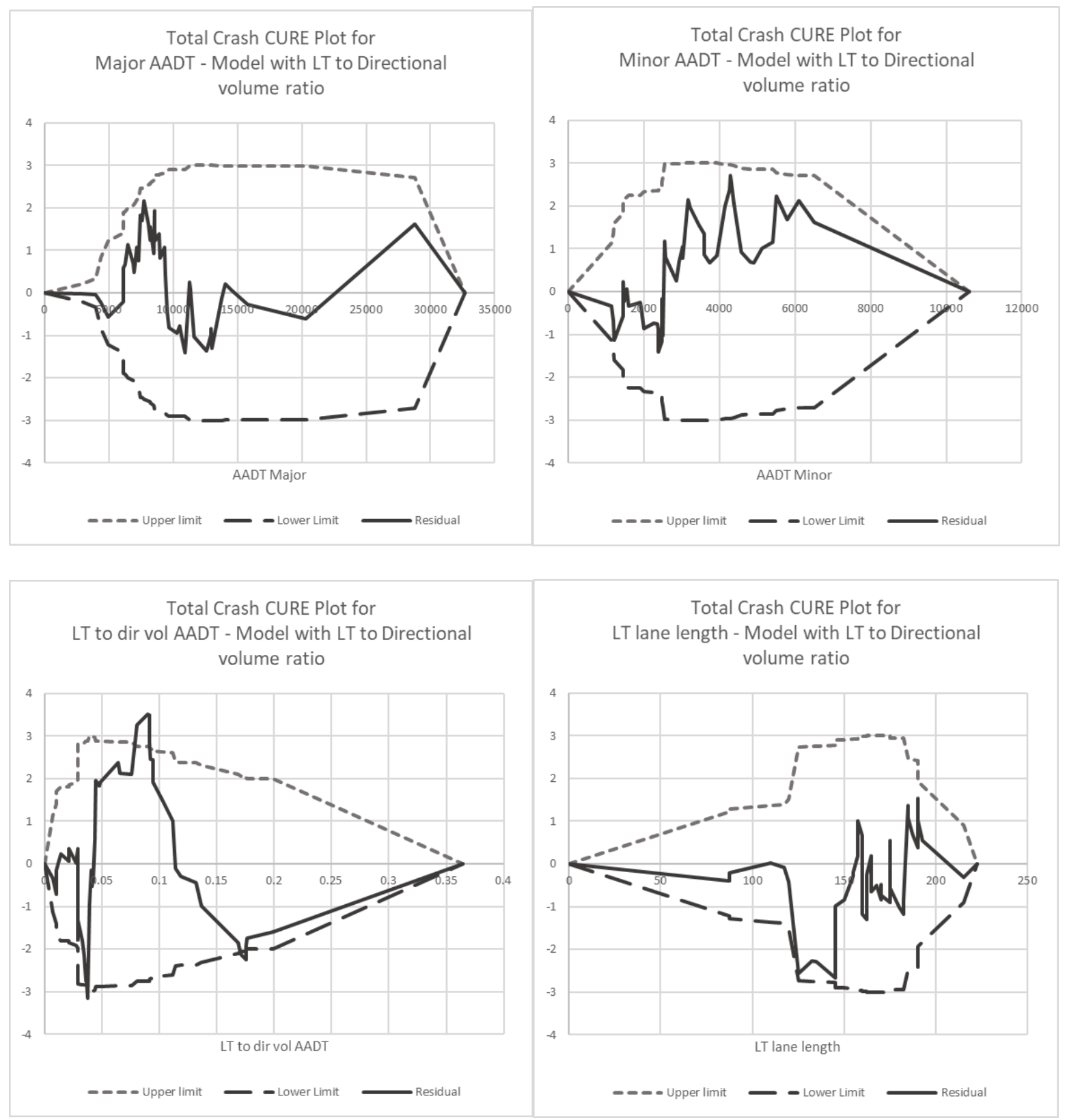

Figure 27 CURE Plots for Major and Minor AADTs, left turn volume ratio, and length of left turn lane for total crashes using left turn to directional volume ratio 

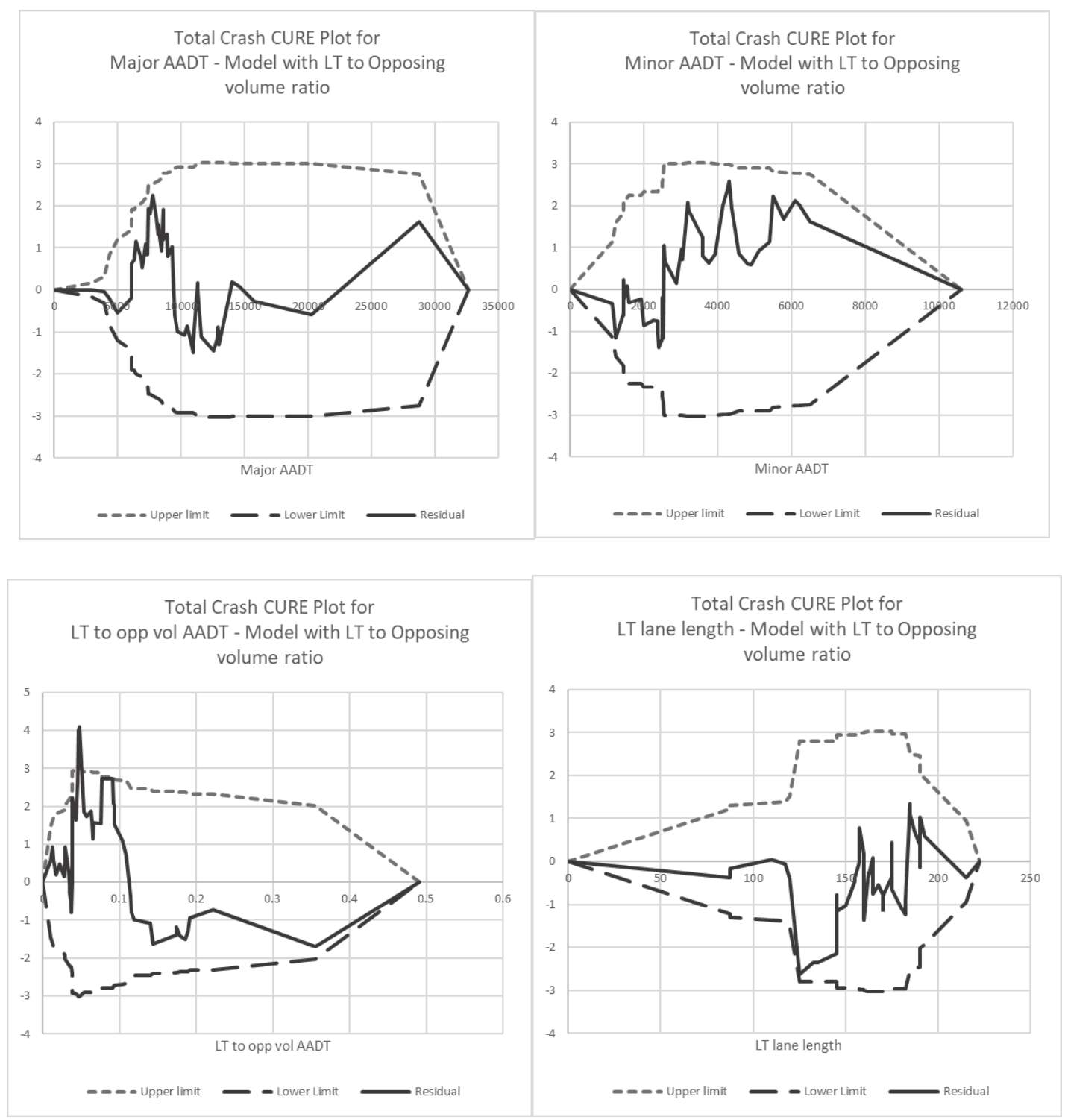

Figure 28 CURE Plots for Major and Minor AADTs, left turn volume ratio, and length of left turn lane for total crashes using left turn to opposing volume ratio

The CURE plots revealed that both models provided accurate crash predictions. 


\subsection{Fatal and Injury Crashes and Property Damage Only Crashes}

The following table shows the parameters used to model crashes involving fatality and injury and property damage only.

Table 15 Parameters for modelling F+I and PDO crashes

\begin{tabular}{|c|c|c|c|c|c|c|}
\hline \multirow[b]{2}{*}{ Parameter } & \multicolumn{2}{|l|}{ AADTs only } & \multicolumn{2}{|c|}{$\begin{array}{l}\text { Average ratio of left turn } \\
\text { to directional through } \\
\text { traffic }\end{array}$} & \multicolumn{2}{|c|}{$\begin{array}{l}\text { Average ratio of left } \\
\text { turn to opposing } \\
\text { through traffic }\end{array}$} \\
\hline & $\begin{array}{l}\mathrm{F}+\mathrm{I} \\
\text { Estimate } \\
(\mathrm{Pr}>\mathrm{ChiSq})\end{array}$ & $\begin{array}{l}\text { PDO } \\
\text { Estimate } \\
(\mathrm{Pr}>\mathrm{ChiSq})\end{array}$ & $\begin{array}{l}\mathrm{F}+\mathrm{I} \\
\text { Estimate } \\
(\mathrm{Pr}>\mathrm{ChiSq})\end{array}$ & $\begin{array}{l}\text { PDO } \\
\text { Estimate } \\
(\mathrm{Pr}>\mathrm{ChiSq})\end{array}$ & $\begin{array}{l}\mathrm{F}+\mathrm{I} \\
\text { Estimate } \\
(\mathrm{Pr}>\mathrm{ChiSq})\end{array}$ & $\begin{array}{l}\text { PDO } \\
\text { Estimate } \\
(\mathrm{Pr}>\mathrm{ChiSq})\end{array}$ \\
\hline$\alpha$ & $\begin{array}{l}-6.7545 \\
(0.0129)\end{array}$ & $\begin{array}{l}-11.8842 \\
(<0.0001)\end{array}$ & $\begin{array}{l}-6.7434 \\
(0.0129)\end{array}$ & $\begin{array}{l}-6.7434 \\
(0.0129)\end{array}$ & $\begin{array}{l}-6.7682 \\
(0.0128)\end{array}$ & $\begin{array}{l}-6.7682 \\
(0.0128)\end{array}$ \\
\hline $\begin{array}{r}\beta 1(L T \text { vol } \\
\text { ratio })\end{array}$ & & & $\begin{array}{l}0.2232 \\
(0.9021)\end{array}$ & $\begin{array}{l}0.2232 \\
(0.9021)\end{array}$ & $\begin{array}{l}-0.2110 \\
(0.8724)\end{array}$ & $\begin{array}{l}-0.2110 \\
(0.8724)\end{array}$ \\
\hline $\begin{array}{c}\beta 2(M a j \\
A A D T)\end{array}$ & $\begin{array}{l}0.3655 \\
(0.1748)\end{array}$ & $\begin{array}{l}0.7633 \\
(0.0011)\end{array}$ & $\begin{array}{l}0.3766 \\
(0.1846)\end{array}$ & $\begin{array}{l}0.3766 \\
(0.1846\end{array}$ & $\begin{array}{l}0.3527 \\
(0.2098)\end{array}$ & $\begin{array}{l}0.3527 \\
(0.2098)\end{array}$ \\
\hline $\begin{array}{c}\text { B3(Min } \\
A A D T)\end{array}$ & $\begin{array}{l}0.6220 \\
(0.0136)\end{array}$ & $\begin{array}{l}0.8703 \\
(0.0001)\end{array}$ & $\begin{array}{l}0.6058 \\
(0.0330)\end{array}$ & $\begin{array}{l}0.6058 \\
(0.0330)\end{array}$ & $\begin{array}{l}0.6409 \\
(0.0214)\end{array}$ & $\begin{array}{l}0.6409 \\
(0.0214)\end{array}$ \\
\hline
\end{tabular}


The results revealed that for F+I crashes the AADT based model was not a good fit for major link volumes, as its P-value was quite high. Nevertheless, the model would be represented by the following equation.

$$
\frac{\text { Crashes }_{F+I}}{1 \text { Year }}=\exp [-9.3936] \times M a j A A D T^{0.3655} \times \operatorname{MinAADT}^{0.6220}
$$

\section{Equation 16}

However, for the PDO crashes, the AADT based model is a good fit and is statistically significant. Equation 17 would be the model for used property damage only crashes.

$$
\frac{\text { Crashes }_{P D O}}{1 \text { Year }}=\exp [-14.5233] \times \text { MajAADT }^{0.7633} \times \operatorname{MinAADT}^{0.8703}
$$

\section{Equation 17}

None of the two left turning volume ratio-based models for either of the two crash categories were a good fit. We can confidently conclude that there was no correlation between the volume of left turns and fatal and injury crashes or PDO in the analyzed intersections.

The following table shows the parameters used to model crashes involving fatalities and injury with the inclusion of the average length of the left turn lanes along major link approaches. 
Table 16 Parameters for modelling fatal and injury crashes including average length of left turn lanes along major link's approaches

\begin{tabular}{|c|c|c|c|c|c|c|}
\hline \multirow[b]{2}{*}{ Parameter } & \multicolumn{2}{|l|}{ AADTs only } & \multicolumn{2}{|c|}{$\begin{array}{l}\text { Average ratio of left turn } \\
\text { to directional through } \\
\text { traffic }\end{array}$} & \multicolumn{2}{|c|}{$\begin{array}{l}\text { Average ratio of left } \\
\text { turn to opposing } \\
\text { through traffic }\end{array}$} \\
\hline & $\begin{array}{l}\mathrm{F}+\mathrm{I} \\
\text { Estimate } \\
(\mathrm{Pr}>\mathrm{ChiSq})\end{array}$ & $\begin{array}{l}\text { PDO } \\
\text { Estimate } \\
\text { (Pr>ChiSq) }\end{array}$ & $\begin{array}{l}\mathrm{F}+\mathrm{I} \\
\text { Estimate } \\
(\mathrm{Pr}>\mathrm{ChiSq})\end{array}$ & $\begin{array}{l}\text { PDO } \\
\text { Estimate } \\
(\mathrm{Pr}>\mathrm{ChiSq})\end{array}$ & $\begin{array}{l}\mathrm{F}+\mathrm{I} \\
\text { Estimate } \\
(\mathrm{Pr}>\mathrm{ChiSq})\end{array}$ & $\begin{array}{l}\text { PDO } \\
\text { Estimate } \\
(\mathrm{Pr}>\mathrm{ChiSq})\end{array}$ \\
\hline$\alpha$ & $\begin{array}{l}-15.3065 \\
(0.0002)\end{array}$ & $\begin{array}{l}-14.5641 \\
(<0.0001)\end{array}$ & $\begin{array}{l}-15.3023 \\
(0.0002)\end{array}$ & $\begin{array}{l}-14.5242 \\
(<0.0001)\end{array}$ & $\begin{array}{l}-15.3290 \\
(0.0002)\end{array}$ & $\begin{array}{l}-14.7485 \\
(<0.0001)\end{array}$ \\
\hline $\begin{array}{r}\beta 1(L T \text { vol } \\
\text { ratio })\end{array}$ & & & $\begin{array}{l}0.0347 \\
(0.9834)\end{array}$ & $\begin{array}{l}1.6261 \\
(0.2735)\end{array}$ & $\begin{array}{l}-0.2561 \\
(0.8341)\end{array}$ & $\begin{array}{l}1.1800 \\
(0.2858)\end{array}$ \\
\hline $\begin{array}{r}\text { B2(length } \\
\text { of } L T \\
\text { lane) }\end{array}$ & $\begin{array}{l}1.7752 \\
(0.0081)\end{array}$ & $\begin{array}{l}0.6133 \\
(0.2915)\end{array}$ & $\begin{array}{l}1.7744 \\
(0.0082)\end{array}$ & $\begin{array}{l}0.6511 \\
(0.2560)\end{array}$ & $\begin{array}{l}1.7788 \\
(0.0080)\end{array}$ & $\begin{array}{l}0.6903 \\
(0.2309)\end{array}$ \\
\hline $\begin{array}{c}B 3(M a j \\
A A D T)\end{array}$ & $\begin{array}{l}0.3894 \\
(0.1247)\end{array}$ & $\begin{array}{l}0.7472 \\
(0.0014)\end{array}$ & $\begin{array}{l}0.3912 \\
(0.1458)\end{array}$ & $\begin{array}{l}0.8269 \\
(0.0006)\end{array}$ & $\begin{array}{l}0.3725 \\
(0.1616)\end{array}$ & $\begin{array}{l}0.8216 \\
(0.0006)\end{array}$ \\
\hline $\begin{array}{c}B 4(\mathrm{Min} \\
A A D T)\end{array}$ & $\begin{array}{l}0.5329 \\
(0.0230)\end{array}$ & $\begin{array}{l}0.8343 \\
(0.0002)\end{array}$ & $\begin{array}{l}0.5304 \\
(0.0437)\end{array}$ & $\begin{array}{l}0.6977 \\
(0.0056)\end{array}$ & $\begin{array}{l}0.5556 \\
(0.0317)\end{array}$ & $\begin{array}{l}0.7089 \\
(0.0044)\end{array}$ \\
\hline
\end{tabular}

The goodness of fit of the AADT based model was similar to the goodness of fit of the model without the length of the left turn lanes. As seen with the model for total crashes, the left turn lane parameter did not match the expected relationship for any of the categories. 
None of the four (two for each of the two categories) left turning volume ratio-based models were a good fit based on the P-values, and none of the models demonstrated the expected crash left turn lane length relationship.

\subsection{Angle Crashes}

The following table shows parameters with respect to the model for angle crashes.

Table 17 Parameters for modeling angle crashes

\begin{tabular}{|c|c|c|c|c|c|c|}
\hline & \multicolumn{2}{|c|}{ AADTs only } & \multicolumn{2}{|c|}{$\begin{array}{l}\text { Average ratio of left } \\
\text { turn to directional } \\
\text { through traffic }\end{array}$} & \multicolumn{2}{|c|}{$\begin{array}{l}\text { Average ratio of left } \\
\text { turn to opposing } \\
\text { through traffic }\end{array}$} \\
\hline Parameter & Estimate & $\begin{array}{l}\operatorname{Pr}> \\
\text { ChiSq }\end{array}$ & Estimate & $\begin{array}{l}\operatorname{Pr}> \\
\text { ChiSq }\end{array}$ & Estimate & $\begin{array}{l}\text { Pr }> \\
\text { ChiSq }\end{array}$ \\
\hline$\alpha$ & -1.4253 & 0.7360 & -6.7434 & 0.0129 & -6.7682 & 0.0128 \\
\hline$\beta 1$ (LT vol ratio) & & & 0.2232 & 0.9021 & -0.2110 & 0.8724 \\
\hline$\beta 2(\operatorname{Maj} A A D T)$ & -0.2540 & 0.5720 & 0.3766 & 0.1846 & 0.3527 & 0.2098 \\
\hline B3(Min AADT) & 0.5896 & 0.1256 & 0.6058 & 0.0330 & 0.6409 & 0.0214 \\
\hline
\end{tabular}

The AADT based model was not a good fit and was dismissed. The two left turning volume ratio models were also not a good fit and were dismissed. 
The following table presents the parameters used to model angle crashes including the average length of the left turn lanes along major link approaches.

Table 18 Parameters for modeling angle crashes including average length of left turn lanes along major link's approaches

\begin{tabular}{|c|c|c|c|c|c|c|}
\hline \multirow[b]{2}{*}{ Parameter } & \multicolumn{2}{|c|}{ AADTs only } & \multicolumn{2}{|c|}{$\begin{array}{l}\text { Average ratio of left } \\
\text { turn to directional } \\
\text { through traffic }\end{array}$} & \multicolumn{2}{|c|}{$\begin{array}{l}\text { Average ratio of left } \\
\text { turn to opposing } \\
\text { through traffic }\end{array}$} \\
\hline & Estimate & $\begin{array}{l}\operatorname{Pr}> \\
\text { ChiSq }\end{array}$ & Estimate & $\begin{array}{l}\text { Pr }> \\
\text { ChiSq }\end{array}$ & Estimate & $\begin{array}{l}\operatorname{Pr}> \\
\text { ChiSq }\end{array}$ \\
\hline$\alpha$ & -16.0164 & 0.0241 & -15.9229 & 0.0247 & -16.0466 & 0.0239 \\
\hline$\beta 1(L T$ vol ratio $)$ & & & 0.8533 & 0.7505 & -0.4040 & 0.8328 \\
\hline $\begin{array}{r}\text { B2(length of } L T \\
\text { lane) }\end{array}$ & 3.0464 & 0.0130 & 3.0476 & 0.0127 & 3.0390 & 0.0133 \\
\hline$B 3$ (Maj AADT) & -0.2274 & 0.5986 & -0.1802 & 0.6929 & -0.2551 & 0.5721 \\
\hline$B 4($ Min $A A D T)$ & 0.4389 & 0.2357 & 0.3640 & 0.4021 & 0.4836 & 0.2553 \\
\hline
\end{tabular}

The estimated AADT based model was not significant and the relationship between angle crashes and the length of left turn lanes did not match the expected relationship.

The two left turning volume ratio-based models were not a good fit, based on their P-values, and were dismissed. 


\subsection{Rear-End Crashes}

The following table shows parameters with respect to the model for rear end crashes.

Table 19 Parameters for modeling rear end crashes

\begin{tabular}{|c|c|c|c|c|c|c|}
\hline & \multicolumn{2}{|c|}{ AADTs only } & \multicolumn{2}{|c|}{$\begin{array}{l}\text { Average ratio of left } \\
\text { turn to directional } \\
\text { through traffic }\end{array}$} & \multicolumn{2}{|c|}{$\begin{array}{l}\text { Average ratio of left } \\
\text { turn to opposing } \\
\text { through traffic }\end{array}$} \\
\hline Parameter & Estimate & $\begin{array}{l}\text { Pr }> \\
\text { ChiSq }\end{array}$ & Estimate & $\begin{array}{l}\text { Pr > } \\
\text { ChiSq }\end{array}$ & Estimate & $\begin{array}{l}\operatorname{Pr}> \\
\text { ChiSq }\end{array}$ \\
\hline$\alpha$ & -14.2215 & $<0.0001$ & -14.2211 & $<0.0001$ & -14.1989 & $<0.0001$ \\
\hline$\beta 1(L T$ vol ratio $)$ & & & 0.0055 & 0.9977 & 0.2738 & 0.8503 \\
\hline$\beta 2(M a j A A D T)$ & 0.8964 & 0.0010 & 0.8967 & 0.0018 & 0.9135 & 0.0014 \\
\hline$B 3(\operatorname{Min} A A D T)$ & 0.9430 & 0.0022 & 0.9426 & 0.0053 & 0.9174 & 0.0061 \\
\hline
\end{tabular}

The P-values revealed that the AADT model was a good estimate for rear end crashes. Equation 18 would therefore be the model for rear end crashes.

$$
\begin{gathered}
\frac{\text { Crashes }_{R E}}{1 \text { Year }}=\exp [-16.639] \times \operatorname{MajAADT}^{0.8964} \times \operatorname{MinAADT}^{0.9430} \\
\text { Equation } 18
\end{gathered}
$$

None of the two left turning volume ratio-based models was a good fit, based on their P-values, and were dismissed. The left turn volume to opposing traffic ratio model was a better match, although still statistically insignificant. 
The following table presents the parameters used to model rear-end crashes including the average length of the left turn lanes along major link approaches.

Table 20 Parameters for modeling rear end crashes including average length of left turn lanes along major link's approaches

\begin{tabular}{|c|c|c|c|c|c|c|}
\hline & \multicolumn{2}{|c|}{ AADTs only } & \multicolumn{2}{|c|}{$\begin{array}{l}\text { Average ratio of left } \\
\text { turn to directional } \\
\text { through traffic }\end{array}$} & \multicolumn{2}{|c|}{$\begin{array}{l}\text { Average ratio of left } \\
\text { turn to opposing } \\
\text { through traffic }\end{array}$} \\
\hline Parameter & Estimate & $\begin{array}{l}\operatorname{Pr}> \\
\text { ChiSq }\end{array}$ & Estimate & $\begin{array}{l}\text { Pr }> \\
\text { ChiSq }\end{array}$ & Estimate & $\begin{array}{l}\operatorname{Pr}> \\
\text { ChiSq }\end{array}$ \\
\hline$\alpha$ & -17.7565 & 0.0002 & -17.7564 & 0.0002 & -17.8468 & 0.0002 \\
\hline$\beta 1(L T$ vol ratio $)$ & & & 0.0022 & 0.9991 & 0.4384 & 0.7616 \\
\hline B2(length of LT lane) & 0.8392 & 0.3044 & 0.8392 & 0.3044 & 0.8670 & 0.2910 \\
\hline$B 3(M a j A A D T)$ & 0.8696 & 0.0015 & 0.8697 & 0.0026 & 0.8970 & 0.0018 \\
\hline B4(Min AADT & 0.8825 & 0.0039 & 0.8823 & 0.0087 & 0.8395 & 0.0123 \\
\hline
\end{tabular}

The AADT based model was not a good fit, particularly with respect to the parameter for the length of the left turn lane. In addition, the relationship between rear-end crashes and the length of left turn lanes did not match the expected pattern.

Neither of the two models was statistically significant based on their P-values and were dismissed.

\subsection{Turning Movement Crashes}


The following table shows parameters with respect to the model for turning movement crashes.

Table 21 Parameters for modeling turning movement crashes

\begin{tabular}{|c|c|c|c|c|c|c|}
\hline \multirow[b]{2}{*}{ Parameter } & \multicolumn{2}{|c|}{ AADTs only } & \multicolumn{2}{|c|}{$\begin{array}{l}\text { Average ratio of left } \\
\text { turn to directional } \\
\text { through traffic }\end{array}$} & \multicolumn{2}{|c|}{$\mid \begin{array}{l}\text { Average ratio of lef } \\
\text { turn to opposing } \\
\text { through traffic }\end{array}$} \\
\hline & Estimate & $\begin{array}{l}\mathrm{Pr}> \\
\text { ChiSq }\end{array}$ & Estimate & $\begin{array}{l}\text { Pr > } \\
\text { ChiSq }\end{array}$ & Estimate & $\begin{array}{l}\text { Pr }> \\
\text { ChiSq }\end{array}$ \\
\hline$\alpha$ & -11.0252 & $<0.0001$ & -10.7475 & $<0.0001$ & -10.9132 & $<0.0001$ \\
\hline$\beta 1(L T$ vol ratio) & & & 2.9639 & 0.0337 & 1.8956 & 0.0639 \\
\hline$\beta 2($ Maj AADT) & 0.6354 & 0.0112 & 0.7799 & 0.0013 & 0.7542 & 0.0023 \\
\hline B3(Min $A A D T$ & 0.8329 & 0.0002 & 0.6021 & 0.0084 & 0.6592 & 0.0036 \\
\hline
\end{tabular}

The AADT based model was a good fit, indicating that this was a good model for the prediction of turning movement crashes. The following equation, Equation 19 would be the model for turning movement crashes.

$$
\frac{\text { Crashes }_{T M}}{1 \text { Year }}=\exp [-13.6643] \times \text { MajAADT }^{0.6354} \times \text { MinAADT }^{0.8329}
$$

\section{Equation 19}

While both of the left turning volume ratio-based models were good, the model using the ratio of a left turn to directional through traffic volume was a better fit than the model using the left turn to opposing traffic volume ratio. Out of the 6 categories discussed, the only category that was 
correlated to the parameters quantifying turning movements was turning movement crashes, which is expected.

Equation 20 would be the model used for turning movement crashes using the ratio of left turn to directional through traffic volumes.

$$
\frac{\text { Crashes }_{T M}}{1 \text { Year }}=\exp \left[-13.3866+2.9639 \times\left[\frac{\sum_{\text {dir }} \text { LT Volume }}{\sum_{\text {dir }} \text { volume }}\right]_{\text {major }}\right] \times \text { MajAADT }^{0.7799} \times \text { MinAADT }^{0.6021}
$$

\section{Equation 20}

Equation 21 would be the model used for turning movement crashes using the ratio of left turn to opposing traffic volumes.

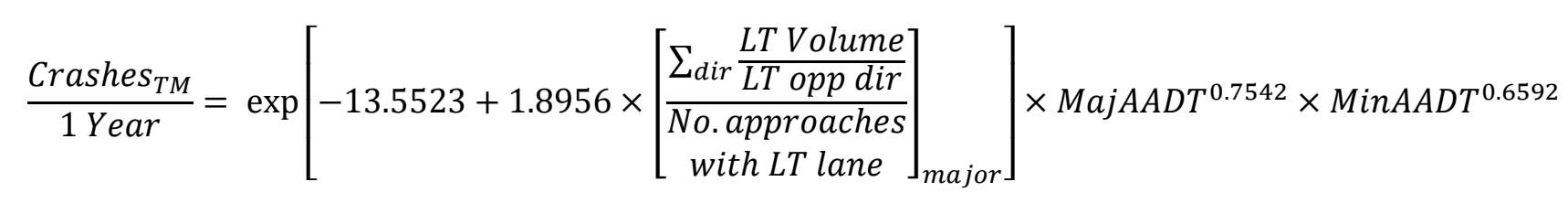

\section{Equation 21}


The following table presents the parameters used to model turning movement crashes including the average length of the left turn lanes along major link approaches.

Table 22 Parameters for modeling turning movement crashes including average length of left turn lanes along major link's approaches

\begin{tabular}{|c|c|c|c|c|c|c|}
\hline & \multicolumn{2}{|c|}{ AADTs only } & \multicolumn{2}{|c|}{$\begin{array}{l}\text { Average ratio of left } \\
\text { turn to directional } \\
\text { through traffic }\end{array}$} & \multicolumn{2}{|c|}{$\begin{array}{l}\text { Average ratio of left } \\
\text { turn to opposing } \\
\text { through traffic }\end{array}$} \\
\hline Parameter & Estimate & $\begin{array}{l}\operatorname{Pr}> \\
\text { ChiSq }\end{array}$ & Estimate & $\begin{array}{l}\operatorname{Pr}> \\
\text { ChiSq }\end{array}$ & Estimate & $\begin{array}{l}\text { Pr }> \\
\text { ChiSq }\end{array}$ \\
\hline$\alpha$ & -13.1017 & 0.0002 & -13.1577 & $\begin{array}{l}<0.000 \\
1\end{array}$ & -13.3093 & $<0.0001$ \\
\hline$\beta 1$ (LT vol ratio) & & & 1.3581 & 0.0266 & 1.9434 & 0.0521 \\
\hline B2(length of LT lane) & 0.4520 & 0.3797 & 0.5066 & 0.2914 & 0.5094 & 0.2980 \\
\hline$B 3(M a j A A D T)$ & 0.6331 & 0.0101 & 0.7854 & 0.0010 & 0.7584 & 0.0017 \\
\hline B4(Min AADT & 0.8082 & 0.0002 & 0.5747 & 0.0101 & 0.6298 & 0.0047 \\
\hline
\end{tabular}

The AADT based model estimated was not a good fit, and it did not depict the expected relationship between turning movement crashes and length of left turn lanes as seen with the calibrated parameters, similar to all other categories of crashes analyzed.

Both derived left turning volume ratio-based models were statistically insignificant, however only with respect to the parameter of the length of left turn lanes. These parameters, similar to all the 
other left turning volume ratio-based models calibrated, didn't make intuitive sense and don't follow what is expected of them. 


\section{CONFLICT-BASED ANALYSIS OF SAFETY PERFORMANCE}

This chapter presents the process of finding a relationship between results obtained from VISSIMSSAM simulation and crash data provided by the MTO. This created models through which the crashes estimated can be used for finding SPF and CMF values for areas with similar driver behaviour, climate, road geometry standards, and similar in other influential attributes, where actual crash data is lacking, or if the crash data is not recorded over a long enough period of time or spread over enough number of intersection. In cases such as these, simulation results can be translated into predicted crashes using estimated models.

The software SSAM allowed for defining a TTC as the maximum threshold for the conflict counts that it presented. Therefore, determining which threshold of TTC would be best fit for representing the relationship between conflicts and crashes for each of the specific types of crashes was one of the objectives of the analysis. In other words, this was a sensitivity analysis on how changing the

TTC threshold would change the Pr > ChiSq value, that is used for determining the goodness of the fit of each model. Other measures were also used to further check the goodness of fit of the models, as explained previously.

The analysis looked at maximum thresholds of $1.5 \mathrm{~S}, 1.0 \mathrm{~S}$ and $0.5 \mathrm{~S}$ for TTC for conflict count to establish a model. As mentioned in methodology, conflicts with TTC equalling to zero were subtracted from the conflict counts as they were most likely VISSIM's error as VISSIM doesn't simulate collisions. Models had their $\mathrm{Pr}>\mathrm{ChiSq}$ values compared, and the best one to fit the data was chosen. 


\subsection{Modelling Total Crashes}

As previously mentioned, total crashes were modeled with total conflicts. Table 19 presents the parameters used to create a model for obtaining predicted crashes from the VISSIM-SSAM simulation outputs, as well as their corresponding $\operatorname{Pr}>$ ChiSq values:

Table 23 Parameters for modeling total crashes using VISSIM-SSAM output

\begin{tabular}{c|lllll}
\multicolumn{1}{c}{$A$} & $\operatorname{Pr}>$ ChiSq & B & Pr $>$ ChiSq \\
\hline TTC $<1.5 S$ & 1.2426 & 0.0256 & 0.3081 & 0.0109 \\
$T T C<1.0 S$ & 2.7707 & $<0.0001$ & 0.0134 & 0.8920 \\
$T T C<0.5 S$ & 2.677 & $<0.0001$ & 0.0265 & 0.8568
\end{tabular}

The results in Table 23 reveal that the only statistically significant parameter was for the number of conflicts for TTC $\leq 1.5 \mathrm{~S}$. All of the other parameters had significantly larger P-values, ranging between $80 \%-90 \%$. Therefore, the following equation is recommended for this model:

$$
\frac{\text { Crashes }_{\text {Total }}}{1 \text { Year }}=\exp [-0.6871] \times\left[\text { No. conflicts in } 1 h_{T T C \leq 1.5 S}\right]^{0.3081}
$$

Equation 22 

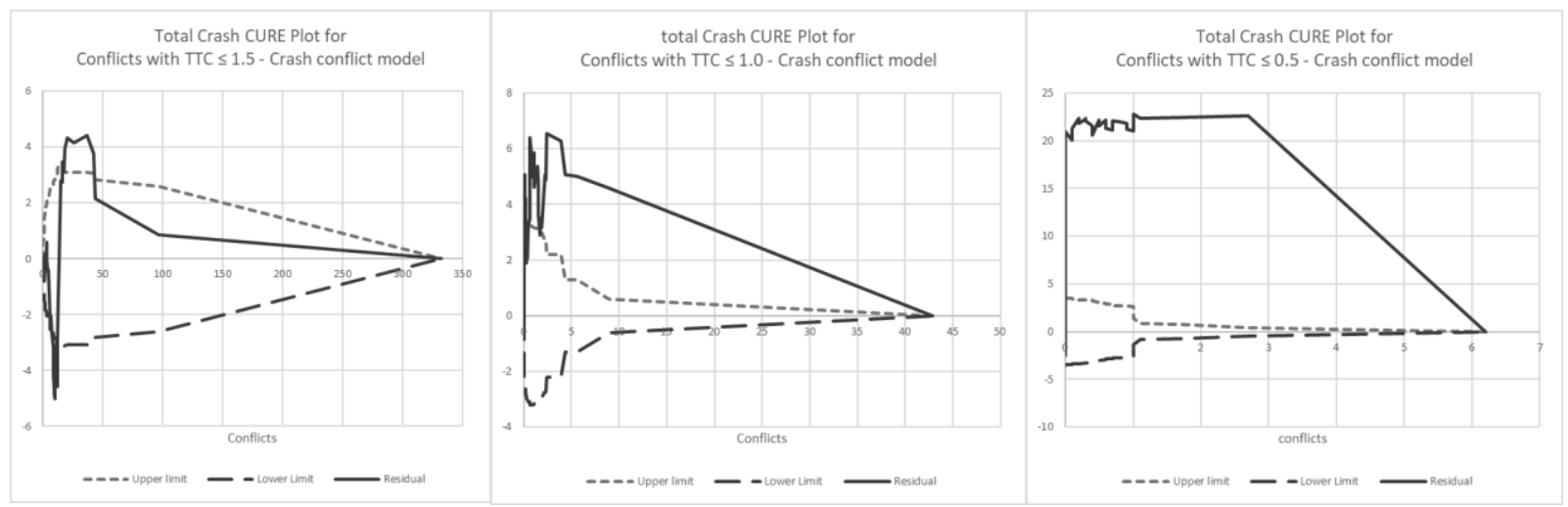

Figure 29 CURE Plots for conflicts for total crash conflict model

As shown in the above CURE plots, the only model that could predict crashes with confidence is the model with a TTC threshold of $1.5 \mathrm{~s}$.

\subsection{Modelling Fatal or Injury crashes}

Total conflicts were also used to model fatal and injury crashes. Table 24 presents the parameters of the models for each of the 3 TTC thresholds and their corresponding Pr $>$ ChiSq values for crashes involving fatality or injury.

Table 24 Parameters for modeling crashes involving fatality or injury using VISSIM-SSAM output

\begin{tabular}{c|llll}
\hline \multicolumn{1}{c}{$\alpha$} & $\operatorname{Pr}>$ ChiSq & $\beta$ & $\operatorname{Pr}>$ ChiSq \\
\hline TTC $<1.5 S$ & 0.6157 & 0.2668 & 0.2231 & 0.0615 \\
TTC $<1.0 S$ & 1.8687 & $<0.0001$ & -0.0462 & 0.6431 \\
& & & & \\
\hline$T T C<0.5 S$ & 1.8884 & $<0.0001$ & -0.1338 & 0.3589
\end{tabular}


The model using conflicts filtered for a TTC $\leq 1.5$ for crashes involving fatality or injury showed the best fit. Firstly, the Pr > ChiSq was not that good for any one of them, but it was still much better, much less, i.e. there is much higher confidence in the model for the TTC threshold of 1.5. More importantly, the coefficients estimated from the other two thresholds were negative and made no logical sense. The expectation was that the number of expected crashes would increase along with an increase in the number of conflicts. Therefore, the other two models were dismissed.

$$
\frac{\text { Crashes }_{F+I}}{1 \text { Year }}=\exp [-1.510] \times\left[\text { No. conflicts in } 1 h_{T T C \leq 1.5 S}\right]^{0.2231}
$$

\section{Equation 23}

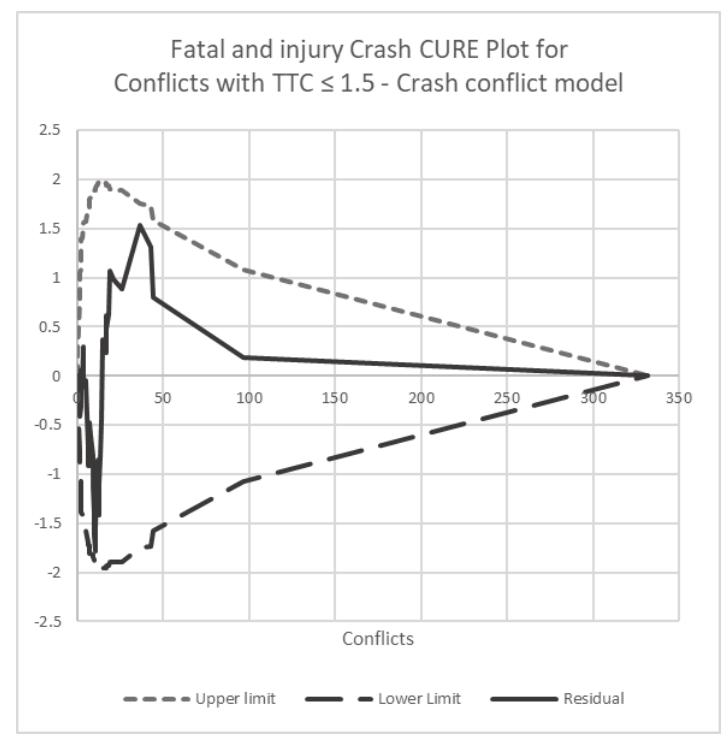

Figure 30 CURE Plot for conflicts for fatal and injury crash conflict model 
We were unable to produce CURE plots for any of the other models since the estimated coefficient was negative. The CURE plot for the model with a TTC threshold of 1.5 revealed a good confidence level.

\subsection{Modeling Property damage only crashes}

There are two different ways to obtain the number of PDO crashes: 1) subtracting crashes involving a fatality or an injury from the number of total crashes, or 2) modeling based on the total conflicts obtained from the simulation. The second method was used in this study and Table 21 presents the parameters of the models for each of the 3 TTC thresholds and their corresponding Pr > ChiSq values for crashes involving fatality or injury.

Table 25 Parameters for modeling PDO crashes involving fatality or injury using VISSIM-SSAM

\begin{tabular}{c|cccc}
\multicolumn{1}{c}{ output } \\
& $\alpha$ & Pr $>$ ChiSq & $\beta$ & Pr $>$ ChiSq \\
\hline TTC $<1.5 S$ & 0.6005 & 0.3166 & 0.3499 & 0.0070 \\
\hline TTC $<1.0 S$ & 2.2563 & $<0.0001$ & 0.0461 & 0.6567 \\
TTC $<0.5 S$ & 2.0528 & $<0.0001$ & 0.5443 & 0.3997
\end{tabular}

Contrary to the models for the fatal and injury collisions, all three of the PDO collision models had acceptable coefficients. However, similar to the two previous models, the best fitting model, based on the P-values was still the one with a TTC threshold of $1.5 \mathrm{~s}$. Therefore, the model would be represented by the following equation: 


$$
\frac{\text { Crashes }_{P D O}}{1 \text { Year }}=\exp [-1.2329] \times\left[\text { No. conflicts in } 1 h_{T T C \leq 1.5 S}\right]^{0.3499}
$$

\section{Equation 24}

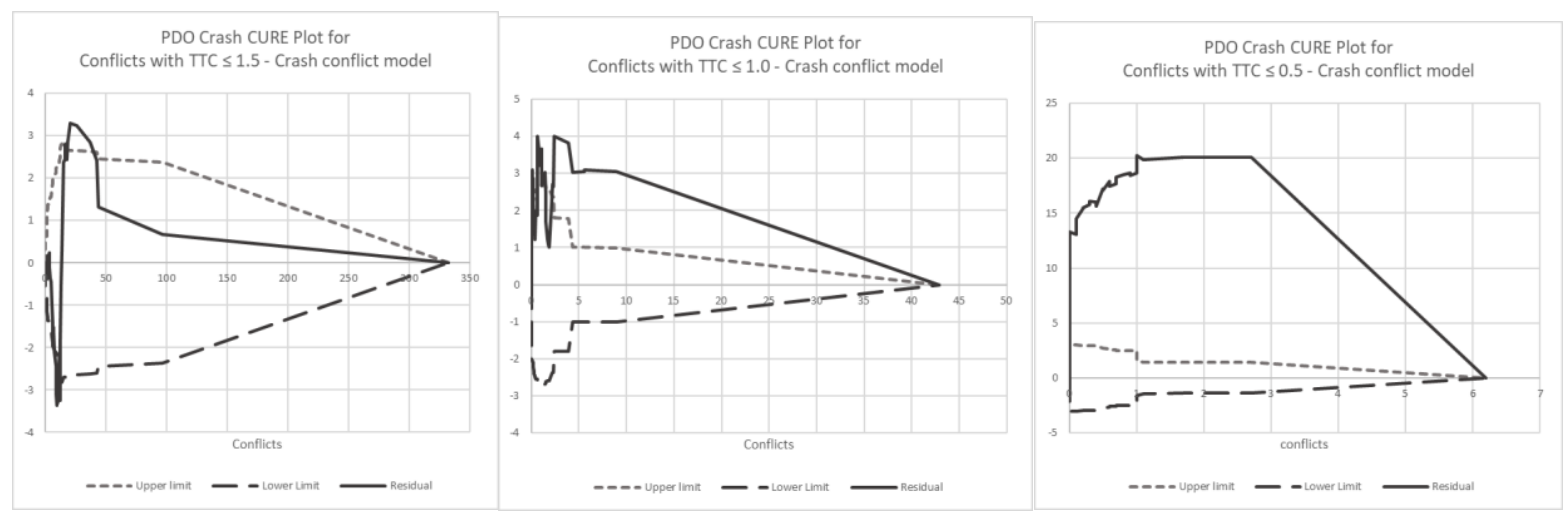

Figure 31 CURE Plots for conflicts for PDO crash conflict model

As shown in the above CURE plots, the only model that was able to predict crashes with confidence was the model with a TTC threshold of $1.5 \mathrm{~s}$.

\subsection{Modeling Angle Crashes}

As previously explained, angle crashes were modeled using crossing conflicts instead of total conflicts. The same three thresholds were still viewed as potentially good models. Table 26 presents the parameters used to model angle crashes and their corresponding Pr $>$ ChiSq values. 
Table 26 Parameters for modeling angle crashes using VISSIM-SSAM output

\begin{tabular}{r|llll}
\multicolumn{1}{c}{$\alpha$} & $\operatorname{Pr}>$ ChiSq & $\beta$ & $\operatorname{Pr}>$ ChiSq \\
\hline TTC $<1.5 S$ & 1.6011 & $<0.0001$ & -0.3562 & 0.0965 \\
$T T C<1.0 S$ & 1.7152 & $<0.0001$ & -0.5320 & 0.0181 \\
$T T C<0.5 S$ & 1.6587 & 0.0002 & -0.7045 & 0.0468
\end{tabular}

None of the estimated models for angle crashes provided a good representation as the conflict coefficient was negative, indicating an increase in angle crashes with decreases in the number of conflicts, which makes no logical sense. We can, therefore, conclude that angle crashes cannot be modeled for the intersections in this dataset.

\subsection{Modelling Rear-End Crashes}

Rear end crashes were modelled based on conflicts of the same name obtained from SSAM, as explained in previous chapters. Table 27 presents the parameters used to model rear-end crashes and their corresponding $\operatorname{Pr}>$ ChiSq values.

Table 27 Parameters for modeling rear-end crashes using VISSIM-SSAM output

\begin{tabular}{c|llll}
\multicolumn{1}{c}{$\alpha$} & $\operatorname{Pr}>$ ChiSq & $\beta$ & $\operatorname{Pr}>$ ChiSq \\
\hline TTC $<1.5 S$ & -0.2453 & 0.7356 & 0.5295 & 0.0069 \\
$T T C<1.0 S$ & 1.7317 & $<0.0001$ & 0.0831 & 0.5577 \\
\hline$T T C<0.5 S$ & 1.6052 & $<0.0001$ & 0.0869 & 0.6225
\end{tabular}


The results in the Pr $>$ ChiSq value column of Table 73 indicated that none of the models was a good fit for the representation of rear-end crashes. The model with a TTC of $1.5 \mathrm{~s}$ as the maximum threshold showed good confidence with regards to the coefficient of the independent variables and a high P-value, indicating low confidence with regards to the intercept. The other two models provided opposite results (low confidence with regards to the coefficient of the independent variable and good confidence based on the P-value for the coefficient of the constant). The model with a higher confidence level for the independent variable would be preferred.

$$
\frac{\text { Crashes }_{\text {R.E. }}}{1 \text { Year }}=\exp [-1.8954] \times\left[\text { No. RearEndConflicts } 1 h_{T T C \leq 1.5}\right]^{0.4295}
$$

\section{Equation 25}
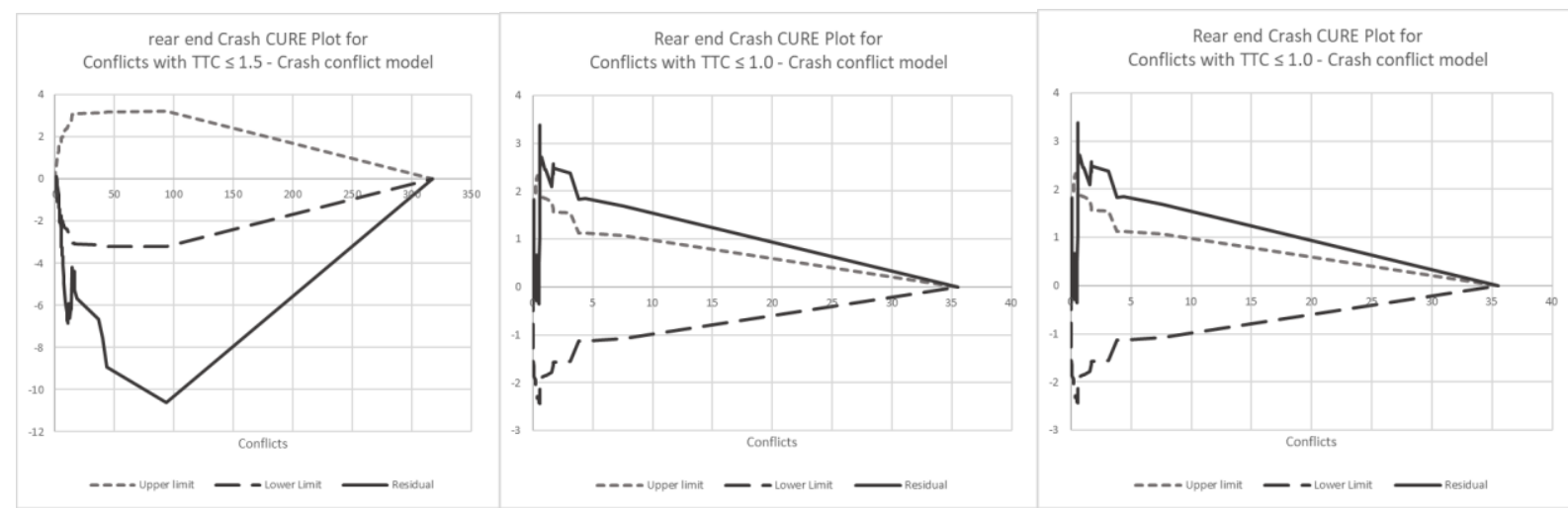

Figure 32 CURE Plots for conflicts for Rear end crash conflict model

The CURE plots indicated that none of the three models are able to predict crashes within the $95 \%$ confidence limits.

\subsection{Modelling Turning Movement Crashes}


Turning movement crashes were modeled using crossing conflicts. Table 28 presents the parameters used to model turning movement crashes and their corresponding $\operatorname{Pr}>\mathrm{ChiSq}$ values.

Table 28 Parameters for modeling turning movement crashes using VISSIM-SSAM output

\begin{tabular}{c|cccc}
\multicolumn{1}{c}{$\alpha$} & $\operatorname{Pr}>$ ChiSq & $\beta$ & $\operatorname{Pr}>$ ChiSq \\
\hline TTC $<1.5 S$ & 1.5588 & $<0.0001$ & 0.1611 & 0.0816 \\
$T T C<1.0 S$ & 2.1110 & $<0.0001$ & -0.2037 & 0.1743 \\
$T T C<0.5 S$ & 2.0043 & $<0.0001$ & -0.2426 & 0.2734
\end{tabular}

The results indicated that the only model that was a good fit was the model that used a maximum TTC threshold of $1.5 \mathrm{~s}$. The other models were therefore dismissed. Turning movement crashes can, therefore, be simulated using the following equation:

$$
\frac{\text { Crashes }_{T . M .}}{1 \text { Year }}=\exp [-0.7094] \times\left[\text { No. Crossing conflicts } 1 h_{T T C \leq 1.5}\right]^{0.1611}
$$

Equation 26 


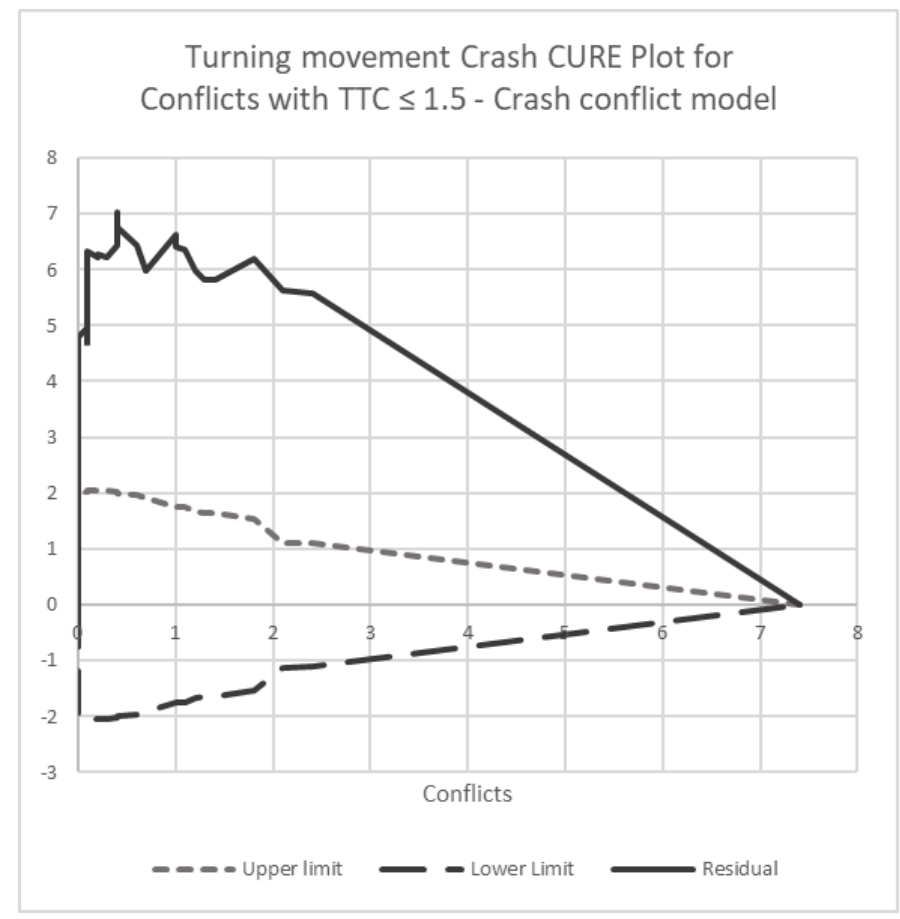

Figure 33 CURE Plot for conflicts for turning movement crash conflict model

The CURE plot indicated that the model cannot predict crashes within the $95 \%$ confidence limits.

\subsection{Conclusion and summary}

The results of the model estimations in this chapter revealed that all of the crash type models achieved the best fit when the maximum TTC threshold value was 1.5, with the exception of angle crashes, which could not be correlated with a statistically significant model. This may be due to the fact that there was more data for larger thresholds. Many of the data rows ranged between 1.0 and 1.5 and became zero conflict counts after the first threshold was applied (the same was true of the 0.5 threshold). 
A summary of the models is presented in the following table:

Table 29 Summary of crash conflict models for each crash type

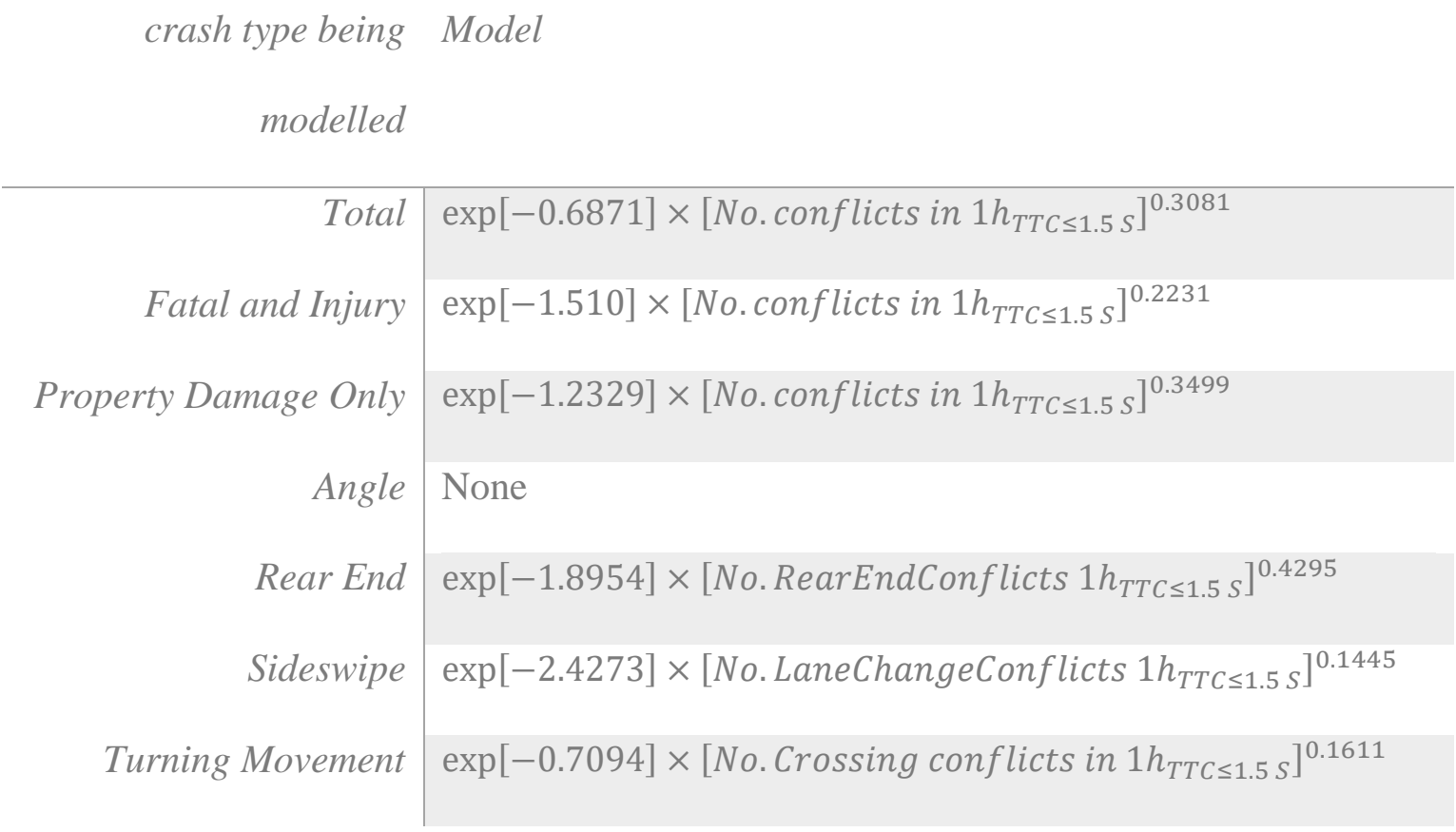




\section{CONFLICT-BASED ANALYSIS OF SAFETY PERFORMANCE}

The purpose of this chapter is to demonstrate relationships between the variables and attributes of the intersections with crashes obtained from conflicts counted using VISSM/SSAM simulations. This chapter applied the crash-conflict models from the previous chapter to conflicts determined for a group of hypothetical intersections, each with 3 left turn lane length levels, in order to find the CMF associated with the treatment (increasing the length of the left turn lane). This chapter also looks at the role played by different variables on the effectiveness of increasing the length of the left turn lane for the safety of the intersection.

The set included 27 intersections, each with a different combination of through directional and opposing traffic of left turning vehicle volumes.

The four-length levels of the left turn lane volumes and different percentages were as follows:

- Adequate, based on MTO's design guidelines (MTO, 1985)

- $40 \%$ less than what is determined as adequate

- $60 \%$ less than what is determined as adequate

- $80 \%$ less than what is determined as adequate

The focus was on the total crashes, fatal and injury crashes, property damage only crashes, rearend crashes, and turning movement crashes, derived from the conflicts extracted from the VISSIM/SSAM microsimulations, using the models estimated in the previous chapter.

CMF was defined as the ratio between the estimated crashes before and after the implementation of the treatment. Various CMF values, for different types of crashes for the proposed treatment 
being an increase in the length of the left turn lane from those less than adequate length to what is defined by the MTO guidelines as adequate. (MTO, 1985)

\subsection{Conflicts}

The following tables present the final conflict counts used to obtain the predicted crashes. The counts were necessary for the crash-conflict models, for TTC threshold of maximum TTC of 1.5 seconds, with the conflicts with TTC of zero subtracted from them. The number of conflicts for each of the intersections is presented in Appendix C.

Table 30 Count of total conflicts simulated

\begin{tabular}{r|llll}
\multicolumn{2}{c}{$\begin{array}{l}\text { Adequate length } \\
\text { left turn lane }\end{array}$} & $\begin{array}{l}40 \% \text { less length } \\
\text { left turn lane }\end{array}$ & $\begin{array}{l}60 \% \text { less length } \\
\text { left turn lane }\end{array}$ & 80\% less length \\
\hline Average & 2313 & 2390 & 2452 & 2706 \\
Std. & 619.5 & 652 & 715 & 820 \\
Maximum lane & 3918 & 4294 & 4430 & 4846 \\
Minimum & 1669 & 1711 & 1708 & 1726
\end{tabular}


Table 31 Count of crossing conflicts simulated

\begin{tabular}{r|llll}
\multicolumn{2}{c}{$\begin{array}{l}\text { Adequate length } \\
\text { left turn lane }\end{array}$} & $\begin{array}{l}40 \% \text { less length } \\
\text { left turn lane }\end{array}$ & $\begin{array}{l}60 \% \text { less length } \\
\text { left turn lane }\end{array}$ & 80\% less length \\
\hline Average & 14 & 13 & 14 & 12.5 \\
Std. & 5.7 & 4.7 & 4.2 & 4.5 \\
Maximum lane & 26 & 26 & 26 & 24 \\
Minimum & 4 & 5 & 7 & 5
\end{tabular}

Table 32 Count of rear end conflicts simulated

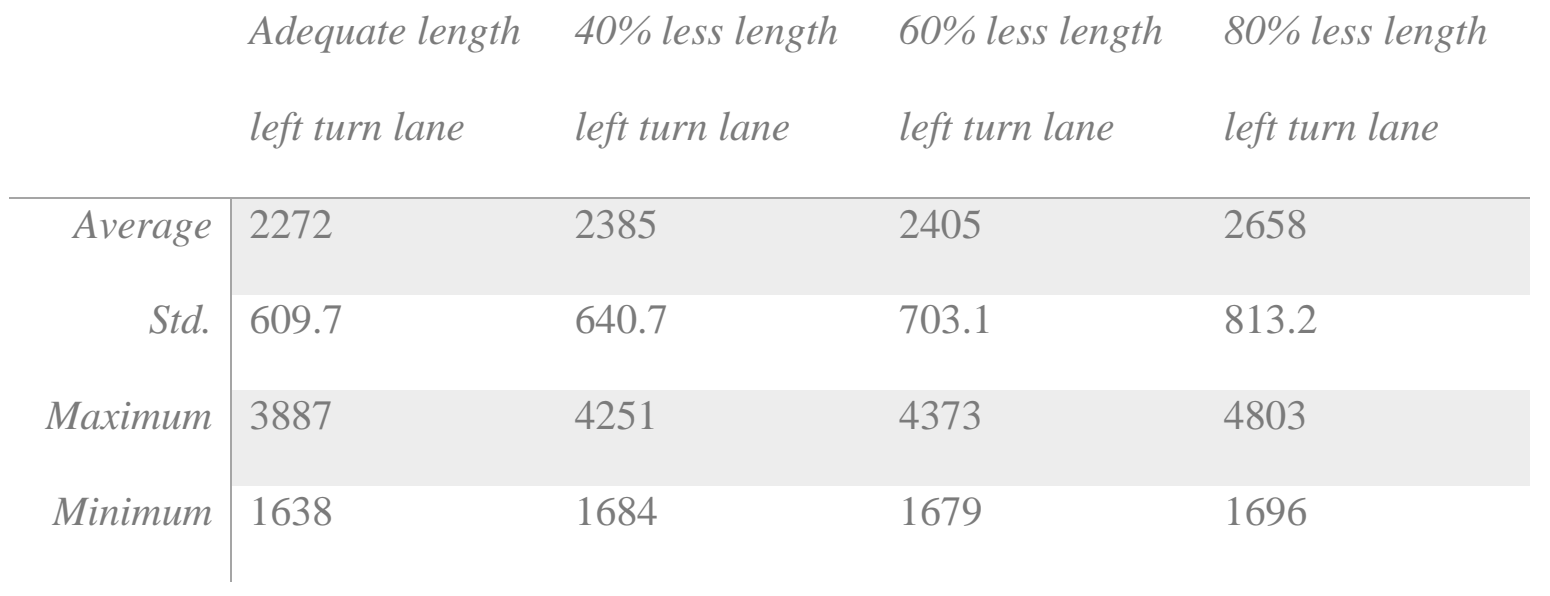




\section{Table 33 Count of lane change conflicts simulated}

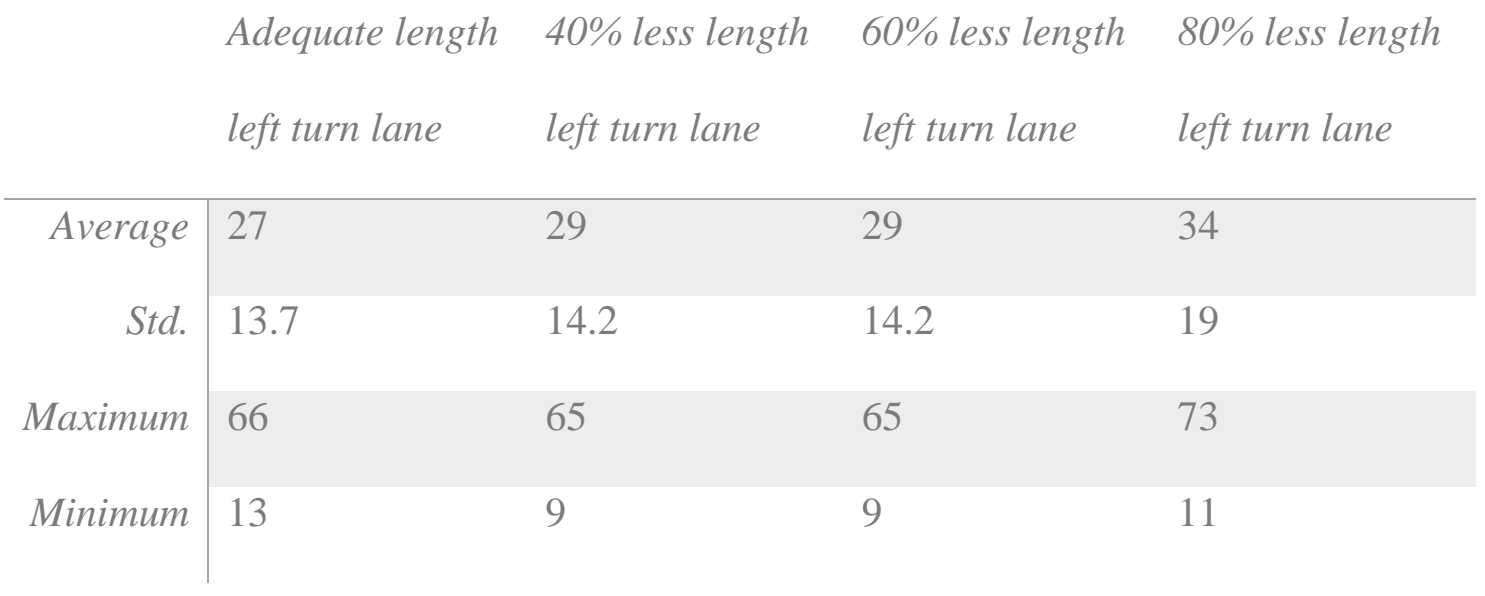

All conflict counts can be seen in the appendices.

\subsection{Total Crashes}

The number code of intersections refers to the number of the corresponding row in table 12 . The following table shows the CMFs obtained for total crashes organized by the initial left turn lane length of each of the proposed treatments.

The CMFs were determined by dividing a number of estimated crashes after treatment by estimated crashes for the scenario at which there is no treatment. The crashes were estimated using the simulated conflict counts and the crash conflict models estimated previously. 
Table 34 CMF for predicted total crashes at the 27 hypothetical intersections

\begin{tabular}{r|lll}
\multicolumn{5}{c}{$40 \%$ less length } & $60 \%$ less length & $80 \%$ less length \\
& left turn lane & left turn lane & left turn lane \\
\hline Average & 0.9903 & 0.9840 & 0.9564 \\
Crash reduction & $1.0 \%$ & $1.6 \%$ & $4.4 \%$ \\
Standard Deviation & 0.0112 & 0.0156 & 0.0304 \\
Maximum & 1.0145 & 1.0244 & 1.0058 \\
Minimum & 0.9716 & 0.9578 & 0.8973
\end{tabular}

As expected, minor reductions were observed in the number of total crashes for all of the proposed treatments. The treatment which proposed an increase from $80 \%$ less adequate length to adequate length showed a much larger reduction of $4.4 \%$.

\subsection{Fatal and injury crashes}

The following table presents the CMFs obtained for fatal and injury crashes for each of the assumed treatments' initial condition of left turn lane length. 
Table 35 CMF for predicted fatal and injury crashes at the 27 hypothetical intersections

\begin{tabular}{|c|c|c|c|}
\hline & $\begin{array}{l}40 \% \text { less length } \\
\text { left turn lane }\end{array}$ & $\begin{array}{l}60 \% \text { less length } \\
\text { left turn lane }\end{array}$ & $\begin{array}{l}80 \% \text { less length } \\
\text { left turn lane }\end{array}$ \\
\hline Average & 0.9929 & 0.9883 & 0.9681 \\
\hline Crash reduction & $0.7 \%$ & $1.2 \%$ & $3.2 \%$ \\
\hline Standard Deviation & 0.0081 & 0.0113 & 0.0223 \\
\hline Maximum & 1.0105 & 1.0176 & 1.0042 \\
\hline Minimum & 0.9794 & 0.9692 & 0.9245 \\
\hline
\end{tabular}

Similar to total crashes, as expected, minor reductions in the number of fatal and injury crashes were observed in all proposed treatments. The treatment which proposed an increase from $80 \%$ less adequate length to adequate length saw a much larger reduction of 3.2\%. Overall, fatal and injury crashes saw less reductions in number than total crashes. 


\subsection{Property damage only crashes}

The following table shows the CMFs obtained for PDO crashes.

Table 36 CMF for predicted PDO crashes at the 27 hypothetical intersections

\begin{tabular}{r|lll}
\multicolumn{2}{c}{$40 \%$ less length } & $60 \%$ less length & $80 \%$ less length \\
& left turn lane & left turn lane & left turn lane \\
\hline Average & 0.9890 & 0.9818 & 0.9507 \\
Crash reduction & $1.1 \%$ & $1.8 \%$ & $4.9 \%$ \\
Standard Deviation & 0.0127 & 0.0177 & 0.0343 \\
Maximum & 1.0165 & 1.0278 & 1.0066 \\
Minimum & 0.9679 & 0.9522 & 0.8842
\end{tabular}

Similar to the two previous categories of crashes, as expected, a minor reduction in the numbers of PDO crashes were observed in all proposed treatments. The treatment which proposed an increase from $80 \%$ less adequate length to adequate length saw a much larger reduction of $4.9 \%$. Overall, PDO crashes saw more reduction than the previous two categories of treatment analyzed. 


\subsection{Rear-end crashes}

The following table shows the CMFs obtained for rear-end crashes. Contrary to previously analyzed crash categories, rear-end crashes were modeled using rear end category of conflicts.

Table 37 CMF for predicted rear-end crashes at the 27 hypothetical intersections

\begin{tabular}{r|lll}
\multicolumn{5}{c}{$40 \%$ less length } & $60 \%$ less length & $80 \%$ less length \\
& left turn lane & left turn lane & left turn lane \\
\hline Average & 0.9802 & 0.9786 & 0.9403 \\
Crash reduction & $2.0 \%$ & $2.1 \%$ & $6.0 \%$ \\
Standard Deviation & 0.0345 & 0.0215 & 0.0417 \\
Maximum & 1.0227 & 1.0352 & 1.0087 \\
Minimum & 0.8260 & 0.9434 & 0.8627
\end{tabular}

Similar to the three previous categories of crashes, as expected, a minor reduction in the numbers of total crashes were observed in all proposed treatments. The treatment which proposed an increase from $80 \%$ less adequate length to adequate length saw a much larger reduction of $6.0 \%$. Overall, rear-end crashes saw the most predicted reduction in crashes by the proposed treatment. 


\subsection{Turning Movement Crashes}

The following table presents the CMFs obtained for turning movement crashes. Turning movement crashes were estimated using the crossing conflict counts.

Table 38 CMF for predicted turning movement crashes at the 27 hypothetical intersections

\begin{tabular}{r|lll}
\multicolumn{5}{c}{$40 \%$ less length } & $60 \%$ less length & $80 \%$ less length \\
& left turn lane & left turn lane & left turn lane \\
\hline Average & 1.0012 & 0.9937 & 1.0138 \\
Crash reduction & $-0.1 \%$ & $0.6 \%$ & $-1.4 \%$ \\
Standard Deviation & 0.0338 & 0.0435 & 0.0576 \\
Maximum & 1.0833 & 1.0577 & 1.1026 \\
Minimum & 0.9271 & 0.8775 & 0.8807
\end{tabular}

No reduction in the numbers of estimated turning movement crashes was observed. It can, therefore, be concluded that increases in the length of the left turn lane would have no impact on turning movement crashes. This observation held true for all three of the proposed treatments. 


\section{COMBINED CMF OF IMPLEMENTATION OF MULTIPLE TREATMENTS}

The chapter compares the combined CMF with what the CMF would have been approximated to had the suggestion made in Highway Safety manual's chapter 3 (HSM, 2010) about CMFs of different treatments being multiplicative been followed. As discussed in the methodology, 5 intersections were used for the analysis of this chapter. This chapter also provides a scenario similar to one where decision-makers would be in, in which they may be given two options they can choose from in order to improve the safety of an intersection. In this scenario, a decision maker would have flexibility in the length of left turn lane that can be installed.

This chapter combined two different treatments, the introduction of a left turn protected phase to the signal, and the addition of a left turn lane. This chapter presents the analysis of the CMF of the combined treatment for 4 different length categories.

The number of conflict counts for the intersections simulated for this chapter is presented in Appendix D. 


\subsection{Total crashes}

The following table presents a summary of the CMF values estimated using simple multiplication and the combined CMF values for total crashes. The first column presents the CMF of solely adding a left turn protective phase.

Table 39 CMF for Total crashes, from base condition of no left turn lane and no left turn protective phase, Mult. indicating multiplied CMF, and Comb the combined CMF

\begin{tabular}{r|l|ll|ll|ll|ll} 
& No LT & $20 \%$ Length & 40\% Length & \multicolumn{2}{|l|}{$60 \%$ Length } & 100\% Length \\
\hline & & Mult & Comb & Mult & Comb & Mult & Comb & Mult & Comb \\
\hline Average & 0.9751 & 0.9238 & 0.9470 & 0.8876 & 0.9076 & 0.8760 & 0.9026 & 0.8637 & 0.8909 \\
C.R. & $2.49 \%$ & $7.62 \%$ & $5.30 \%$ & $11.24 \%$ & $9.24 \%$ & $12.40 \%$ & $9.74 \%$ & $13.63 \%$ & $10.91 \%$ \\
STD & 0.0109 & 0.0554 & 0.0422 & 0.0619 & 0.0331 & 0.0598 & 0.0319 & 0.0629 & 0.0329 \\
Maximum & 0.9892 & 0.9889 & 1.0035 & 0.9543 & 0.9375 & 0.9324 & 0.9291 & 0.9256 & 0.9219 \\
Minimum & 0.9615 & 0.8417 & 0.8850 & 0.7863 & 0.8517 & 0.7766 & 0.8523 & 0.7625 & 0.8505
\end{tabular}

Multiple conclusions were drawn from these results. Firstly, the addition of a left turn lane resulted in a reduction in the number of crashes, as expected. Secondly, increases in the length of the left turn lane led to smaller CMF values and larger expected crash reductions. Thirdly, the multiplication of the CMFs resulted in an overestimation of $20 \%$ to $45 \%$ in the reduction of crashes, and an unrealistically optimistic overestimation of the positive impact of the combination of the two treatments. This finding was in agreement with the results obtained by Park and AbdelAty's (2014), as discussed in the literature review. 
The following figure illustrates the observations discussed on a graph for average total crash CMFs.

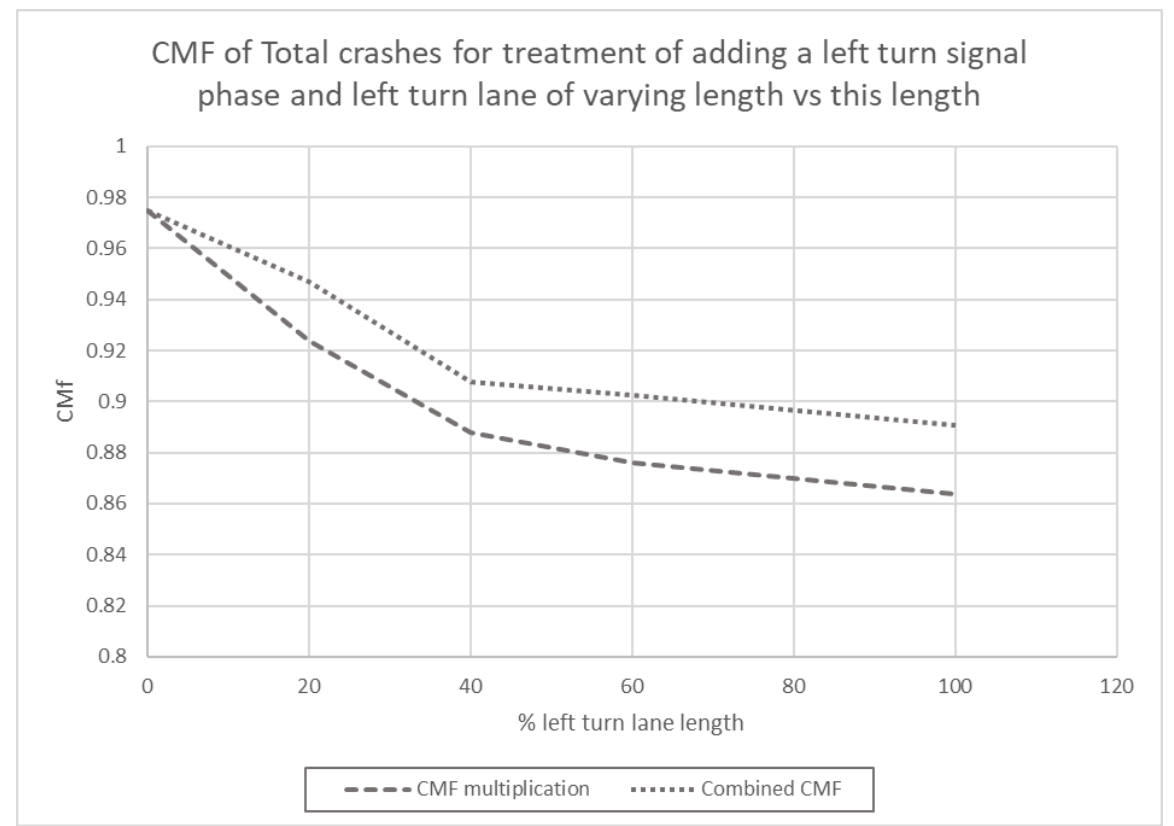

Figure 34 Average total crash CMF vs length of left turn lane graph 


\subsection{Fatal and Injury Crashes}

The following table presents a summary of the CMF values estimated using simple multiplication and the combined CMF values for fatal and injury crashes.

Table 40 CMF for Fatal and injury crashes, from base condition of no left turn lane and no left turn protective phase

\begin{tabular}{r|l|ll|ll|ll|ll|l} 
& No LT & \multicolumn{2}{|c|}{$20 \%$ Length } & \multicolumn{2}{|c|}{ 40\% Length } & \multicolumn{2}{|c|}{ 60\% Length } & \multicolumn{2}{|c}{ 100\% Length } \\
\hline & & Mult & Comb & Mult & Comb & Mult & Comb & Mult & Comb \\
\hline Average & 0.9819 & 0.9439 & 0.9612 & 0.9169 & 0.9321 & 0.9082 & 0.9284 & 0.8989 & 0.9197 \\
C.R. & $1.81 \%$ & $5.61 \%$ & $3.88 \%$ & $8.31 \%$ & $6.79 \%$ & $9.18 \%$ & $7.16 \%$ & $10.11 \%$ & $8.03 \%$ \\
STD & 0.0080 & 0.0411 & 0.0310 & 0.0467 & 0.0248 & 0.0453 & 0.0239 & 0.0478 & 0.0246 \\
Maximum & 0.9922 & 0.9920 & 1.0026 & 0.9667 & 0.9544 & 0.9506 & 0.9482 & 0.9456 & 0.9428 \\
Minimum & 0.9720 & 0.8827 & 0.9154 & 0.8402 & 0.8903 & 0.8327 & 0.8907 & 0.8217 & 0.8893
\end{tabular}

Similar conclusions were drawn from these results. The CMFs for fatal and injury crashes are larger than the CMFs for total crashes, as discussed in chapter 7.

The following figure illustrates the observations discussed on a graph for average fatal and injury crash CMFs. 


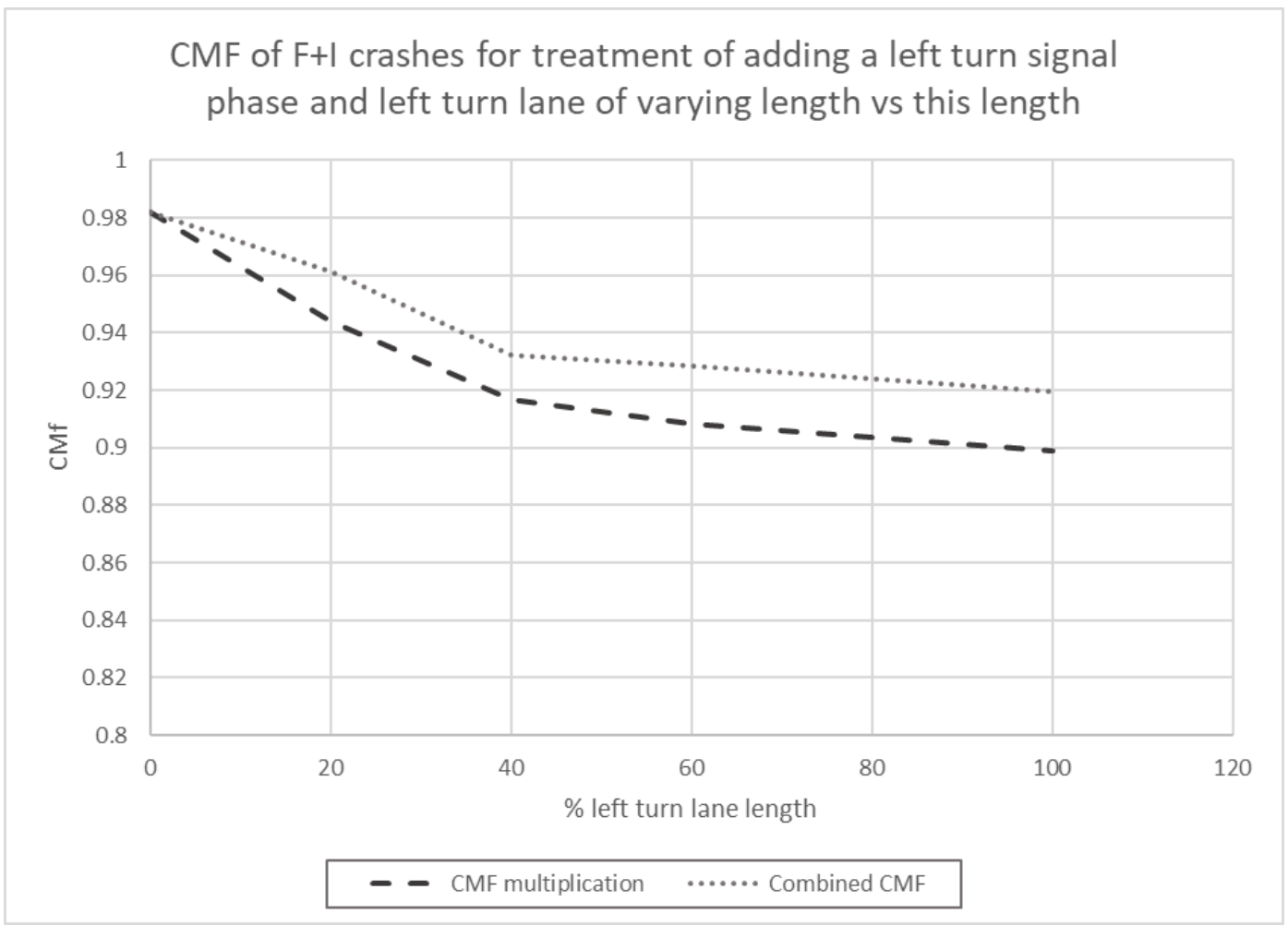

Figure 35 Average fatal and injury crash CMF vs length of left turn lane graph 


\subsection{Property Damage Only Crashes}

The following table presents a summary of the CMF values estimated using simple multiplication and the combined CMF values for PDO crashes.

Table 41 CMF for PDO crashes, from base condition of no left turn lane and no left turn

$$
\text { protective phase }
$$

\begin{tabular}{r|l|ll|ll|ll|ll} 
& No LT & \multicolumn{2}{|c|}{ 20\% Length } & \multicolumn{2}{|l|}{ 40\% Length } & \multicolumn{2}{l|}{$60 \%$ Length } & \multicolumn{2}{l}{ 100\% Length } \\
\hline & & Mult & Comb & Mult & Comb & Mult & Comb & Mult & Comb \\
\hline Average & 0.9717 & 0.9141 & 0.9401 & 0.8736 & 0.8958 & 0.8607 & 0.8902 & 0.8469 & 0.8771 \\
C.R. & $2.83 \%$ & $8.59 \%$ & $5.99 \%$ & $12.63 \%$ & $10.42 \%$ & $13.93 \%$ & $10.98 \%$ & $15.30 \%$ & $12.29 \%$ \\
STD & 0.0124 & 0.0621 & 0.0475 & 0.0689 & 0.0370 & 0.0664 & 0.0357 & 0.0698 & 0.0367 \\
Maximum & 0.9878 & 0.9874 & 1.0040 & 0.9483 & 0.9293 & 0.9236 & 0.9199 & 0.9160 & 0.9118 \\
Minimum & 0.9564 & 0.8222 & 0.8705 & 0.7610 & 0.8333 & 0.7504 & 0.8341 & 0.7349 & 0.8320
\end{tabular}

The same conclusions were made for PDO crashes. In addition, the reduction in PDO crashes was larger than the reduction in total crashes and $\mathrm{F}+\mathrm{I}$ crashes, similar to what was discussed in chapter 7. These observations are visually demonstrated in the following graph. 


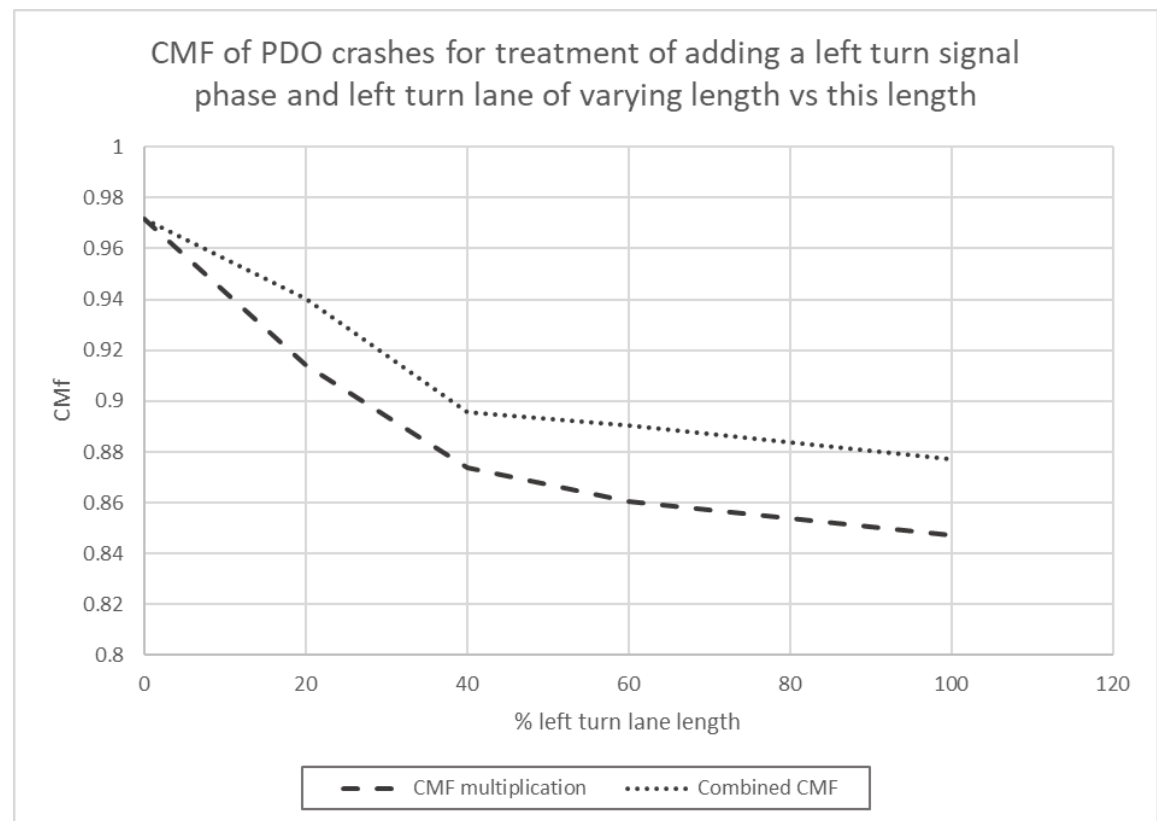

Figure 36 Average PDO crash CMF vs length of left turn lane graph 


\subsection{Rear-End Crashes}

The following table presents a summary of the CMF values estimated using simple multiplication and the combined CMF values for rear-end crashes.

Table 42 CMF for rear end crashes, from base condition of no left turn lane and no left turn protective phase

\begin{tabular}{r|l|ll|ll|ll|ll|l} 
& No LT & \multicolumn{2}{|c|}{$20 \%$ Length } & \multicolumn{2}{|l|}{$40 \%$ Length } & \multicolumn{2}{|c|}{$60 \%$ Length } & \multicolumn{2}{|c}{ 100\% Length } \\
\hline & & Mult & Comb & Mult & Comb & Mult & Comb & Mult & Comb \\
\hline Average & 0.9659 & 0.8925 & 0.9244 & 0.8438 & 0.8705 & 0.8289 & 0.8645 & 0.8120 & 0.8571 \\
C.R. & $3.41 \%$ & $10.75 \%$ & $7.56 \%$ & $15.62 \%$ & $12.95 \%$ & $17.11 \%$ & $13.55 \%$ & $18.80 \%$ & $14.29 \%$ \\
STD & 0.0158 & 0.0770 & 0.0590 & 0.0839 & 0.0459 & 0.0789 & 0.0438 & 0.0827 & 0.0515 \\
Maximum & 0.9862 & 0.9827 & 1.0015 & 0.9351 & 0.9119 & 0.9043 & 0.9027 & 0.8943 & 0.9010 \\
Minimum & 0.9463 & 0.7791 & 0.8357 & 0.7078 & 0.7933 & 0.6988 & 0.7954 & 0.6802 & 0.7923
\end{tabular}

Similar conclusions were drawn for rear-end crashes. The results also revealed that rear-end crash reductions were highest after the introduction of left turn lanes and were correlated with the length of the left turn lanes. 


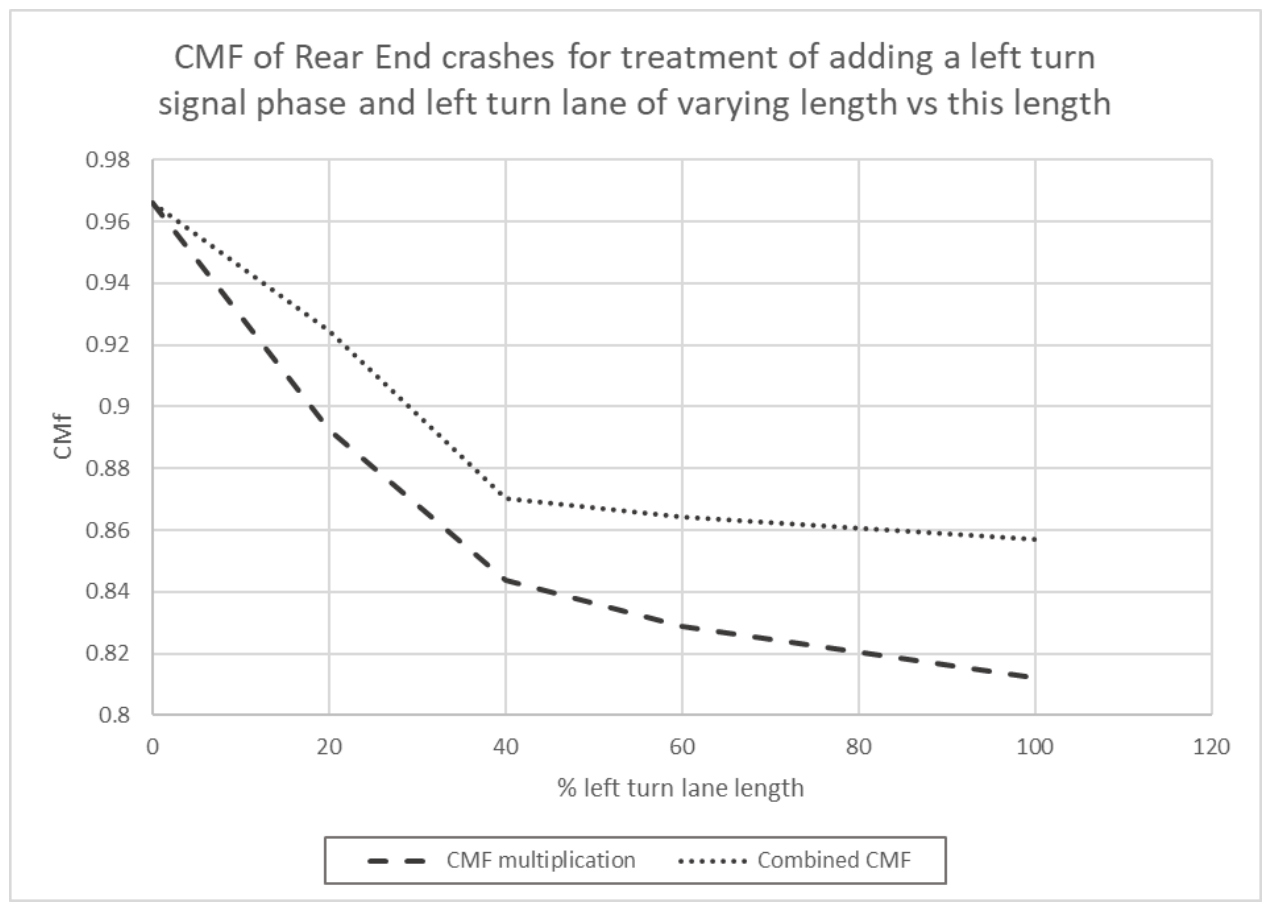

Figure 37 Average Rear end crash CMF vs length of left turn lane graph 


\subsection{Turning Movement Crashes}

The following table presents a summary of the CMF values estimated using simple multiplication and the combined CMF values for turning movement crashes.

Table 43 CMF for turning movement crashes, from base condition of no left turn lane and no left turn protective phase

\begin{tabular}{r|l|ll|ll|ll|ll} 
& No LT & \multicolumn{2}{|l|}{ 20\% Length } & \multicolumn{2}{|c|}{ 40\% Length } & \multicolumn{2}{|c|}{ 60\% Length } & \multicolumn{2}{|c}{ 100\% Length } \\
\hline & & Mult & Comb & Mult & Comb & Mult & Comb & Mult & Comb \\
\hline Average & 0.9965 & 1.0541 & 1.0543 & 1.0819 & 1.0678 & 1.0871 & 1.0428 & 1.0929 & 1.0244 \\
C.R. & $0.35 \%$ & $-5.41 \%$ & $-5.43 \%$ & $-8.19 \%$ & $-6.78 \%$ & $-8.71 \%$ & $-4.28 \%$ & $-9.29 \%$ & $-2.44 \%$ \\
STD & 0.0822 & 0.1513 & 0.0810 & 0.1345 & 0.0815 & 0.1296 & 0.1032 & 0.1378 & 0.1177 \\
Maximum & 1.0591 & 1.2642 & 1.1936 & 1.1843 & 1.2026 & 1.2100 & 1.2196 & 1.1975 & 1.2112 \\
Minimum & 0.8589 & 0.8427 & 0.9812 & 0.8510 & 0.9908 & 0.8736 & 0.9603 & 0.8586 & 0.8943
\end{tabular}

No reduction was observed in the number of estimated turning movement crashes. This was in line with the results of Chapter 7 which revealed that the length of the left turn lane had no positive impact on turning movement crashes. The addition of a left turn protective phase showed no positive impact on turning movement crashes. 


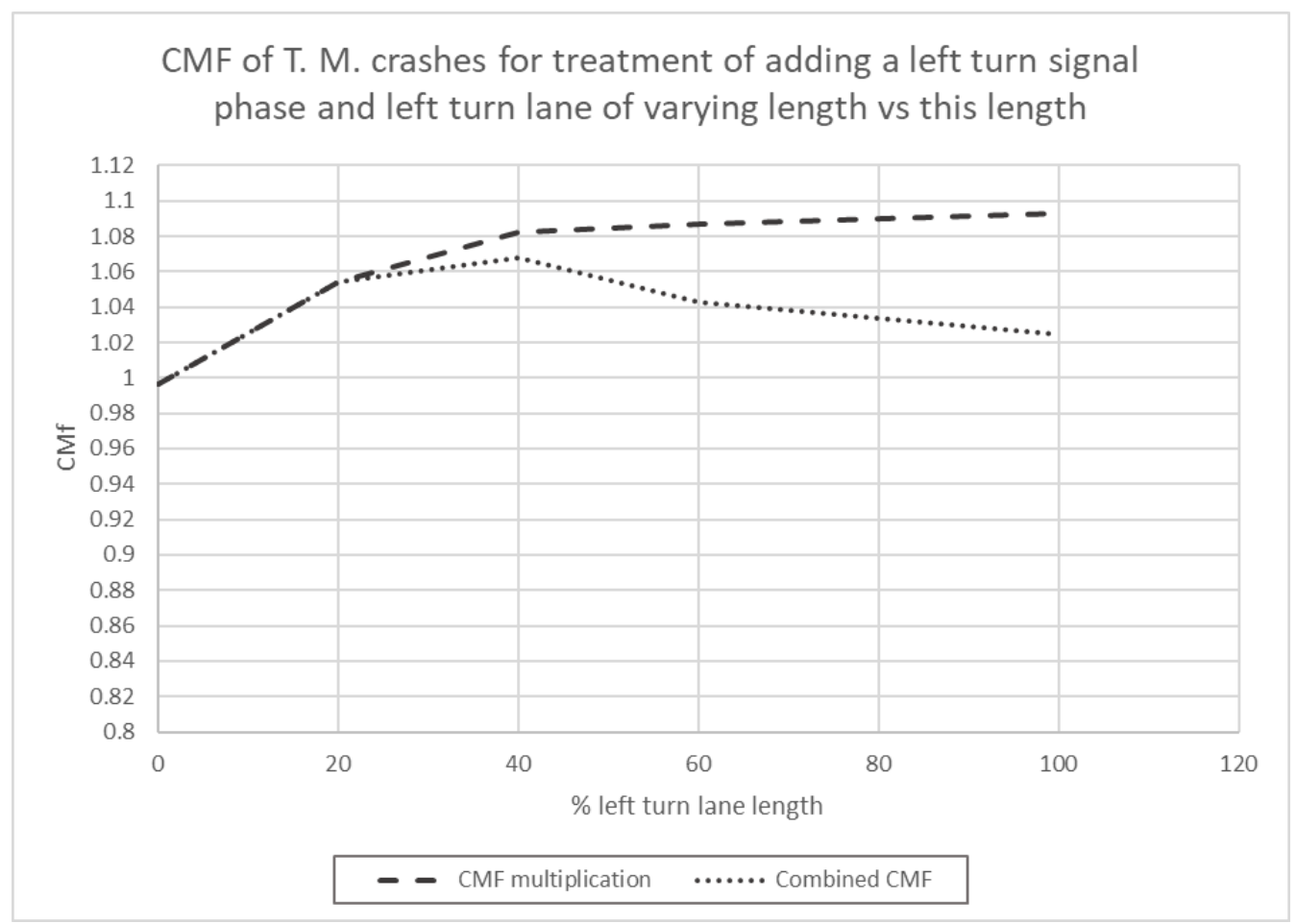

Figure 38 Average turning movement crash CMF vs length of left turn lane graph 


\section{CONCLUSION AND SUGGESTIONS}

The purpose of this study was to analyze the nature of the correlation between the length of left turn lanes and the safety performance of signalized intersections. Two approaches were used for the analysis. The first approach involved the use of the crash counts obtained from the MTO crash records. The second approach involved the use of MTO intersections to simulate and obtain conflict counts as a surrogate measure of safety in order to estimate crash-conflicts models. The crash-conflict models were then used to estimate crashes from conflict counts obtained for a series of hypothetical intersections with varying attributes, each with 4 versions differing only in the length of the left turn lanes.

The crash-based analysis did not yield the expected correlation between the length of the left turn lanes and the safety performance of intersections. The total, PDO, rear end, and turning movement crashes showed a good fit with the model relating AADTs to crashes. However, angle and fatal and injury crashes did not reveal a good fit. When the length of the left turn lane was included in the analysis, none of the categories with the exception of turning movement crashes revealed a good fit. The model for turning movement crashes did not yield the expected relationship between the length of the left turn lanes and the safety performance of intersections (a reduction in the number of crashes as the length of the left turn lane is increased). The reason for the inconclusiveness of the analysis may have been that there was an insufficient number of sites included in the sample or that the existing sample of 48 intersections contained other variables impacting safety performance that were unknown or not considered in the scope of the analysis. 
Using conflict counts as a surrogate measure of safety obtained using microsimulation was deemed a suitable approach. This allowed for the omission of all of the unknown factors that may have impacted the safety performance of the intersection from the analysis, placing the focus on the variable of interest. This chapter involved the creation of 27 hypothetical intersections, each assigned with four different left turn lane lengths, allowing for the simulation of variations in the estimations of crashes at intersections that are identical in every aspect with the exception of the length of the left turn lanes.

The next step was finding CMF values for increases from each of the progressively shorter lengths of left turn lanes to what was defined as an adequate length of left turn lanes. Total, fatal and injury, PDO, and rear-end crash all predicted minor yet consistent reductions in the number of crashes following increases in the length of the left turn lanes. These reductions increased as the length of the left turn lanes was increased by larger increments. Rear end crashes revealed the largest reduction, indicating that most of the crashes that were being mitigated involved vehicles decelerating and attempting to change lanes into the left turn lane at the approach of the intersection. Overall, PDO crashes showed a greater reduction and fatal and injury crashes showed a lower reduction compared to total crash counts. In all four categories, the estimated crash reduction was greater for intersections with larger left turning to through directional volume and left turning to opposing volume ratios, indicating that an increase in the length of the left turn lanes would be a more effective solution for intersections with higher left turning volume ratios.

In chapter 8, the combined CMF of the installation of multiple treatments was examined. The specific crash reduction trends observed in the various crash categories were in line with the results observed in the previous chapters. The results also revealed that the HSM suggestion of 
multiplying the CMFs of multiple treatments to estimate the CMF of their combined impact leads to overestimates of the expected crash reductions.

Unlike the other four crash categories, there were no observed reductions in turning movement crashes with increases in the length of the left turn lane. The interpretation of this finding is that the behavior of vehicles in the intersection, and while conducting the actual turning movement is independent of the left turn lane they just decelerate and waited for an adequate gap in.

Future research should make use of larger samples of actual intersections in order to obtain better fitting models. In addition, intersections with more AADT variations with similar geometrical aspects can be used in the analysis, in order to for the analysis to resemble the one conducted in this study using microsimulation. The use of microsimulation software capable of a more detailed simulation would also be useful. 


\section{APPENDICES}

\section{Appendix A: MTO Intersections}

Table 44 Location of the 48 MTO intersections

$\begin{array}{lllll}\text { No. } & \text { LHRT }+ & \text { Hwy } & \text { Street 1 } & \text { Offset } \\ \text { Off } \mathrm{SB}) & \text { No } & & \text { Street } 2(\text { EB or NB }) & \text { Coordinates }\end{array}$

\begin{tabular}{|c|c|c|c|c|c|}
\hline 1 & 118200770 & 3 & $\begin{array}{l}\text { Haldimand Rd } 18 \text { - Sandusk } \\
\text { Rd (SB) }\end{array}$ & $\begin{array}{l}\text { Haldimand Rd } 18 \text { - Sandusk } \\
\text { Rd (NB) }\end{array}$ & $\begin{array}{l}42.8936469 \\
-80.0490773\end{array}$ \\
\hline 2 & 120450000 & 3 & $\begin{array}{l}\text { Elgin Road 25- Wellington } \\
\text { Rd. (SB) }\end{array}$ & $\begin{array}{l}\text { Elgin Road 25- Wellington } \\
\text { Rd. (NB) }\end{array}$ & $\begin{array}{l}42.8029489, \\
-81.2103764\end{array}$ \\
\hline 3 & 122050370 & 3 & $\begin{array}{l}\text { Essex Road 31- Albuna } \\
\text { Townline Rd. (SB) }\end{array}$ & $\begin{array}{l}\text { Essex Road 31- Albuna } \\
\text { Townline Rd. (NB) }\end{array}$ & $\begin{array}{l}42.0670196, \\
-82.6435516\end{array}$ \\
\hline 4 & 122290690 & 3 & Essex Rd 19 (SB) & Essex Rd 19 (NB) & $\begin{array}{l}42.1966317, \\
-82.8769605\end{array}$ \\
\hline 5 & 134300000 & 6 & $\begin{array}{l}\text { Haldimand Rd } 9 \text { - } \\
\text { Concession } 12 \text { (WB) }\end{array}$ & $\begin{array}{l}\text { Haldimand Rd } 9 \text { - Parkview } \\
\text { Drive (EB) }\end{array}$ & $\begin{array}{l}42.9559148, \\
-80.0574582\end{array}$ \\
\hline 6 & 134460000 & 6 & Argyle St (WB) & N/A & $\begin{array}{l}\text { 43.0492169, } \\
-79.9744342\end{array}$ \\
\hline 7 & 140840000 & 7 & N/A & $\begin{array}{l}\text { Lanark County Road } 511 \\
\text { (NB) }\end{array}$ & $\begin{array}{l}44.9060503, \\
-76.2707585\end{array}$ \\
\hline 8 & 142500000 & 7 & Stewart Line Road (WB) & $\begin{array}{l}\text { North Monaghan Parkway / } \\
\text { County Road } 15 \text { (EB) }\end{array}$ & $\begin{array}{l}44.2538974, \\
-78.406647\end{array}$ \\
\hline 9 & 142600000 & 7 & Maple Grove Road (WB) & $\begin{array}{l}\text { Lansdowne Street / } \\
\text { Peterborough Road } 5 \text { (EB) }\end{array}$ & $\begin{array}{l}\text { 44.2667647, } \\
-78.4083032\end{array}$ \\
\hline 10 & 142700640 & 7 & $\begin{array}{l}\text { Kawartha Lakes Road } 10 \text { / } \\
\text { Emily Park Road (SB) }\end{array}$ & $\begin{array}{l}\text { Kawartha Lakes Road } 10 \\
\text { (NB) }\end{array}$ & $\begin{array}{l}44.3070495 \\
-78.5114925\end{array}$ \\
\hline 11 & 143100000 & 7 & Dew Drop Inn Road (SB) & $\begin{array}{l}\text { Highway } 35 \text { West Junction } \\
\text { (NB) }\end{array}$ & $\begin{array}{l}44.3461705 \\
-78.7758593\end{array}$ \\
\hline 12 & 145400410 & 7 & Wellington Rd 29 (SB) & Wellington Rd 29 (NB) & $\begin{array}{l}43.5900867, \\
-80.1781008\end{array}$ \\
\hline 13 & 145700680 & 7 & $\begin{array}{l}\text { Waterloo Rd } 30 \text { - Shantz } \\
\text { Station Rd (SB) }\end{array}$ & $\begin{array}{l}\text { Waterloo Rd } 30 \text { - Shantz } \\
\text { Station Rd (NB) }\end{array}$ & $\begin{array}{l}43.5025703, \\
-80.3810798\end{array}$ \\
\hline 14 & 149400000 & $7 A$ & $\begin{array}{l}\text { DURHAM ROAD } \\
\text { 57/BLACKSTOCK ROAD (WB) }\end{array}$ & $\mathrm{N} / \mathrm{A}$ & $\begin{array}{l}\text { 44.1186334, } \\
-78.8295649\end{array}$ \\
\hline 15 & 194100000 & 12 & N/A & HIGHWAY 48-N JCT & $\begin{array}{l}44.4825855 \\
-79.1481138\end{array}$ \\
\hline 16 & 195000000 & 12 & COLDWATER ROAD (WB) & WOODROW ROAD (EB) & $\begin{array}{l}44.6980979, \\
-79.6405407\end{array}$ \\
\hline 17 & 201200105 & 15 & Beckwith Fourth Line (WB) & $\begin{array}{l}\text { Richmond Road / Lanark } \\
\text { Road } 10 \text { North Jct (EB) }\end{array}$ & $\begin{array}{l}45.045318,- \\
76.0674834\end{array}$ \\
\hline
\end{tabular}




\begin{tabular}{|c|c|c|c|c|c|}
\hline No. & $\begin{array}{l}\text { LHRT + } \\
\text { Offset }\end{array}$ & $\begin{array}{l}\text { Hwy } \\
\text { No }\end{array}$ & Street 1 (WB or $S B)$ & Street $2(E B$ or $N B)$ & Coordinates \\
\hline 18 & 207610000 & 17 & $\begin{array}{l}\text { Renfrew Road } 58 \text { / Round } \\
\text { Lake Road (SB) }\end{array}$ & $\begin{array}{l}\text { Renfrew Road } 58 \text { / Round } \\
\text { Lake Road (NB) }\end{array}$ & $\begin{array}{l}\text { 45.7936295, } \\
-77.186419\end{array}$ \\
\hline 19 & 207710000 & 17 & $\begin{array}{l}\text { Renfrew Road } 26 \text { / Doran } \\
\text { Road (SB) }\end{array}$ & $\begin{array}{l}\text { Renfrew Road } 26 \text { / Doran } \\
\text { Road (NB) }\end{array}$ & $\begin{array}{l}45.8384333 \\
-77.249445\end{array}$ \\
\hline 20 & 247600080 & 24 & $\begin{array}{l}\text { Brant Road 4/Oakland Rd } \\
\text { (WB) }\end{array}$ & $\begin{array}{l}\text { Brant Road 4/Oakland Rd } \\
\text { (EB) }\end{array}$ & $\begin{array}{l}43.0270425 \\
-80.3670815\end{array}$ \\
\hline 21 & 248010000 & 24 & Brant Road 53 (WB) & Brant Road 53 (EB) & $\begin{array}{l}43.1214793 \\
-80.3612051\end{array}$ \\
\hline 22 & 256100390 & 26 & PADDY DUNNS CIR (WB) & CARSON RD (NB) & $\begin{array}{l}44.4285759 \\
-79.724328\end{array}$ \\
\hline 23 & 285400330 & 37 & $\begin{array}{l}\text { Cannifton Road North } \\
\text { Junction (WB) }\end{array}$ & Blessington Road (EB) & $\begin{array}{l}44.2198601 \\
-77.3797783\end{array}$ \\
\hline 24 & 285400250 & 37 & Tank Farm Road (WB) & Casey Road (EB) & $\begin{array}{l}44.2133425 \\
-77.3768199\end{array}$ \\
\hline 25 & 285400600 & 37 & Harmony Road (WB) & Harmony Road (EB) & $\begin{array}{l}44.2425401 \\
-77.380418\end{array}$ \\
\hline 26 & 291950270 & 40 & Moore Line (WB) & Moore Line (EB) & $\begin{array}{l}42.8387578, \\
-82.4161778\end{array}$ \\
\hline 27 & 292050270 & 40 & $\begin{array}{l}\text { Lambton Road 35/LaSalle } \\
\text { Line (WB) }\end{array}$ & $\begin{array}{l}\text { Lambton Road 35/LaSalle } \\
\text { Line (EB) }\end{array}$ & $\begin{array}{l}42.9121653 \\
-82.4132438\end{array}$ \\
\hline 28 & 391190000 & 93 & $\begin{array}{l}\text { SIMCOE ROAD 23/ VASEY } \\
\text { ROAD (WB) }\end{array}$ & SIMCOE ROAD 27 (EB) & $\begin{array}{l}44.6413728 \\
-79.8230959\end{array}$ \\
\hline 29 & 454300000 & 138 & $\begin{array}{l}\text { Stormont D\&G Road } 43 \\
\text { (WB) }\end{array}$ & Stormont D\&G Road 43 (EB) & $\begin{array}{l}45.1937447, \\
-74.8817809\end{array}$ \\
\hline 30 & 117200000 & 3 & RIDGE ROAD N (SB) & RIDGE ROAD N (NB) & $\begin{array}{l}42.9035413 \\
-79.0452027\end{array}$ \\
\hline 31 & 118201140 & 3 & Haldimand Rd 55 (SB) & $\begin{array}{l}\text { Haldimand Rd } 55 \text { - } \\
\text { Nanticoke Rd (NB) }\end{array}$ & $\begin{array}{l}42.8872375 \\
-80.0928894\end{array}$ \\
\hline 32 & 118400000 & 3 & $\begin{array}{l}\text { Norfolk Rd } 5 \text { - Cockshutt Rd } \\
\text { (SB) }\end{array}$ & $\begin{array}{l}\text { Norfolk Rd } 5 \text { - Cockshutt Rd } \\
\text { (NB) }\end{array}$ & $\begin{array}{l}42.8595645 \\
-80.2202819\end{array}$ \\
\hline 33 & 118400350 & 3 & Blue Line $\mathrm{Rd}(\mathrm{SB})$ & Blue Line Rd (NB) & $\begin{array}{l}42.8529443 \\
-80.2636633\end{array}$ \\
\hline 34 & 118500000 & 3 & N/A & $\begin{array}{l}\text { Norfolk Rd } 41 \text { - Hillcrest Rd } \\
\text { (NB) }\end{array}$ & $\begin{array}{l}42.8387457, \\
-80.3431679\end{array}$ \\
\hline 35 & 118600000 & 3 & N/A & $\begin{array}{l}\text { Norfolk Rd } 46 \text { - Pinegrove } \\
\text { Rd (NB) }\end{array}$ & $\begin{array}{l}42.8302196 \\
-80.4840686\end{array}$ \\
\hline 36 & 118900110 & 3 & Bell Mill Rd (SB) & Bell Mill Rd (NB) & $\begin{array}{l}42.851139,- \\
80.7046757\end{array}$ \\
\hline 37 & 122290000 & 3 & Essex Rd 23 (SB) & Essex Rd 23 (NB) & $\begin{array}{l}42.1546702 \\
-82.8147661\end{array}$ \\
\hline & 122290190 & 3 & Victoria Ave (SB) & North Malden Rd (NB) & $\begin{array}{l}42.1665481 \\
-82.8353008\end{array}$ \\
\hline
\end{tabular}




\begin{tabular}{|c|c|c|c|c|c|}
\hline No. & $\begin{array}{l}\text { LHRT + } \\
\text { Offset }\end{array}$ & $\begin{array}{l}H w y \\
N o\end{array}$ & Street 1 (WB or $S B)$ & Street 2 (EB or $N B)$ & Coordinates \\
\hline 39 & 127900260 & 4 & $\begin{array}{l}\text { Middlesex Rd } 28 \text { - Medway } \\
\text { Rd (WB) }\end{array}$ & Middlesex Rd 28 (EB) & $\begin{array}{l}43.0503346 \\
-81.2953082\end{array}$ \\
\hline 40 & 128000000 & 4 & $\begin{array}{l}\text { Middlesex Rd } 16 \text { - Ilderton } \\
\text { Rd (WB) }\end{array}$ & $\begin{array}{l}\text { Middlesex Rd } 16 \text { - Ilderton } \\
\text { Rd (EB) }\end{array}$ & $\begin{array}{l}43.0972513 \\
-81.3193305\end{array}$ \\
\hline 41 & 128100000 & 4 & Hwy 7 (WB) & Elginfield Rd 7 (EB) & $\begin{array}{l}43.1667385 \\
-81.3568586\end{array}$ \\
\hline 42 & 136200000 & 6 & Marden Rd (WB) & Wellington Rd 30 (EB) & $\begin{array}{l}43.5860022 \\
-80.2994965\end{array}$ \\
\hline 43 & 165300000 & 10 & Dufferin Rd 124 (WB) & Dufferin Rd 11 (EB) & $\begin{array}{l}44.0813648 \\
-80.1883198\end{array}$ \\
\hline 44 & 165570000 & 10 & Dufferin Rd 9 (WB) & Grey Rd 9 (WB) & $\begin{array}{l}44.1785189 \\
-80.38188\end{array}$ \\
\hline 45 & 248300000 & 24 & $\begin{array}{l}\text { Brant Road 99/Governor's } \\
\text { Rd (WB) }\end{array}$ & $\begin{array}{l}\text { Brant Road 5/Governor's Rd } \\
\text { (EB) }\end{array}$ & $\begin{array}{l}43.2048837 \\
-80.2803258\end{array}$ \\
\hline 46 & 273150800 & 33 & $\mathrm{~N} / \mathrm{A}$ & Coronation Boulevard (NB) & $\begin{array}{l}44.2248855 \\
-76.6290028\end{array}$ \\
\hline 47 & 273200000 & 33 & N/A & Sherwood Avenue (NB) & $\begin{array}{l}44.2186714 \\
-76.643133\end{array}$ \\
\hline 48 & 276401155 & 34 & Sandy Hill Road (WB) & N/A & $\begin{array}{l}45.5927118 \\
-74.6219978\end{array}$ \\
\hline
\end{tabular}


Table 45 Years 2000 to 2013, 14-year crash count, and 10 hour long simulated conflicts for maximum TTC threshold of 1.5 seconds for MTO intersections

No. Tot F+I PDO Angle R.E. T.M. Total Crossing R.E. L.C.

\begin{tabular}{l|llllllllll} 
& crash & crash & crash & crash & crash & crash & conflict & conflict & conflict & conflict \\
\hline 1 & 3 & 2 & 1 & 1 & 2 & 0 & 2 & 0 & 2 & 0
\end{tabular}

\begin{tabular}{r|llllllllll}
2 & 20 & 11 & 9 & 7 & 3 & 9 & 108 & 4 & 105 & 1 \\
3 & 23 & 9 & 14 & 5 & 11 & 7 & 104 & 0 & 104 & 0 \\
4 & 23 & 5 & 18 & 1 & 14 & 6 & 208 & 0 & 163 & 45 \\
5 & 1 & 1 & 0 & 0 & 0 & 1 & 123 & 0 & 121 & 2 \\
6 & 13 & 4 & 9 & 0 & 6 & 7 & 424 & 24 & 398 & 2 \\
7 & 17 & 5 & 12 & 0 & 12 & 4 & 107 & 0 & 104 & 3 \\
8 & 12 & 2 & 10 & 1 & 2 & 9 & 95 & 4 & 87 & 4 \\
9 & 29 & 12 & 17 & 8 & 5 & 16 & 186 & 10 & 163 & 13 \\
10 & 16 & 5 & 11 & 3 & 4 & 7 & 61 & 1 & 51 & 9 \\
11 & 37 & 9 & 28 & 6 & 14 & 13 & 131 & 18 & 110 & 3 \\
12 & 32 & 11 & 21 & 4 & 19 & 6 & 138 & 0 & 135 & 3 \\
13 & 57 & 17 & 40 & 5 & 39 & 11 & 148 & 4 & 142 & 2 \\
14 & 11 & 0 & 11 & 0 & 6 & 5 & 964 & 13 & 937 & 14 \\
15 & 16 & 7 & 9 & 1 & 5 & 7 & 3321 & 14 & 3174 & 133 \\
16 & 17 & 9 & 8 & 10 & 1 & 5 & 33 & 3 & 30 & 0 \\
17 & 0 & 0 & 0 & 0 & 0 & 0 & 55 & 0 & 55 & 0 \\
18 & 17 & 9 & 8 & 9 & 1 & 5 & 22 & 0 & 22 & 0 \\
19 & 25 & 16 & 9 & 17 & 4 & 2 & 367 & 1 & 366 & 0 \\
20 & 15 & 8 & 7 & 2 & 6 & 6 & 178 & 11 & 163 & 4 \\
21 & 15 & 4 & 11 & 2 & 7 & 4 & 69 & 0 & 69 & 0 \\
22 & 16 & 4 & 12 & 1 & 8 & 5 & 165 & 4 & 137 & 24 \\
23 & 14 & 5 & 9 & 6 & 1 & 6 & 21 & 0 & 21 & 0 \\
24 & 6 & 2 & 4 & 0 & 4 & 2 & 87 & 12 & 74 & 1 \\
25 & 8 & 5 & 3 & 0 & 3 & 2 & 62 & 6 & 56 & 0 \\
26 & 0 & 0 & 0 & 0 & 0 & 0 & 15 & 0 & 15 & 0 \\
27 & 11 & 4 & 7 & 1 & 4 & 4 & 47 & 0 & 36 & 11 \\
28 & 5 & 2 & 3 & 0 & 0 & 5 & 36 & 1 & 35 & 0 \\
29 & 10 & 5 & 5 & 5 & 2 & 3 & 30 & 0 & 30 & 0 \\
30 & 6 & 1 & 5 & 0 & 1 & 4 & 94 & 2 & 81 & 11 \\
31 & 6 & 1 & 5 & 1 & 4 & 1 & 12 & 0 & 12 & 0 \\
32 & 7 & 2 & 5 & 2 & 1 & 2 & 37 & 0 & 36 & 1 \\
33 & 12 & 3 & 9 & 4 & 4 & 3 & 102 & 0 & 100 & 2 \\
34 & 5 & 3 & 2 & 1 & 0 & 4 & 75 & 1 & 73 & 1 \\
35 & 1 & 1 & 0 & 0 & 1 & 0 & 91 & 21 & 70 & 0 \\
36 & 8 & 1 & 7 & 2 & 4 & 2 & 23 & 0 & 23 & 0 \\
37 & 28 & 9 & 19 & 4 & 18 & 6 & 116 & 2 & 113 & 1 \\
38 & 14 & 4 & 10 & 1 & 7 & 4 & 169 & 10 & 151 & 8 \\
39 & 7 & 2 & 5 & 2 & 2 & 2 & 60 & 0 & 50 & 11 \\
& & & & & & & & & & \\
\hline
\end{tabular}


No. Tot F+I PDO Angle R.E. T.M. Total Crossing R.E. L.C.

\begin{tabular}{l|llllllllll}
\multicolumn{2}{c}{ crash } & crash & crash & crash & crash & crash & conflict & conflict & conflict & conflict \\
\hline 40 & 6 & 3 & 3 & 4 & 1 & 1 & 41 & 0 & 41 & 0 \\
41 & 17 & 5 & 12 & 2 & 7 & 5 & 259 & 74 & 184 & 1 \\
42 & 40 & 10 & 30 & 7 & 9 & 22 & 123 & 1 & 103 & 19 \\
43 & 6 & 2 & 4 & 1 & 2 & 3 & 117 & 4 & 98 & 15 \\
44 & 17 & 11 & 6 & 3 & 7 & 6 & 71 & 0 & 58 & 13 \\
45 & 27 & 11 & 16 & 3 & 10 & 10 & 166 & 1 & 154 & 11 \\
46 & 1 & 0 & 1 & 0 & 1 & 0 & 59 & 0 & 59 & 0 \\
47 & 11 & 5 & 6 & 0 & 6 & 4 & 46 & 0 & 45 & 1 \\
48 & 0 & 0 & 0 & 0 & 0 & 0 & 440 & 7 & 432 & 1
\end{tabular}




\section{Appendix B: CURE plots - Chapter 6}

The CURE Plots of the models in chapter 6 are presented here.
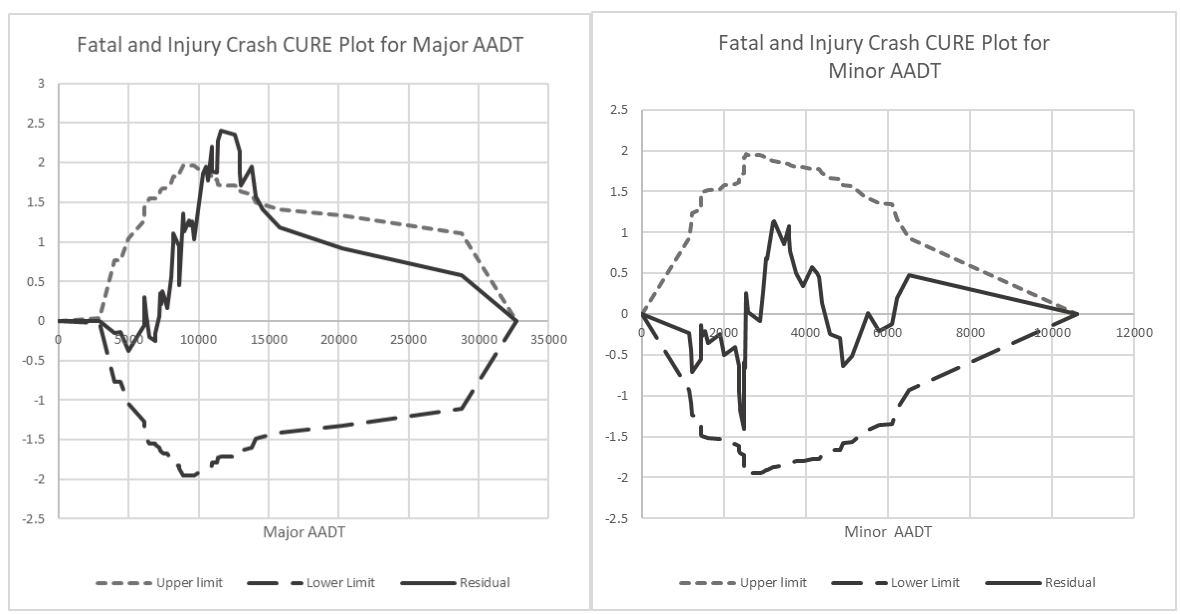

Figure 39 CURE Plots for Major and Minor AADTs for fatal and injury crashes

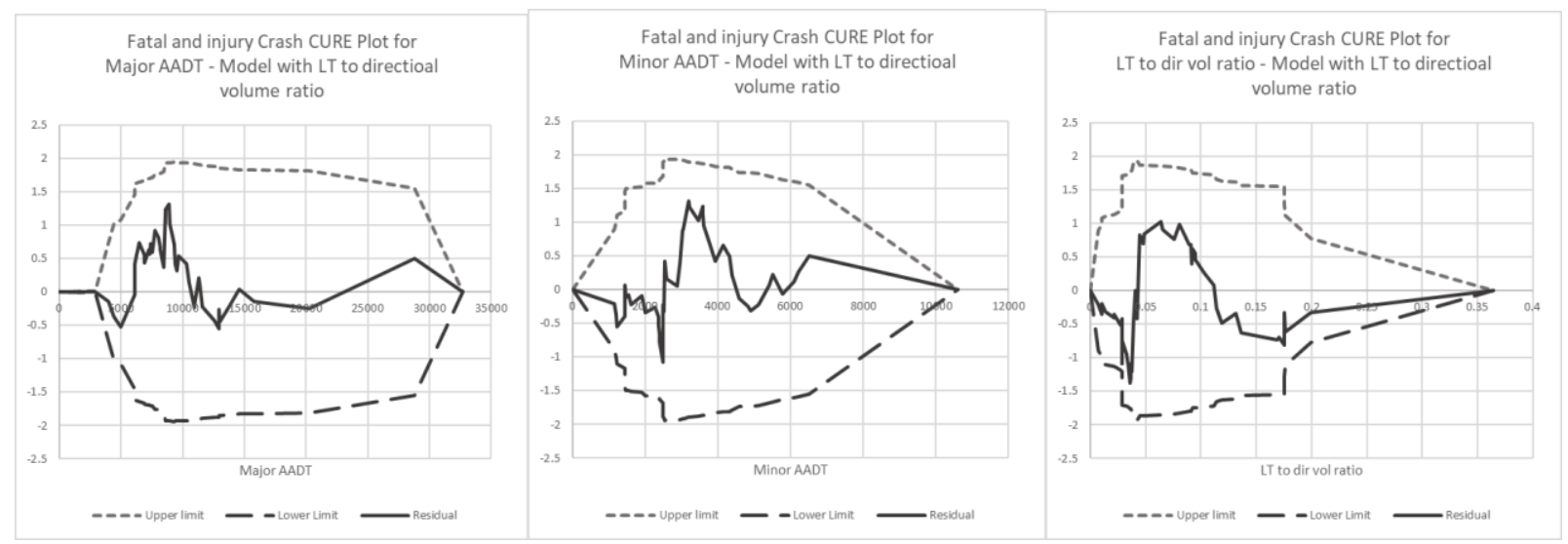

Figure 40 CURE Plots for Major and Minor AADTs and left turn volume ratio for fatal and injury crashes using a left turn to directional volume ratio 

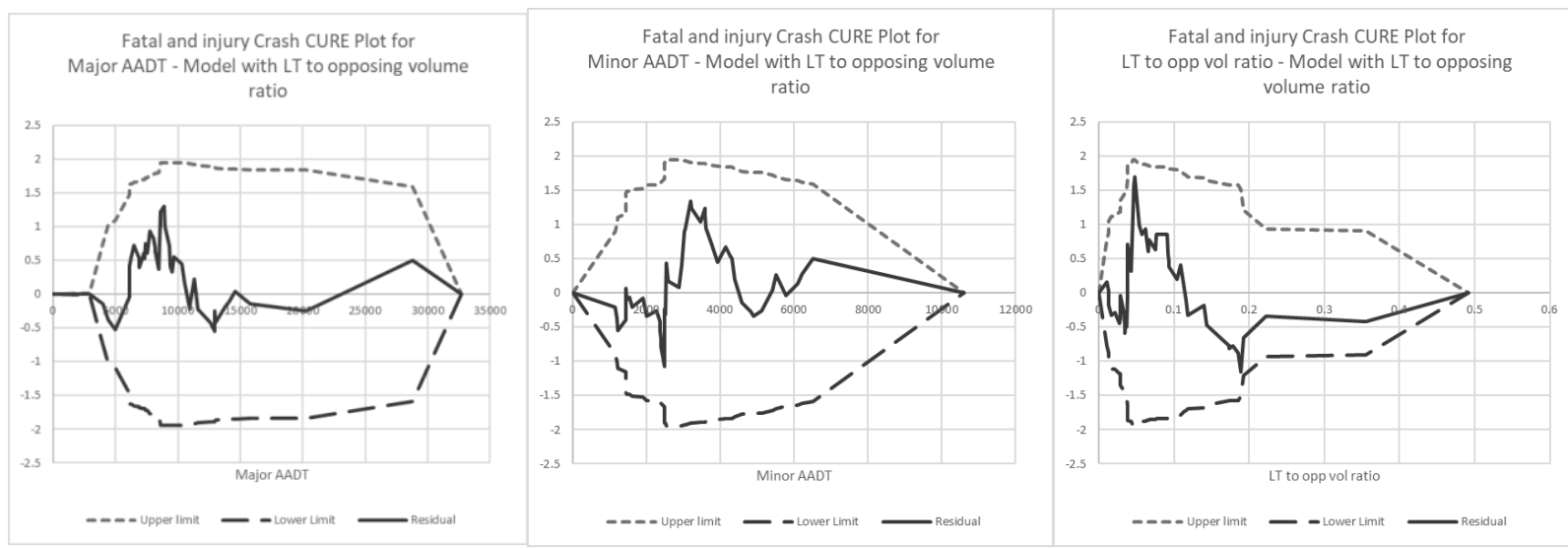

Figure 41 CURE Plots for Major and Minor AADTs and left turn volume ratio for fatal and injury crashes using a left turn to opposing volume ratio
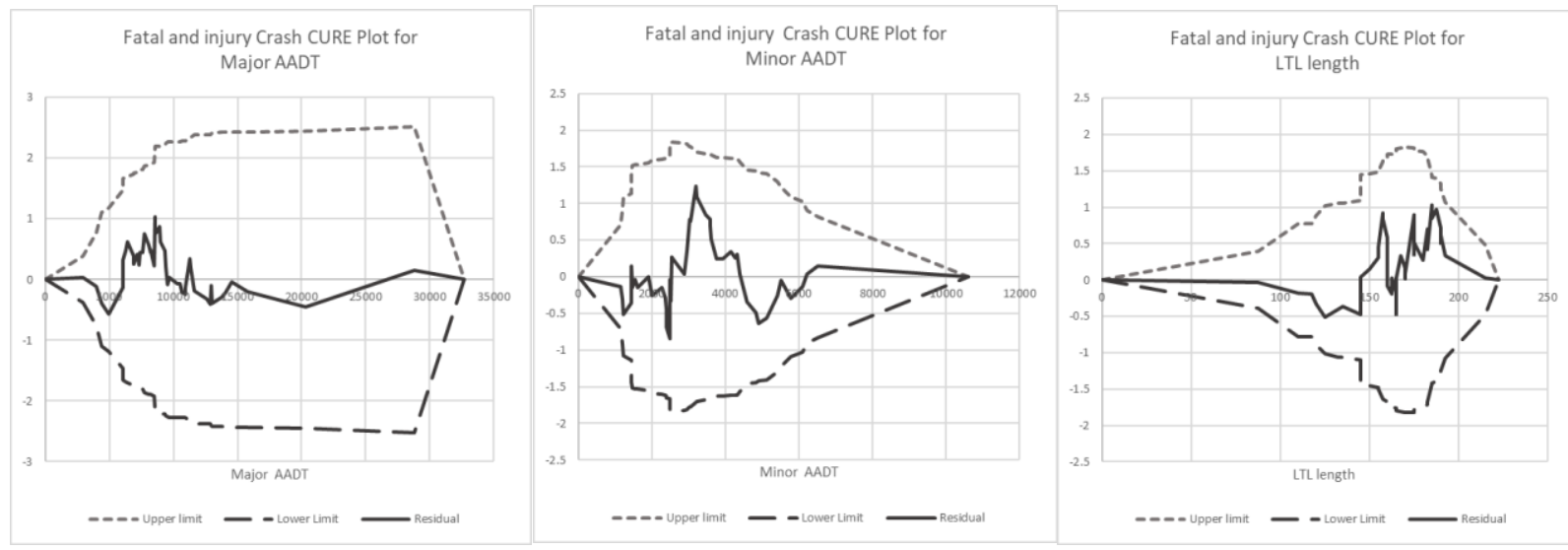

Figure 42 CURE Plots for Major and Minor AADTs and length of a left turn lane for fatal and injury crashes 

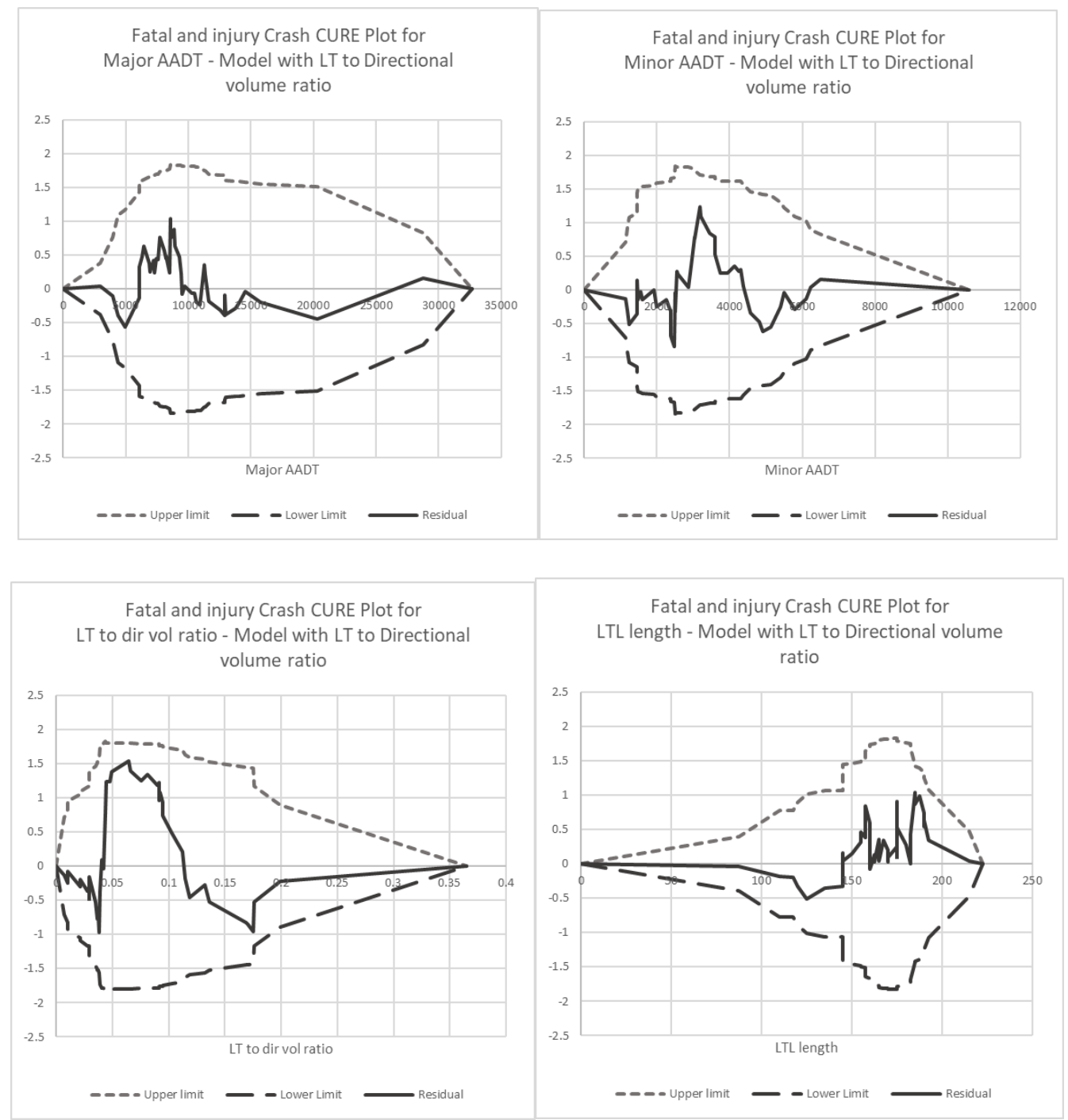

Figure 43 CURE Plots for Major and Minor AADTs, left turn volume ratio, and length of a left turn lane for fatal and injury crashes using a left turn to directional volume ratio 

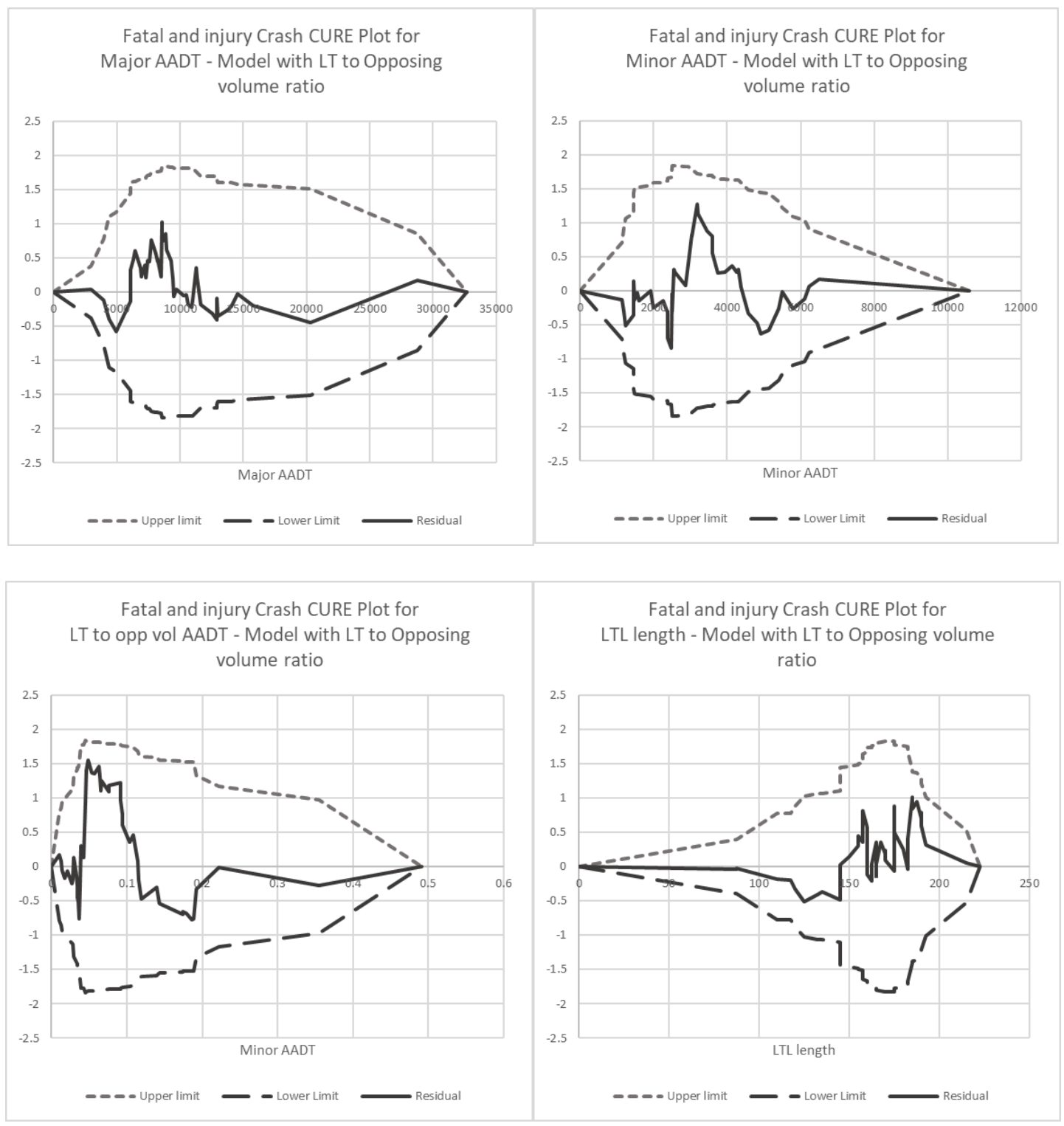

Fatal and injury Crash CURE Plot for LTL length - Model with LT to Opposing volume ratio

Figure 44 CURE Plots for Major and Minor AADTs, left turn volume ratio, and length of a left turn lane for fatal and injury crashes using a left turn to opposing volume ratio 

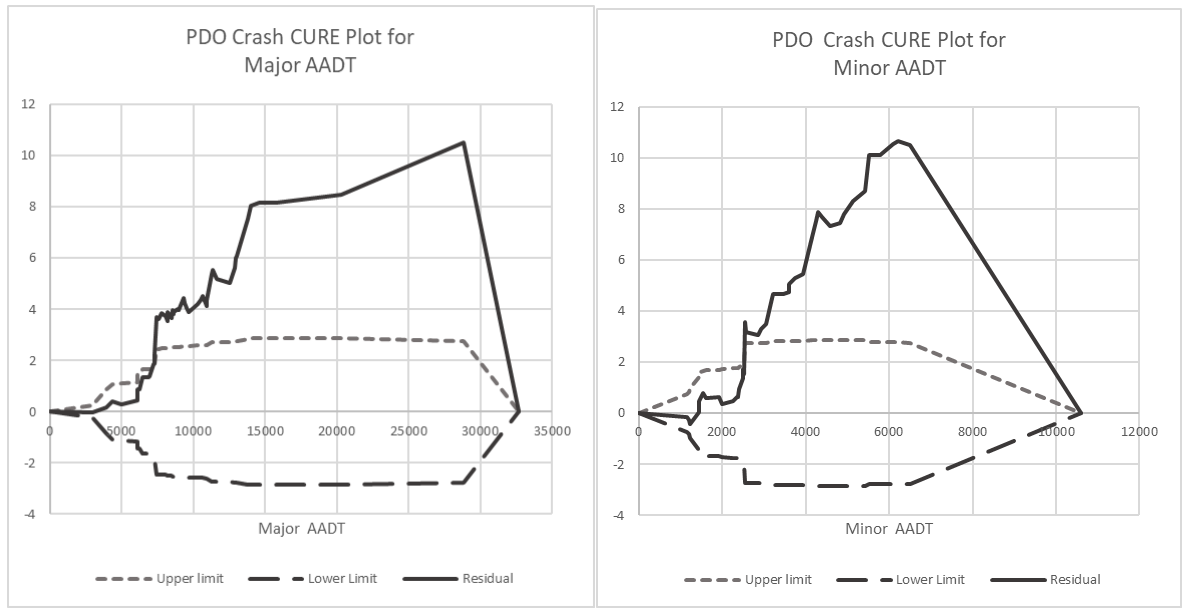

Figure 45 CURE Plots for Major and Minor AADTs for PDO crashes

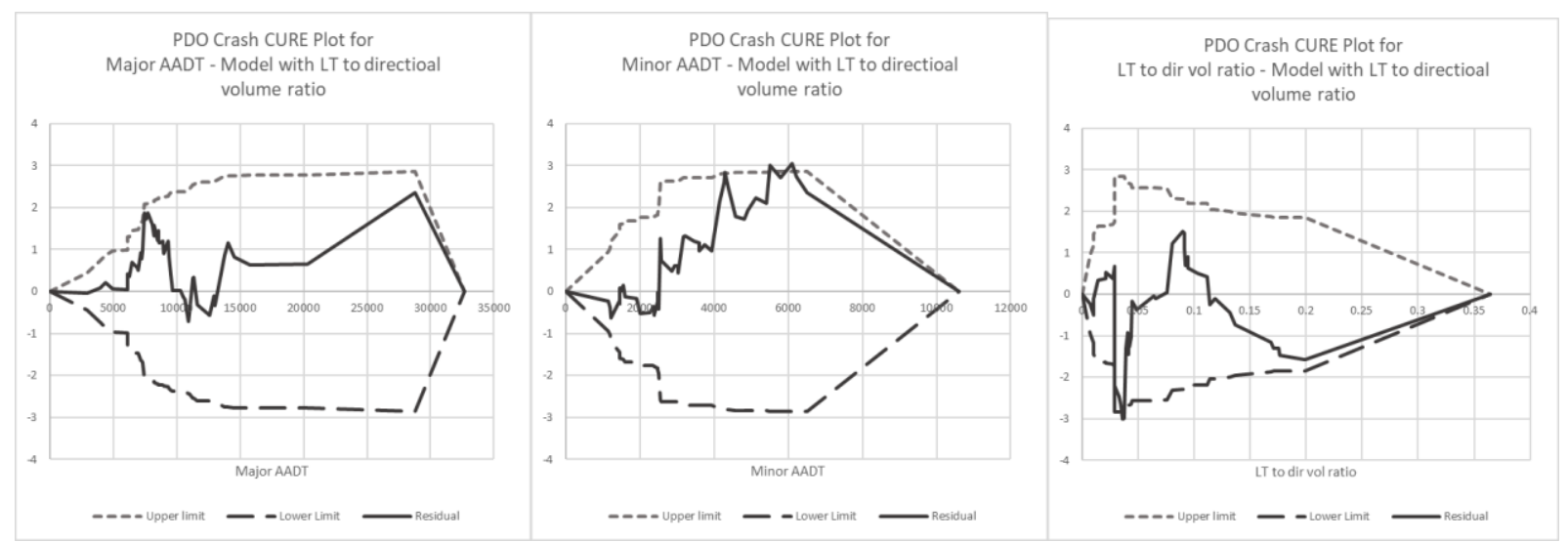

Figure 46 CURE Plots for Major and Minor AADTs and left turn volume ratio for PDO crashes using a left turn to directional volume ratio 

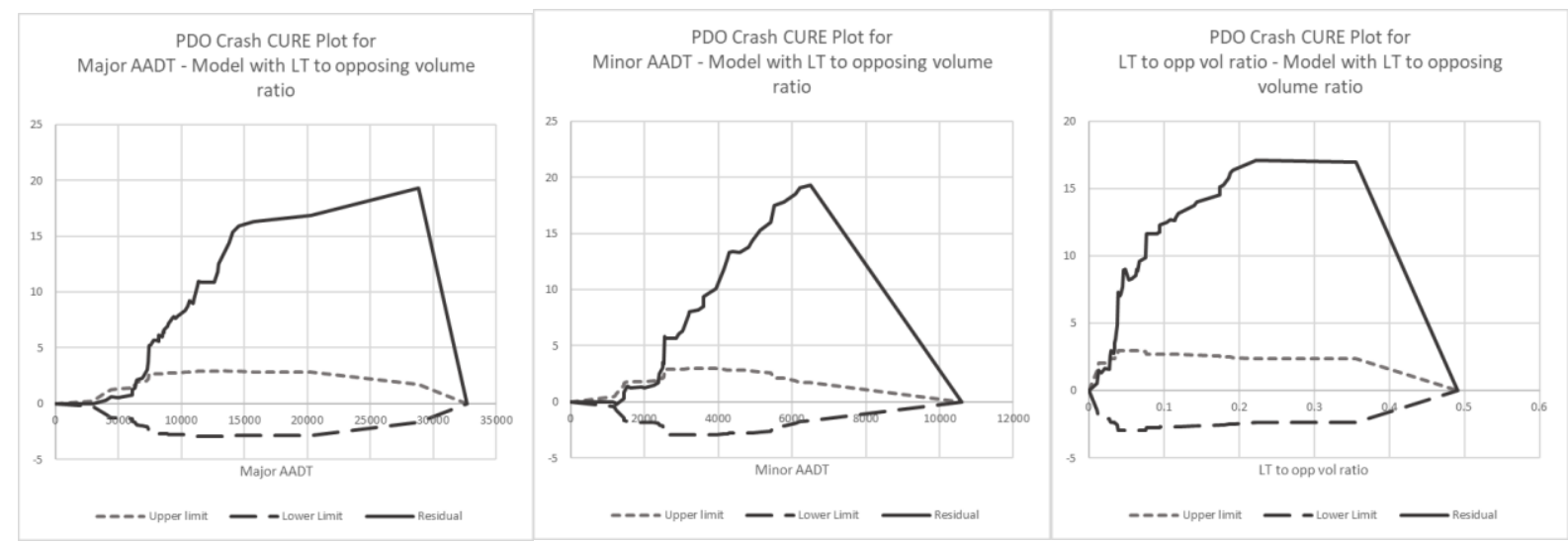

Figure 47 CURE Plots for Major and Minor AADTs and left turn volume ratio for PDO crashes using a left turn to opposing volume ratio
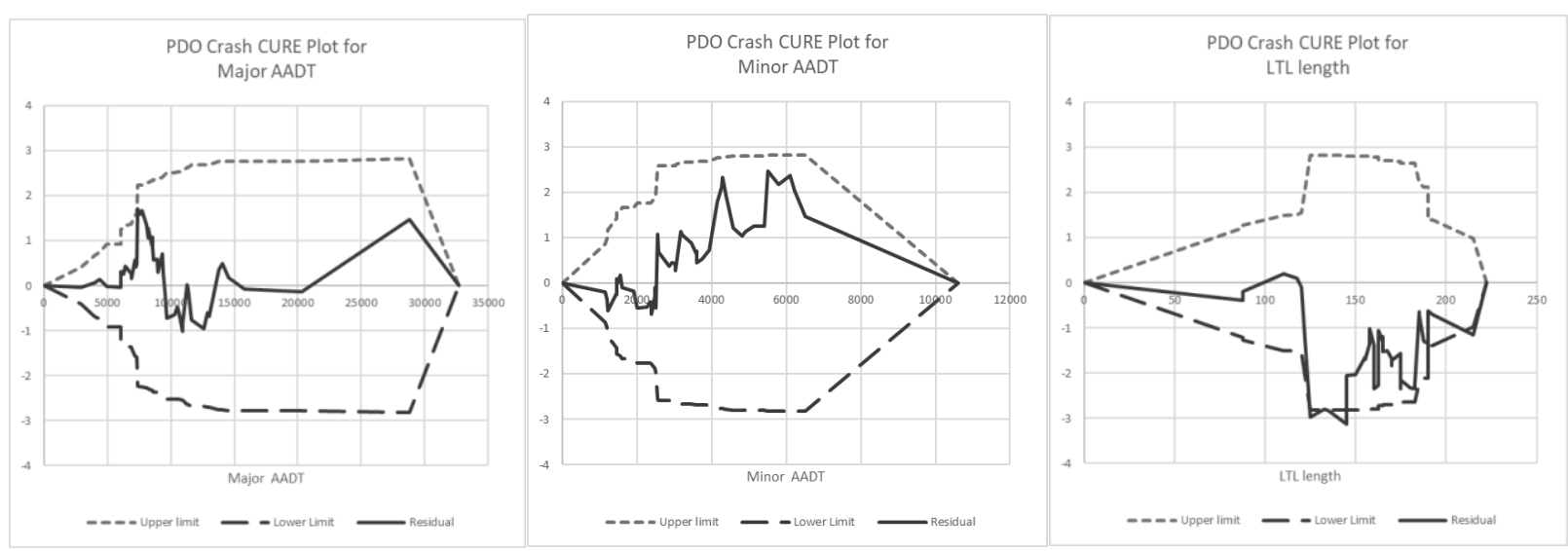

Figure 48 CURE Plots for Major and Minor AADTs and length of a left turn lane for PDO crashes 

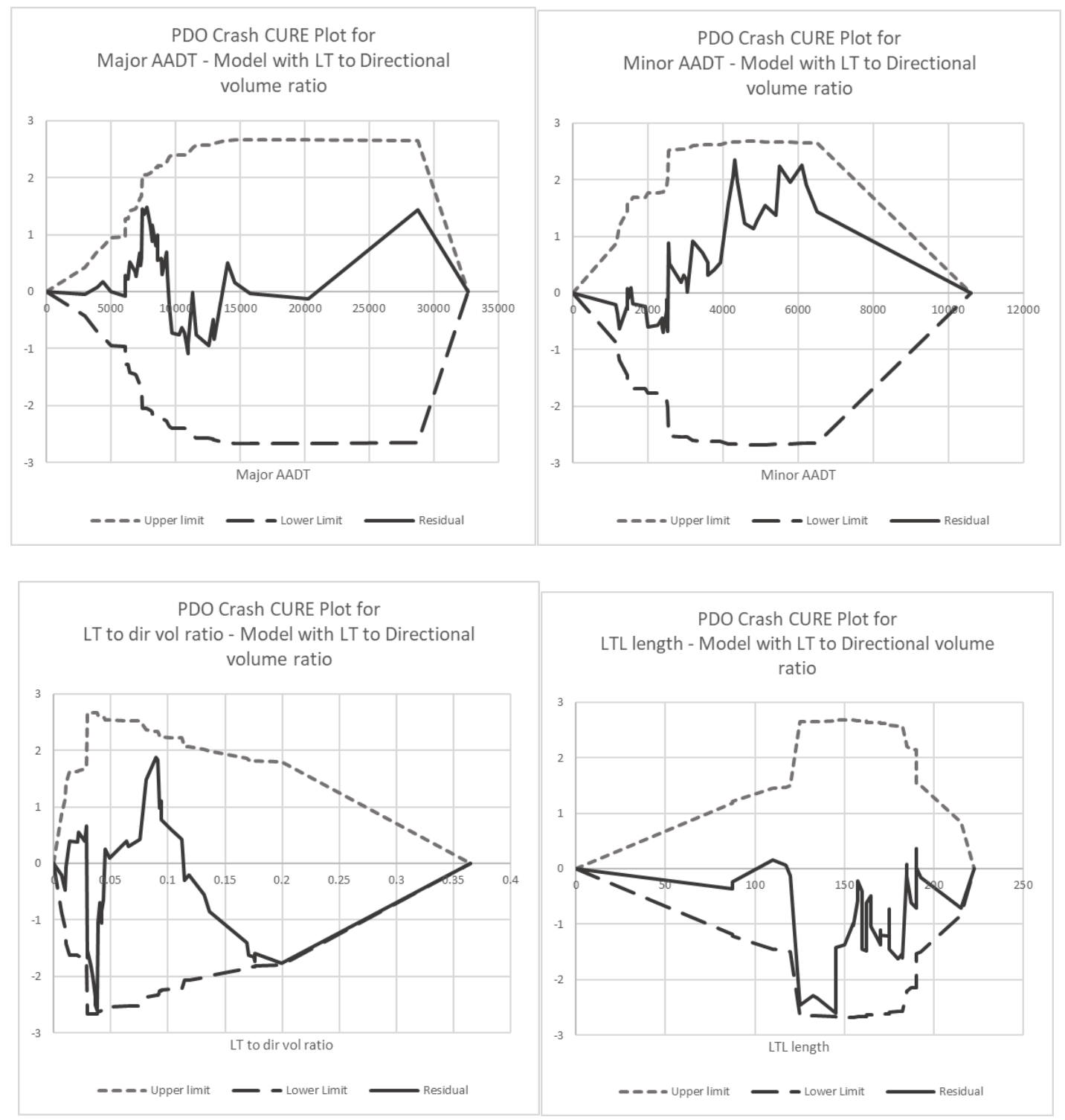

Figure 49 CURE Plots for Major and Minor AADTs, left turn volume ratio, and length of left turn lane for PDO crashes using a left turn to directional volume ratio 

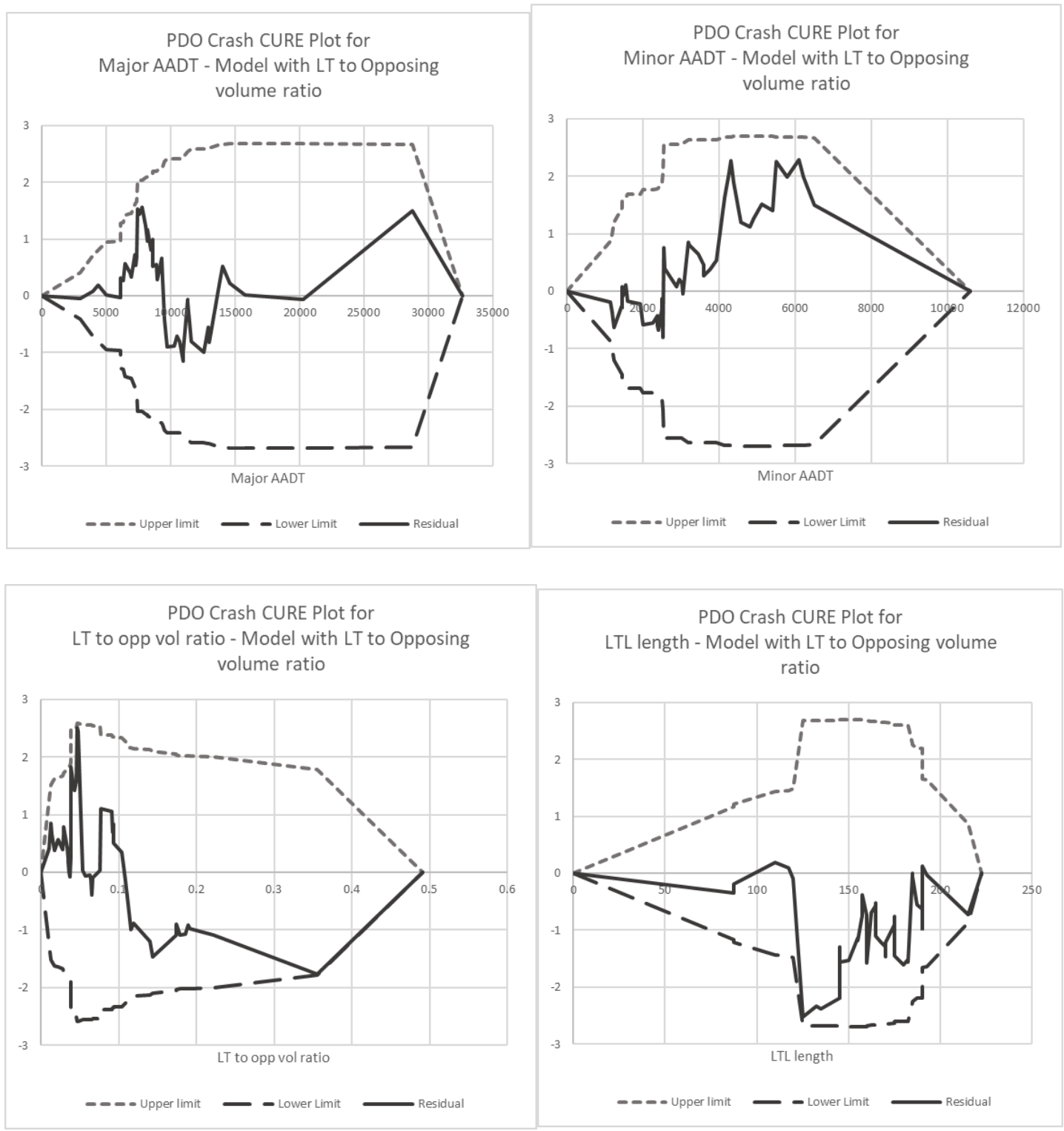

Figure 50 CURE Plots for Major and Minor AADTs, left turn volume ratio, and length of a left turn lane for PDO crashes using a left turn to opposing volume ratio 

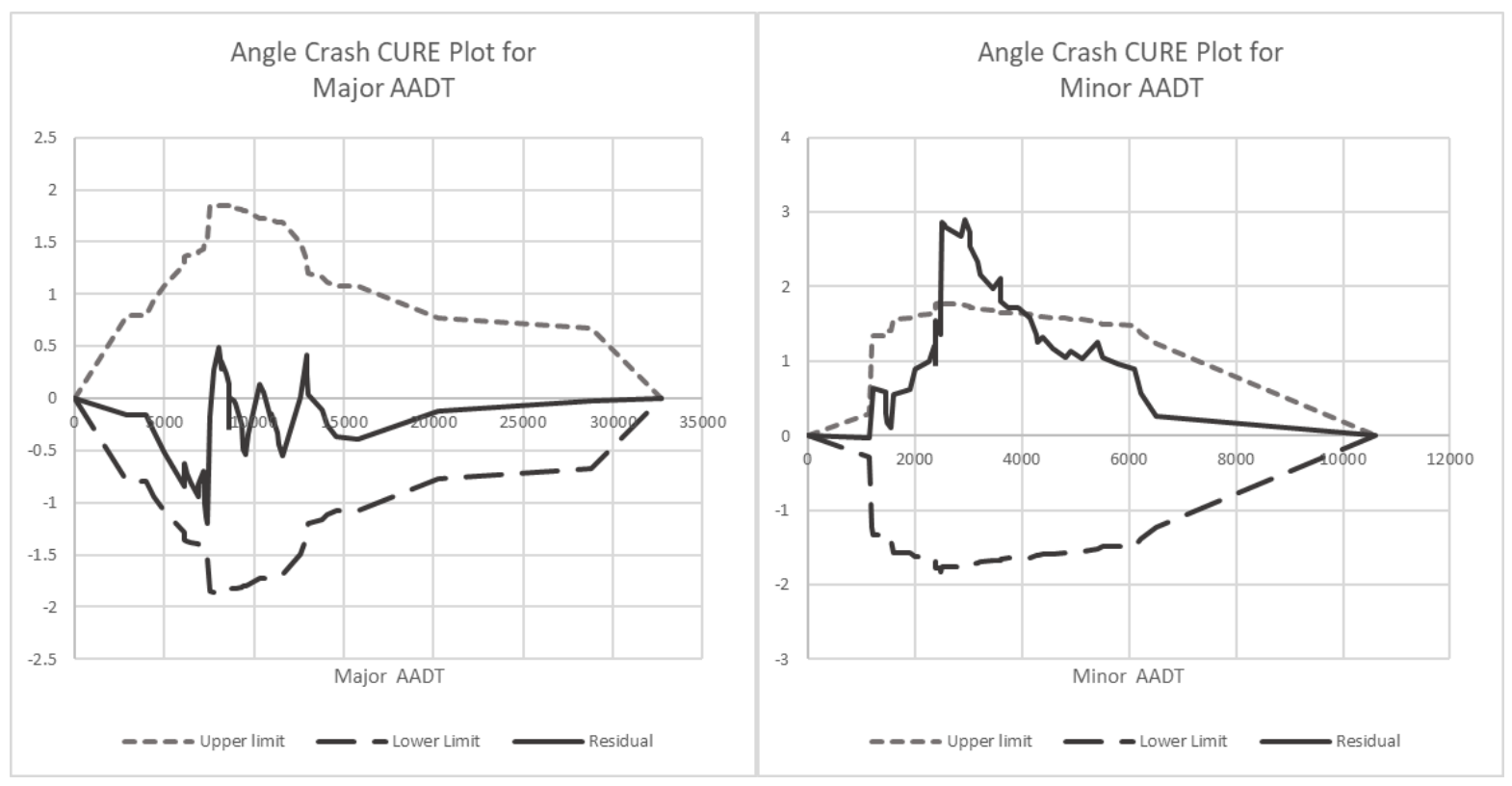

Figure 51 CURE Plots for Major and Minor AADTs for angle crashes
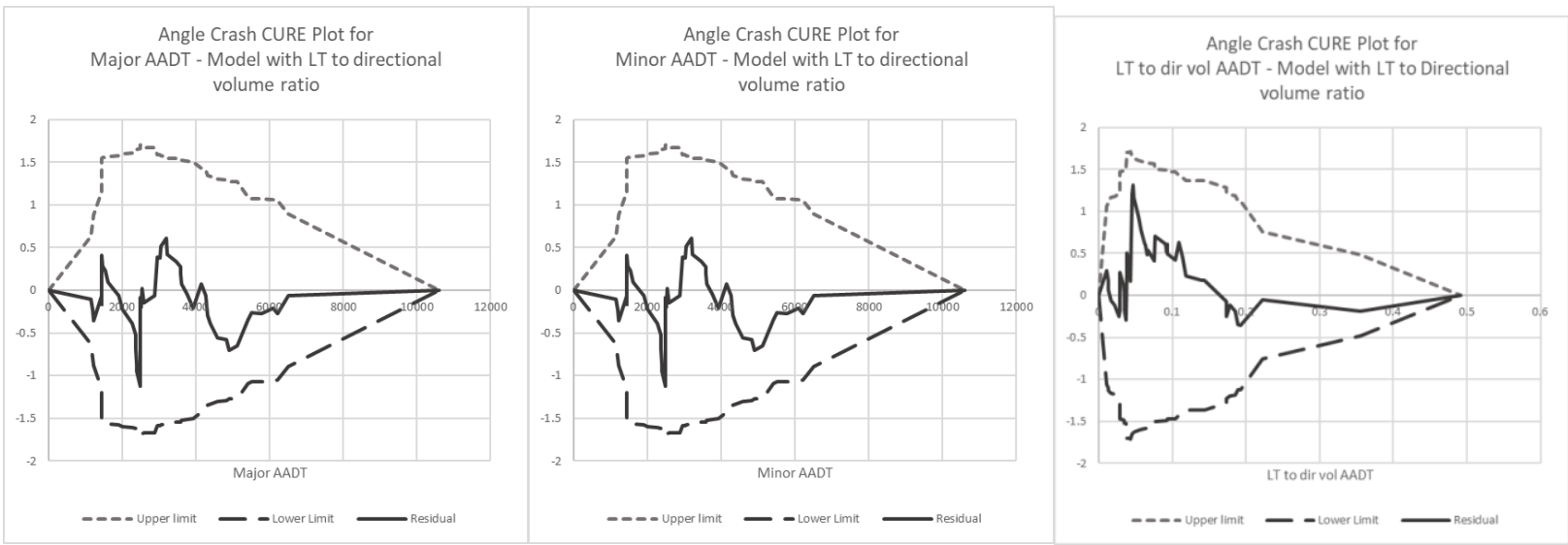

Figure 52 CURE Plots for Major and Minor AADTs and left turn volume ratio for angle crashes using a left turn to directional volume ratio 

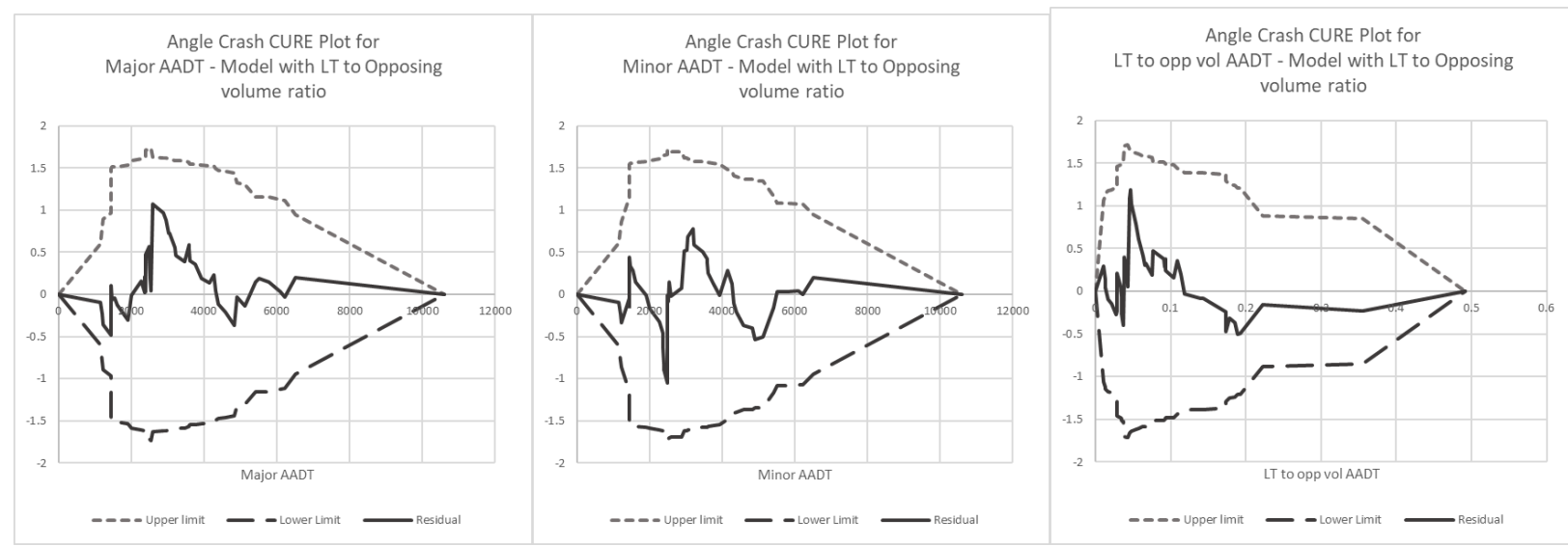

Figure 53 CURE Plots for Major and Minor AADTs and left turn volume ratio for angle crashes using a left turn to opposing volume ratio

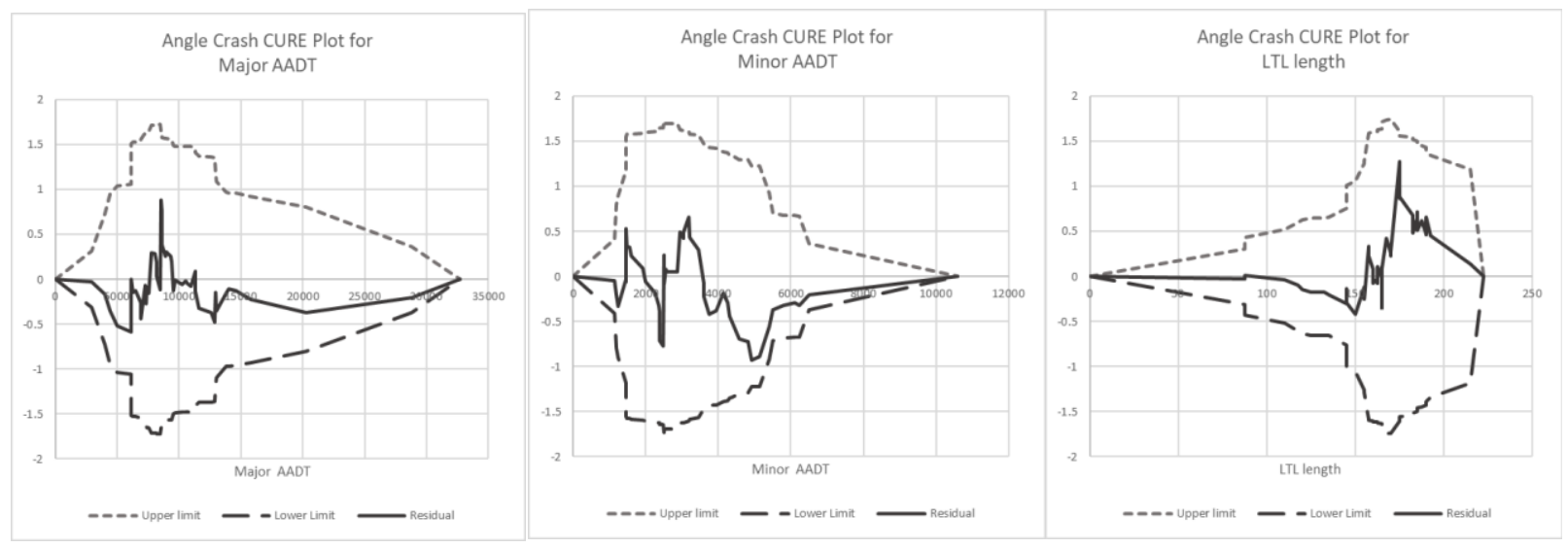

Figure 54 CURE Plots for Major and Minor AADTs and length of a left turn lane for angle crashes 

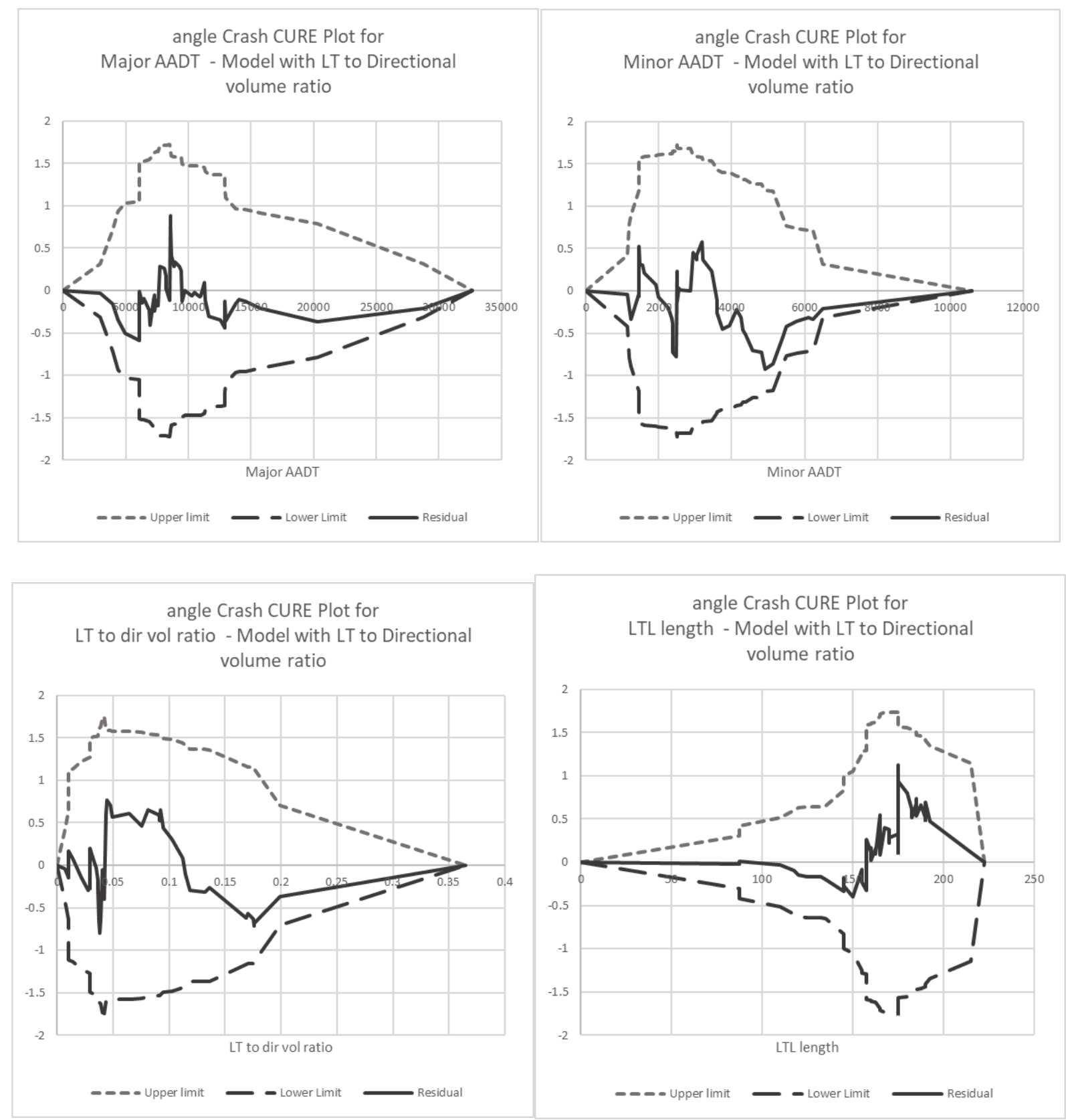

Figure 55 CURE Plots for Major and Minor AADTs, left turn volume ratio, and length of left turn lane for angle crashes using a left turn to directional volume ratio 

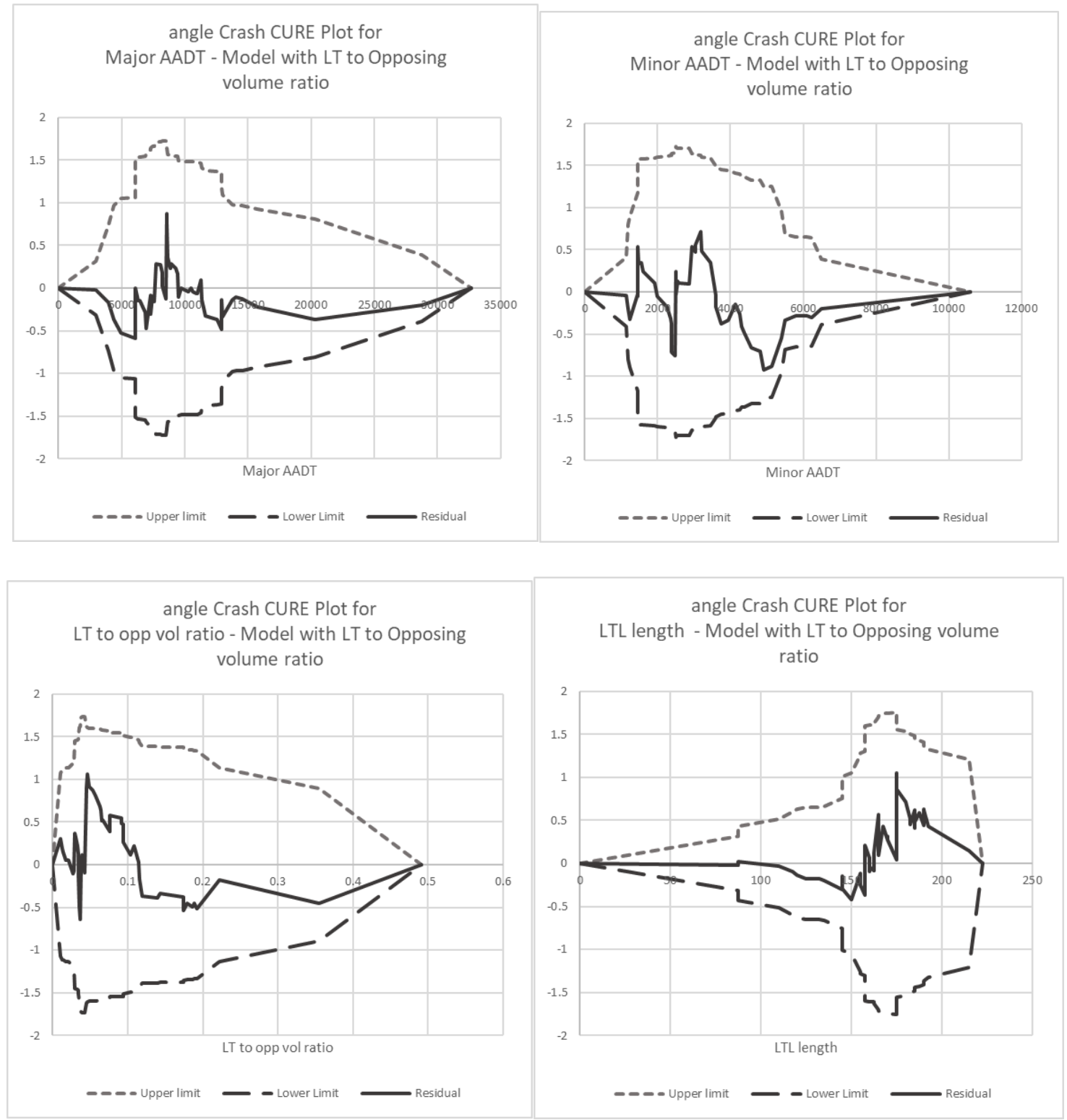

Figure 56 CURE Plots for Major and Minor AADTs, left turn volume ratio, and length of a left turn lane for angle crashes using a left turn to opposing volume ratio 

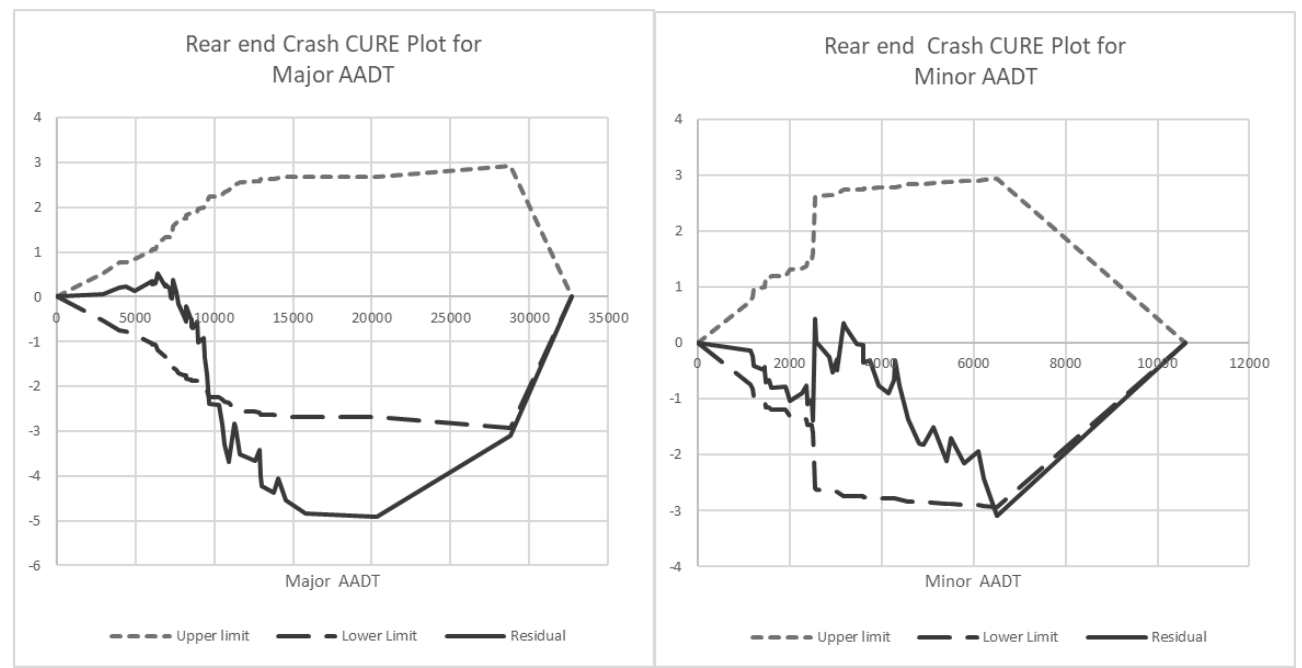

Figure 57 CURE Plots for Major and Minor AADTs for rear-end crashes
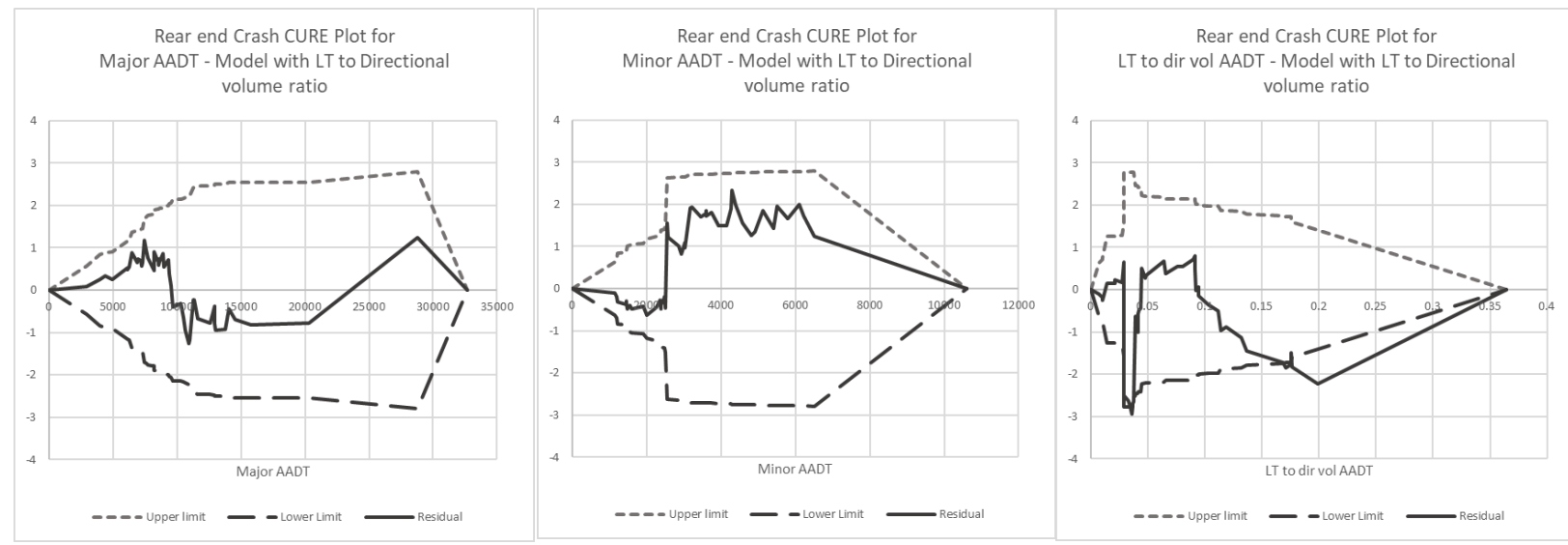

Figure 58 CURE Plots for Major and Minor AADTs and left turn volume ratio for rear-end crashes using a left turn to directional volume ratio 

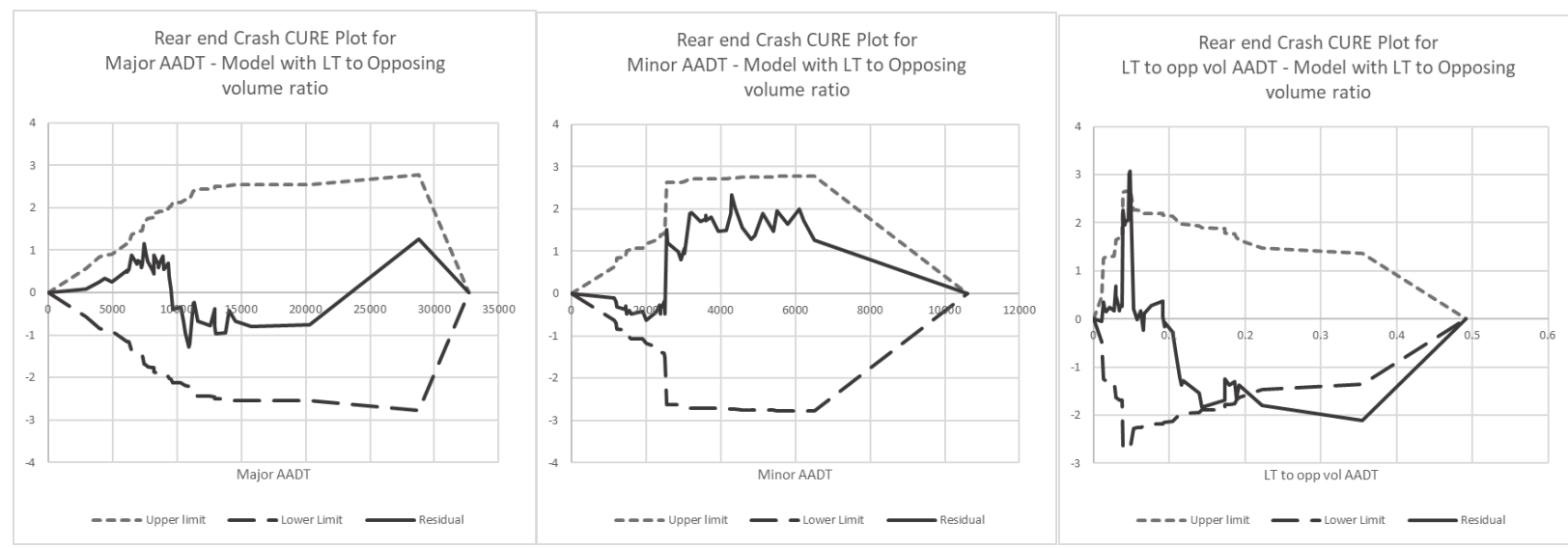

Figure 59 CURE Plots for Major and Minor AADTs and left turn volume ratio for-rear end crashes using a left turn to opposing volume ratio
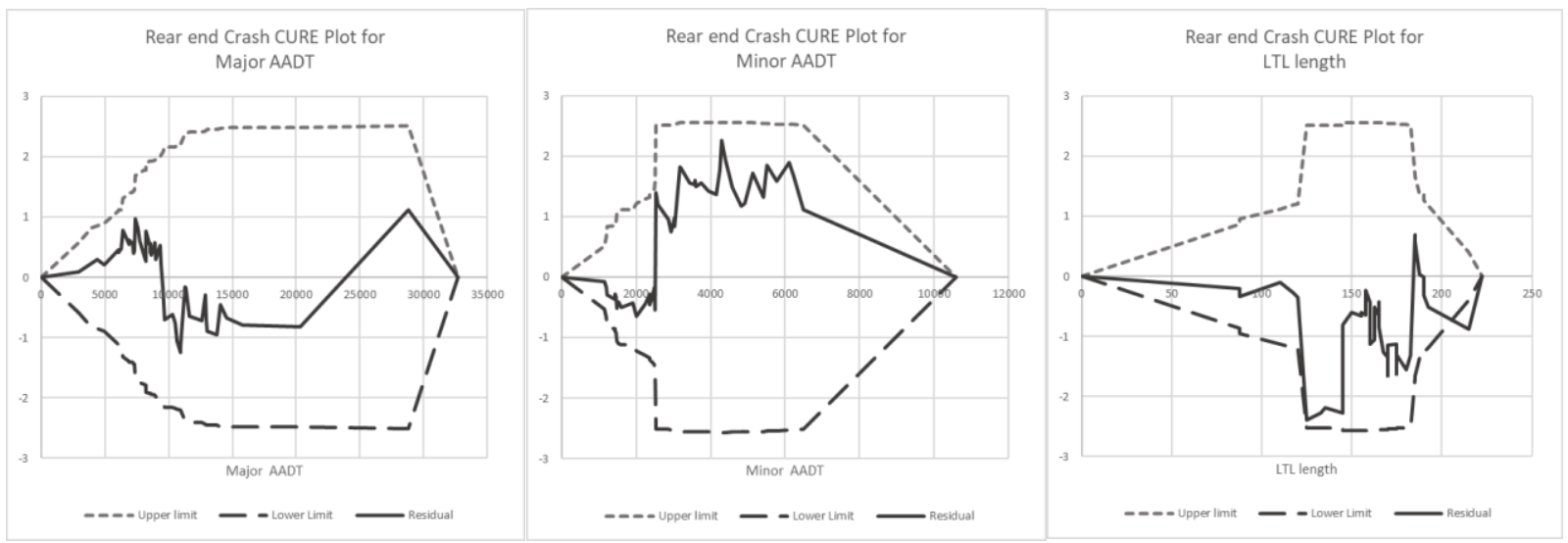

Figure 60 CURE Plots for Major and Minor AADTs and length of a left turn lane for rear-end crashes 

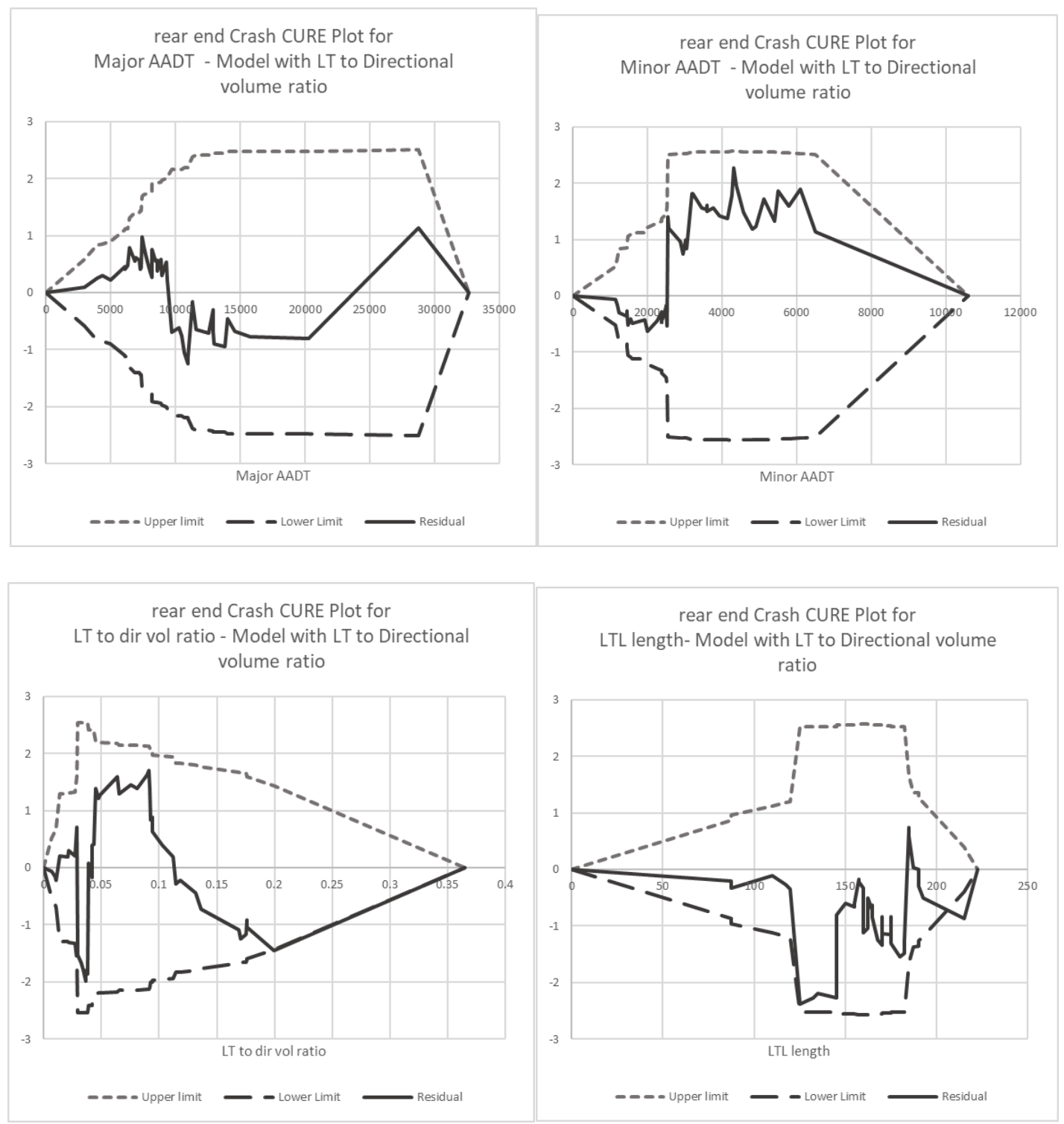

Figure 61 CURE Plots for Major and Minor AADTs, left turn volume ratio, and length of a left turn lane for rear-end crashes using a left turn to directional volume ratio 

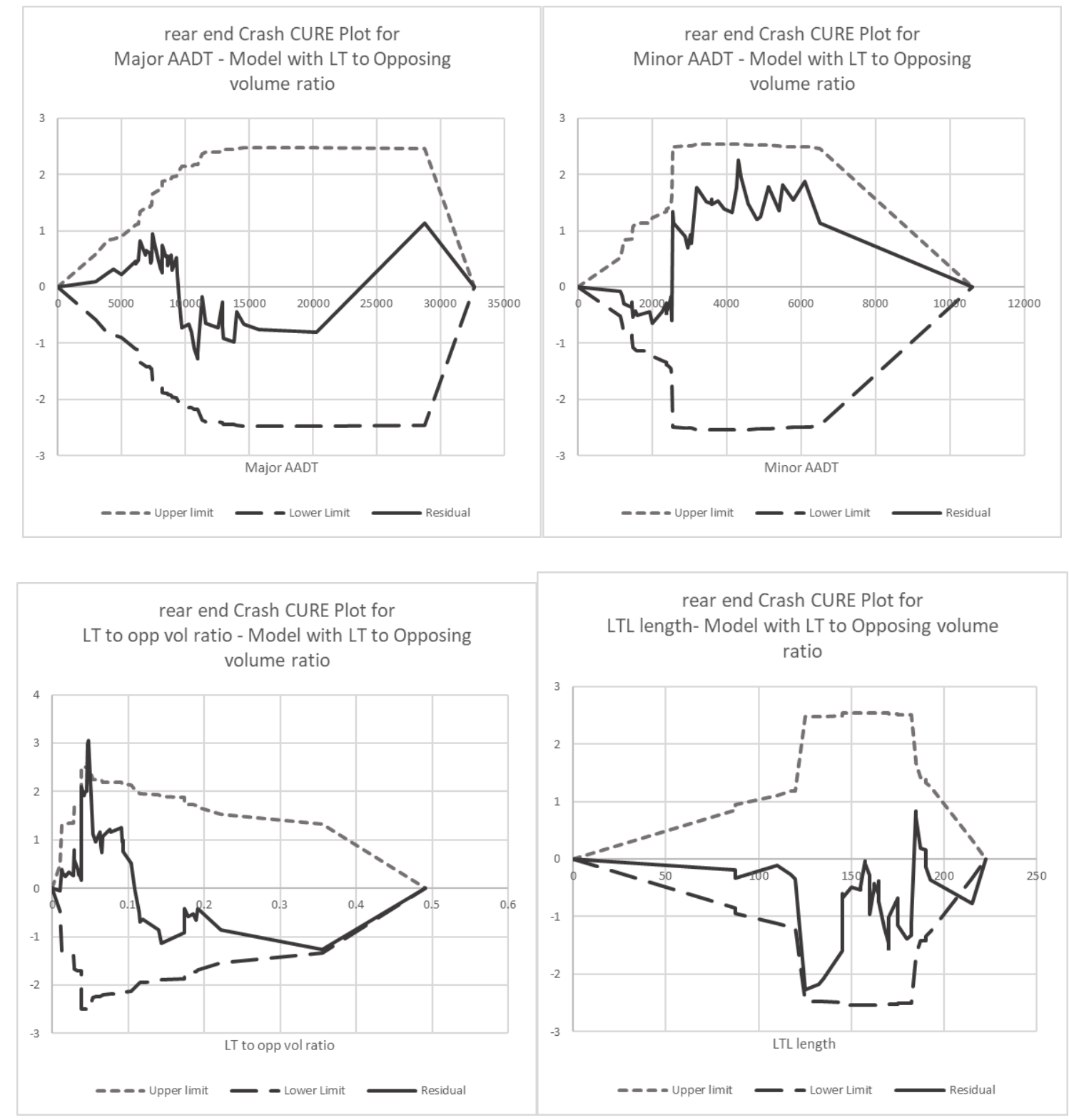

Figure 62 CURE Plots for Major and Minor AADTs, left turn volume ratio, and length of a left turn lane for rear-end crashes using a left turn to opposing volume ratio 

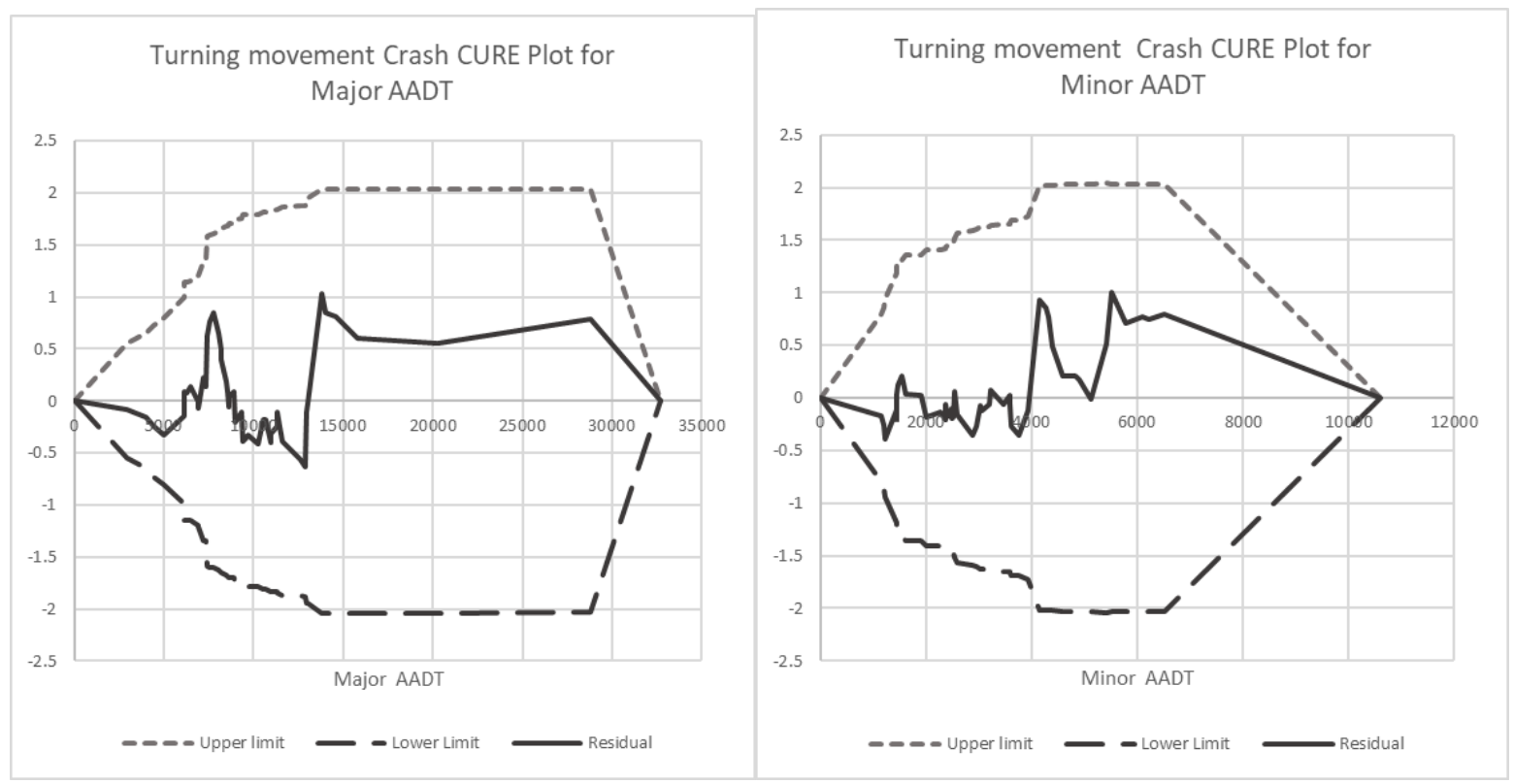

Figure 63 CURE Plots for Major and Minor AADTs for turning movement crashes

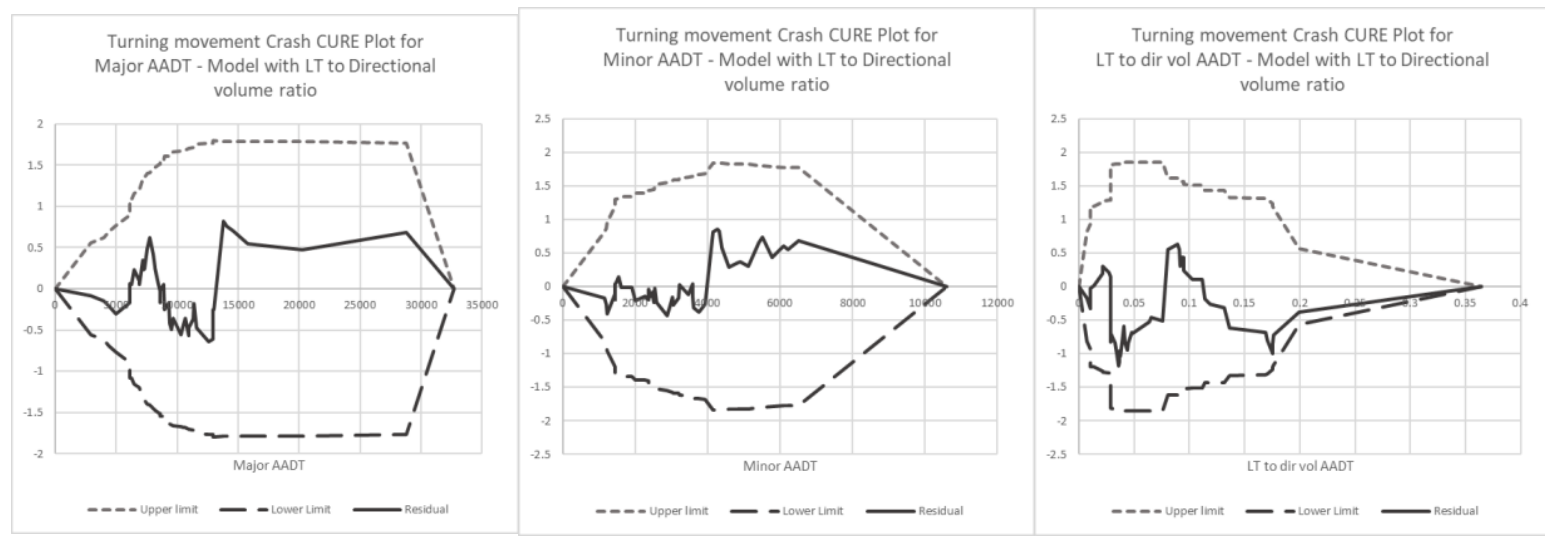

Figure 64 CURE Plots for Major and Minor AADTs and left turn volume ratio for turning movement crashes using a left turn to directional volume ratio 


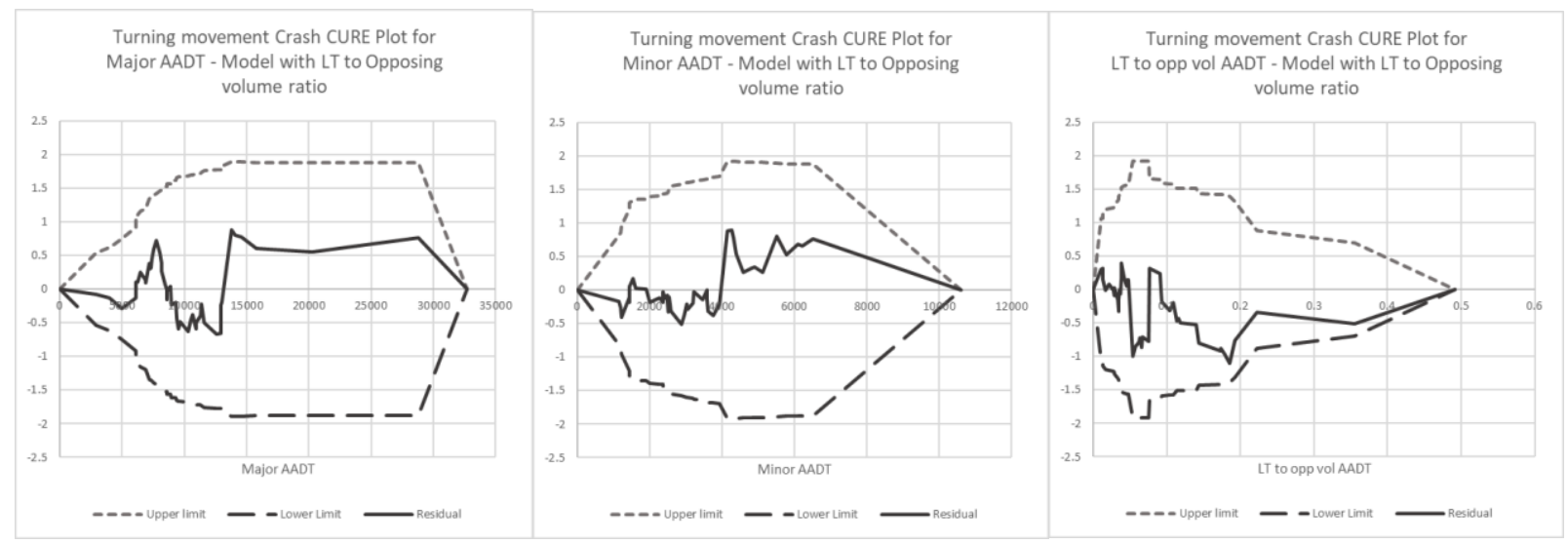

Figure 65 CURE Plots for Major and Minor AADTs and left turn volume ratio for turning movement crashes using a left turn to opposing volume ratio
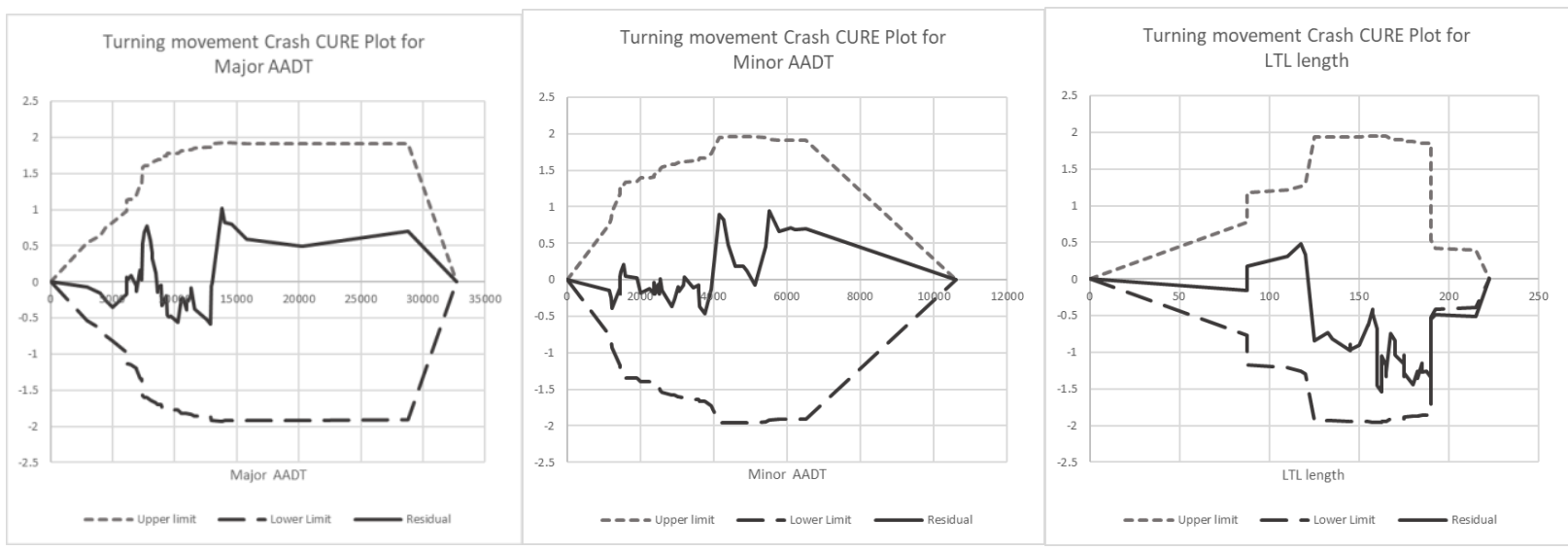

Figure 66 CURE Plots for Major and Minor AADTs and length of a left turn lane for turning movement crashes 


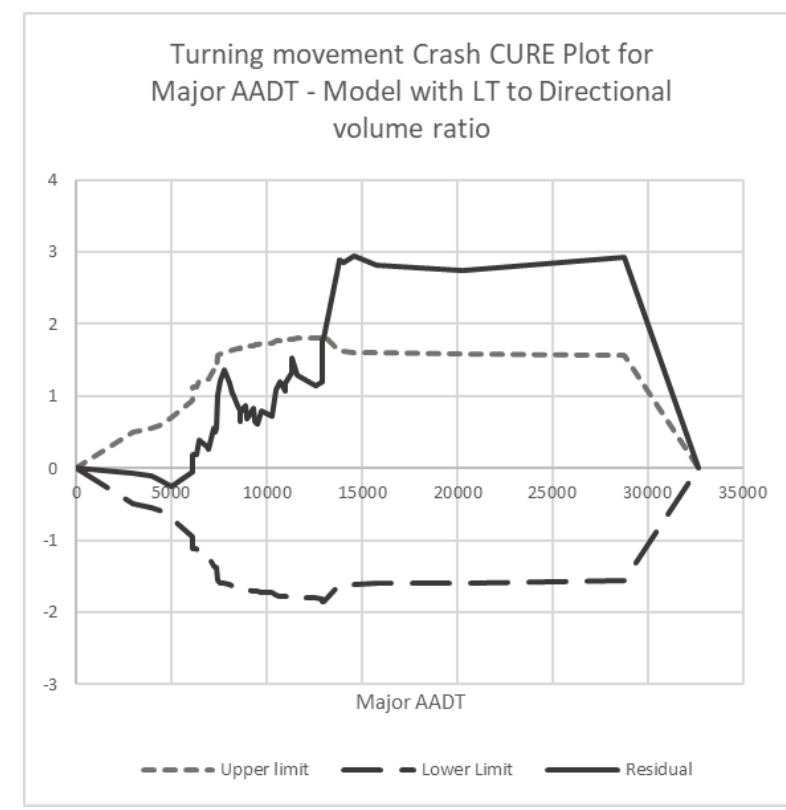

Turning movement Crash CURE Plot for Minor AADT - Model with LT to Directional volume ratio

Turning movement Crash CURE Plot for

LT to dir vol ratio - Model with LT to Directional volume ratio

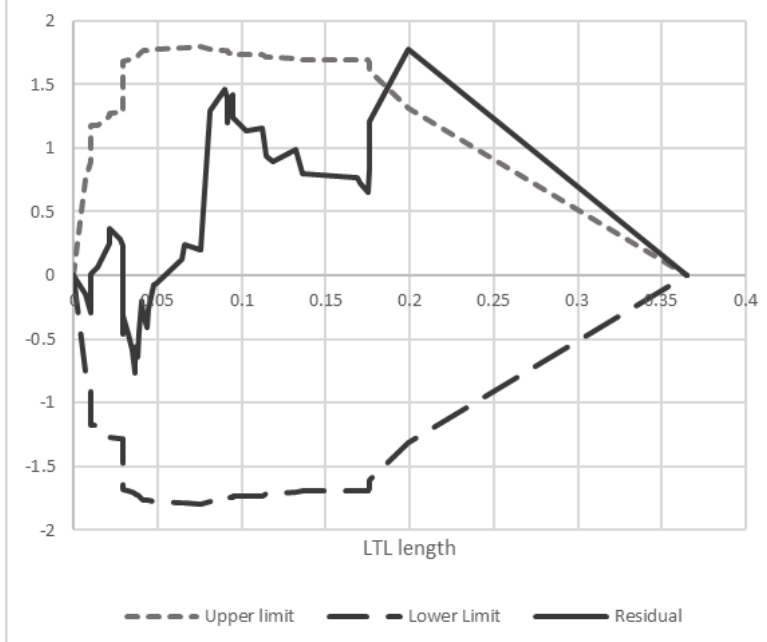

Turning movement Crash CURE Plot for LTL length - Model with LT to directional volume ratio

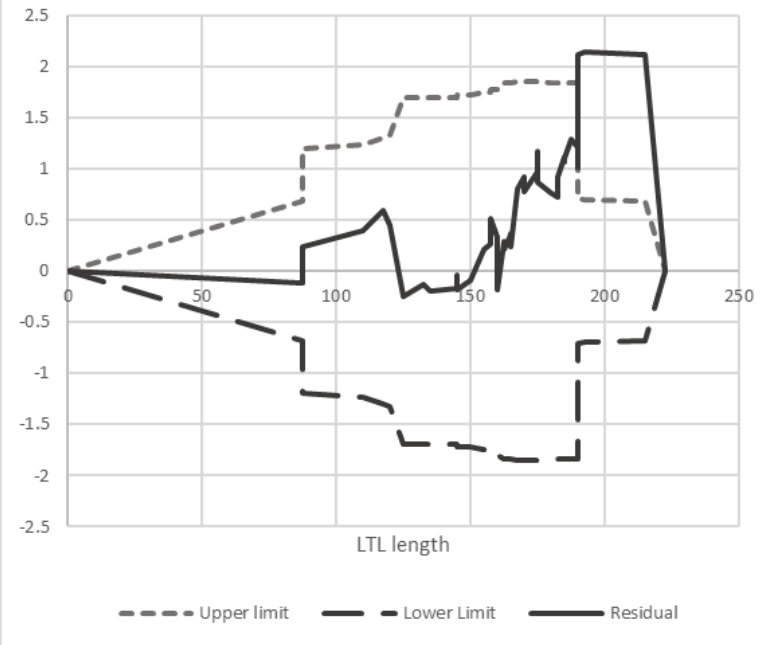

Figure 67 CURE Plots for Major and Minor AADTs, left turn volume ratio, and length of left turn lane for turning movement crashes using a left turn to directional volume ratio 

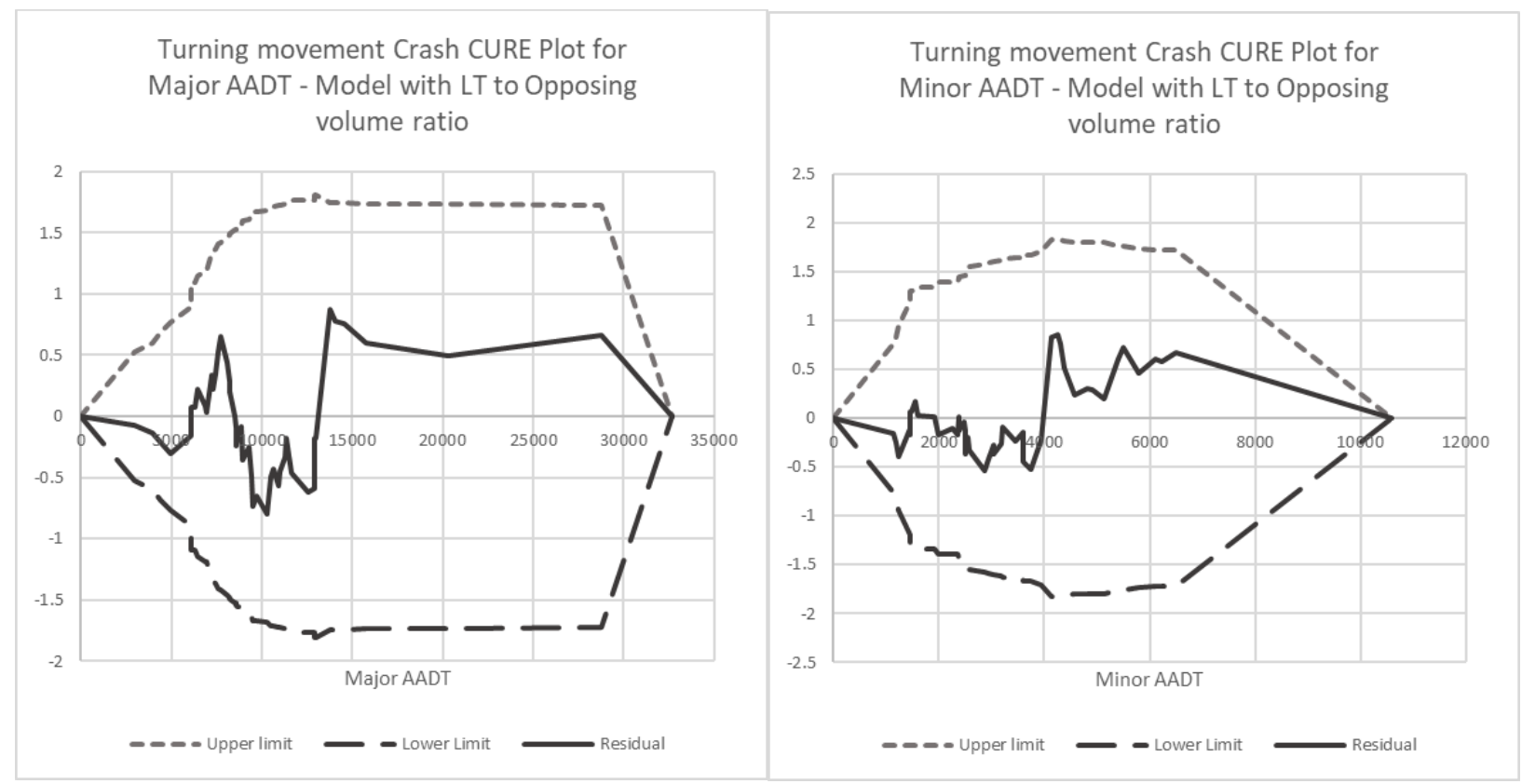

Turning movement Crash CURE Plot for

LT to opp vol ratio - Model with LT to Opposing volume ratio

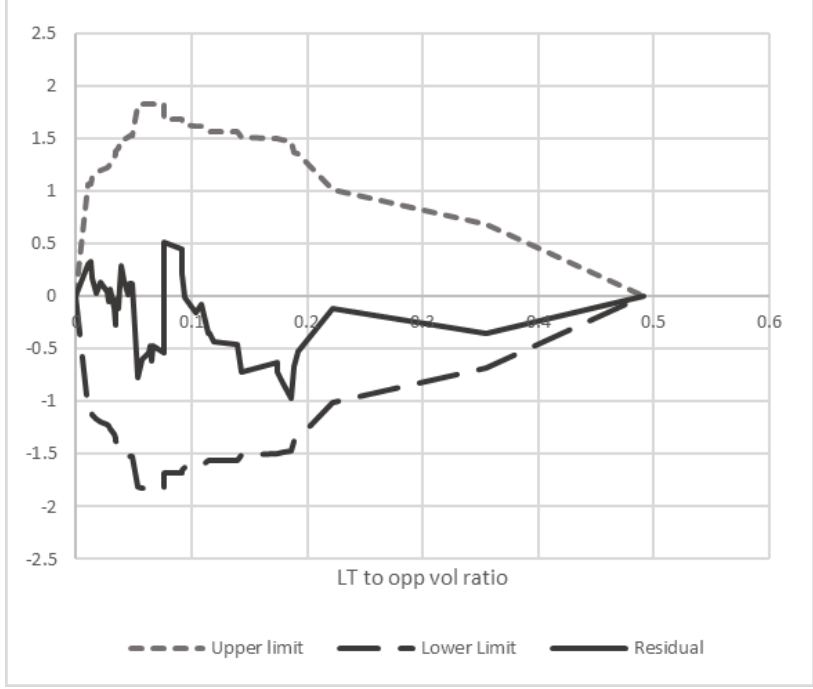

Turning movement Crash CURE Plot for

LTL length - Model with LT to Opposing volume ratio

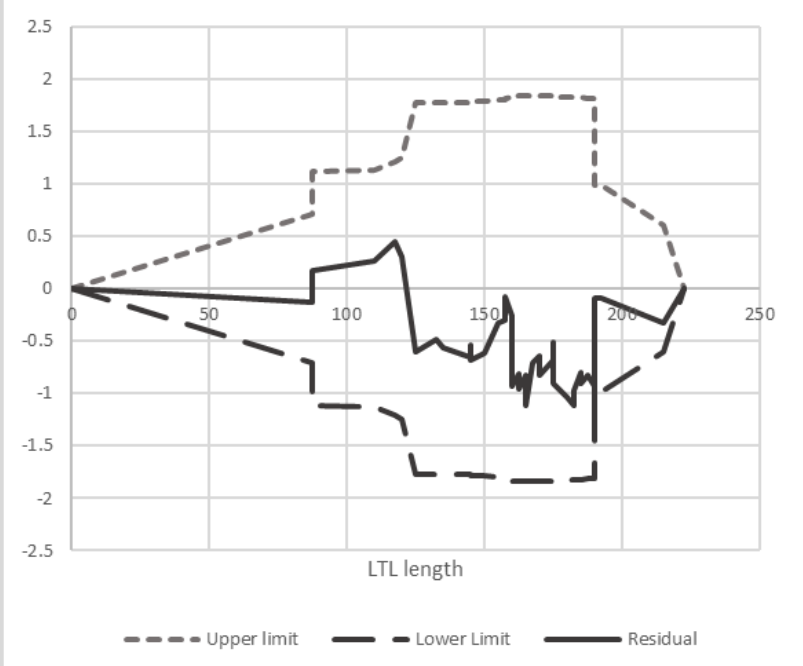

Figure 68 CURE Plots for Major and Minor AADTs, left turn volume ratio, and length of a left turn lane for turning movement crashes using a left turn to opposing volume ratio 


\section{Appendix C: Conflict counts - Chapter 6}

Table 46 Number of total conflict counts recorded from the hypothetical intersections

\begin{tabular}{c|llll} 
Intersection & $\begin{array}{l}\text { Adequate length } \\
\text { left turn lane }\end{array}$ & $\begin{array}{l}40 \% \text { less length } \\
\text { left turn lane }\end{array}$ & $\begin{array}{l}60 \% \text { less length } \\
\text { left turn lane }\end{array}$ & $\begin{array}{l}80 \% \text { less length } \\
\text { left turn lane }\end{array}$ \\
\hline 1 & 2483 & 2622 & 2680 & 3378 \\
2 & 2348 & 2397 & 2398 & 2858 \\
3 & 2058 & 2167 & 2251 & 2340 \\
4 & 2269 & 2262 & 2420 & 2464 \\
5 & 2098 & 2248 & 2209 & 2239 \\
6 & 1852 & 1932 & 1938 & 1981 \\
7 & 2016 & 2011 & 2037 & 2046 \\
8 & 1885 & 1893 & 1743 & 1850 \\
9 & 1669 & 1711 & 1708 & 1726 \\
10 & 3627 & 3476 & 3588 & 3822 \\
11 & 1819 & 1997 & 2029 & 2586 \\
12 & 2296 & 2272 & 2339 & 2836 \\
13 & 2964 & 3135 & 3223 & 3844 \\
14 & 1878 & 1896 & 1896 & 2064 \\
15 & 2058 & 1964 & 2040 & 2155 \\
16 & 2025 & 2119 & 2156 & 2246 \\
17 & 1883 & 1985 & 1966 & 1990 \\
18 & 1848 & 1875 & 1855 & 1874 \\
19 & 3918 & 4294 & 4430 & 4846 \\
20 & 2527 & 2741 & 2907 & 3231 \\
21 & 2527 & 2654 & 2907 & 3220 \\
22 & 3752 & 3859 & 4089 & 4310 \\
23 & 1859 & 1973 & 2054 & 2562 \\
24 & 2037 & 2083 & 2096 & 2584 \\
25 & 2966 & 3037 & 3275 & 3676 \\
26 & 1846 & 1984 & 1991 & 2155 \\
27 & 1942 & 1944 & 1982 & \\
& & & & \\
\hline
\end{tabular}


Table 47 Number of crossing conflict counts recorded from the hypothetical intersections

\begin{tabular}{|c|c|c|c|c|}
\hline Intersection & $\begin{array}{l}\text { Adequate length } \\
\text { left turn lane }\end{array}$ & $\begin{array}{l}40 \% \text { less length } \\
\text { left turn lane }\end{array}$ & $\begin{array}{l}60 \% \text { less length } \\
\text { left turn lane }\end{array}$ & $\begin{array}{l}80 \% \text { less length } \\
\text { left turn lane }\end{array}$ \\
\hline 1 & 17 & 13 & 12 & 16 \\
\hline 2 & 18 & 20 & 17 & 24 \\
\hline 3 & 26 & 26 & 26 & 16 \\
\hline 4 & 12 & 12 & 14 & 14 \\
\hline 5 & 12 & 12 & 14 & 15 \\
\hline 6 & 9 & 7 & 13 & 6 \\
\hline 7 & 20 & 19 & 19 & 19 \\
\hline 8 & 9 & 9 & 9 & 8 \\
\hline 9 & 11 & 11 & 11 & 10 \\
\hline 10 & 13 & 16 & 14 & 11 \\
\hline 11 & 11 & 13 & 15 & 15 \\
\hline 12 & 23 & 14 & 19 & 15 \\
\hline 13 & 12 & 15 & 14 & 10 \\
\hline 14 & 18 & 16 & 17 & 17 \\
\hline 15 & 14 & 17 & 12 & 10 \\
\hline 16 & 10 & 11 & 8 & 13 \\
\hline 17 & 8 & 9 & 10 & 6 \\
\hline 18 & 9 & 10 & 7 & 5 \\
\hline 19 & 5 & 8 & 11 & 11 \\
\hline 20 & 22 & 17 & 18 & 12 \\
\hline 21 & 22 & 20 & 18 & 14 \\
\hline 22 & 8 & 9 & 8 & 7 \\
\hline 23 & 15 & 16 & 14 & 16 \\
\hline 24 & 15 & 11 & 15 & 10 \\
\hline 25 & 18 & 14 & 15 & 14 \\
\hline 26 & 11 & 10 & 13 & 17 \\
\hline 27 & 4 & 5 & 9 & 7 \\
\hline
\end{tabular}


Table 48 Number of rear end conflict counts recorded from the hypothetical intersections

\begin{tabular}{|c|c|c|c|c|}
\hline Intersection & Adequate length & $40 \%$ less length & $60 \%$ less length & $80 \%$ less length \\
\hline & left turn lane & left turn lane & left turn lane & left turn lane \\
\hline 1 & 2446 & 2586 & 2641 & 3329 \\
\hline 2 & 2303 & 2357 & 2363 & 2811 \\
\hline 3 & 2002 & 2117 & 2205 & 2301 \\
\hline 4 & 2232 & 2230 & 2381 & 2424 \\
\hline 5 & 2067 & 2216 & 2176 & 2198 \\
\hline 6 & 1829 & 1901 & 1908 & 1957 \\
\hline 7 & 1983 & 1983 & 2007 & 2015 \\
\hline 8 & 1861 & 1867 & 1717 & 1824 \\
\hline 9 & 1638 & 1684 & 1679 & 1696 \\
\hline 10 & 3548 & 3395 & 3501 & 3758 \\
\hline 11 & 1791 & 1964 & 1985 & 2526 \\
\hline 12 & 2247 & 2235 & 2295 & 2796 \\
\hline 13 & 2907 & 3063 & 3138 & 3787 \\
\hline 14 & 1828 & 2853 & 1856 & 2002 \\
\hline 15 & 2027 & 1924 & 2004 & 2105 \\
\hline 16 & 1996 & 2087 & 2126 & 2206 \\
\hline 17 & 1858 & 1958 & 1939 & 1957 \\
\hline 18 & 1820 & 1848 & 1827 & 1847 \\
\hline 19 & 3887 & 4251 & 4373 & 4803 \\
\hline 20 & 2463 & 2675 & 2821 & 3151 \\
\hline 21 & 2463 & 2586 & 2821 & 3137 \\
\hline 22 & 3688 & 3795 & 4033 & 4257 \\
\hline 23 & 1816 & 1934 & 1991 & 2491 \\
\hline 24 & 2003 & 2045 & 2028 & 2534 \\
\hline 25 & 2904 & 2980 & 3222 & 3617 \\
\hline 26 & 1819 & 1950 & 1943 & 2094 \\
\hline 27 & 1922 & 1913 & 1942 & 2131 \\
\hline
\end{tabular}


Table 49 Number of crossing conflict counts recorded from the hypothetical intersections

Intersection Adequate length $40 \%$ less length $\quad 60 \%$ less length $\quad 80 \%$ less length

\begin{tabular}{|c|c|c|c|c|}
\hline & left turn lane & left turn lane & left turn lane & left turn lane \\
\hline 1 & 20 & 23 & 27 & 33 \\
\hline 2 & 27 & 20 & 18 & 23 \\
\hline 3 & 30 & 24 & 20 & 23 \\
\hline 4 & 25 & 20 & 25 & 26 \\
\hline 5 & 19 & 20 & 19 & 26 \\
\hline 6 & 14 & 24 & 17 & 18 \\
\hline 7 & 13 & 9 & 11 & 12 \\
\hline 8 & 15 & 17 & 17 & 18 \\
\hline 9 & 20 & 16 & 18 & 20 \\
\hline 10 & 66 & 65 & 73 & 53 \\
\hline 11 & 17 & 20 & 29 & 45 \\
\hline 12 & 22 & 23 & 25 & 25 \\
\hline 13 & 45 & 57 & 71 & 47 \\
\hline 14 & 32 & 27 & 23 & 45 \\
\hline 15 & 17 & 23 & 24 & 40 \\
\hline 16 & 19 & 21 & 22 & 27 \\
\hline 17 & 17 & 18 & 17 & 27 \\
\hline 18 & 19 & 17 & 21 & 22 \\
\hline 19 & 26 & 35 & 46 & 32 \\
\hline 20 & 42 & 46 & 68 & 68 \\
\hline 21 & 42 & 48 & 68 & 69 \\
\hline 22 & 56 & 55 & 48 & 46 \\
\hline 23 & 28 & 23 & 49 & 55 \\
\hline 24 & 19 & 27 & 53 & 40 \\
\hline 25 & 44 & 43 & 38 & 45 \\
\hline 26 & 16 & 24 & 35 & 44 \\
\hline 27 & 16 & 26 & 31 & 50 \\
\hline
\end{tabular}




\section{Appendix D: Estimated CMFs - Chapter 7}

Table 50 Estimated CMFs for total crashes at the 27 hypothetical intersections

\begin{tabular}{|c|c|c|c|}
\hline No. & $\begin{array}{l}40 \% \text { less length } \\
\text { left turn lane }\end{array}$ & $\begin{array}{l}60 \% \text { less length } \\
\text { left turn lane }\end{array}$ & $\begin{array}{l}80 \% \text { less length } \\
\text { left turn lane }\end{array}$ \\
\hline 1 & 0.983 & 0.977 & 0.910 \\
\hline 2 & 0.994 & 0.994 & 0.941 \\
\hline 3 & 0.984 & 0.973 & 0.961 \\
\hline 4 & 1.001 & 0.980 & 0.975 \\
\hline 5 & 0.979 & 0.984 & 0.980 \\
\hline 6 & 0.987 & 0.986 & 0.979 \\
\hline 7 & 1.001 & 0.997 & 0.995 \\
\hline 8 & 0.999 & 1.024 & 1.006 \\
\hline 9 & 0.992 & 0.993 & 0.990 \\
\hline 10 & 1.013 & 1.003 & 0.984 \\
\hline 11 & 0.972 & 0.967 & 0.897 \\
\hline 12 & 1.003 & 0.994 & 0.937 \\
\hline 13 & 0.983 & 0.975 & 0.923 \\
\hline 14 & 0.997 & 0.997 & 0.971 \\
\hline 15 & 1.015 & 1.003 & 0.986 \\
\hline 16 & 0.986 & 0.981 & 0.969 \\
\hline 17 & 0.984 & 0.987 & 0.983 \\
\hline 18 & 0.996 & 0.999 & 0.996 \\
\hline 19 & 0.972 & 0.963 & 0.937 \\
\hline 20 & 0.975 & 0.958 & 0.927 \\
\hline 21 & 0.985 & 0.958 & 0.928 \\
\hline 22 & 0.991 & 0.974 & 0.958 \\
\hline 23 & 0.982 & 0.970 & 0.906 \\
\hline 24 & 0.993 & 0.991 & 0.929 \\
\hline 25 & 0.993 & 0.970 & 0.936 \\
\hline 26 & 0.978 & 0.977 & 0.953 \\
\hline 27 & 1.000 & 0.994 & 0.964 \\
\hline
\end{tabular}


Table 51 Estimated CMFs for Fatal and injury crashes at the 27 hypothetical intersections

\begin{tabular}{r|lll} 
No. & $\begin{array}{l}40 \% \text { less length } \\
\text { left turn lane }\end{array}$ & $\begin{array}{l}60 \% \text { less length } \\
\text { left turn lane }\end{array}$ & $\begin{array}{l}80 \% \text { less length } \\
\text { left turn lane }\end{array}$ \\
\hline 1 & 0.988 & 0.983 & 0.934 \\
2 & 0.995 & 0.995 & 0.957 \\
3 & 0.989 & 0.980 & 0.972 \\
4 & 1.001 & 0.986 & 0.982 \\
5 & 0.985 & 0.989 & 0.986 \\
6 & 0.991 & 0.990 & 0.985 \\
7 & 1.001 & 0.998 & 0.997 \\
8 & 0.999 & 1.018 & 1.004 \\
9 & 0.994 & 0.995 & 0.993 \\
10 & 1.010 & 1.002 & 0.988 \\
11 & 0.979 & 0.976 & 0.925 \\
12 & 1.002 & 0.996 & 0.954 \\
13 & 0.988 & 0.981 & 0.944 \\
14 & 0.998 & 0.998 & 0.979 \\
15 & 1.010 & 1.002 & 0.990 \\
16 & 0.990 & 0.986 & 0.977 \\
17 & 0.988 & 0.990 & 0.988 \\
18 & 0.997 & 0.999 & 0.997 \\
19 & 0.980 & 0.973 & 0.954 \\
20 & 0.982 & 0.969 & 0.947 \\
21 & 0.989 & 0.969 & 0.947 \\
22 & 0.994 & 0.981 & 0.970 \\
23 & 0.987 & 0.978 & 0.931 \\
24 & 0.995 & 0.994 & 0.948 \\
25 & 0.995 & 0.978 & 0.953 \\
26 & 0.984 & 0.983 & 0.966 \\
27 & 1.000 & 0.995 & 0.974 \\
& & & \\
\hline
\end{tabular}


Table 52 Estimated CMFs for PDO crashes at the 27 hypothetical intersections

\begin{tabular}{r|lll} 
No. & $\begin{array}{l}40 \% \text { less length } \\
\text { left turn lane }\end{array}$ & $\begin{array}{l}60 \% \text { less length } \\
\text { left turn lane }\end{array}$ & $\begin{array}{l}80 \% \text { less length } \\
\text { left turn lane }\end{array}$ \\
\hline 1 & 0.981 & 0.974 & 0.898 \\
2 & 0.993 & 0.993 & 0.934 \\
3 & 0.982 & 0.969 & 0.956 \\
4 & 1.001 & 0.978 & 0.972 \\
5 & 0.976 & 0.982 & 0.977 \\
6 & 0.985 & 0.984 & 0.977 \\
7 & 1.001 & 0.996 & 0.995 \\
8 & 0.999 & 1.028 & 1.007 \\
9 & 0.991 & 0.992 & 0.988 \\
10 & 1.015 & 1.004 & 0.982 \\
11 & 0.968 & 0.962 & 0.884 \\
12 & 1.004 & 0.994 & 0.929 \\
13 & 0.981 & 0.971 & 0.913 \\
14 & 0.997 & 0.997 & 0.967 \\
15 & 1.016 & 1.003 & 0.984 \\
16 & 0.984 & 0.978 & 0.964 \\
17 & 0.982 & 0.985 & 0.981 \\
18 & 0.995 & 0.999 & 0.995 \\
19 & 0.968 & 0.958 & 0.928 \\
20 & 0.972 & 0.952 & 0.918 \\
21 & 0.983 & 0.952 & 0.919 \\
22 & 0.990 & 0.970 & 0.953 \\
23 & 0.979 & 0.966 & 0.894 \\
24 & 0.992 & 0.990 & 0.920 \\
25 & 0.992 & 0.966 & 0.928 \\
26 & 0.975 & 0.974 & 0.947 \\
27 & 1.000 & 0.993 & 0.959 \\
\hline & & & \\
\hline
\end{tabular}


Table 53 Estimated CMFs for rear end crashes at the 27 hypothetical intersections

\begin{tabular}{r|lll} 
No. & $\begin{array}{l}40 \% \text { less length } \\
\text { left turn lane }\end{array}$ & $\begin{array}{l}60 \% \text { less length } \\
\text { left turn lane }\end{array}$ & $\begin{array}{l}80 \% \text { less length } \\
\text { left turn lane }\end{array}$ \\
\hline 1 & 0.976 & 0.968 & 0.876 \\
2 & 0.990 & 0.989 & 0.918 \\
3 & 0.976 & 0.959 & 0.942 \\
4 & 1.000 & 0.973 & 0.965 \\
5 & 0.971 & 0.978 & 0.974 \\
6 & 0.984 & 0.982 & 0.971 \\
7 & 1.000 & 0.995 & 0.993 \\
8 & 0.999 & 1.035 & 1.009 \\
9 & 0.988 & 0.989 & 0.985 \\
10 & 1.019 & 1.006 & 0.976 \\
11 & 0.961 & 0.957 & 0.863 \\
12 & 1.002 & 0.991 & 0.910 \\
13 & 0.978 & 0.968 & 0.893 \\
14 & 0.826 & 0.993 & 0.962 \\
15 & 1.023 & 1.005 & 0.984 \\
16 & 0.981 & 0.973 & 0.958 \\
17 & 0.978 & 0.982 & 0.978 \\
18 & 0.993 & 0.998 & 0.994 \\
19 & 0.962 & 0.951 & 0.913 \\
20 & 0.965 & 0.943 & 0.900 \\
21 & 0.979 & 0.943 & 0.901 \\
22 & 0.988 & 0.962 & 0.940 \\
23 & 0.973 & 0.961 & 0.873 \\
24 & 0.991 & 0.995 & 0.904 \\
25 & 0.989 & 0.956 & 0.910 \\
26 & 0.971 & 0.972 & 0.941 \\
27 & 1.002 & 0.996 & 0.957 \\
\hline & & & \\
\hline
\end{tabular}


Table 54 Estimated CMFs for turning movement crashes at the 27 hypothetical intersections

\begin{tabular}{r|lll} 
No. & $\begin{array}{l}40 \% \text { less length } \\
\text { left turn lane }\end{array}$ & $\begin{array}{l}60 \% \text { less length } \\
\text { left turn lane }\end{array}$ & $\begin{array}{l}80 \% \text { less length } \\
\text { left turn lane }\end{array}$ \\
\hline 1 & 1.044 & 1.058 & 1.010 \\
2 & 0.983 & 1.009 & 0.955 \\
3 & 1.000 & 1.000 & 1.081 \\
4 & 1.000 & 0.975 & 0.975 \\
5 & 1.000 & 0.975 & 0.965 \\
6 & 1.041 & 0.942 & 1.068 \\
7 & 1.008 & 1.008 & 1.008 \\
8 & 1.000 & 1.000 & 1.019 \\
9 & 1.000 & 1.000 & 1.015 \\
10 & 0.967 & 0.988 & 1.027 \\
11 & 0.973 & 0.951 & 0.951 \\
12 & 1.083 & 1.031 & 1.071 \\
13 & 0.965 & 0.975 & 1.030 \\
14 & 1.019 & 1.009 & 1.009 \\
15 & 0.969 & 1.025 & 1.056 \\
16 & 0.985 & 1.037 & 0.959 \\
17 & 0.981 & 0.965 & 1.047 \\
18 & 0.983 & 1.041 & 1.099 \\
19 & 0.927 & 0.881 & 0.881 \\
20 & 1.042 & 1.033 & 1.103 \\
21 & 1.015 & 1.033 & 1.076 \\
22 & 0.981 & 1.000 & 1.022 \\
23 & 0.990 & 1.011 & 0.990 \\
24 & 1.051 & 1.000 & 1.068 \\
25 & 1.041 & 1.030 & 1.041 \\
26 & 1.015 & 0.973 & 0.932 \\
27 & 0.965 & 0.878 & 0.914 \\
& & & \\
\hline & & & \\
\hline
\end{tabular}




\section{REFERENCES}

AASHTO (HSM), (2010). Highway Safety Manual, $1^{\text {st }}$ Edition, ISBN 978-56051-477-0

Abdel-Aty, M.A., C. Lee, J. Park, J.Wang, M. Abuzwidah, and S. Al-Arifi (2014). Validation and Application of Highway Safety Manual (Part D) in Florida. - Florida Department of Transportation. Tallahassee, Florida.

Espinosa Granados, M., Persaud, B., Rajeswaran, T., Saleem, T. (2017), 'Using Microsimulation to Evaluate the Impact of Automated Vehicles on Safety Performance of Signalized Intersections’ Ryerson University

Federal Highway Administration (2008). Surrogate Safety Assessment Model and Validation: Final Report. FHWA Report, FHWA-HRT-08-051,

Federal Highway Administration (2010). Highway Safety Improvement Program Manual. Cambridge Systematics Inc. Chicago, Illinois, for Federal Highway Administration U.S. Department of Transportation. Report No. FHWA- SA-09-029 [Online] Available: https://safety.fhwa.dot.gov/hsip/resources/fhwasa09029/fhwasa09029.pdf

Federal Highway Administration (2016). Introduction To Safety Performance Functions. [Online] Available:

https://safety.fhwa.dot.gov/tools/crf/resources/cmfs/docs/safety_performance_funtions.pd $\underline{f}$

Ford, C. (2016). Getting started with Negative Binomial Regression Modeling. Statistical Research Consultant, University of Virginia Library. [Online]. Available: http://data.library.virginia.edu/getting-started-with-negative-binomial-regressionmodeling/ 
Hayward, J., (1971). Near misses as a measure of safety at urban intersections, Pennsylvania Transportation and Traffic Safety Center

Jain, N., Gupta, R., Gupta, R. (2017). Generalized Additive and Generalized Linear Modeling for Children Diseases. Quest Journals - Journal of Research in Applied Mathematics, Volume 3, Issue 5, Pps. 0-10. Online ISSN: 2394-0743

Lorion, A. (2014) Investigation of Surrogate Measures for Safety Assessment of Two-Way StopControlled Intersections. Ryerson University

Ministry of Transportation Ontario (1985), 'Geometric Design Standards for Ontario Highways Part 3 - Chapter E At-Grade Intersections', Ministry of Transportation Ontario - Surveys and Design Office, Downsview, Ontario [Online] Available: https://www.middlesex.ca/sites/default/files/Geometric\%20Design\%20Manual\%20Part\% $\underline{203 . p d f}$

Ministry of Transportation Ontario (2017), '2016 Provincial Highways Annual Average Daily Traffic (AADT)', Ministry of Transportation Ontario - Highway Standards Branch Traffic office, [Online], Available: http://www.raqsa.mto.gov.on.ca/techpubs/traffic volumes.nsf/fa027808647879788525708a004b5df8/f51986ea499a13b08525745f006dd30 b/\$FILE/Provincial\%20Highways\%20Traffic\%20Volumes\%202016\%20AADT\%20Only .pdf [Accessed: 12 December 2017]

Ministry of Transportation Ontario, (2004). Accident Information System MS Access Query User Guide - June 2004 - Version 1.4, Ministry of Transportation Traffic Office and Systems Development Office 
Park, J and Abdel-Aty, M. (2014). Development of adjustment functions to assess combined safety effects of multiple treatments on rural two-lane roadways. Accident Analysis and Prevention Journal, edition 75 (2015), Pgs. 310-319

Perkins, S.R. \& Harris, J.I., (1967). Criteria for Traffic Conflict Characteristics, Signalized Intersections, Research Laboratories, General Motors Corporation

Persaud, B. et al., (2012). Safety Performance Functions for Estimating the Safety Benefits of Proposed or Implemented Countermeasures. Draft Report for Transport Canada under Canada ${ }^{e e}$ s National Road Safety Research and Outreach Program

PTV Group. (2018) PTV Vissim Use Cases, [Online], Available: http://visiontraffic.ptvgroup.com/en-uk/products/ptv-vissim/use-cases/

Qin, L. (2016) 'Safety Evaluation Of Freeway Speed-Change Lanes Based On Crashes And Simulated Conflicts', Ryerson University

SAS Institute Inc. 2008. SAS/STAT® 9.2 User's Guide. Cary, NC: SAS Institute Inc.

Sayed, T., Brown, G., and Naveen, F. (1994). Simulation of Traffic Conflicts at Unsignalized Intersections with TCS-Sim. Accident Analysis and Prevention, Vol.26, Issue 5, pp. 593607, 1994.

Shahdah, U. E. (2014). Integrating Observational and Microscopic Simulation Models for Traffic Safety Analysis. The University of Waterloo.

Shahdah, U., Saccomanno, F., Persaud, B. (2014). Integrated traffic conflict model for estimating crash modification factors, Accident Analysis and Prevention Journal, Issue 71, Pp. 228 to 235

Srinivasan, R., B. Lan, and D. Carter. (2014) "Safety Evaluation of Signal Installation With and Without Left-Turn Lanes on Two-Lane Roads in Rural and Suburban Areas." Report No. 
FHWA/NC/2013-11. North Carolina Department of Transportation. Raleigh, North Carolina.

The University of California, Los Angeles (UCLA) (2017), Negative Binomial Regression - SAS Data Analysis Examples, Institute for digital research and education (IDRE) [Online]. Available: https://stats.idre.ucla.edu/sas/dae/negative-binomial-regression/

Trafficware (2018) Synchro Studio - Planning \& Analysis Software, [Online] Available: http://www.trafficware.com/synchro.html

VanDelen, P., Penton, S., Haniff, A., (2008), 'Typical Hourly Traffic Distribution for Noise Modelling', RWDI AIR Inc., Canadian Acoustics/Acoustique Canadienne, Vol. 36 No. 3 Pgs. 60-61 [Online], Available: https://jcaa.caaaca.ca/index.php/jcaa/article/download/2037/1784 [Accessed: 12 December 2017]

Washington State Department of Transportation (WSDOT) (2014, September). Protocol for VISSIM Simulation. [Online] Available: http://www.wsdot.wa.gov/NR/rdonlyres/378BEAC9-FE26-4EDA-AA1FB3A55F9C532F/0/VissimProtocol.pdf

Wasserstein, R. L.; Lazar, N. A. (2016). The ASA's Statement on p-Values: Context, Process, and

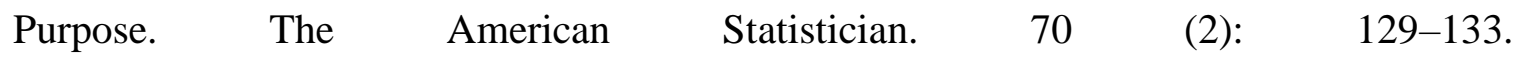
doi:10.1080/00031305.2016.1154108. $\underline{\text { http://conf.tac- }}$ atc.ca/english/annualconference/tac2012/docs/session15/persaud.pdf 